PNL-3194

UC-62

\title{
Heliostat Mirror Survey and Analysis
}

M. A. Lind

C. Q. Buckwalter

J. L. Daniel

J. S. Hartman

M. T. Thomas

L. R. Pederson

September 1979

Prepared for

Sandia Laboratories, Livermore, CA

under Related Services Agreement 300A01308

and the U.S. Department of Energy

under Contract EV-76-C-06-1830

Pacific Northwest Laboratory

Operated for the U.S. Department of Energy

by Battelle Memorial Institute 
NOTICE

This report was prepared as an account of work sponsored by the United States Government. Neither the United States nor the Department of Energy, nor any of their employees, nor any of their contractors, subcontractors, or their employees, makes any warranty, express or implied, or assumes any legal liability or responsibility for the accuracy, completeness or usefulness of any information, apparatus, product or process disclosed, or represents that its use would not infringe privately owned rights.

The views, opinions and conclusions contained in this report are those of the contractor and do not necessarily represent those of the United States Government of the United States Department of Energy.

\author{
PACIFIC NORTHWEST LABORATORY \\ operated by \\ BATTELLE \\ for the \\ UNITED STATES DEPARTMENT OF ENERGY \\ Under Contract EY-76-C-06-1830
}

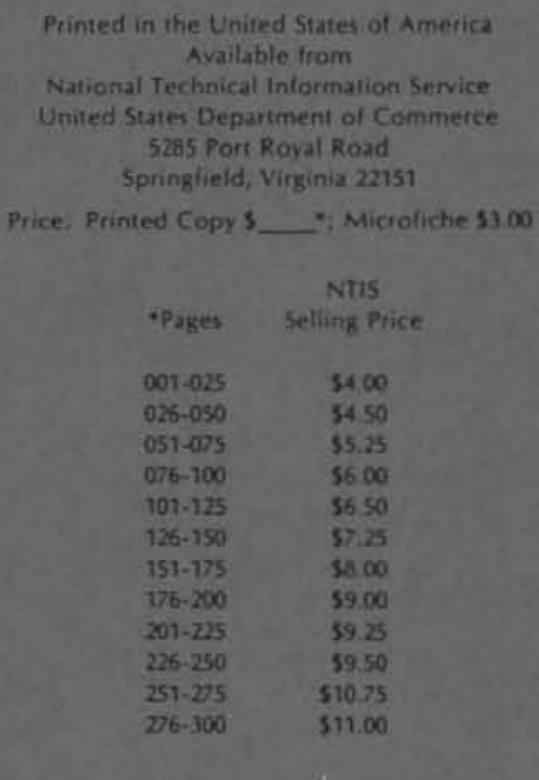




\section{0}

HELIOSTAT MIRROR SURVEY AND ANALYSIS
M. A. Lind
J. S. Hartman
C. Q. Buckwalter
M. T. Thomas
J. L. Daniel
L. R. Pederson

September 1979

Prepared for

Sandia Laboratories

Livermore, CA

under Related Services

Agreement 300A01308 and

the U.S. Department of Energy

under Contract EY-76-C-06-1830

Pacific Northwest Laboratory

Richland, WA 99352 


\section{FOREWORD}

This report is the result of comprehensive surveys and technical analyses performed for Sandia Laboratories in support of the U.S. Department of Energy Solar Thermal Large Power Systems authorized under Sandia Livermore integrated order 92-8165. The purpose of this work is to provide background information and procurement specifications for materials and processes which have potential applications in heliostat construction. This report covers the work performed under three tasks: the mirror industry survey, mirror degradation analysis, and advanced concepts for mirror protection. 


\section{SUMMARY AND CONCLUSIONS}

The mirrors used on concentrating solar systems must be able to withstand severe and sustained environmental stresses for long periods of time if they are to be economically acceptable. Little is known about how commercially produced wet process silvered second surface mirrors will withstand the test of time in solar applications. Field experience in existing systems has shown that the performance of the reflective surface varies greatly with time and is influenced to a large extent by the construction details of the mirror module. Degradation of the reflective layer has been seen that ranges from non-observable to severe. The exact mechanisms involved in the degradation process are not well understood from either the phenomenological or microanalytical points of view and are thus subject to much debate.

The three chapters of this report summarize the work recentiy performed in three general areas that are key to understanding and ultimately controlling the degradation phenomena. These areas are: a survey of the present commercial mirroring industry, the microanalytical examination of numerous degraded and nondegraded mirrors, and an investigation of several novel techniques that might be used to extned the life of heliostat mirrors. While the results presented here are by no means conclusive, they are a solid first step in what should be a much more comprehensive investigation of the solar mirror lifetime problem.

As a first step in attempting to define the "state of the art" of the commercial mirroring industry, a survey of a number of the industry leaders was conducted. The survey concentrated on the most common mirror type, the second surface float glass, wet process silvered mirror. This type of mirror is found in most bathrooms and is projected for use in nearly all the major heliostat systems because of its potentially high optical performance and environmental stability.

These mirrors are a multilayer structure. The basic structure, which varies slightly between manufacturers, consists of a float glass superstrate coated first with roughly $700 \AA$ of silver, and then $300 \AA$ of copper and 
0.001 in. of paint. The silver, which has the highest solar reflectivity of any natural metal, acts as the primary reflective layer. The copper presumably acts to protect the silver layer and allows better bonding of the paint, but its function is not well understood. The paint acts as a protective cover intended mainly to prevent abrasion of the silver layer during shipping and handling. The common industry practices for making these mirrors based on a wet chemistry process are described in the text along with the present industry practices for testing and evaluation of their product.

Alternate technologies relying on vacuum deposition also exist for high volume deposition of metallic layers. These technologies include e-beam and sputter deposition. They are also discussed briefly in the first chapter.

The microchemical and optical analysis of a number of new and degraded mirrors is discussed in the second chapter. Surface analytical tools including SEM, EDX, AES, SIMS, and ESCA were combined with optical microscopy and spectroscopy to examine several degraded mirrors obtained from Sandia Livermore and various mirror manufacturers. New mirrors taken off the manufacturing lines in various stages of completion were also examined.

Although few definitive statements about the degradation phenomena can be made, a number of preliminary conclusions can be inferred from these studies. The degradation of the silver layer is accelerated in the presence of water and can be affected by mechanical stress on the back surface of the mirror such as might be incurred during mirror module processing. Early stages of degradation are characterized by individual nucleation sites which are surrounded by concentric reaction rings as the deterioration progresses. Interestingly enough, reaction by-products such as residual chlorides or sulfides are rarely found at the degradation sites.

The silver to glass bond appears to be one of the weakest links in the mirror structure. There is some evidence to suggest that some types of degradation are initiated at this interface. The bonding at the interface appears to be weak and nonuniform at best. "Islands" of adhesion can be implied from some of the experimental data. The silver deposition step used in the commercial wet process mirroring operation may actually accelerate the 
debonding process especially when used on soda-lime glasses which readily react with basic solutions. In many cases the glass actually appears to be corroded at the degradation site.

The picture is complicated by the observation that the copper backing is absent from severely degraded areas of the mirrors, suggesting the copper is acting as a sacrificial layer. But no copper salts are present. It also appears that on nondegraded mirrors the copper layer is of nonuniform thickness and is well intermixed with the silver layer down to the two micron dimensional scale.

The solar reflectivity of the mirror is influenced primarily by the thickness of the silver layer for films less than $700 \AA$ thick. Variations of about two percent have been observed on new mirrors with the same metallic layer thickness that were produced using different deposition techniques. Heating the mirrors in excess of $150^{\circ} \mathrm{C}$ has a detrimental effect on reflectivity caused by agglomeration of the silver. However, some heating may actually enhance reflectivity.

The output from the mirror industry survey and the preliminary results from the analytical investigations have been used to generate a recommended specification for heliostat mirrors. This specification is based heavily on' current industry practice used in the production of quality mirrors and supplemented where possible by our own experimental work. It is expected that it will evolve considerably as more is understood about the mechanisms of mirror degradation.

The final chapter of the report addresses some advanced concepts for extending the lifetime of silver mirrors. The concepts fall into two general categories: encapsulation and modification of the deposition process. Since water plays such an important roll in the degradation process, excluding it may extend lifetime. Several novel techniques currently being investigated for encapsulation are discussed. In addition some exciting new work on modifying the chemistry at the glass/silver interface is discussed. Preliminary investigations show that significant improvements in lifetime can be achieved 
by using lanthanides in the sensitization step before silver deposition. The technique is readily adaptable to existing commercial silvering lines.

The most important conclusions that this document is intended to demonstrate are: 1) the problem of mirror degradation is severe, 2) it is not well understood, 3) a good deal of research will be required before a solution can be proposed with any degree of confidence, and 4) the solution to the degradation problem is probably not beyond the limits of present technology given the resources to attack the roots of the problem. 


\section{ACKNOWLEDGEMENTS}

The authors wish to express their appreciation to T. Stewart, M. Nordmeyer, and D. Nelson for their contributions to the optical evaluations and sample preparation. They also wish to thank J. Coleman for his contributions to the SEM photomicrographs and D. Parks and R. Beauchamp for their optical microscopy and metallographic work. G. McVay, R. Turcotte and D. Baer are also gratefully acknowledged for their many enlightening discussions on the degradation mechanisms. Finally we wish to thank the following companies for their time and cooperation in the mirror industry survey: Airco Temescal, Binswanger Mirror Company, Buchmin Industries, Carolina Mirror Corporation, Falconer Glass Industries, Inc., Gardner Mirror Corporation, Guardian Industries, Libbey-Owens-Ford Company, London Laboratories Limited, and PPG Industries, Inc. 
. 


\section{CONTENTS}

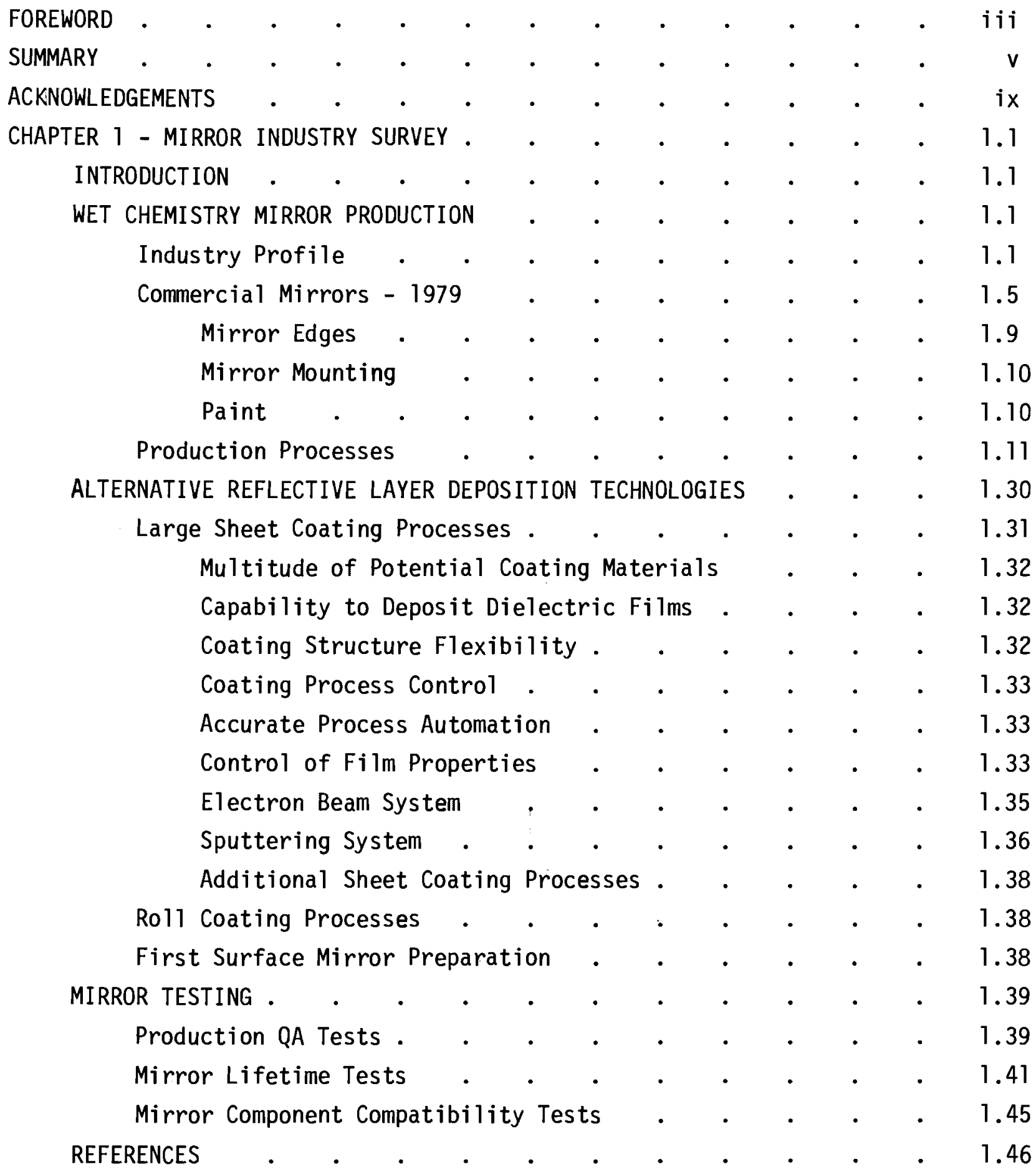




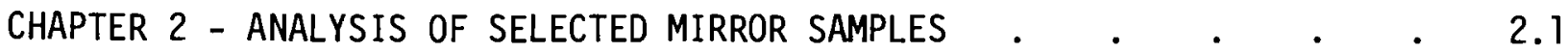

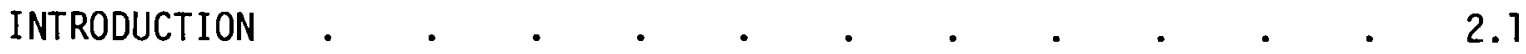

SEM, EDX, AND MICROSCOPY EXAMINATION

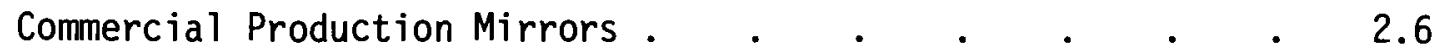

Laboratory Variations of Process Parameters . . . . 2.18

Effects of Surface Contaminants on the Glass Substrate . . 2.27

Studies of Degraded Mirrors . . . . . . . . 2.29

The Sandia Mirrors . $\quad . \quad$. $\quad . \quad$. $\quad . \quad$. $\quad$. 2.29

The Carolina Mirrors . $\quad . \quad$. $\quad . \quad$. $\quad$. 2.41

Effects of Heat on Silver Structure . . . . . $\quad . \quad 2.49$

Effects of Water on Mirror Integrity . . . . . 2.49

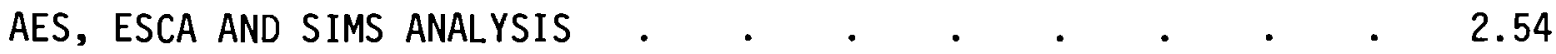

Introduction to the Techniques $. \quad . \quad . \quad . \quad . \quad . \quad 2.54$

Analysis of Sandia Mirrors . . . . . . . . . 2.55

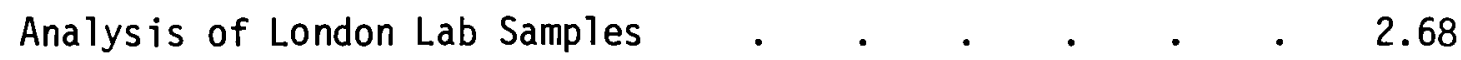

Analysis of the Carolina Mirror . . . . . . . 2.78

Analys is of Tin Chloride Sensitization . . . . . 2.80

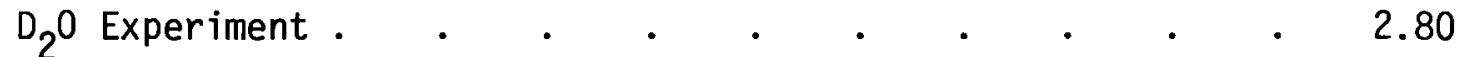

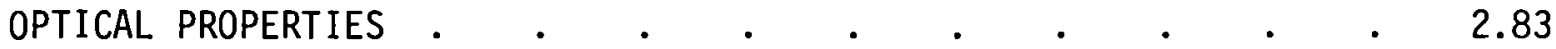

Effect of Silver Thickness on Solar Reflectance . . . 2.83

Effects of Silver Agglomeration on Solar Reflectance . $\quad 2.84$

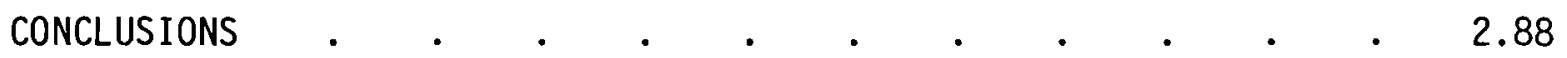

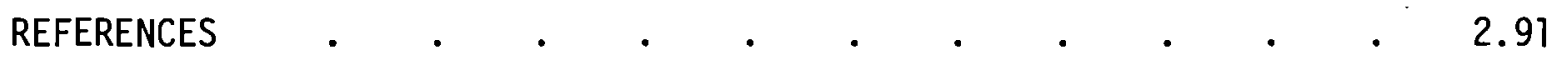

CHAPTER 3 - SILVER DEPOSITION AND PROTECTION:
ADVANCED CONCEPTS ...
.

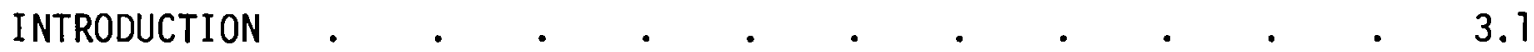

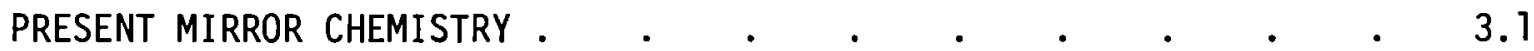

Deposition Overview .

Glass . . . . . . . . . . . . 3.2

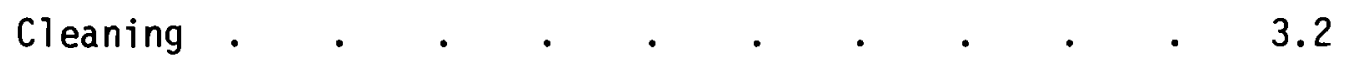

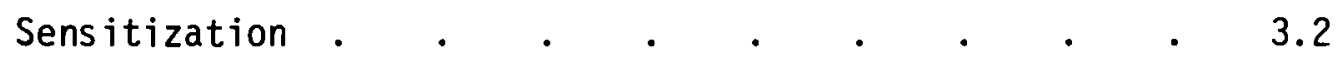

Silvering . . . . . . . . . . . . .

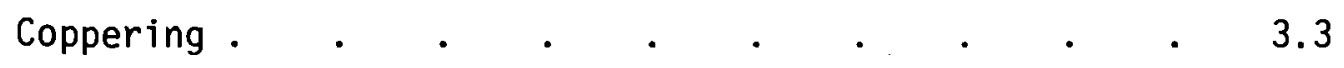

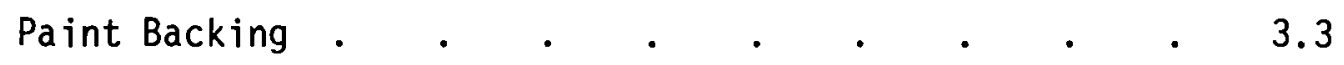


ADVANCED CONCEPTS FOR MIRROR PROTECTION •

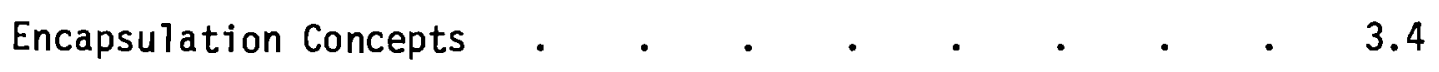

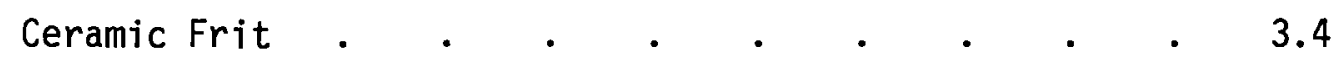
Electrostatic Bonding . . . . . . . . 3.5 Aluminum-Ethyl Vinyl Acetate . . . . . . $\quad$. 3.5

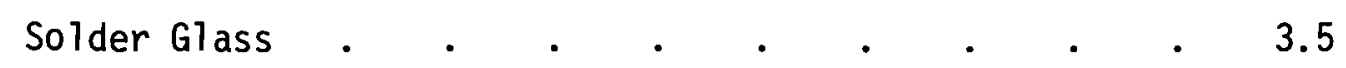
Modifying the Deposition Chemistry . . . . . . 3.5 Lanthanide Doped Mirrors . $\quad . \quad$. $\quad . \quad$. $\quad . \quad 3.7$

CONCLUSIONS

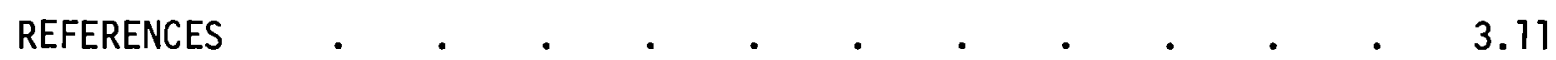

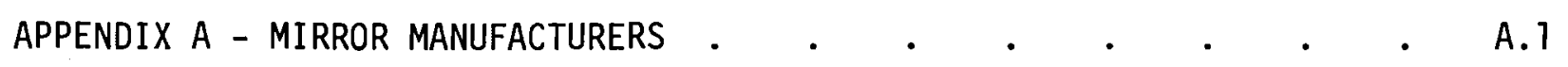
APPENDIX B - RECOMMENDED SPECIFICATIONS FOR SECOND SURFACE SILVERED MIRRORS FOR CENTRAL RECEIVER HELIOSTAT APPLICATIONS $\cdot$. 
FIGURES

1.1 Mirror Industry Profile, 1979 . $\quad$. $\quad . \quad \ldots \quad$. $\quad . \quad$. 1.3

1.2 Structure of the Commercial Second Surface

Silvered Mirrors $. \quad . \quad . \quad . \quad . \quad . \quad . \quad . \quad . \quad 1.6$

1.3 Conversion Curves Between Mass/Unit Area and Thickness

Based on Theoretical Metallic Densities . . . . . 1.8

1.4 Wet Chemistry Mirror Production Sequence $\quad . \quad$. $\quad . \quad$. 1.13

$\begin{array}{lll}1.5 & \text { Abrasive Glass Scrubber Using Continuous Slurry } \\ \text { Application and Oscillating Assemblies of Rotating Brushes } & \text { • } 1.16\end{array}$

1.6 Water Rinse Mechanism Using Directed Water Spray to Rinse

Process Residuals Off the Rear Edge of the Glass . . . 1.18

1.7 Reciprocating Spray Chemical Applicator for Wet

Chemistry Mirroring Solutions . . . . . . . 1.20

1.8 Air Jet Drying Station Using Directed Air Flow to Force Process Residuals off the Back Edge of the Moving Glass Sheet

1.9 Cross Section View of Paint Applicators . . . . . . . $\quad$. 1.24

1.10 Curtain Coater Operation a) Between Applications
and b) During Application

$\begin{array}{llll}1.11 & \text { Production Sequence for Variable Speed Roller Section } \\ \text { Associated with Curtain Coater Operation } & . & \text {. } & \text {. }\end{array}$

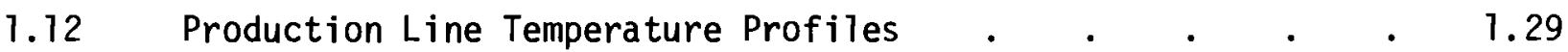

1.13 Step Gauge Used for Evaluating Paint Thickness . . . 1.40

1.14 Sample Mounting Geometry in a "Cleveland Tester" . . $\quad$ • 1.44

2.1 Normal Sequence of Initial Steps in Mirror Production . . 2.9

2.2 Production Mirrors by Buchmin Industries $\quad . \quad$. $\quad$. 2.10

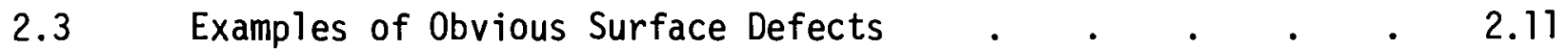

2.4 Production Mirrors by Gardner . . . . . . . . 2.12

2.5 Production Mirrors by Carolina.$\quad$. $\quad$. $\quad . \quad$. . $\quad 2.13$

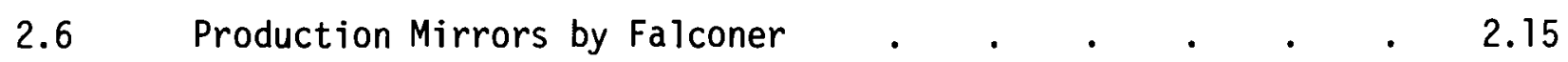




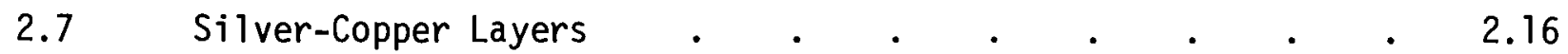

2.8 Production Mirrors by Binswanger . . . . . . . . . 2.17

2.9 Copper/Silver Surfaces After Removal of Backing Paint . . 2.19

2.10 Bonding Between Silver and Glass on New Mirrors . • . $\quad 2.20$

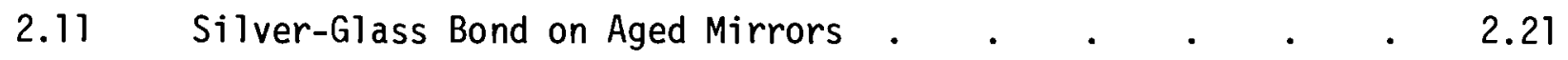

2.12 Laboratory Mirror Production by PPG . . . . . . . $\quad 2.22$

2.13 Effect of Changes in Mirror Fabrication Method . . . $\quad 2.24$

2.14 Effect of Changes in Mirror Fabrication Method . . . . 2.25

2.15 Effect of Changes in Mirror Fabrication Method . . . 2.26

2.16 Effect of Precleaning Glass Surfaces on Mirror

2.17 Large Defect Spots in Sandia Field Test Mirror . • . $\quad 2.30$

2.18 Typical Mirror Surface Features of Sandia Mirror . . . . $\quad$ 2.31

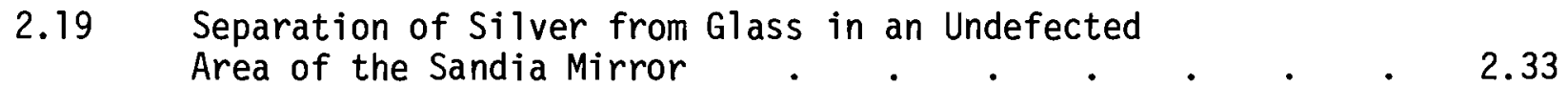

2.20 Looking Down into Opening Between Glass and Silver . . $\quad 2.34$

2.21 Fine-Spot Degradation on Sandia Mirror . . . . . . . $\quad$. 2.35

2.22 Edge View Details of Fine Spot Degradation . . . . . . $\quad 2.37$

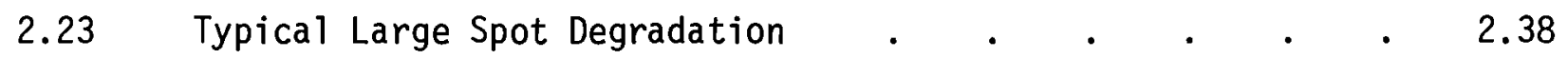

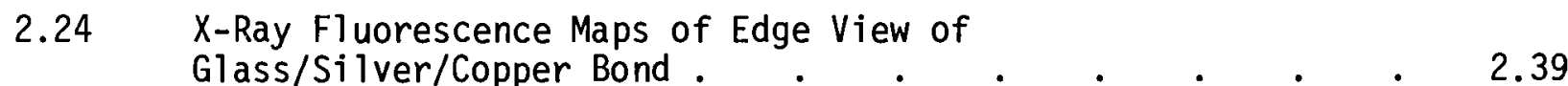

2.25 X-Ray Fluorescence Maps of Edge View of Large Defect Spot $\quad 2.40$

2.26 Details of Paint-Side View of Large Defect Spot . . . . $\quad 2.42$

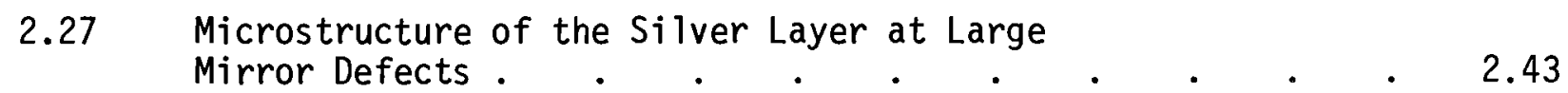

2.28 Camera "Self-Portrait" View of Exterior-Aged Mirrors • • 2.44

\begin{tabular}{l} 
2.29 Failure of Glass/Silver Bond with Progressive \\
Degradation \\
\hline
\end{tabular} 
2.30 Features of an Extensively Degraded Aged Mirror . . . 2.47

2.31 Details of Ring Structure of 01d Mirror Degradation . . 2.48

2.32 EDX Spectra of Corresponding Concentric Rings of

Degradation Product . . . . . . . . . 2.50

2.33 Reference EDX Spectra for Clean, Uncoated Glass

and for Paint Alone..$\quad \cdot \quad \cdot \quad \cdot \quad \cdot \quad \cdot \quad \cdot \quad \cdot 2.51$

2.34 Silver Agglomeration . . . . . . . . . . 2.52

2.35 Mirror Degradation in Hot Water . . . . . . . 2.53

2.36a Front (Glass) Side of the Degraded Sandia Heliostat Mirror . 2.56

2.36b Back (Paint, Adhesive and Residual Foam) Side of the
Same Mirror

2.36c Two Sections with Backing Paint Stripped Using P-Xylene • 2.57

2.37 SEM And Scanning Auger Micrographs of a Degraded

Section of the Sandia Mirror Showing the Inverse

Relationship Between Copper and Silver . . . . . 2.59

2.38 Auger Depth Profile of an Uncorroded Section

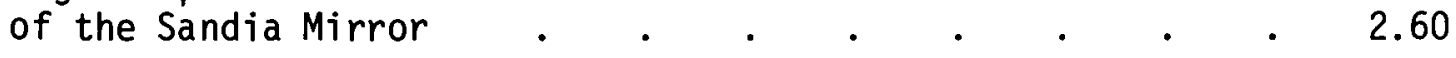

2.39 Auger Depth Profile of a Section of the Sandia
Mirror Having Numerous Corrosion Pits . . . $\quad 2.61$

$\begin{array}{ll}\text { 2.40 Auger Depth Profile of a Section of the Sandia } & \\ & \text { Mirror Showing More Extensive Degradation }\end{array}$

2.41 SEM Micrograph of a Degraded Section of the Sandia Removed . 2.65

2.42 Auger Point Scans Taken at Positions a-d of Figure $2.41 \quad 2.66$

2.43 Auger Depth Profile of the Sandia Mirror
Taken Adjacent to a Corrosion Spot. . . . . 2.67

$\begin{array}{ll}2.44 & \text { Auger and SIMS Depth Profiles of the London Lab } \\ \text { Mirror Coated on the Hard Scrubbed Glass } & 2.70\end{array}$

2.45 ESCA Point Scan of London Labs Cleaned Substrate
Mirror after 215 Minutes of Sputtering . . . . 2.72

2.46 Changes in the 350-355 eV Silver Auger Peak Shape

from the Metal Layer Through the Glass-Metal Interface

to Glass 
2.47 ESCA Point Scan of London Labs Cleaned Substrate Mirror after 300 Minutes of Sputtering . . . . . 2.76

2.48 Auger and SIMS Depth Profiles of the London Lab Mirror Coated on Unscrubbed Glass . . . . . . 2.77

2.49 Auger Depth Profile of a 17-Year-01d Mirror Supplied by the Carolina Mirror Corporation . . . $\quad 2.79$

2.50 ESCA Survey of a Soda-Lime-Silicate Glass Which had been Cleaned with Cerium Oxide and Rinsed in Distilled Water . 2.81

2.51 ESCA Survey of Soda-Lime-Silicate Glass After it Had Been Dipped into a Dilute $\mathrm{SnCl}_{2}$ Solution . $\quad . \quad \cdot \quad . \quad$. 2.82

2.52 SIMS Profile of a Silvered Mirror Which Was Chemically Deposited Using $\mathrm{D}_{2} 0$ in the Silvering Solution . . . 2.83

2.53 Variations in the Silver Thickness and Deposition Technique Influence the Solar Reflectance of the Mirror . 2.86

2.54 The Solar Reflectance as Influenced by the Amount of Silver Agglomeration . $. \quad . \quad . \quad . \quad . \quad . \quad .2 .87$

3.1 Mirror After Leach Bath Test . . . . . . . . 3.9 


\section{TABLES}

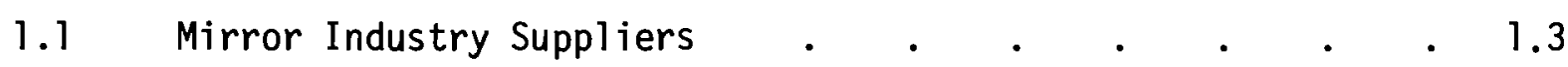

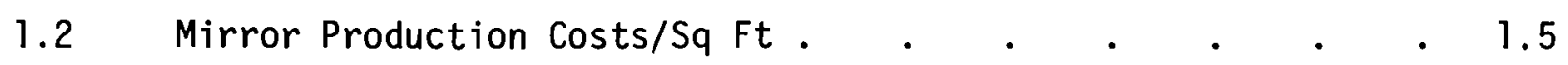

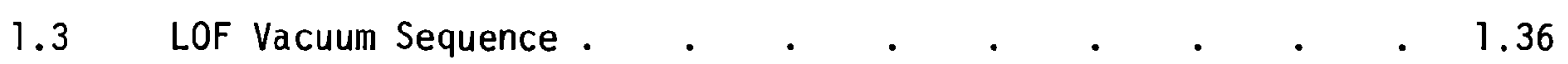

2.1 Sources of Specimens for Study of Mirror Quality . . . 2.3

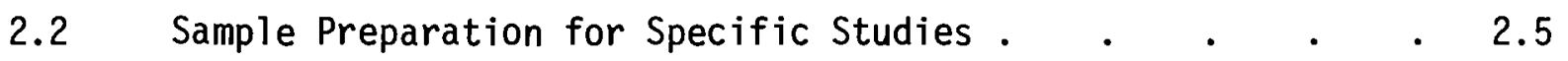

2.3 Potential Sources of Mirror Degradation and Failure $\quad$ • 2.7

2.4 Mirror Fabrication Conditions Used in Comparison Tests . $\quad 2.27$

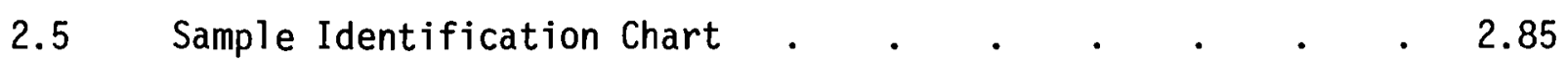


CHAPTER 1

MIRROR INDUSTRY SURVEY 


\section{CHAPTER 1}

\section{MIRROR INDUSTRY SURVEY}

\section{INTRODUCTION}

A survey of the domestic, wet chemistry mirror industry has been conducted to provide the basis for understanding the strengths, weaknesses, and flexibility of today's production sequence and finished product. This background is necessary to evaluate the utility of commercial mirrors for exterior solar applications and to determine approaches that may exist to improve exterior mirror performance and lifetime. The survey examined the scope and structure of the industry, its marketplace, its product, the wet chemistry production sequence, and the mirror testing procedures currently in use.

The major survey effort was limited to wet chemistry silvered mirrors due to the short-term need of the solar thermal program for heliostats that provide:

- high solar reflectance,

- low production cost,

- established production capacity,

- established production capability for large mirrors (4 x $10 \mathrm{ft}$ ), and

- acceptable mirror durability.

Vacuum deposited first surface chromium mirrors (automotive) were not examined due to their low solar reflectivity, while front surface silver mirrors were not considered due to poor durability. Several alternate technology approaches were studied and wi 11 be discussed briefly in later sections of this report.

\section{WET CHEMISTRY MIRROR PRODUCTION}

\section{Industry Profile}

Wet chemistry production techniques are used for the majority of domestic mirrors made for interior applications. The industry consists of roughly 30 manufacturers, but it is estimated that the largest dozen firms prepare 
70-80\% of the product volume. Most firms involved are privately owned and do not publish their production and sales volumes. This results in large uncertainty in figures quoted for total production capability and sales. Domestic production for 1979 is estimated to be $300,000,000$ square $\mathrm{ft}$, providing roughly $\$ 285 \mathrm{M}$ in manufacturers' sales. Twenty-three firms are affiliated through the National Association of Mirror Manufacturers (see Appendix A).

The major industry markets are for furniture, architectural applications, and decorative uses. Mirrors are sold as components to other manufacturers for inclusion in furniture, wardrobe doors, medicine cabinets, and framed mirrors. Mirror sheet is also sold to glass and mirror distributors and shops for local cutting and installation. Some manufacturers also market their own finished products such as framed mirrors, "install-it-yourself" mirror squares, etc.

The mirror industry is not vertically integrated and the manufacturers buy the mirroring ingredients from a limited number of specialty suppliers. The four major supply areas as shown in Figure 1.1 are glass, wet chemistry, paint, and mirror manufacturing equipment. Glass purchases are dictated primarily by price, availability, and delivery cost. This resulted from the ability of many glass manufacturers to meet the quality requirements of the industry. The major suppliers of wet chemistry, paint, and equipment are shown in Table 1.1 .

One result of this modular industry structure is that the best materials expertise (chemistry, paint, etc.) is found with the suppliers and not with the mirror manufacturers. This allows all manufacturers to pursue the pertinent data through their customer-supplier relationship and has tended to reduce differences in the basic product quality. It also has hastened the spread of new innovations across the industry. However, this common supply base for the industry has not resulted in a uniform quality for mirrors across the industry. Significant differences are found as a result of equipment differences, process temperatures and times, water purity, glass 


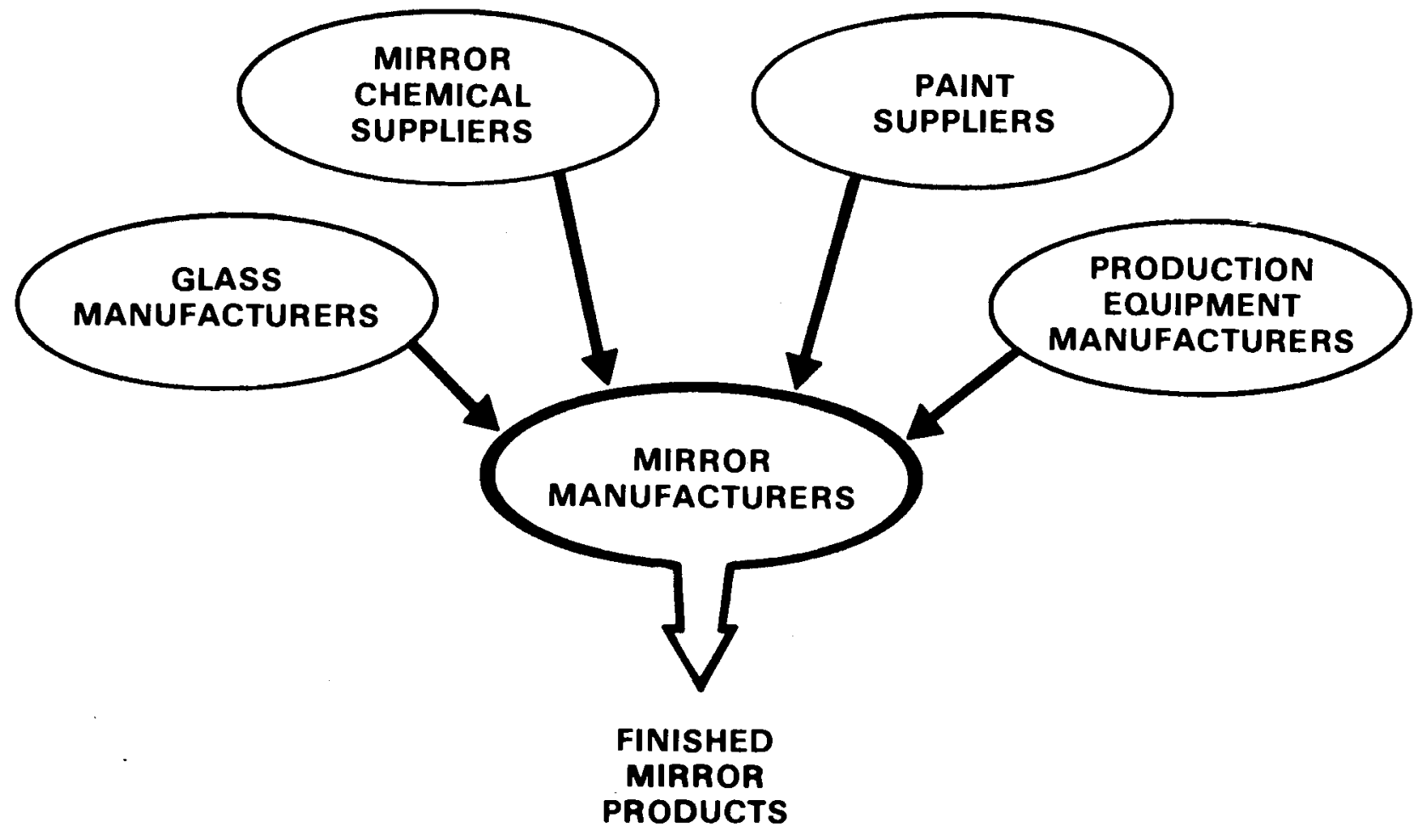

FIGURE 1.1. Mirror Industry Profile, 1979

TABLE 1.1 Mirror Industry Suppliers

Mirror Chemistry Manufacturers:

London Laboratory Limited

Hi leman Laboratory

Mirrolab

Peacock

Paint Manufacturers:

$P P G$

Glidden

Equipment Manufacturers (Domestic):

Century

Sommer and Maca 
cleaning procedures, etc. Significant differences also can probably be attributed to highly skilled and experienced craftsmen who operate the production lines for the top firms. Their importance to the company's product is a direct result of the fact that the production sequence has not been automated sufficiently to allow its control by an unskilled operator.

The wet chemistry mirror industry is currently running at near capacity to meet the demand of the traditional interior mirror market. Several of the firms visited were operating more than one production shift. One major production facility (Binswanger, Chandler, AZ) has been opened during the past year and several other firms have already scoped potential expansions to their facilities. At the same time the industry is interested in the potential market associated with solar mirror applications. Their attitudes are tempered by the fact that the near-term market impact will be small and of an isolated, "one-shot" nature.

It appears that the industry interest is unlikely to be supported by the expenditure of corporate R\&D funds to improve their products for exterior solar applications. This is in part due to the relatively small size of the firms involved and the anticipated time delay before potential payback might be expected. The heavy involvement of the federal government in the development of solar energy systems and the accompanying use of low bid purchases may also deter the expenditure of corporate R\&D funds. This purchasing procedure has the effect of providing the lowest quality product compatible with the purchase specifications. It does not allow the purchaser to select a higher priced product even if the performance is felt to justify the cost. Purchases without superior performance incentives may not allow the innovative firms to recover their development costs.

Estimated production costs (Spring, 1979) for single sheet and laminated mirrors are shown in Table 1.2. The largest single constituent cost is for the glass superstrate. Future trends in glass costs will be strongly affected by energy costs and labor rates. Silver costs have increased significantly in recent years (now more than $\$ 7$ per ounce) but are not expected to cause major changes in mirror costs due to the small amount used in a standard coating. Increases in labor costs for the mirroring process could cause significant product cost increases. 
TABLE 1.2. Mirror Production Costs/sq ft (estimated)

Commercial Production

\begin{tabular}{|c|c|c|}
\hline Materials & $1 / 8$ in. glass & $1 / 4$ in. glass \\
\hline $\begin{array}{l}\text { Glass } \\
\text { Coatings }\end{array}$ & $\begin{array}{r}\$ 0.35 \\
0.06\end{array}$ & $\begin{array}{r}\$ 0.55 \\
0.06\end{array}$ \\
\hline Labor \& Overhead & 0.30 & 0.30 \\
\hline Total Production Cost & $\$ 0.71$ & $\$ 0.91$ \\
\hline \multicolumn{3}{|l|}{ Laminated Mirror Production } \\
\hline \multicolumn{3}{|l|}{ Materials } \\
\hline $\begin{array}{l}\text { Glass (2 at } 1 / 8 \text { in.) } \\
\text { PVB Layer } \\
\text { Coatings }\end{array}$ & $\begin{array}{r}\$ 0.70 \\
0.35 \\
0.06\end{array}$ & \\
\hline Labor \& Overhead & $0.50-0.60$ & \\
\hline Total Production Cost & $\sim \$ 1.65$ & \\
\hline
\end{tabular}

Commercial Mirrors - 1979

Commercial wet chemistry mirrors are second surface mirrors and have a four layer structure as shown in Figure 1.2. This structure has changed very little since the 1860s (Schweig, 1973), although significant changes have been made in the deposition chemistries, the process sequence, and the mechanical handling systems. The glass serves as a superstrate for the mirror deposition process and also provides a hard, cleanable surface for the finished product. Mirrors are commonly coated on 1/8-in. and 1/4-in. glass. Sheets as thin as 0.060 in. have been coated successfully but these thin sheets require very careful handling by the continuous process mechanisms. The transmittance of the glass substrate can significantly affect the reflectance of the final product. A theoretical comparison (Lind and Rusin, 1978) of a silver layer coated on 1/8-in. thick soda lime glass and 1/8-in. low iron glass revealed weighted solar reflectances of 0.818 and 0.958 . This change was a direct result of absorption within the glass.

The silver layer serves as the reflective layer and provides a flat reflectance across the visible spectrum. Silver is also well suited for use 


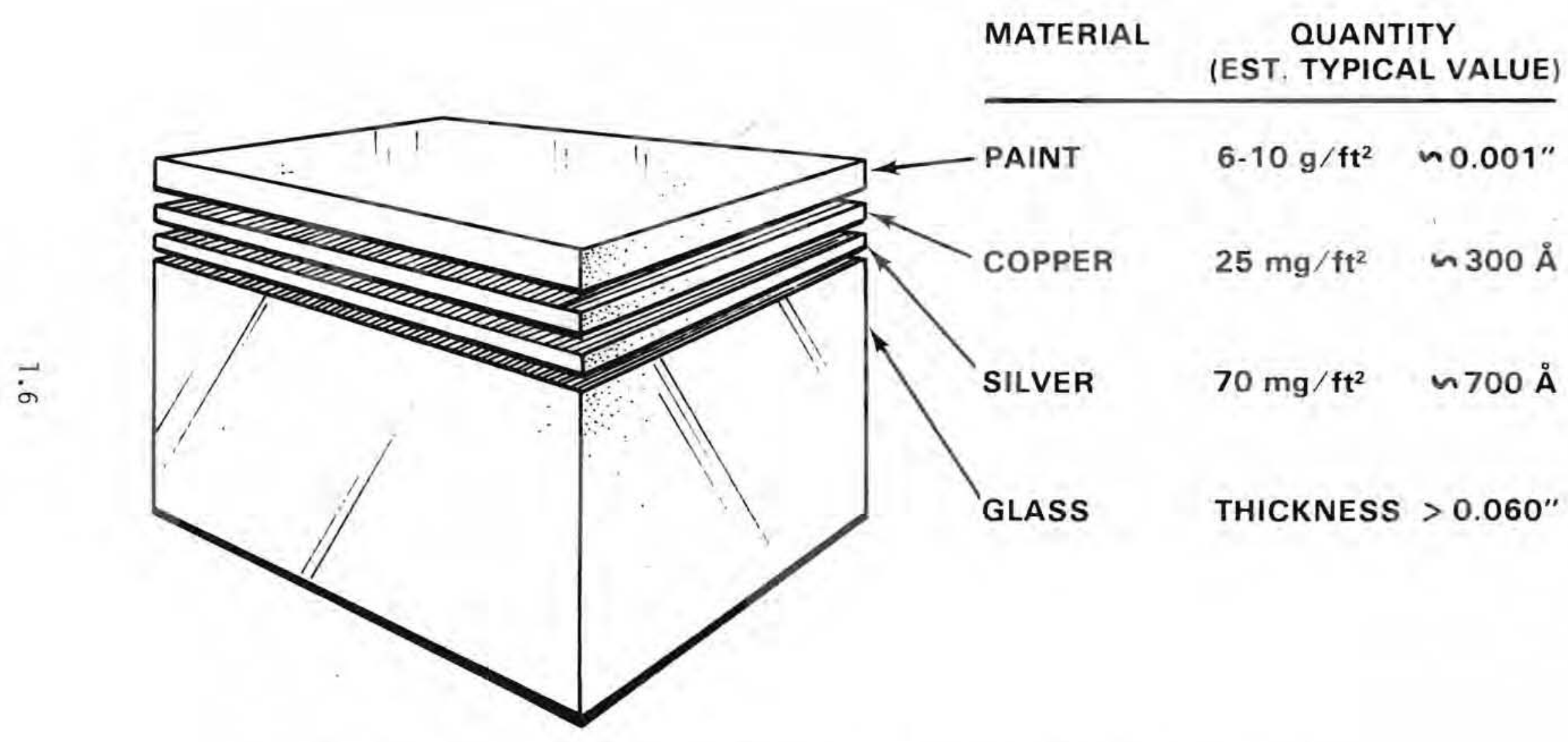

FIGURE 1.2. Structure of the Commercial Second Surface Silvered Mirrors 
in solar energy heliostats, as it has an extremely high solar weighted reflectance of 0.98 for an air-metal interface (Pettit, 1978). This compares to a value of 0.92 calculated for aluminum. Conventional mirroring practice aims for a silver layer thickness of about $700 \AA$, which corresponds to $\sim 70 \mathrm{mg} / \mathrm{ft}^{2}$ as seen in Figure 1.3. Different manufacturers accept coatings from $60-90 \mathrm{mg} / \mathrm{ft}^{2}$. Films lighter than $\sim 57 \mathrm{mg} / \mathrm{ft}^{2}$ were associated with degraded performance under visual examination. The target value of $70 \mathrm{mg} / \mathrm{ft}^{2}$ provides sufficient margin (compared to $57 \mathrm{mg} / \mathrm{ft}^{2}$ ) to maintain acceptable visual performance over large mirrors even with practical fluctuations in coating thicknesses.

The function of the copper layer is not as well understood. One possible function is to serve as a stress relief layer between the silver and paint layers. It would accommodate differential dimension changes due to paint shrinkage upon curing and thermal expansion that could occur during paint drying or normal use. An alternate function would be to serve as a sacrificial layer for preservation of the silver layer. The copper layer is also felt to provide improved adhesion between the metal and paint layers. This uncertainty clearly illustrates that today's basic mirror structure evolved over the years without strong technical motivation. Yet recent attempts to engineer a "better" mirror structure have altered only the wet chemistry solutions and the mechanical handlers. Most domestic firms deposit $2300 \AA$ of copper, which corresponds to $25 \mathrm{mg} / \mathrm{ft}^{2}$. Product acceptance ranges for different manufacturers varied from $18 \mathrm{mg} / \mathrm{ft}^{2}(220 \AA)$ to $30 \mathrm{mg} / \mathrm{ft}^{2}(360 \AA)$. European mirrors reportedly employ up to $1200 \AA$.

The paint layer provides a protective layer over the metallic films to prevent damage. This includes abrasion resistance for the mirror between production and final mounting. But the paint must also be quick drying to allow handling immediately after production, porous enough to accommodate continued curing of the metal layers in the days following production, and it must allow accurate mirror cutting after production by secondary manufacturers and local glass shops. These requirements have governed the evolution of 


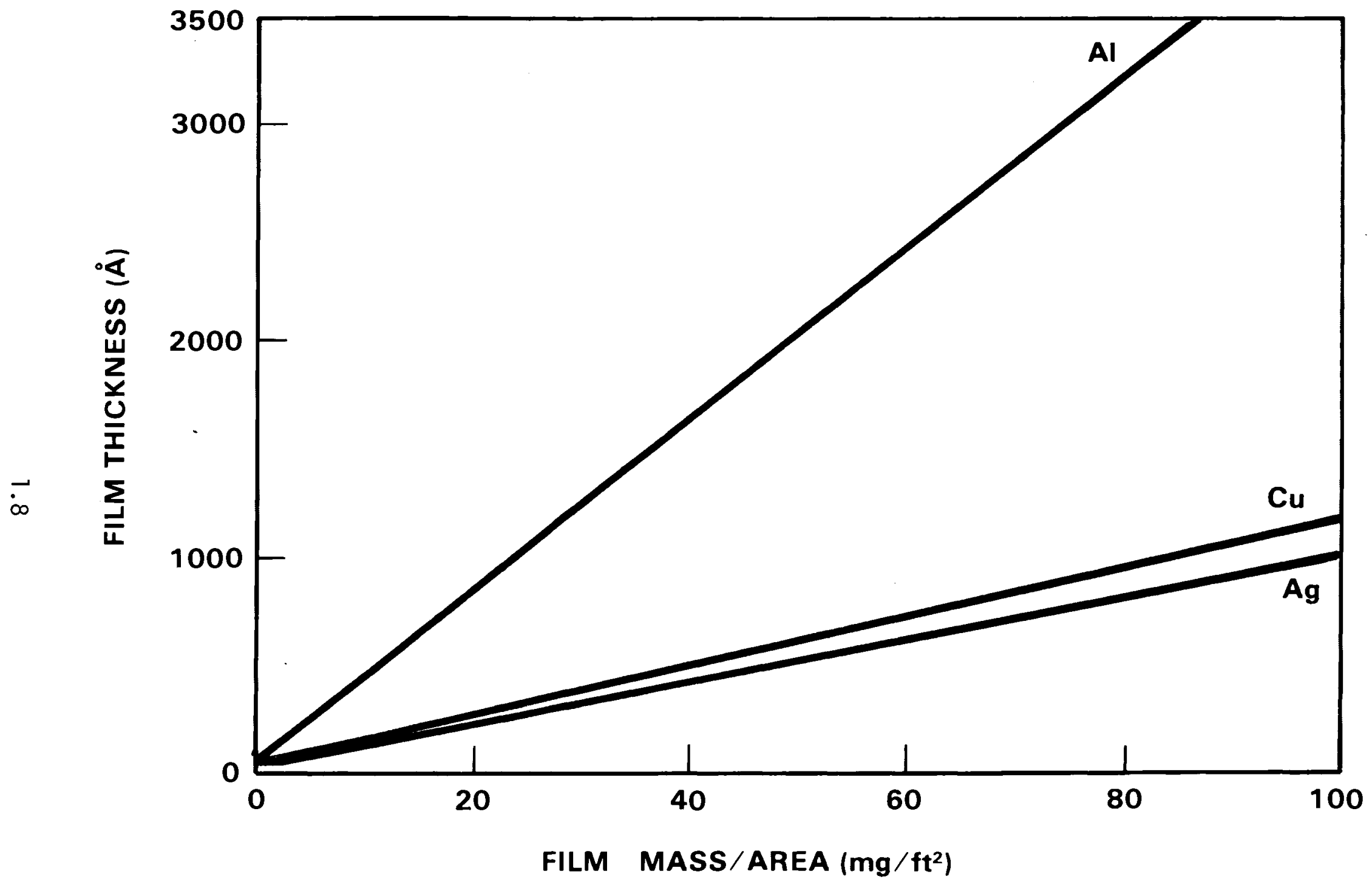

FIGURE 1.3. Conversion Curves Between Mass/Unit Area and Thickness Based on Theoretical Metallic Densities 
today's paint which is "pigment rich and vehicle starved." The paint is very similar to automotive primer. It is brittle, which allows accurate cutting after drying. This means that the paint layer breaks cleanly as the mirror is snapped rather than serving as small hinges across the glass break line. Such hinging would tend to leave uneven edges along the break line where the metallic layers were totally exposed to the environment. This paint formulation is also suited to drilling and beveling of finished mirrors. Generally coatings with common paints used today are from 6 to $10 \mathrm{~g} / \mathrm{ft}^{2}$, which corresponds to roughly $0.001 \mathrm{in}$.

It must be kept in mind that the mirrors under consideration have evolved for interior uses and optical performance in the visible spectrum. Recommended mounting procedures include the use of a breathable mounting arrangement and the prevention of extended exposure to moisture. These rules are based on experience and are required to prevent the degradation of today's mirror structure. Similarly, the mirror structure is not designed to minimize the impact of a corrosive atmosphere as might be encountered with regional air poliution. Since the end use of today's mirrors is tied to the response of the human eye, visual color balance of the image is more important than absolute reflectance. For a solar application, the importance of these criteria would be interchanged.

Several key areas of the mirror system can be identified as requiring special attention if today's mirrors are to be adapted for exterior use in solar energy systems.

- Mirror edges - The edges represent the weakest region of the mirror against degradation. This is a result of potential exposure at the edges of both metal layers and the silver-glass interface to the exterior environment. The risk of edge degradation can be immediately reduced if all glass is cut to size before coating and painting. This would prevent the use of a mirror with a totally exposed edge. Other process changes could be made to insure cleaning and painting of the glass edges during production to reduce edge exposure. Another concept mentioned $(a)$

(a) Discussed by PPG and currentiy in use by at least one European mirror manufacturer. 
employed a silk-screened paint border on the rear surface of the glass before metal coating. The standard metal application did not alter this border and coated only the area inside the border. Subsequent painting then isolated the metal layers in a continuous envelope of paint and glass.

- Mirror mounting - The design of the mirror mount should prevent extended exposure to moisture. Graphic evidence of the importance of this practice was noted on 17-year-old mirrors exposed to a roof-top environment. Samples produced the same day were exposed in two different configurations. Some were vertically mounted with a 1/2-in. air space separating adjacent mirrors while others were stacked on top of each other. The vertical mirrors showed very little degradation while the horizontally stacked mirrors showed significant degradation with total loss of all coatings over a large fraction of the mirrors' area. While this experiment lacks sufficient documentation and control, the qualitative significance of the results should not be overlooked in the design of mirror mounts. Two approaches that would prevent extended exposure to moisture are breathing structures and completely sealed dry structures. A laminated mirror structure could provide such a dry seal system.

Care must also be taken with any mounting adhesives that are used to insure their compatibility with the mirror components. This includes chemical and dimensional (expansion and/or shrinkage) compatibility.

- Paint - The formulation of today's paint makes it relatively porous and leaves the mirror vulnerable to atmospheric moisture and pollutants. Potential solutions include the application of a second, nonporous paint layer over a totally cured commercial mirror. The curing would be required to allow the metallic layers and conventional paint to dry and prevent the entrapment of their drying products within the sealed mirror structure. This would be compatible with standard production techniques plus a subsequent run through a paint applicator.

It may also be possible to replace the conventional paint with a formulation that would allow the metal layers to cure before the paint 
sealed the structure completely. This might be accomplished with a low temperature drying cycle at the time of application and then a higher temperature cure before shipment and installation. Such a paint formulation would require development and testing and may not represent a short-term solution to the problem.

\section{Production Processes}

The evolution of mirror production techniques have been reviewed by Schweig (1973). He concluded that the generic chemical silvering solutions and reactions used today have been available since 1876. Significant advances have been made during that time in the solution constituents (variety and amount) to improve the film quality, deposition rates, and suitability for mass production. Early solutions required 2 to 5 min to deposit a silver layer and were suitable for batch production using stationary or rocking tables with the solution covering the glass. Spray application was introduced in the 1920s but slow deposition times still limited production. Fast silver deposition became available in 1940 when Peacock introduced reducing solutions based on hydrazine and its related salts. Further reducing solution improvements became available in the early 1960s when formaldehyde-dextrose solutions were patented. These solutions and a method for continuous processing had become almost universal for domestic mirror production by the early 1970s.

The copper deposition processes have experienced a more pronounced change. Galvanic deposition techniques were used until the 1950s with early applications requiring mirror dipping and later use allowing a conveyor belt motion. Patents filed in 1953 and 1954 introduced solutions for the spray application of copper employing copper sulphate solutions and metal1ic dust as a reducing agent. Variations on this generic approach are in common usage today using iron filings. These solutions are suitable for use on a continuous process production line.

Today the major chemical houses market competitive forms of both the silver and copper solutions. The products are used interchangeably by the

mirror firms. Purchases were based on cost and a desire to avoid a dependence on only one supplier. Differences in chemical performance and/or process reliability were not mentioned by the coaters. 
The following discussion will describe the sequence on a typical mirror production line. Details of the chemistry of solutions and actual deposition processes will be discussed in another chapter of this report.

Modern mirroring lines provide for continuous production and are based on a horizontal moving conveyor system using turning rollers. Individual glass sheets are fed into the front of the system and no further handling occurs until the finished mirrors are removed from the line output. A typical production sequence is shown schematically in Figure 1.4. Primary steps include:

- load glass,

- scrub surface,

- rinse,

- sensitize surface,

- rinse,

- apply silver,

- rinse,

- apply copper,

- rinse,

- blow dry surface,

- dry metal layer,

- apply paint,

- dry paint,

- flip mirror over,

- clean front surface,

- total rinse,

- two sided air dryer, and

- pack glass.

Although all manufacturers visited during this survey operated this generic sequence, there were notable differences in the production lines. Many of the differences were related to the age of equipment and the willingness demonstrated by the respective firms to upgrade their equipment.

The basic configuration and physical layout of the production line are determined at the time of the original equipment purchase. The design of the the line is generally a variation of a design recommended by the equipment 


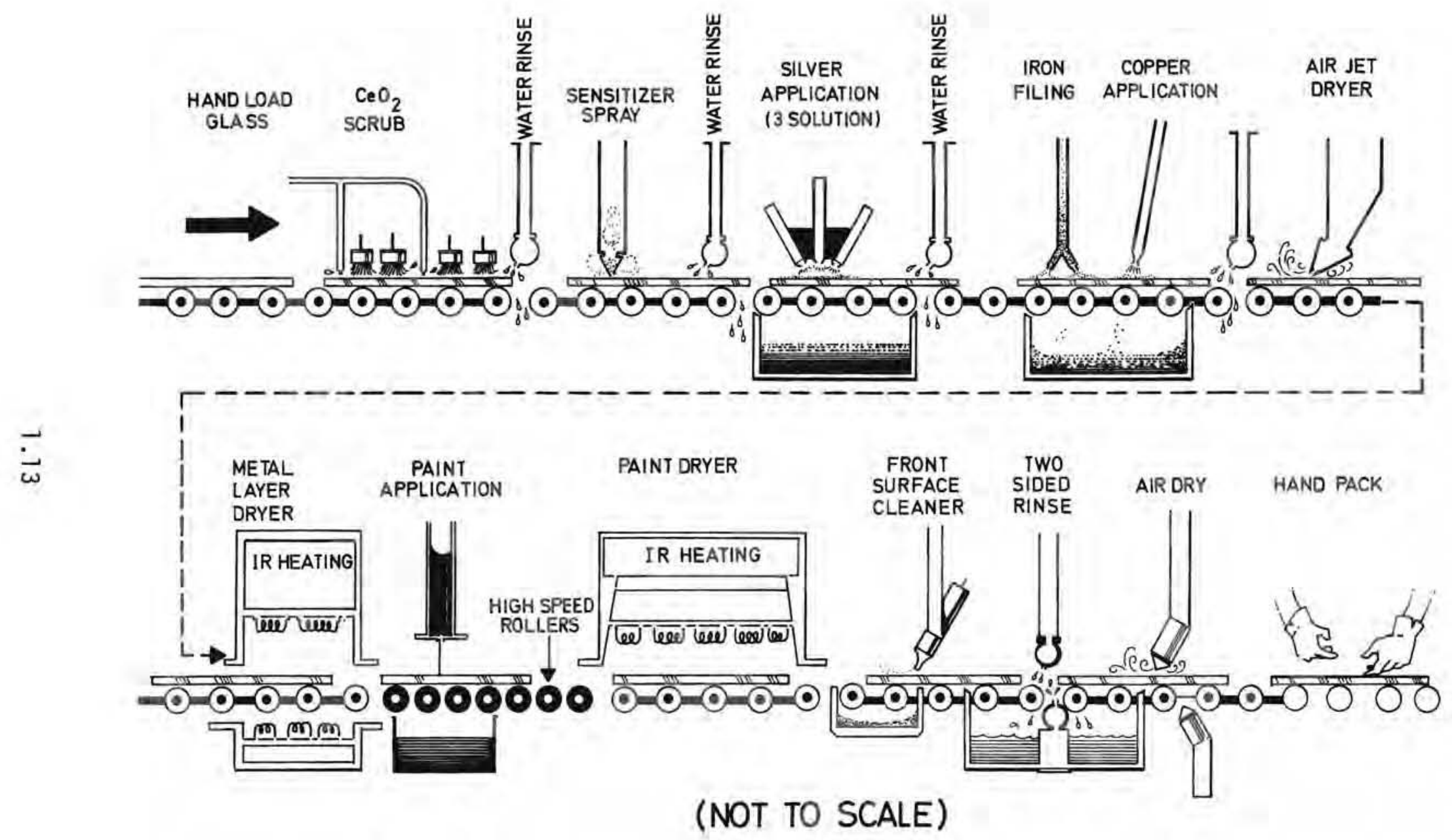

FIGURE 1.4. Wet Chemistry Mirror Production Sequence 
manufacturer and modified by the purchaser's technical and operating staff. A new line thus represents the current industry status as determined by the equipment supplier, yet the line will incorporate any advances or component preferences that the coaters have, based on their own experience. This mode of operation allows the equipment manufacturer to benefit from many of the advances being made by their customers without having to perform all the development effort. This gain is then passed along to the current generation of customers.

The conveyor system is the most stable part of a production line. Most firms visited had upgraded selected areas of their equipment (scrubbers, dryers, paint applicator, etc.) but had maintained the conveyer system essentially as purchased. This allowed the modular improvement of equipment with minimum downtime and no building changes required to house a larger system. Most conveyor systems observed were fabricated from power and idler rollers. Other systems use flat belts, waffle type belts, or cables covered with a resilient material that will survive the chemical environment and the production temperature sequence without degrading the mirror surface. Line widths ranged from $84 \mathrm{in.}(7 \mathrm{ft})$ to $130 \mathrm{in.}(10 \mathrm{ft}, 10 \mathrm{in}$.). Most conveyor systems were in excess of $100 \mathrm{ft}$ in length with the newer lines tending to be longer. The trend to longer lines allows improved line speed and product throughput. Common line speeds were in the range of $9 \pm 3 \mathrm{ft} / \mathrm{min}$. The size of sheets that could be easily handled ran up to 96 in. $x 208$ in.

The production sequence begins with the transfer of individual glass sheets from shipping cases to the conveyor line. Small to moderate stock is transferred to the line by hand with all personnel wearing gloves. Some firms had vacuum cup/mechanical handlers available for use with very large glass sheets. Care is taken to load float glass with its untinned (air) surface up to receive the mirror coatings. This is done because their production experience has shown a higher probability of good mirror quality when the untinned surface is coated. Incorrect loading is felt to increase the chances for poor visual performance and lower silver/glass adhesion.

It was also suggested that mirror quality could be improved by specifying that glass be paper-packed rather than powder-packed. These terms describe 
alternative techniques available to glass manufacturers to insure the separation of adjacent glass sheets during shipment and storage. Failure to provide this separation frequently can result in adjacent sheets bonding to each other and subsequent attempts to separate them will damage the glass surfaces. Powder-pack is the industry standard and is accomplished by spraying a light powder coating on the glass sheet just before it is taken from the production line for packaging. Some powders contain adipic acid to reduce glass staining during shipment. Preliminary evidence indicates that standard glass cleaning procedures are not totally effective in removing the adipic acid from the surface. Related studies are now under way to determine if residual adipic acid is a possible source of degradation in finished mirrors. An alternate packing method employs a sheet of paper between the surfaces of each adjacent glass sheet. This prevents bonding and does not require the use of adipic acid. This does require additional labor and material for packaging and thus will generally be at increased cost. Also, the use of low grade packing paper may introduce similar problems associated with the acidity of the paper which is left from the milling process.

The mirror coating procedure is a wet process from the initial glass cleaning until the deposition of the metal layers is completed. The top surface is not allowed to dry in an effort to minimize the detrimental effects that would result from the deposition of solution residues on the surface.

A typical glass scrubbing unit is shown in Figure 1.5. The scrubber employs an abrasive slurry applied to the glass by small-flow nozzles which move across the conveyor line transverse to the direction of glass motion. The transverse speed is coupled to the conveyor line speed to insure that the surface is adequately cleaned. Cerium oxide slurry is the most commonly used abrasive. Wetting agents are generally added to the slurry to improve cleaning. Surface abrasion was felt to be important and is accomplished by rotating brushes or pads that actually scrub the surface. The rotating brush assemblies oscillate back and forth across the glass to provide uniform cleaning. City water was used as the carrier for the abrasive slurry.

A related scrubbing mechanism is termed "blocking." This employs felt pads on heavy blocks that are moved back and forth across the glass surface. 


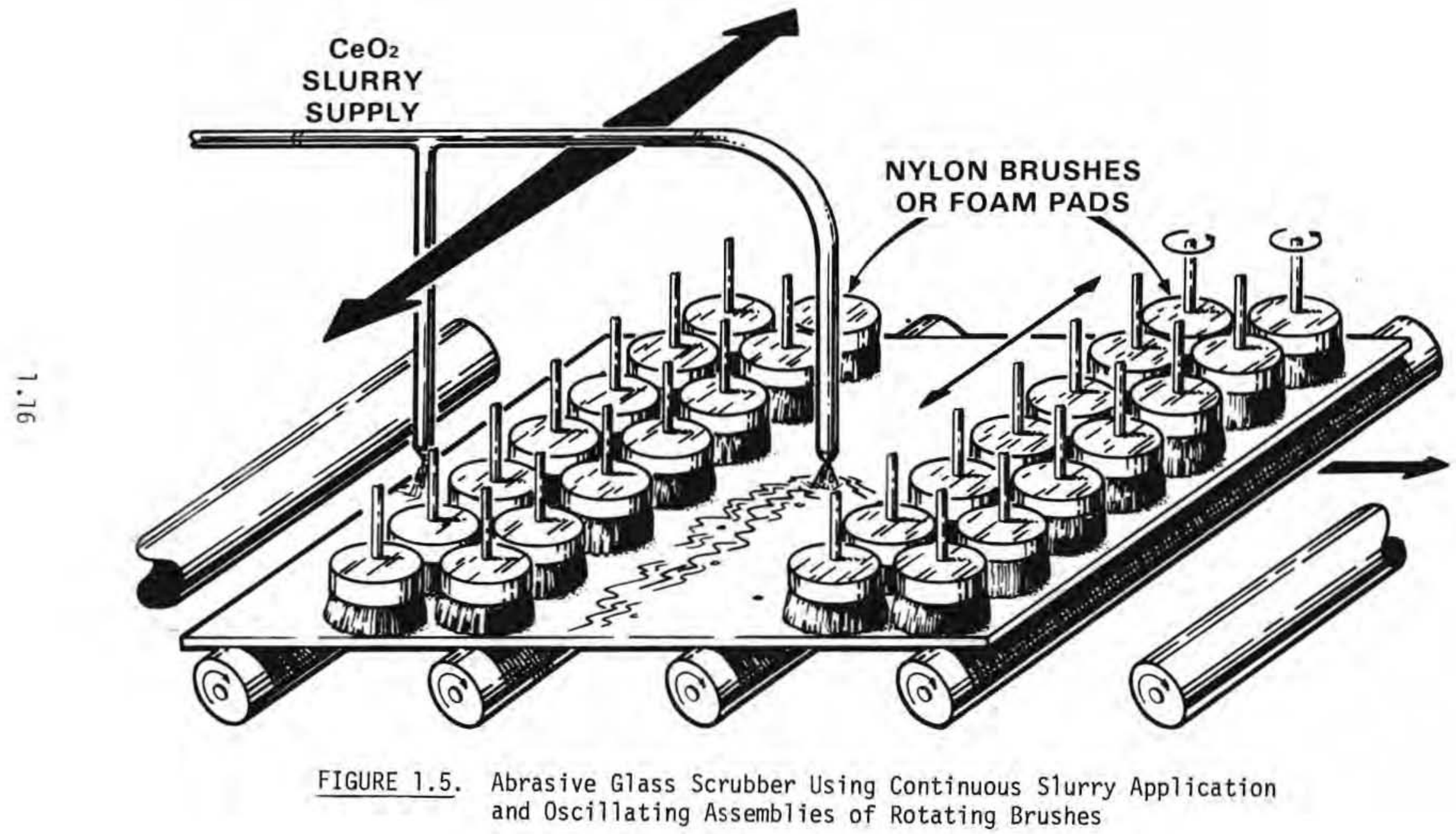


An abrasive slurry is used to enhance surface cleaning. Blocking has gone from the most common cleaning system to relatively small usage due to damage to the glass surface from contaminants that became embedded in the felt pad. Blocking is being re-examined with new slurries to see if it can reduce problems associated with incomplete surface scrubbing.

The slurry residue was then rinsed from the surface using water nozzles directed against the direction of glass motion (Figure 1.6). This moves the residue toward the trailing edge of the glass where it finally drops into a recovery tray under the conveyor rollers. Incomplete removal of the cerium oxide slurry will generally result in a milky appearance of the deposited silver layer. This rinse water was deionized to prevent contamination of subsequent coating solutions and reduce the chances of staining or clouding of the metal layers. The use of deionized water was continued from this step through the deposition of the copper layer. Significant differences were noted in the minimum resistivity values accepted by the different companies for their deionized water. The lowest value cited was $0.5 \mathrm{M} \Omega-\mathrm{cm}$, while others were an order of magnitude larger.

The glass surface is then sprayed with a sensitizing solution which serves to hasten the silver deposition rate and improve the silver/glass adhesion. The use of stannous chloride $\left(\mathrm{SnCl}_{2}\right)$ was first introduced in 1876, and it is still the most common sensitizer used for domestic mirror production, although palladium chloride is occasionally used instead. The sensitizer solution is sprayed onto the glass by a moving nozzle that oscillates back and forth across the conveyor line (similar to that used for $\mathrm{Ce}_{2}$ as seen in Figure 1.5). The role of the sensitizer is not completely understood. It is felt that the resulting tin sites serve as nucleation centers for the silver layer deposition process. The chemical state of the tin atoms must also be important as this is the same element that is intentionally avoided by coating only the "untinned" side of float glass.

The sensitizer solution is then thoroughly rinsed from the surface using deionized water and a spray bar. Poor rinsing will cause a poor quality mirror. 


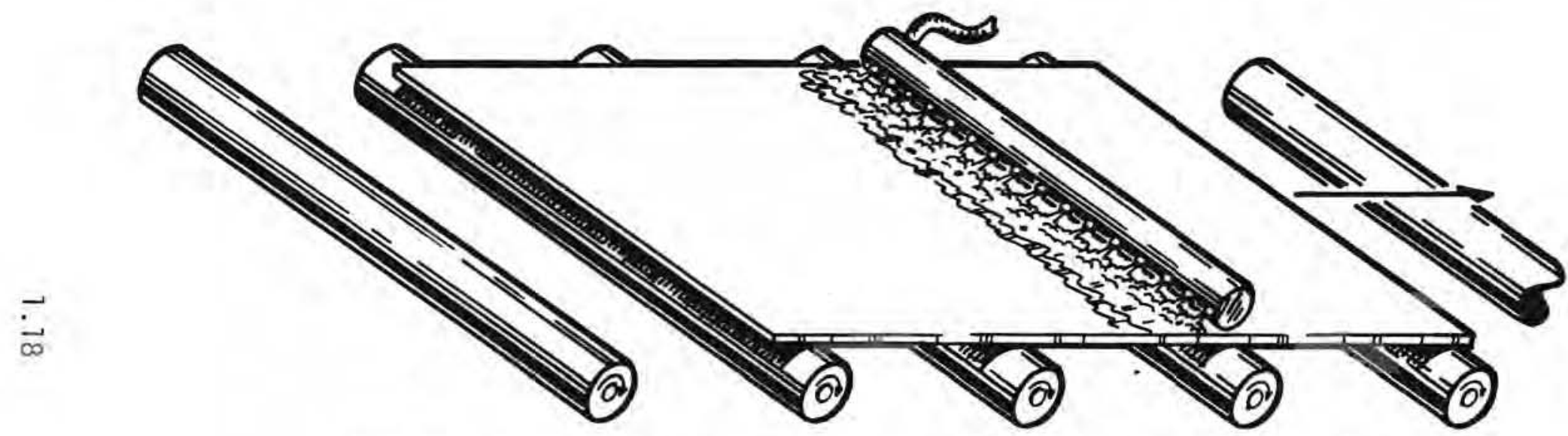

FIGURE 1.6. Water Rinse Mechanism using Directed Water Spray to Rinse Process Residuals off the Rear Edge of the Glass 
A light water spray is applied to the glass to provide a moisture layer and facilitate the spread of the forthcoming silver solutions in a uniform layer on the glass.

The silvering chemicals are then sprayed on the sensitized glass. The commonly used chemical systems consist of three distinct solutions (silver, caustic, and reducer). The chemical reaction that results in the precipitation of a silver layer begins when the three solutions are mixed. This reaction is localized to the glass surface by using a spray applicator that simultaneously sprays the solutions at a common target point on the surface (Figure 1.7). Mixture and initiation of the reaction therefore only occurs on the surface of the glass. All manufacturers used multiple sets of spray nozzles spaced along the direction of glass travel to renew the chemical solution periodically and produce a thicker silver layer. The transverse spray assembly speed, conveyor speed, and nozzle spacings were selected to insure that each region of the mirror was multiply sprayed (generally 6 to 12 times) to provide the required film thickness and uniformity. This coverage was generally obtained with 4 or 5 sets of spray nozzles and a transverse nozzle speed that allow 212 strokes/min across the mirror line.

The most commonly used silvering chemical system utilizes formaldehyde and dextrose solutions as two of the separate component solutions. This system was commercially developed in the late 1960s and achieved general acceptance by the early 1970s. It has the advantages of being a fast chemical reaction (suitable for fast production rates) and being a highly efficient reaction for silver transfer from the solution to the glass. It is estimated that $85-90 \%$ of the silver sprayed onto the glass deposits into the reflective layer. The process is also felt to provide improved silver/glass adhesion. The chemical suppliers market the three component solutions in chemical concentrations that require their 1:1:1 mixture on the glass. This is accomplished reliably by using metered pumping systems for each solution to reduce product variability and simplify the required production adjustments. The metered pumping systems provide an airless spray that reduces problems of overspray and chemical cross-talk from step to step. Production quality metered pumping systems can be purchased from at least one of the chemical suppiy houses. 

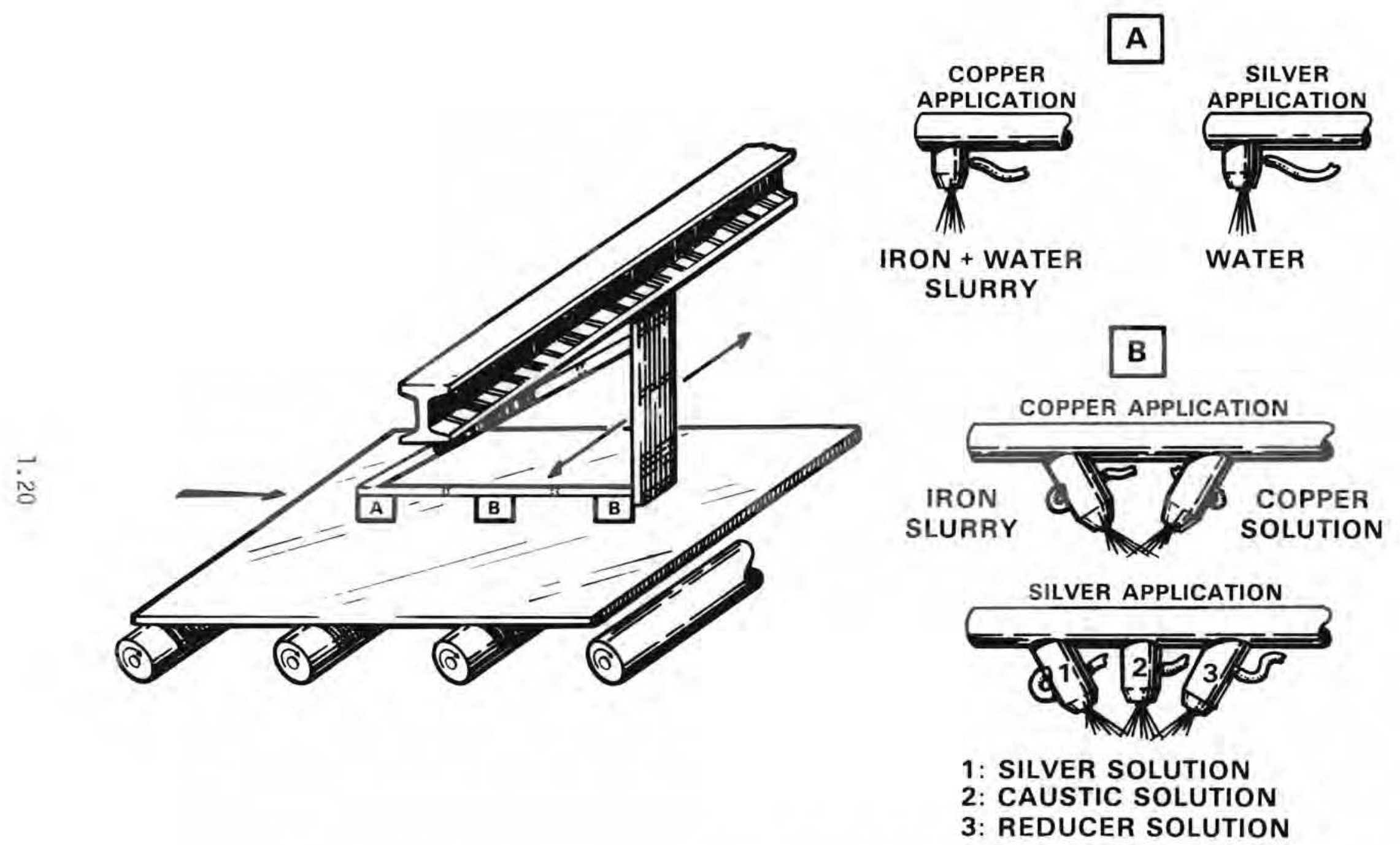

FIGURE 1.7. Reciprocating Spray Chemical Applicator for Wet Chemistry Mirroring Solutions. Specific nozzle arrangements are shown for a galvanic copper and a three-part silver process. 
The silvering solutions are thoroughly rinsed from the glass to terminate the silver reaction and to prevent the entry of residual silver solutions into the copper deposition portion of the line. Such chemical cross-talk or contamination is expected to degrade the quality of the copper layer.

Copper deposition occurs next and commonly uses an iron filing/water slurry and a copper solution. The precipitation reaction begins as soon as the two solutions are mixed. The solutions are sprayed from an oscillating transverse nozzle system (Figure 1.7). The surface is first sprayed with the iron slurry to allow it to spread across the silver layer before the copper is introduced. The copper solution is then sprayed simultaneously with another iron filing slurry. All manufacturers used multiple sets of double nozzles to reach the desired copper thickness and film uniformity. An air sprayer is typically used for chemical application. An alternate chemical system is now available for copper deposition that does not employ an iron filing slurry. It has the potential advantage of reducing any copper layer defects that may be caused by the granular nature of the iron filings in the conventional process. This uses a metered pumping two-component application and airless spraying. The copper solutions are then completely rinsed from the glass with deionized water using a spray bar.

The deposition of the metal layers is now complete and the procedure ceases to be a water-based process. An air knife (Figure 1.8) is employed to remove water from the coated surface of the glass before attempts are made to drive residual water from the metal layers. Visual inspection of the surface after the air jet dryer revealed no evidence of standing water or stray droplets on the copper.

The mirror is then heated with infrared radiation from the uncoated glass side to partially cure the metal layers by driving residual water from them. Heating from the glass side raises the temperature of the entire mirror structure. Heating from the coated side would not effectively heat the substrate due to the reflective nature of the metal layers. This would tend to create significant thermal gradients within the mirror structure which could degrade the final adhesion behavior of the metal layers. Heating from the glass side also tends to drive the moisture away from the silver/glass interface rather 


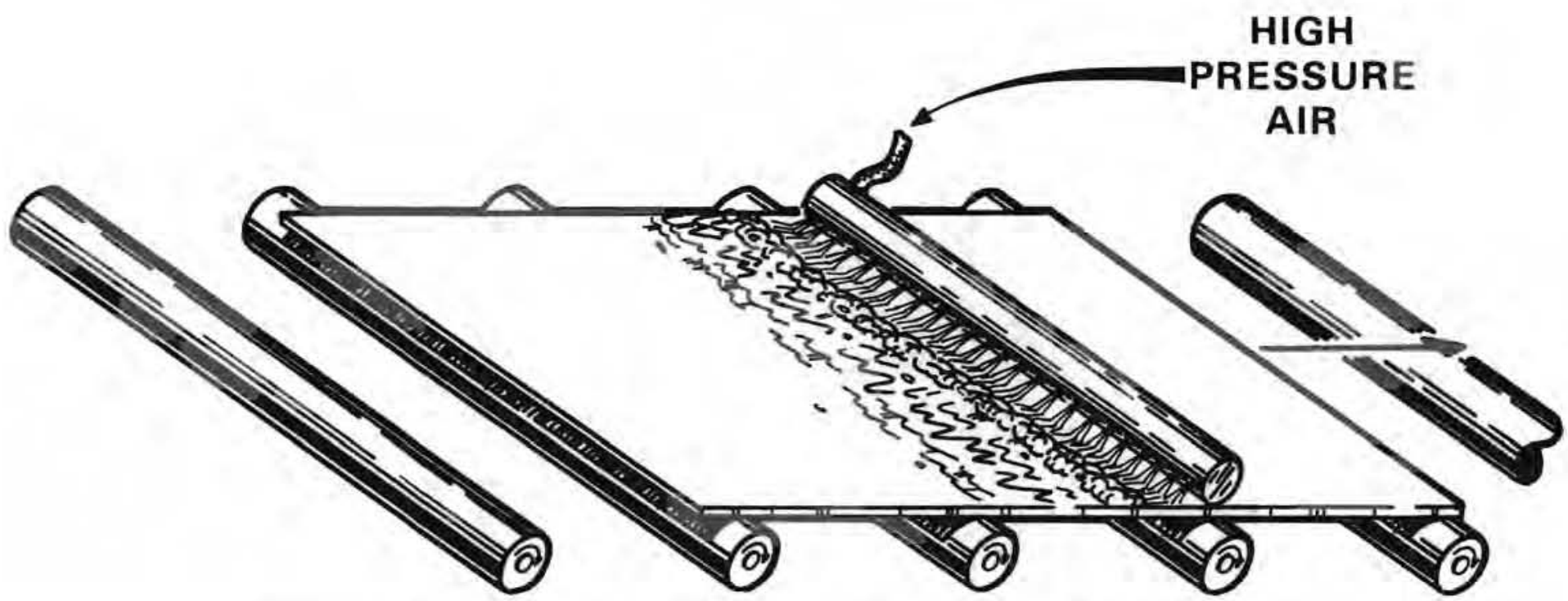

FIGURE 1.8. Air Jet Drying Station Using Directed Air Flow to Force Process Residuals off the Back Edge of the Moving Glass Sheet 
than toward it. The metal layer drying also reduces the chance of problems that could occur with the application of an oil based paint on a wet surface. Dryers were seen that employed either resisitively heated radiant ceramic cups or quartz tube heaters. The differences in these devices impact operating costs, dryer box sizes, and maintenance requirements. No evidence was given to indicate preference for either type based on the curing mechanism as long as they raised the mirror temperature to the same level. Some manufacturers have suggested that optimal metal curing will occur when the layers are near $212^{\circ} \mathrm{F}$. This is significantly higher than the typical values of $110-150^{\circ} \mathrm{F}$ used in the industry today. The actual temperatures used must also be low enough to allow good paint adhesion in the next process step.

One paint application method predominately used for the production of quality domestic mirrors is the "curtain coater". It is seen in a crosssection view in Figure 1.9a. A thin curtain of paint is created that flows continuously from the adjustable knife edge drain in the upper reservoir. As the mirror passes through the curtain a very uniform paint layer is deposited. Roll coaters (Figure 1.9b) are still used for some applications but are not preferred on the basis of product quality. The roll coater transfers paint from a reservoir to the mirror with a series of roller-to-roller exchanges. This is similar to the ink transfer mechanisms used on many printing presses. Roll coated mirrors tend to exhibit fairly nonuniform paint layers with corrugations seen in the paint that are reminiscent of the texture left by a household paint roller. Typical roll-coated paint exhibits a $50 \%$ thickness variation associated with the corrugated pattern.

Curtain coater operation is further illustrated in Figure 1.10. Paint is pumped into the upper reservoir. The curtain then results from the gravitational feed of paint through the adjustable knife edge drain which allows the adjustment of both curtain uniformity across the line and the nominal curtain thickness. This type of feed system requires reasonable control on the paint viscosity and its particulate content. Most firms were filtering the paint supplied to the upper reservoir. A fixed wire is mounted at each end of the knife edge drain to serve as a guide for the end of the curtain. This prevents the breakup of the curtain ends that would normally occur. The 
(A) CURTAIN COATER

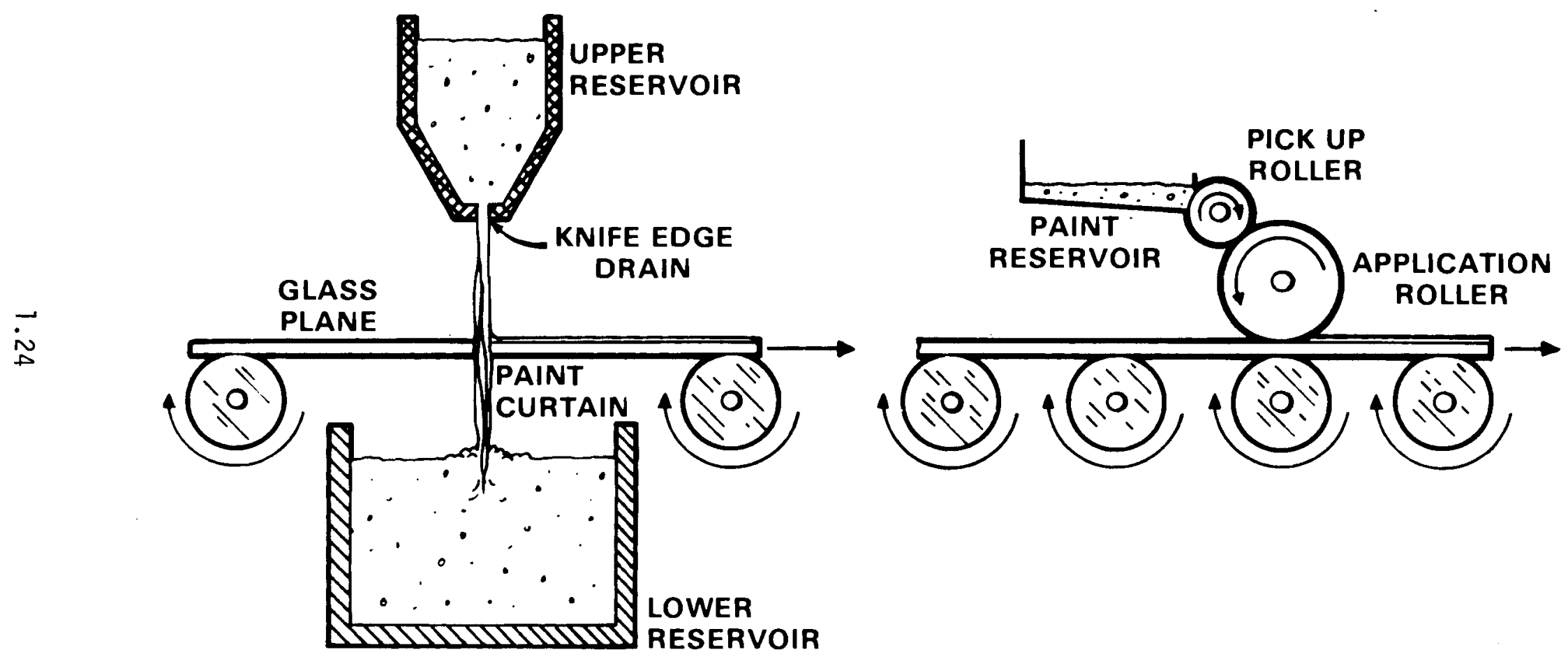

FIGURE 1.9. Cross Section View of Paint Applicators 
(A) CURTAIN COATER BETWEEN APPLICATIONS PAINT RESERVOIR WITH

\section{BETWEEN APPLICATIONS}

FROM RECIRCULATION SYSTEM O PAINT RECOVERY TRAY

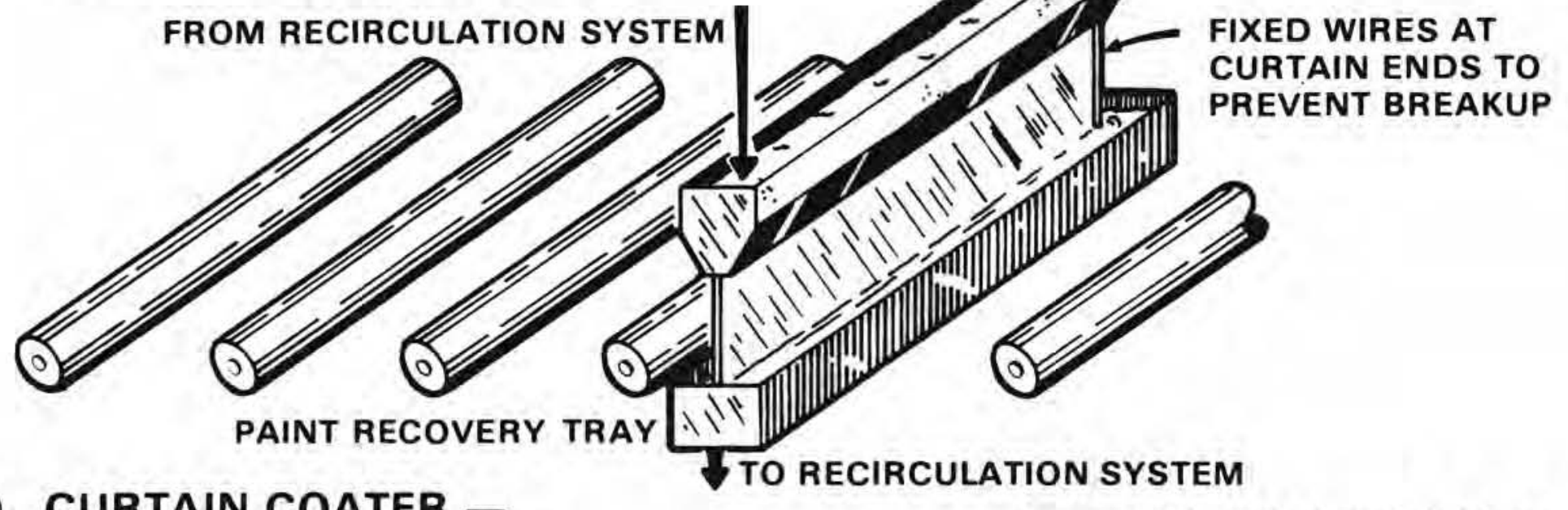
(B) CURTAIN COATER -
DURING APPLICATION FROM RECIRCULATION SYSTEM

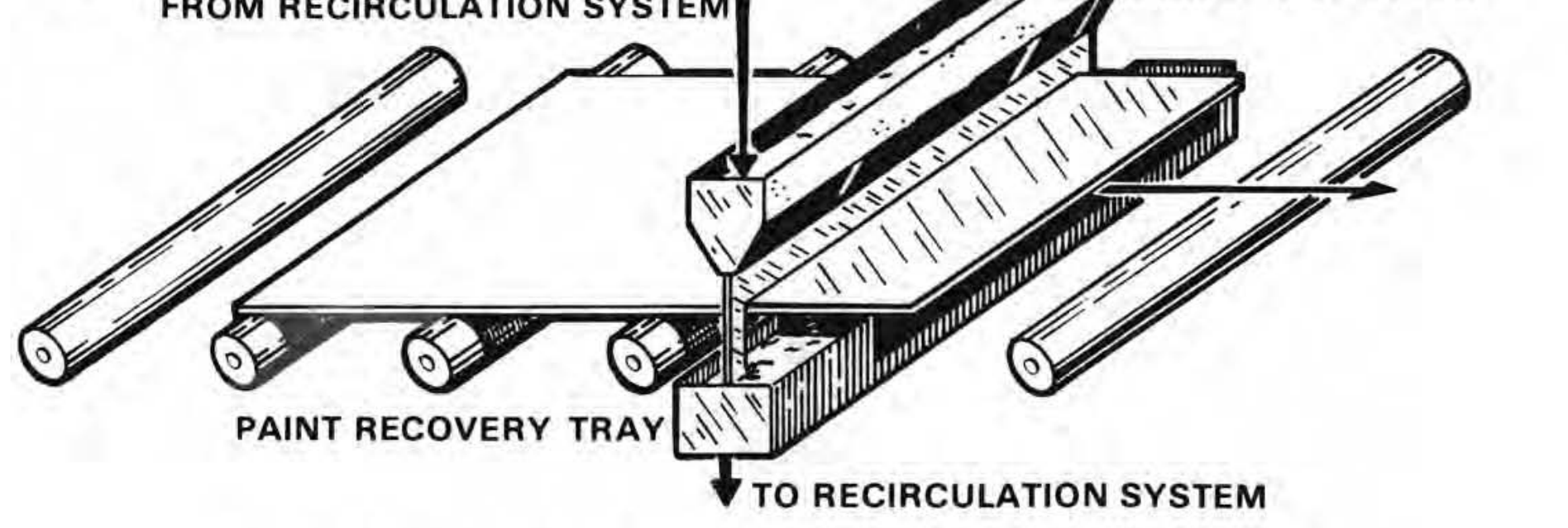

FIGURE 1.10. Curtain Coater Operation a) Between Applications, and b) During Application 
edge wires extend into the lower paint recovery tray. The paint from the recovery tray is filtered and pumped back to the upper reservoir. Between mirror sheets the paint simply circulates through the system. When a mirror passes through the coater, most of the paint is intercepted by the mirror. This requires an automatic fill system for the reservoir in the standard production process.

Practical implementation of a curtain coater also requires the use of a variable speed section in the glass conveyor system to achieve paint layer thicknesses desired. This is required because the standard line speed would produce very thick paint films for easily controlled paint flow rates. The compromise solution uses practical paint flow rates and accelerated mirror transfer through the curtain coater. This is illustrated in Figure 1.11. The variable speed rollers are accelerated when a preselected light beam is broken by the mirror's presence. The section continues at high speed long enough for the mirror to clear the paint curtain. The roller section then slows down to transfer out the painted mirror and to load the next mirror. The photo-detector location and high speed operating time are selected on the basis of the mirror size being coated during a given production run. Typical speed changes required are from 6 to $8 \mathrm{ft} / \mathrm{min}$ on most of the 1 ine to $180 \mathrm{ft} / \mathrm{min}$ through the curtain coater.

The alternate paint application techniques not only affect the layer quality, but also the painting costs. Spray painting (an early technique) required the use of $\sim 10 \mathrm{~g} / \mathrm{sq} \mathrm{ft}$ and additional paint was lost due to overspray problems. Roll coating generally is done at $\sim 11 \mathrm{~g} / \mathrm{sq} \mathrm{ft}$ to insure that even the thin regions provide good mirror protection. But the curtain coater can provide good mirror protection at $\sim 8 \mathrm{~g} / \mathrm{sq} \mathrm{ft}$ due to its excellent uniformity. The net effect of these differences in required thicknesses and paint wastage represent a significant difference in painting costs. Estimated costs per square ft (1976) were roughly $\$ 0.012, \$ 0.015$, and $\$ 0.024$ for roll coating, curtain coating, and spraying, respectively.

The mirror then passes through a vent hood that employs a circulating air sweep across the mirror to remove solvents from the paint before entering the paint dryer. The mirror temperature (residual from the metal dryer) and 
a) ALL ROLLERS ARE SLOW DURING LOADING

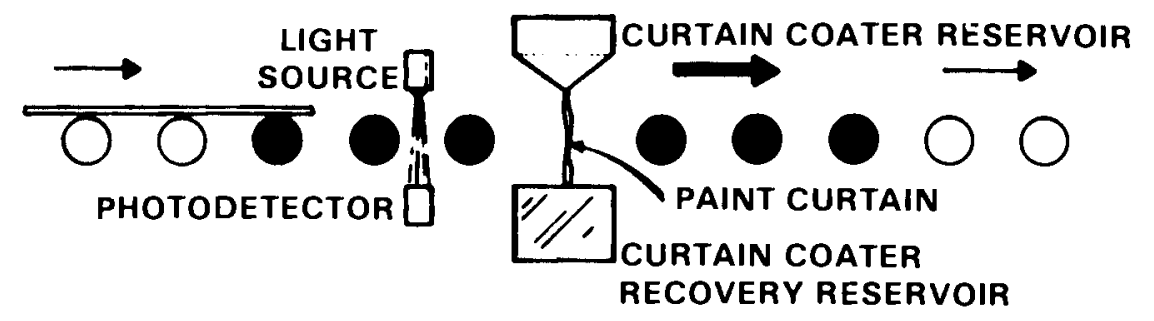

b) MIRROR BREAKS LIGHT BEAM, HIGH SPEED ROLLERS ACCELERATE

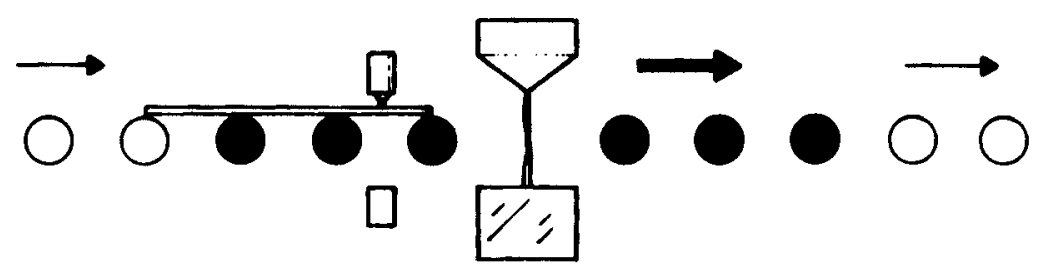

c) HIGH SPEED ROLLERS MOVE MIRROR QUICKLY THROUGH PAINT CURTAIN

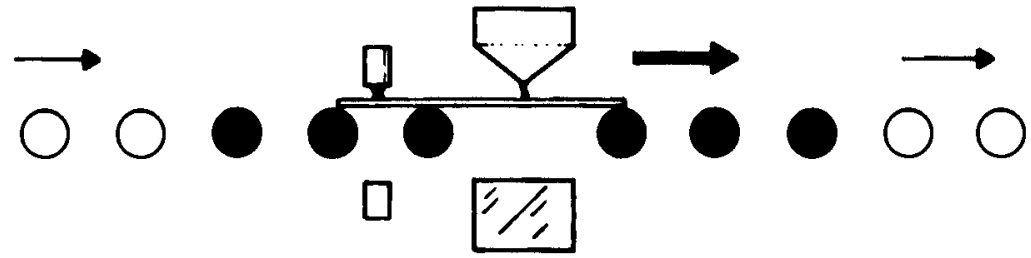

d) HIGH SPEED ROLLERS DECELERATE AFTER PRESET TIME

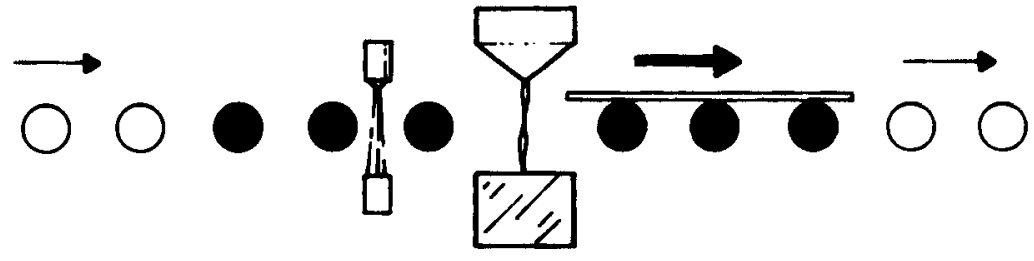

e) ALL ROLLERS ARE SLOW DURING UNLOADING

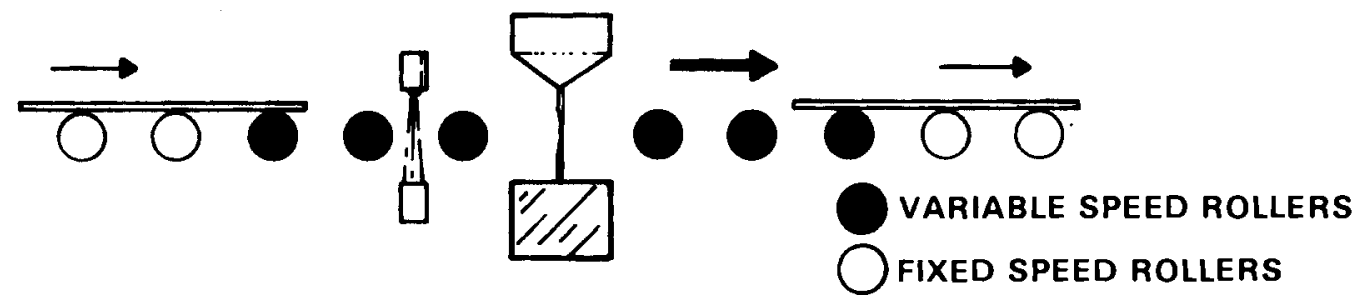

FIGURE 1.11. Production Sequence for Variable Speed Roller Section Associated with Curtain Coater Operation 
the forced air flow remove the bulk of the solvent. The use of preheated and ambient airflow for this flash-off process were observed. The fumes were exhausted from the production area.

The painted mirrors then pass through an infrared dryer to dry the paint to allow handling, packing, and storage. Typical baking times are several minutes and temperatures employed are near $250^{\circ} \mathrm{F}$. This is not intended to fully cure the paint. The ideal drying temperatures depend on the paint formulation, and the paint manufacturers' recommendations should be heeded to provide optimum product quality. However, practical temperatures may be governed by the production line's capability to cool the finished mirror for final packing without themally inducing breakage. Figure 1.12 shows the comparison between the typical production temperature profile and one designed for the suppliers' recommendations.

The mirror then rolls across several rollers that carry a chemical solution to the uncoated glass surface, which removes any metal deposited by overspray. A variety of solutions are used but they fall into the generic category of aluminum desmutters.

Top and bottom surfaces of the mirror are then cleaned before removal from the conveyor. Rotating cylindrical brushes may be used to scrub the glass surface with the weight of the mirror holding the glass on the brush. Another approach employs a water spray. Both surfaces are then dried with air knife blowers.

Most manufacturers then roll-stamp the back of the mirror with their name and the production date to allow product identification.

On-line product $Q A$ was limited to visual inspections for pinholes and blemishes. Mirrors were mechanically turned over before attempting front surface inspection. Some firms employed front- and backlighting with an observation point over the moving mirror. Others simply used overhead lights and observation from the perimeter of the production conveyor.

Removal from the conveyor system is done by hand for small and moderately sized mirrors. Mechanical handlers are available at some firms for use with large mirrors. Mirrors are repacked in the original glass shipping crates. 


\section{TYPICAL PRODUCTION LINE TEMPERATURE PROFILE}

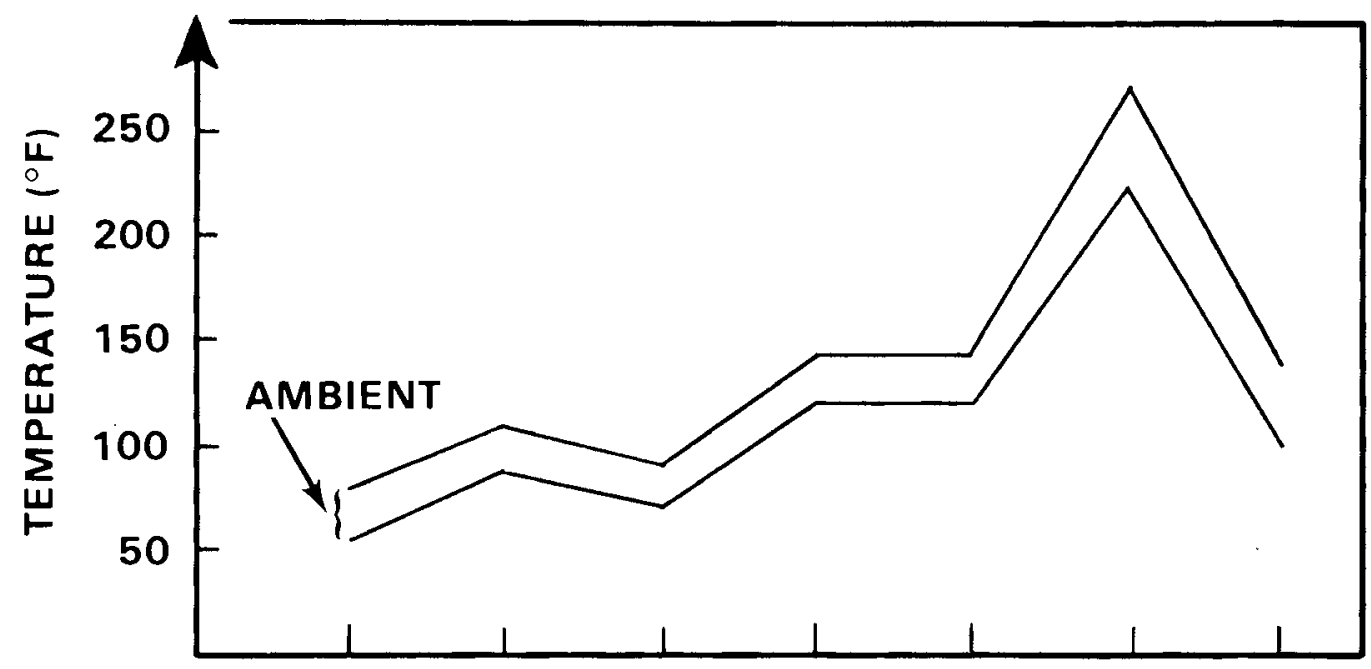

PREFERRED PRODUCTION LINE TEMPERATURE PROFILE

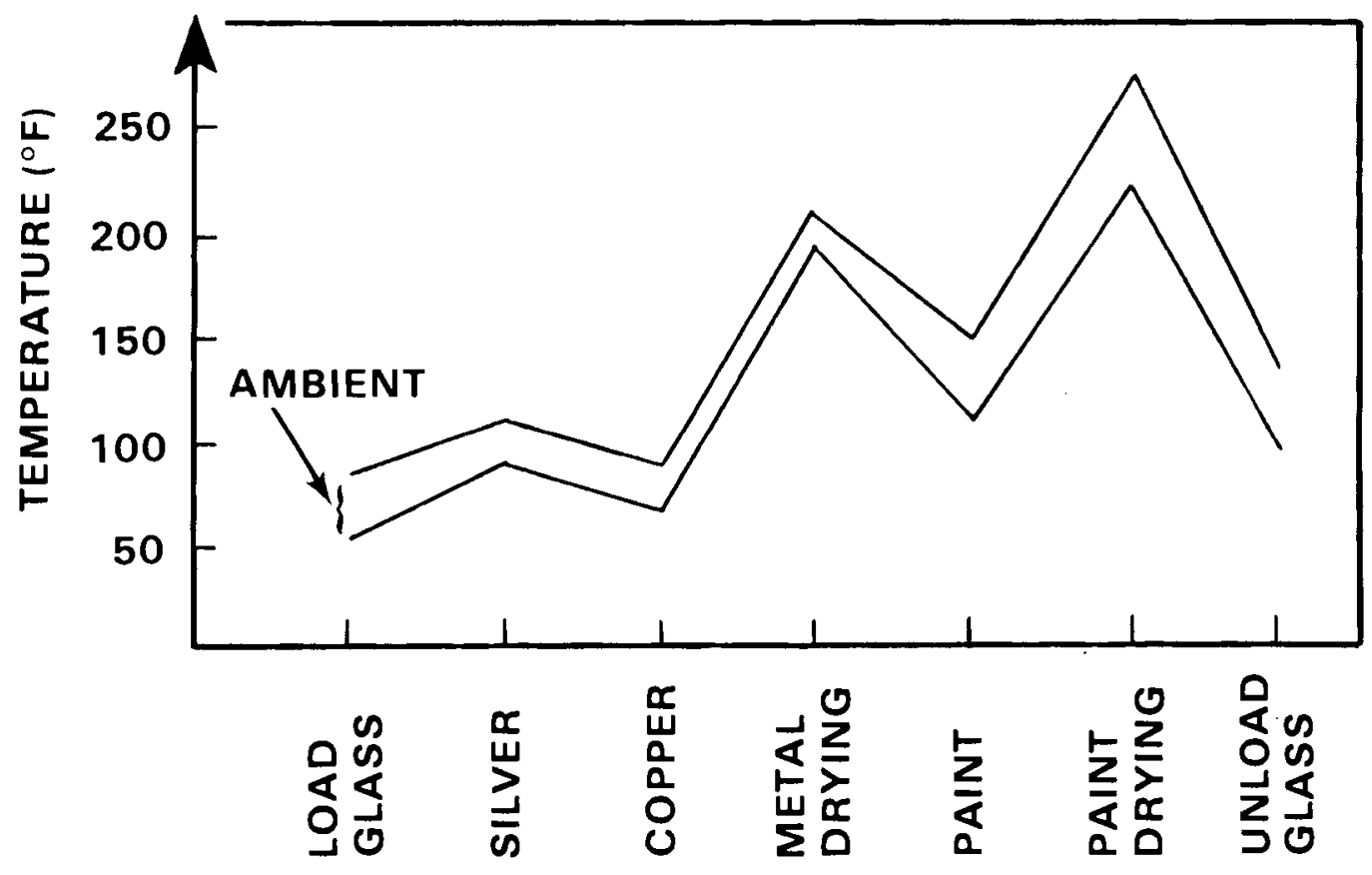

FIGURE 1.12. Production Line Temperature Profiles 
Small felt pads were applied to the front surface of the mirrors to prevent damage to the finished product during shipment.

The operating speed for the integrated production line should then be selected to maximize the output volume while maintaining the product quality. The speed may be limited by:

- deposition times required for silver or copper,

- desired glass temperature profile along the line,

- power rating of IR dryers,

- component spacing,

- heat capacity of the glass substrate (proportional to thickness), or

- glass handling rates for loading and unloading.

Several examples of these limitations should clarify the possible interactions. The use of thicker glass substrates will require the use of slower line speeds. The increased heat capacity of the glass will require longer times to heat and cool during the processing. The speed must therefore be reduced to maintain the same temperature profile along the line. Component spacing and required process times (e.g., silver spray-rinse separation and silver deposition time) may impose a maximum line speed compatible with maintaining product quality. Typical production line speeds varied from 7 to $12 \mathrm{ft} / \mathrm{min}$ for the different firms. The potential of reaching $18 \mathrm{ft} / \mathrm{min}$ with an optimized line configuration was mentioned.

\section{ALTERNATIVE REFLECTIVE LAYER DEPOSITION TECHNOLOGIES}

A preliminary survey of alternate coating technologies has been initiated to determine if potential process advantages exist for long-term applications. Candidate technologies include the vacuum deposition of films on large sheet mirrors, the deposition of films on continuous roll substrates, and the deposition of long-lived first surface mirrors. This preliminary examination did not stress the capacity of the industry today (yearly volume or sample size range) but was centered on the potential advantages of the different coating approaches. Projections of coating capacity and high volume production costs were pursued. Additional inquiries will be required to complete this preliminary industry examination. 


\section{Large Sheet Coating Processes}

Electron beam and sputtering deposition processes have been adapted for coating large sheet samples of architectural glass. Both processes have now demonstrated satisfactory performance in a high volume production environment using glass sheet substrates in excess of $6-1 / 2 \mathrm{ft} \times 10 \mathrm{ft}$.

The architectural glass products produced at this time are typically coated with metallic and/or dielectric layers that provide a tailored reflectivity response for the product. Coatings are designed to provide either a flat response across the visible spectrum (similar to silver or aluminum) or a spectrally weighted response that changes the color balance of the reflected image (typically similar to copper, gold, bronze, etc.). The coated glass is commonly fabricated into double sheet, thermally insulating window assemblies. The coated surface is placed in the central air space which provides a controlled environment for the lifetime of the window sealer. The air space is sealed at the time of manufacture and includes a small quantity of desiccant to control internal condensation problems that could occur with changing ambient temperatures. The interior location of the film also prevents surface abrasion of the coating by either natural causes or cleaning procedures. Film life is warranted for up to 10 years in this type of application.

Architectural glass products that exhibit a wide range of visible wavelength transmittance ( $\sim 7$ to $35 \%$ ) are commercially available. The reflective coatings reduce the heat transfer (IR spectrum) through the windows and are also used to create architectural design effects. It is estimated that the annual domestic architectural glass market is 30 million square ft $( \pm 10 \mathrm{million}$ square $\mathrm{ft}$ ). Demand has apparently been boosted by the recent escalation of energy costs as these reflective windows reduce energy losses associated with conventional windows and still maintain an open appearance from the room interior. Production also has been stimulated recently by the demand for automotive sun-roof panels. This preliminary survey did not determine if these deposition techniques are in standard use for large mirror production. 
Both the electron beam and sputtering techniques offer potentially significant advantages over wet chemistry processes if today's second surface silvered mirrors cannot be successfully tailored to the exterior environment. These advantages are also important for the possible preparation of first surface mirrors. The advantages, which are primarily in the areas of coating flexibility and process control, include:

- Multitude of potential coating materials - Both processes can easily be extended to a broad range of materials by changing the targets and/or the species of background gas in the chamber. This flexibility includes both metallic layers and dielectric films. The use of alloy targets would also allow the deposition of many alloy films that might provide advantageous optical performance and/or improved lifetime. Magnetic target materials (iron and nickel) cannot be used with the present sputtering system.

- Capability to deposit dielectric films - Both processes can be used to deposit dielectric films. This may be necessary if interference type, multilayer films or first surface mirrors are required to provide the desired optical and lifetime performance. Electron beam systems can use dielectric targets directly for the required film deposition. The present sputtering systems require that metallic targets and a reactive background gas be used for the deposition of dielectric films. The use of dielectric sputtering targets would require the adaptation of $r f$ sputtering techniques for these large scale systems. Both coating systems are providing a variety of reliable dielectric films on a routine basis for the architectural glass market.

- Coating structure flexibility - Both systems offer the flexibility to coat multilayer film structures if they are shown to provide significant advantages in performance. The layers can be either metallic or dielectric. The alternate layers must be chemically compatible, but this requirement is not as strict as in the wet chemistry processes, where the layers also must be compatible with the subsequent deposition solutions. 
- Coating process control - Both processes provide very reproducible film deposition using easily measured and controlled deposition parameters (fill gas partial pressure, power applied to the target, substrate speed, target material, etc.). Metallic layers for partially transmitting architectural glass are easily controlled to yield transmission fluctuations of less than $\pm 1 \%$.

- Accurate process automation - The deposition of films by both systems can be monitored on a real-time basis using either optical or crystal monitors. This can be combined with the electrical process control units to allow the automation of the deposition process control. The production of good films with these vacuum deposition techniques is therefore less dependent on the availability of skilled craftsmen to run the process than today's wet chemistry mirror industry.

- Control of film properties - The accurate control of the deposition parameters will yield fairly constant film properties including film morphology. Further, the adjustment of selected parameters (substrate temperature, deposition rate, etc.) may allow desired changes in the film's properties. The range of acceptable process changes will be 1 imited by the need for high production rates and the existing process line configuration.

These potential advantages are countered at the present time by production costs that are greater than for the wet chemistry products. Estimated production costs for these vacuum deposition processes are 3-4 times that of the uncoated glass. These costs must be referenced to the comparable costs for wet chemistry mirrors, which are $11.6-2$ times the glass substrate costs. The vacuum coated mirrors are thus expected to cost about twice that of the wet chemistry mirrors.

The two coating facilities visited exhibit some significant similarities. These arise primarily from their use of a common glass stock (commercial float) and the use of sequential reduction (increase) in chamber pressure as the glass moves toward (away) from the actual coating chamber. 
Both firms use float glass as the substrate material. Coatings are deposited on the untinned side of the glass as this is felt to statistically improve the product performance. Both processes can produce acceptable coating on the tinned surface, but this practice is felt to cause an increase in random defects due to surface contaminants pulled from the tin bath. No specific problems were identified with the use of a "clean" tinned surface on the glass.

Each manufacturer employs a similar wash cycle prior to inserting the glass into the vacuum chamber. The scrub cycle utilizes nylon brushes with warm water and a detergent. The wash cycle differs from the wet chemistry sequence in that no abrasive slurrys are being used at this time. The surface is then rinsed with tap water, thoroughly rinsed with deionized water, and dried using a high pressure air knife to remove the residual water from the surface.

Similar evacuation sequences are also employed on both systems. Multiple vacuum chambers are connected sequentially with automatically operated vacuum doors between adjacent chambers. Each system employs two buffer chambers on both the input and output end of the line for sequencing to and from atmospheric pressure. The end chambers have an ultimate pressure of 100 microns ( +50 microns). The second chamber on each end serves as a buffer chamber for the loading and unloading of the central coating chamber. Pressures are further reduced in this chamber before the glass is transferred to or from the coating chamber. The actual pressures employed in the buffer chamber and coating chamber are governed by the optimum pressure conditions for sputter and e-beam deposition ( $\sim 3$ microns and $\sim 0.005$ microns, respectively). This sequential pumping approach optimizes the process throughput and allows each chamber segment to be pumped efficiently with a single type of pump. The exterior chambers are rough pumped while the four interior chambers employ large diffusion pumps. The sequence approach also prevents the atmospheric contamination of the central coating chamber during the standard production sequence. The coating chambers are opened to the atmosphere only for target replacement or system repairs. 
Electron beam system. The Libbey-Owens-Ford facility in Toledo, Ohio utilizes e-beam sources for film deposition. The system was designed and built by Airco-Temescal and began production in 1965. The system has been previously described by Grubb (1969 and 1970). The glass is moved through the system in a vertical orientation by suspending the sheets from individual monorail cars. Production rates are doubled by the simultaneous processing of two glass sheets that are moved through the system in a back-to-back configuration. Identical coating stations are employed on both sides of the coating chamber.

The vacuum system consists of six discrete chambers with automatic glass transfer and pumping sequences between each. The chambers are listed in Table 1.3 with their functions and pressure ranges. Pumping speeds allow chambers 1 and 6 to cycle in 100 seconds.

\section{TABLE 1.3. LOF Vacuum Sequence}

\begin{tabular}{|c|c|c|}
\hline $\begin{array}{l}\text { Chamber } \\
\text { Number }\end{array}$ & Function & Pressure Range \\
\hline 1 & Preliminary pump down & $1 \mathrm{~atm} . \rightarrow 0.05$ torr \\
\hline 2 & Glow discharge cleaning & $0.050 \rightarrow 0.015$ torr \\
\hline 3 & Substrate heating ${ }^{(a)}$ & $0.015 \rightarrow 5 \times 10^{-6}$ torr \\
\hline 4 & Deposition of films & 3 to $5 \times 10^{-6}$ torr \\
\hline 5 & Vacuum buffer & $5 \times 10^{-6}+0.05$ torr \\
\hline 6 & Vent to atmosphere & 0.05 torr $+1 \mathrm{~atm}$. \\
\hline
\end{tabular}

(a) If required for coating, temperatures up to $500^{\circ} \mathrm{F}$.

Chamber 4 contains the electron gun coating sources. Each side of the chamber contains three vertical stacks of four targets. The three distinct stacks allow the sequential coating of up to three distinct thin films. At 
the standard coating pressures, the mean free path of particles leaving each source is roughly $60 \mathrm{in}$. The source-to-substrate distance is thus set at v60 in. to minimize film nonuniformity associated with geometrical effects.

The configuration of the four sources within each stack provides coverage of the full vertical extent of the maximum substrate size. Layer uniformity is improved by the insertion of masks between the sources and the substrate which are specially prepared to balance the coating thickness. Typical production layer uniformity is sufficient to maintain changes in transmittance or reflectance of less than $\pm 1 \%$.

The vertical orientation of the glass substrates creates a unique requirement. The source must be vertically mounted so that the ejected material is projected horizontally toward the glass substrate. This has been accomplished using three electron guns per source $\left(120^{\circ}\right.$ spacing) and a rotating ( $400 \mathrm{rpm}$ ) crucible that holds the target material uniformly against the crucible perimeter. Each crucible holds up to $125 \mathrm{lb}$ of target material and is designed to allow the insertion of more material without breaking the vacuum seal. Metallic layers are deposited using a metallic target (wire, etc.). Dielectric layers are prepared using dielectric target materials. For example, $\mathrm{SiO}_{2}$ films are prepared using a silica sand target material. Production coatings have been prepared using chromium, copper, aluminum, $\mathrm{SiO}_{2}$, and $\mathrm{Al}_{2} \mathrm{O}_{3}$

It is felt that current production is high enough and that significant advances have not been made since 1965 to allow a new generation system to produce coatings at a significantly reduced cost. Changes have occurred in control circuits, vacuum pumps, and process monitors, but these would not be expected to significantly affect product costs.

Sputtering system. The Guardian Industries architectural glass is prepared using a new sputtering system located in Carleton, Michigan. The coating facility is owned by the Temescal Division of Airco, Inc. and operated under an exclusive agreement with Guardian. The line began production in September 1977. 
The Airco coating system is based on the use of planar magnetron sputtering targets that were developed by Airco Temescal. These targets are DC sputtering devices that utilize externally generated magnetic fields to significantly enhance the deposition rates. The enhanced deposition rates are the key to using the process on large area deposition problems. Coating uniformity is improved by using targets which are long enough to extend well beyond the glass edge on both sides of the conveyer line. Efficient glass loading on the Airco line deposits up to $88 \%$ of the sputtered target material on the substrate. The Airco line capacity is $10-12 \mathrm{M}$ square $\mathrm{ft} / \mathrm{yr}$ on a three-shift production schedule.

The Airco production line is based on a horizontal glass handling system which employs rollers as in the conventional mirroring lines. The line can handle glass up to $78 \mathrm{in}$. wide and with a maximum length of $120 \mathrm{in.}$ The interfaces between vacuum chambers are of small vertical size to minimize leakage while they are open and are sealed by mechanical doors hinged above the openings.

Present system usage involves the use of argon, nitrogen, and oxygen as potential gases introduced to the coating chamber. Other gases could be used but they are not on line today. Airco has had successful experience on line with stainless steel, chromium, copper, copper alloys, aluminum, titanium, and tantalum. Silver has been coated at the Airco Berkeley laboratory but has not been used on the production line. Nickel and iron cannot be coated due to their ferromagnetic properties and their interference with the magnetic fields required for magnetron sputtering. Successful overcoat production has used titanium oxide, titanium nitride, and a stainless steel oxide. Silicon oxides are not used due to the cost of silicon targets. Inexpensive silicon dioxide targets cannot be used in DC sputtering due to charge buildup effects that terminate the process. Experience with aluminum oxides has been less successful. Neither aluminum nor silver layers were considered useful for first surface mirrors at this time due to their rapid degradation under environmental effects. Presently, there is no overcoat layer that is sufficiently durable to provide extended protection for these metal layers. 
The sputter deposition is suitable for a variety of substrate materials. The production line has been used with glass thicknesses from 0.10 to $0.50 \mathrm{in}$. Airco also has successfully coated plastics, acrylics, and mylar using R\&D coating equipment. The process has been used successfully on both sheet stock and continuous roll stock. Glass stock should not be powder packed for use with the coating process. This was based purely on the reliability of cleaning for powder packed glass and paper packed glass. They felt that the powder will sometimes bond to the glass due to glass temperature at the time of application. This is not easily removed from the glass. Most problems are associated with plastic introduced to the process line that remains long after the powder packed glass is off the production line.

Additional sheet coating processes. The examination of additional sheet coating processes has not been completed at this time. One technique not yet examined employs a flame treatment of the coating material. Completion of the alternate coating technologies will also determine if additional candidate processes exist.

\section{Roll Coating Processes}

Roll coating processes are in use for film deposition on flexible, continuous web substrates. Manufacturers using these processes have not been surveyed at this time.

\section{First Surface Mirror Preparation}

The successful preparation of long-lived first surface mirrors would provide significant improvements in heliostat performance. The major gain would result from the removal of losses associated with the second surface mirror superstrate. The major problem with the production of durable first surface mirrors today is the isolation of the reflective metal layer from the environment. The best reflective layer materials (silver and aluminum) are both very vulnerable to attack by components of the ambient environment.

This is the same problem that the standard wet chemistry mirrors must survive. Processes are available for the deposition of dielectric overcoats that provide acceptable optical performance at the time of preparation; however, satisfactory environmental protection has not been demonstrated. Further 
film development may be required to examine the effects of film morphology (deposition parameters), stoichiometry, and thickness on the resultant protective performance.

Additional protective materials must also be considered. These coatings must provide good durability and prevent the environmental constituents from reaching the reflective metal layer. The coating must also exhibit good surface wettability to facilitate effective surface cleaning during its lifetime.

One organic candidate is parylene, a generic name of a family of polymers, based on poly-p-xylylene. These vapor deposited films are reported to form pinhole-free one micron films. The short- and long-term performance of these films deposited on silver and aluminum reflective layers should be evaluated. The problem of UV degradation in oxidizing atmospheres has not been adequately investigated. The costs of the coating may also limit its usefulness for this high volume application.

Multilayer dielectric films could also be used to provide high performance front surface mirrors. The suitability for high volume production and their cost and survivability should be evaluated for the solar performance requirements.

\section{MIRROR TESTING}

\section{Production QA Tests}

There has been little requirement for quantitative production QA testing because of the market requirements of the industry. The predominant requirement is for a visually pleasing image without noticeable blemishes. The reflected tones preferred are "warmer" than the natural colors rather than "colder". The value of the absolute reflectance has not been critical as long as it is uniform across a given mirror. Such market criteria have traditionally been satisfied with a visual examination of the finished mirrors before they were packed.

Quantitative measurements are made on a periodic basis to monitor the production process. These tests determine the amount of metallic film (both 
copper and silver) deposited on the glass. Quantities are evaluated by dissolving each metal layer into separate solutions. The solutions are then titrated to the end points. The titration results and the area of the mirror stripped are used to calculate the film mass per unit area. The frequency of quantitative film evaluation is far from an industry standard. Some firms run the test pieces every two hours, while others run several at start-up and then again only if the visual inspection starts to reveal problems. The tests are run on glass test coupons inserted on the line for evaluation.

Paint thickness is generally checked using a weight gain measurement on a test coupon sent through the production line. Another method used is a small metal gauge pressed against the rear mirror surface between the painting and drying steps. The gauge consists of two posts (one at each end) with a series of steps between the end posts (Figure 1.13). When placed on a flat surface, each step in the sequence is progressively farther from the flat. Each step increment is marked on the gauge. The paint thickness is thus evaluated by noting the closest step to the mirror surface that did not come in contact with the wet paint layer. This test is useful for on-line adjustment of the curtain coater to produce the proper paint thickness and for very quick checks during operation.

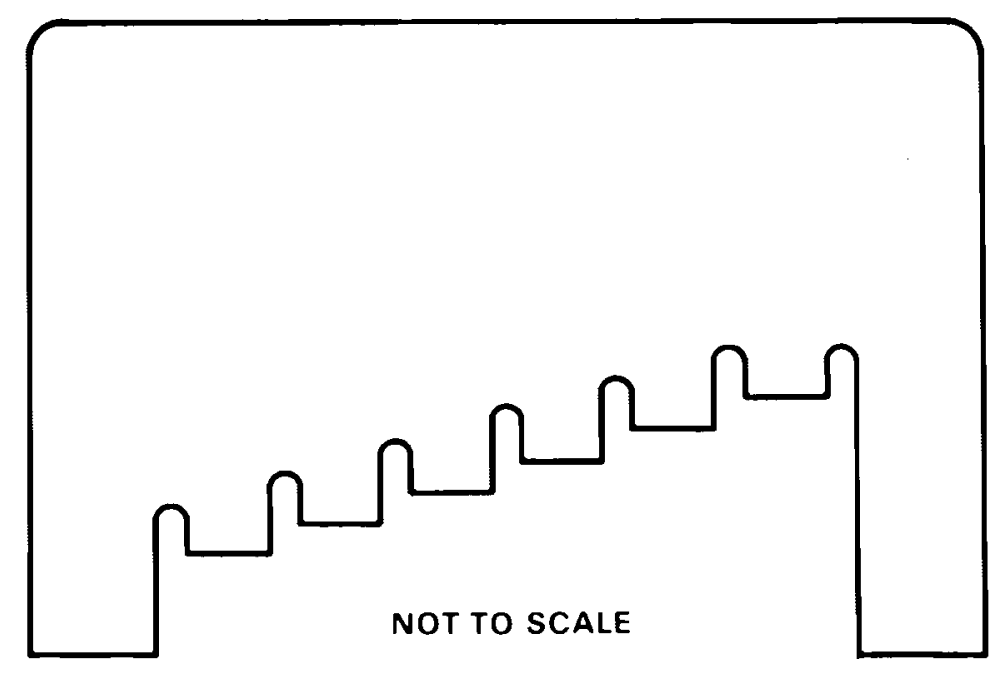

FIGURE 1.13. Step Gauge Used for Evaluating Paint Thickness 
Film adhesion is not monitored on a routine basis in the industry. When spot checks are made, the "Scotch tape" test is used. No consistent procedure of sample preparation (drying, temperature, etc.) was specified for making the results more reproducible.

\section{Mirror Lifetime Tests}

No testing procedures are known today that provide a reliable indication of useful mirror lifetime on an accelerated basis. This presents a significant problem for the development and purchase of mirrors for solar energy, as they will be used in the potentially hostile outdoor environment. The problem is not as severe for traditional indoor mirrors since the manufacturers have extensive experience with such uses and can utilize traditional tests to compare results with those of their earlier products.

Some of the traditional mirror tests are considered useful to evaluate a mirror's susceptibility to certain failure mechanisms. Their practical value is also enhanced by the fact that the short-term performance of a mirror in these tests will reveal a major portion of the long-term defects. This results from the relatively rapid attack of the test environment on defect sites on the mirror followed by an extended period of stable mirror performance. The validity of these general beliefs must be confirmed for individual tests under consideration.

a. The salt spray test is commonly used in the industry to assess product durability. Some manufacturers perform this test internally, while many firms contract with external test facilities to evaluate their mirrors. Samples are tested on a daily basis by some coaters to provide a check on product durability. Less frequent sample evaluations were also noted. The salt spray test has been adopted as a 300-hour test by the mirror industry. Its strength is that it clearly indicates the number and location of pinholes through the paint layer. Edge degradation is felt to occur primarily at existing glass/silver separations. Detailed test procedures are described in ASTM Standard B117-64 with the single exception that the mirror industry has adopted a stronger salt solution for their own use. The industry uses a $20 \%$ salt solution (by weight) 
in water while the ASTM standard specifies a $5 \%$ solution. The $20 \%$ solution was chosen for its increased rate of mirror attack and hence more rapid product evaluation. The industry has accepted a 300-hour test as the standard time period.

It is perhaps significant to note that in the salt spray test, the short-term performance reveals most defects. Industry experience has clearly stated that the 300-hour test period reveals the majority of defects. Performance in the next several thousand hours was characterized as continuing growth of established defects but not a significant growth of new defects for most samples.

Test results are generally classified according to the size of defects and the number of defects.

b. A ferric chloride solution submersion test is a candidate for an "accelerated salt spray test" due to its rate of attack and similarity of defects that are revealed. This test has not been adopted as an ASTM standard. The test solution is made using $5 \%$ ferric chloride (by weight) in water. The samples are freshly cut coupons $(3 \times 6$ in.). A 1.5-hour dip test at 20 to $25^{\circ} \mathrm{C}$ is felt to be equivalent to a $150-\mathrm{hr}$ salt spray test. Mirror performance with degradation of less than $150 \mu \mathrm{m}$ along the freshly cut mirror edge is considered acceptable.

The use of ferric chloride solution is expected to be a significant threat to the copper layer in the standard mirror structure. Ferric chloride solutions have been commonly used in the electronics industry to remove the copper coating from printed circuit boards during their fabrication. Edge incursion could therefore be initiated by the direct attack of exposed copper edges. This would also be expected at pinhole locations in the protective paint layer.

c. A variety of temperature and humidity tests are in use, but an industry standard has not been adopted. Specific tests used are related to the anticipated end use of the product. 
- One test involves a 10 -day exposure to a $140^{\circ} \mathrm{F}, 95 \%$ relative humidity atmosphere. The test is felt to reveal the effects of relative expansions and contractions between the layers of the mirror structure (glass, silver, copper, and paint). Specific information is obtained on the success of the copper layer for stress relief. Layer separation can result from inadequate copper performance.

- Thermal cycling is performed to assess the durability of the mirror structure under repeated thermal expansion/contraction cycles. One automotive industry test lasts 10 days and consists of $4 \mathrm{hr}$ at $190^{\circ} \mathrm{F}$, $4 \mathrm{hr}$ at $100^{\circ} \mathrm{F}$ and $95-100 \%$ relative humidity, and $16 \mathrm{hr}$ at $-40^{\circ} \mathrm{F}$ during every day of the test. This has been developed to evaluate survival under the severe temperature ranges that may be encountered in an exterior application. Such tests have not been necessary in the traditional wet chemistry mirror market because of their use for predominantly interior applications.

- The "Cleveland Tester" is a commercial test chamber that allows cyclic environmental testing. The tester contains a tray of water at the bottom of the chamber whose temperature can be controlled. The samples are then mounted to form portions of the chamber roof with the coated mirror surfaces facing the chamber interior (Figure 1.14). The chamber provides a closed atmosphere where the moisture content is controlled by the water bath temperature. For water bath temperatures greater than room temperature this results in moisture condensation on the coated mirror surfaces. The chamber geometry causes this condensate to drip down the mirrors and back into the reservoir. This system allows sample exposure to varying temperature and humidity conditions as well as water which is not stagnant.

- "Weatherometers" represent a generic type of sample exposure system that may include a wide range of environmental parameters. The systems generally allow the sequential application of different inputs by moving the samples to different positions inside the 


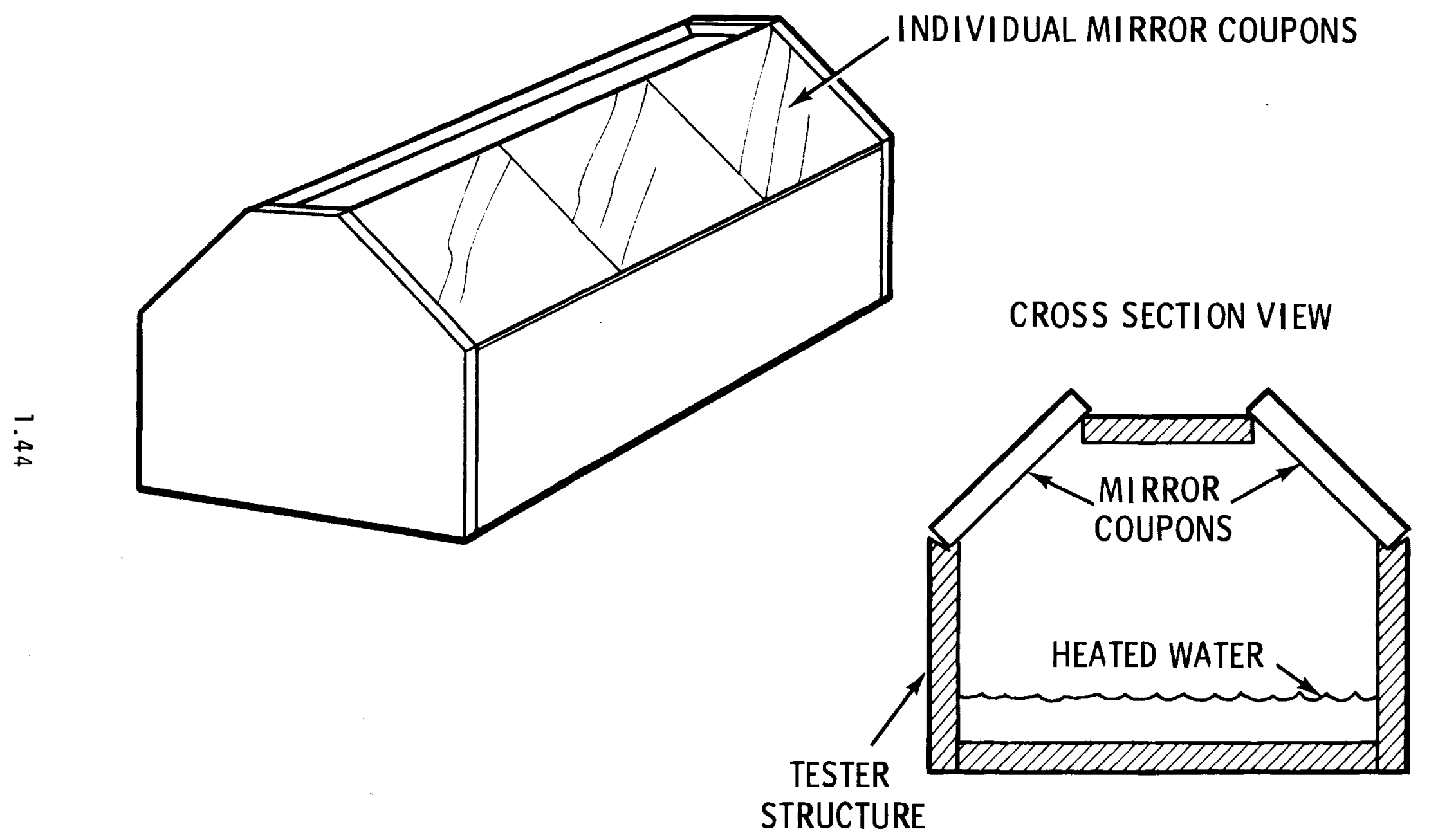

FIGURE 1.14. Sample Mounting Geometry in a "Cleveland Tester" 
chamber. Adjustable environmental parameters can include UV radiation (from xenon arc lamps), temperature, humidity, water spray, salt spray, and specialized chemical pollutant gases ( $\mathrm{H}_{2} \mathrm{~S}$, etc.). These devices are available from a number of manufacturers and may contain significant differences depending on the ultimate testing capability desired.

- Three-day boiling water tests were mentioned as a less common procedure. The mirror is placed vertically in the test vessel so that it is partially submerged and partially above the liquid. The most severe damage occurs just above the liquid level. No correlations were noted between results of this test and normal mirror performance. No suggestions were given for the failure mechanisms that would be preferentially tested by this procedure.

\section{Mirror Component Compatibility Tests}

The "sandwich test" provides a technique for the relatively quick screening of mirror system components for chemical compatibility. This is relevant for heliostat development as the structures and designs for the solar application are expected to differ significantly from the traditional interior mounting. The test concept is easily applied to the evaluation of paints and adhesives.

Test preparation begins by coating two groups of glass test pieces with a silver layer and a silver/copper layer structure, respectively. The silver/ copper layer structure is used rather than a copper only film to insure film adhesion. The adhesive or paint material to be tested is then applied to the metalized surface of one sample from the first group, and a sample from the second group is then pressed into contact with the test material. This sandwich structure then holds the material under test in contact with both metallic constituents of the standard mirror. Chemical attack is seen visually through the uncoated front surfaces of the two mirrors that make up the sandwich. 
The effect of adhesives on the final mirror assembly is assessed by painting the sandwich components from both mirror groups already discussed. These samples are then allowed to dry before the test adhesive is sandwiched between two of the test pieces. Degradation can again be seen through the uncoated front surfaces of the mirror.

\section{REFERENCES}

Grubb, A. D., "The L-O-F semi-continuous thermal evaporation plant", Research/Development 20: 6, 42-46, June 1969.

Grubb, A. D., "Control of optical properties on large substrates $(10 \times 12 \mathrm{ft})$ produced in a semicontinuous production coater", J. Vac. Sci. and Tech. 7, 220-224, 1970.

Lind, M. A., and J. M. Rusin, Heliostat Glass Survey and Analysis, PNL-2868, 1978.

Pettit, R. B., Summary of Reflector Materials Properties, Summary Report of the Solar Reflective Materials Technology Workshop, (M. A. Lind and L. E. Ault, Eds.), PNL-2763, 1978.

Schweig, Bruno, Mirrors, A Guide to the Manufacture of Mirrors and Reflecting Surfaces, Pelham Brooks, London, 1973. 
CHAPTER 2

ANALYSIS OF SELECTED MIRROR SAMPLES 
CHAPTER 2

\section{ANALYSIS OF SELECTED MIRROR SAMPLES}

\section{INTRODUCTION}

The examination of wet chemistry mirrors has included a study of the microstructure, microanalytical, and optical properties of selected mirror samples. These detailed data have been sought to provide a more complete understanding of new commercial mirrors and the occurrence of mirror degradation. Special attention has been given to the variabilities seen in new mirror products and trends seen in aged samples that may be indicative of basic degradation mechanisms. The purpose of this investigation is to identify important degradation mechanisms, evaluate the "survival quality" of selected mirrors, and to identify mirror fabrication procedures to improve the product lifetime.

The detailed mirror analysis has been conducted with a variety of surface analytical tools including:

- SEM (scanning electron microscopy),

- Electron microprobe analysis with EDX (energy dispersive x-ray fluorescence spectroscopy),

- AES (Auger electron spectroscopy),

- SIMS (secondary ion mass spectroscopy),

- ESCA (electron spectroscopy for chemical analysis), and

- Optical examination (microscopy, spectral reflectance).

These techniques allow the detailed examination of the mirror morphology, its chemical composition both on the surface and into the bulk of the sample, and the details of actual chemical bonding. SEM and EDX experiments and AES, SIMS, and ESCA were used concurrently to provide cross correlated data in many cases. However, sufficient time has not been available to thoroughly analyze all the complementing data sets recorded. Many significant correlations and trends have been noted but further analysis is expected to improve our understanding of both the mirror structure and its degradation. 
Both new and aged mirror samples have been examined. New samples from a variety of sources were characterized to determine the variation that may occur normally in mirrors produced across the industry. These data establish a product baseline from which degradation effects develop. These preliminary results do not allow the control of desired mirror characteristics but rather may only indicate the net effects of small changes in process conditions (water purity, process temperatures, glass cleanliness, etc.). Further studies are needed to provide a definitive correlation between the new mirror properties and product durability, if one exists.

Samples were examined from five commercial production lines and from three noncontinuous, single piece coating processes (See Table 2.1). Mirrors from the commercial coaters were provided at selected steps during the coating process to allow evaluation of the effects of the sequential coating process. The selected process points were:

1) before glass cleaning,

2) after glass cleaning and rinse,

3) after sensitization and rinse,

4) after silver deposition and rinse,

5) after copper deposition and rinse, and

6) after complete mirror processing.

A11 samples were test coupons inserted during a continuing production run.

Aged samples were examined using the same analytical techniques in an attempt to determine the correlation of degradation with variations in the properties of new mirrors. The one-year-old mirror obtained from Sandia/ Livermore was originally part of a heliostat structure. It is likely that the structure design allowed the coated mirror surface to be exposed to standing water for extended periods of time. Two 17-year-old mirror samples were provided by Carolina Mirror Corporation. These samples were exposed to natural aging in such a way that one was allowed to "breathe freely", while the other experienced limited air circulation and probably was subjected occasionally to standing water. Examination of degradation resulting from 
TABLE 2.1. Sources of Specimens for Study of Mirror Quality

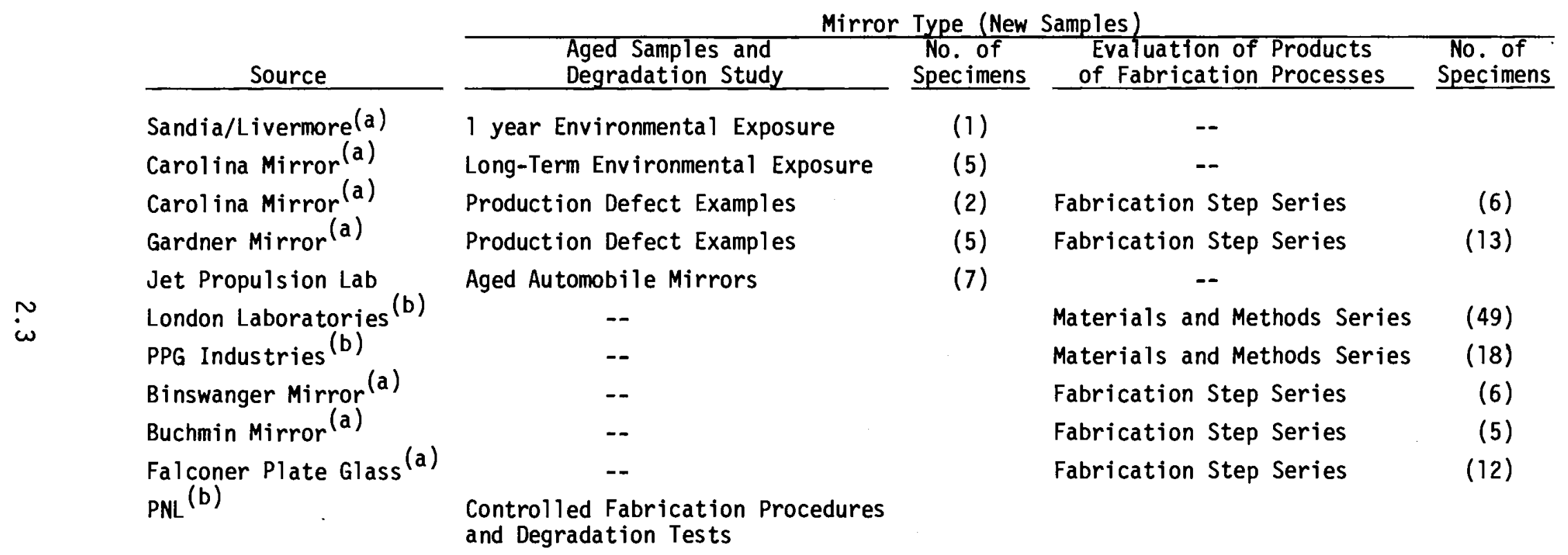

Total number of different mirror specimens acquired (not including PNL fabrications): 129.

(a) Commercial coating line product

(b) Scaled down, single piece coating process 
controlled exposures will be useful in the future to better define the causes and effects seen in the degradation of wet chemistry mirrors.

Some samples have been physically prepared in ways to expose certain features of the mirror for examination. Other samples have been exposed to controlled environments in order to deduce structural and chemical changes that may be related to specific "aging" processes. These techniques are summarized in Table 2.22 and will be discussed in more detail when the respective data are reviewed.

This section of the report begins with an examination of data obtained using SEM, EDX, and optical microscopy. These techniques yield significant information about the sample surface morphology, with a resolution of $150 \AA$. Chemical composition of the structural features also can be determined, with an analytical resolution of about a $1-\mu \mathrm{m}$ volume centered on the specific locations examined. Many samples have been examined by looking at their exposed surfaces and at their cross-sectional structure revealed by metallographic polishing. Since the nominal metal layers on a commercial mirror are typically $21000 \AA$, these techniques clearly describe the surface microstructures, but cannot uniquely define the surface composition.

Data will also be discussed from AES, SIMS, and ESCA experiments that reveal the nature of the first 1 to 10 molecular monolayers of the sample, but with a spatial resolution usually about $4 \mu \mathrm{m}$ or larger. Ion milling techniques have been employed to extend the experiments to provide detailed depth profile information about the chemical species and their chemical bonding states. Again these techniques have been applied to both the flat, coated surface of the mirror and to the cross-sectional structure of the mirror as revealed by metallographic polishing. The combination of SEM, AES and the related techniques thus provides high resolution structural and composition information both on the surfaces and in-depth profiles.

This analytical examination of mirrors and their degradation mechanisms began with an attempt to catalog the possible sources of degradation proposed by the industry and previous independent studies. The industry understanding was determined through discussions during the on-site visits associated with 
TABLE 2.2. Sample Preparation for Specific Studies

Type

None

Cross-sectioning by metallographic

procedure

N

in
Reason

Evaluate samples as received

\section{Expose edge views of mirror} components
Expose metallic layers on finished mirrors

Expose "used" glass surface

- physical stripping of paint and metal layers:

Controlled environmental exposures

Separation of mirror layers

- chemical paint removal

Study effects of different ambient atmospheric conditions
Use

Glass

Partially finished mirrors

Completed mirrors

Aged mirrors

New mirror structure

Aged mirror structure

- good region

- defective region

New and aged mirrors

New and aged mirrors

Partially coated mirrors

Completed new mirrors 
the industry survey discussed previously. Additional possible mechanisms were suggested from a review of the literature and a study of the surface reaction phenomena. Table 2.3 lists the potential sources of mirror degradation that were identified in the initial phases of our study. An awareness of these possible mechanisms served as a preliminary checklist during the evaluation of analytical data. Special care was exercised to determine if the characteristics of localized defect sites were consistent with the proposed degradation sources.

SEM, EDX, AND MICROSCOPY EXAMINATION

Commercial Production Mirrors

A series of partially completed mirrors provided by the manufacturers during the on-site industry survey visits was analyzed. These samples allowed the analysis of the mirror surface as it developed sequentially. Most observations were made from the coated side of the mirror although visual observations from the glass side did reveal many of the characteristics of the thin metallic films. Partially completed mirrors were rinsed, dried, and packaged individually in plastic bags for transportation to PNL. Storage since production has been provided for some in a vacuum desiccator while others were stored in the ambient laboratory air. No discernible or consistent effect on the metal layers has been detected that correlates with the different storage conditions.

At least two samples from each manufacturer have been examined. One is the tin-sensitized glass + silver structure and the second is the tinsensitized glass + silver + copper structure. Additional samples were selected to examine the condition of the glass surfaces as received and after the scrubbing process. Samples were also examined in an attempt to clarify the role of the tin chloride sensitizing solution applied before silvering.

As noted earlier, most float glass is sprayed lightly. with a dry powder before crating and shipment in order to reduce problems with staining and adhesion of adjacent glass sheets. A commonly used powder is made of small 
TABLE 2.3. Potential Sources of Mirror Degradation and Failure

- Inadequate cleaning of glass prior to mirroring (especially contaminants related to glass manufacture and shipping)

- Inadequate control of mirroring steps, preventing optimized production and deposit of silver, copper, or other components

- Contamination (especially particulates) during mirroring process.

- Reactions of sitver/copper:

- thermal degradation of the fine metal particle layers

- reactions with the backing (paint, adhesive, others)

- penetration of water, metal debonding from glass

- reactions involving gas, vapor or solutions $\left(\mathrm{H}_{2} \mathrm{~S}, \mathrm{HCl}, \mathrm{NaCl}, \ldots\right)$

- photostimulated oxidation

- Glass surface corrosion or other reaction of the glass itself:

- leaching of glass with water

- reactions with weak solutions of chemicals dissolved from atmosphere, paint, etc.

- Stressing at interfaces:

- drying shrinkage or solvent swelling of paint

- improper copper thickness or deposition method

- Gas generation or accumulation in the mirror layer:

- hydrogen from copper reduction process

- other sources: external, decomposition of backing paint, etc. 
plastic (PMA, Lucor) granules that have been impregnated with adipic acid to reduce glass staining. Figure 2.1 shows the initial glass surface and illustrates that the conventional cerium oxide scrubbing procedure often is not sufficient to completely remove all powder particles.

Samples taken from the production sequence after sensitizing with a stannous chloride spray were also examined. No evidence of change was detected on the surface. This null result is useful as an indication that large amounts of tin and/or chlorine are not being left on the glass after the rinse and that no surface microstructural changes occur. It should be noted however that the analytical techniques used here are not very sensitive to thin surface layers or very small concentrations.

Examination of the silver and silver + copper surfaces revealed a wide variety of metallic surface textures even though the manufacturers were using very similar chemical solutions. The mirrors generally displayed uniform metallic layers but frequent small defects were noted (Figure 2.2). These included holes, impurities, and abnormally large particles of layer metal. Some residual surface defects were thin surface stains which had no apparent effect on the actual microstructure of the deposited metal.

Other obvious defects such as fingerprints directly on the silver surface (Figure 2.3) are unlikely to occur during normal fabrication processes and probably resulted from the midprocess removal of the sample by an ungloved hand. The average size of the particles that make up the metallic layers is roughly $0.1 \mu \mathrm{m}$, which is comparable to the nominal thickness of the silver + copper layers $(0.07 \mu \mathrm{m}$ and $0.03 \mu \mathrm{m}$, respectively). But individual particles were noted in a size range \pm a factor of 2 above and below the average size on the samples examined. In spite of the common average particle size noted for all manufacturers, the general surface structure may differ in smoothness from one mirror to another (Figure 2.4). A few pores are of ten found on individual mirrors. Occasionally, more than a few of these black spot holes are present (Figure 2.5). The cause for the holes is not obvious since no reaction product, such as chloride or sulfide, could be detected in these cases. Inadequate glass cleaning might cause this kind of failure through reduced silver adhesion. 

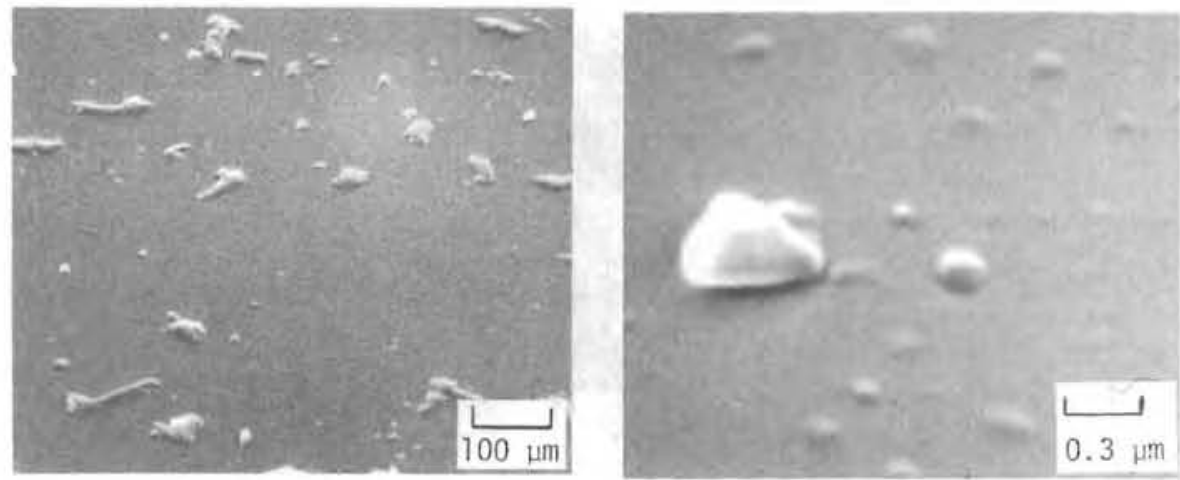

A. TOP ROW - GLASS SURFACE AS RECEIVED

B. AFTER SCRUBBING WITH $\mathrm{CeO}_{2} / \mathrm{H}_{2} \mathrm{O}$ SLURRY AND RINSE

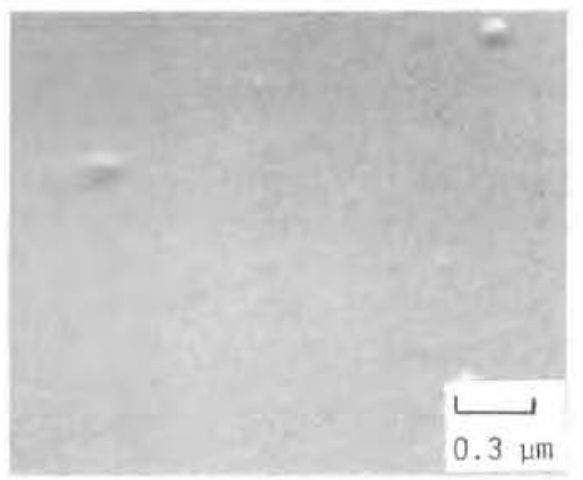

C. GLASS SURFACE AFTER APPLICATION OF DILUTE $\mathrm{SnCl}_{2}$ SENSITIZING SOLUTION AND RINSE

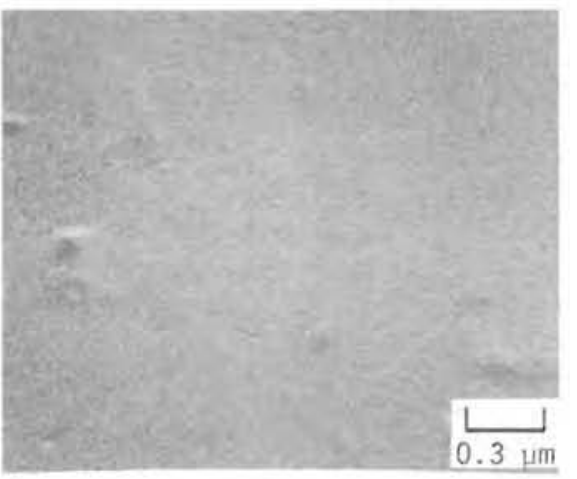

FIGURE 2.1. Normal Sequence of Initial Steps in Mirror Production. The as-received glass surface usually retains the Lucor/adipic acid powder. Most of the powder particles are removed by a ceric oxide scrub. The $\mathrm{SnCl}_{2}$ sensitization step has no visible effect on the glass surface. 

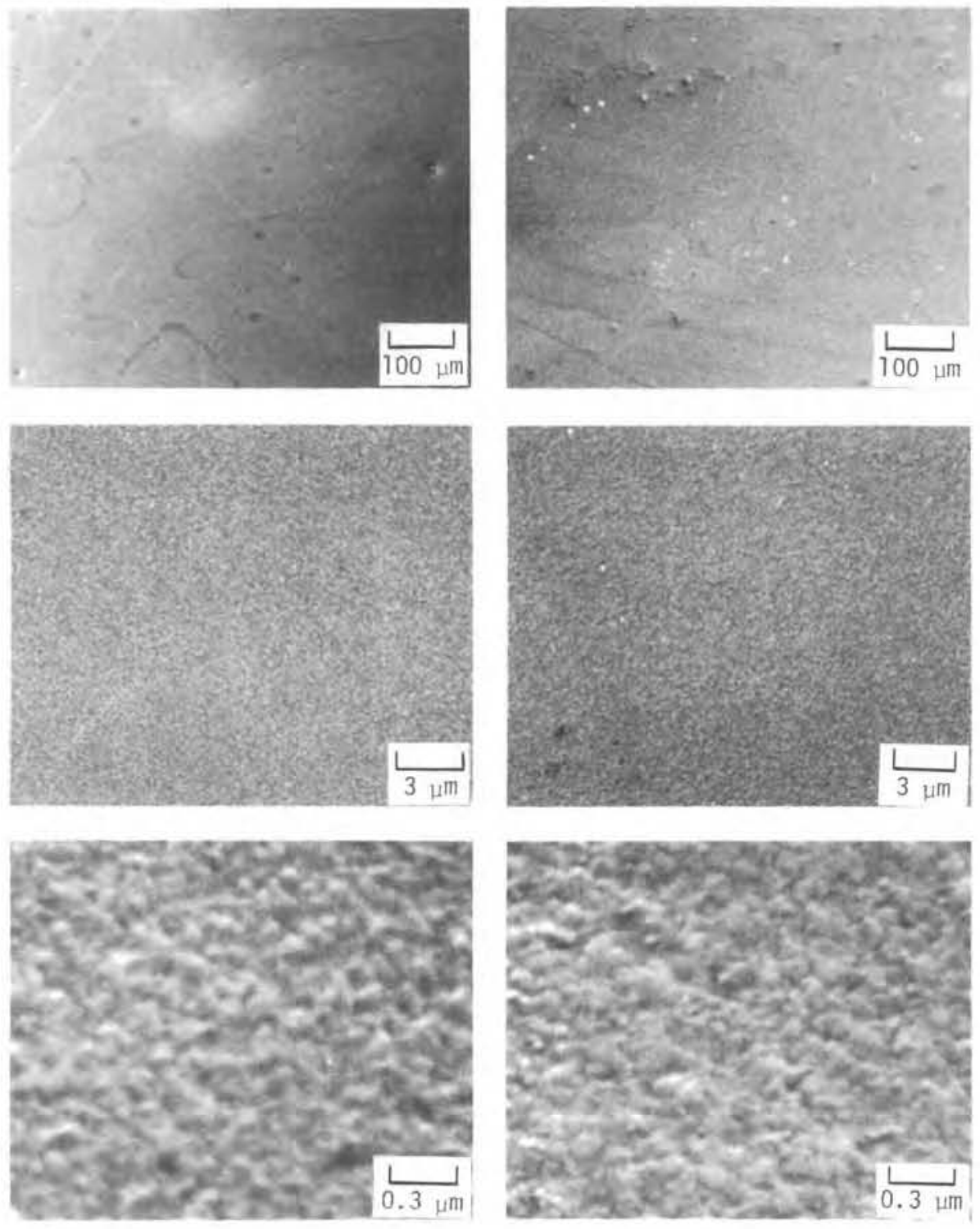

A. SILVERED ONLY

B. COPPER OVER SILVER

FIGURE 2.2. Production Mirrors by Buchmin Industries. Both the silveronly surface and the coppered silver surface show a uniform nonporous deposit. Only a few small free metallic particles are visible, also suggesting evenly applied metallic layers. The stains visible at low magnification apparently do not affect layer quality. 

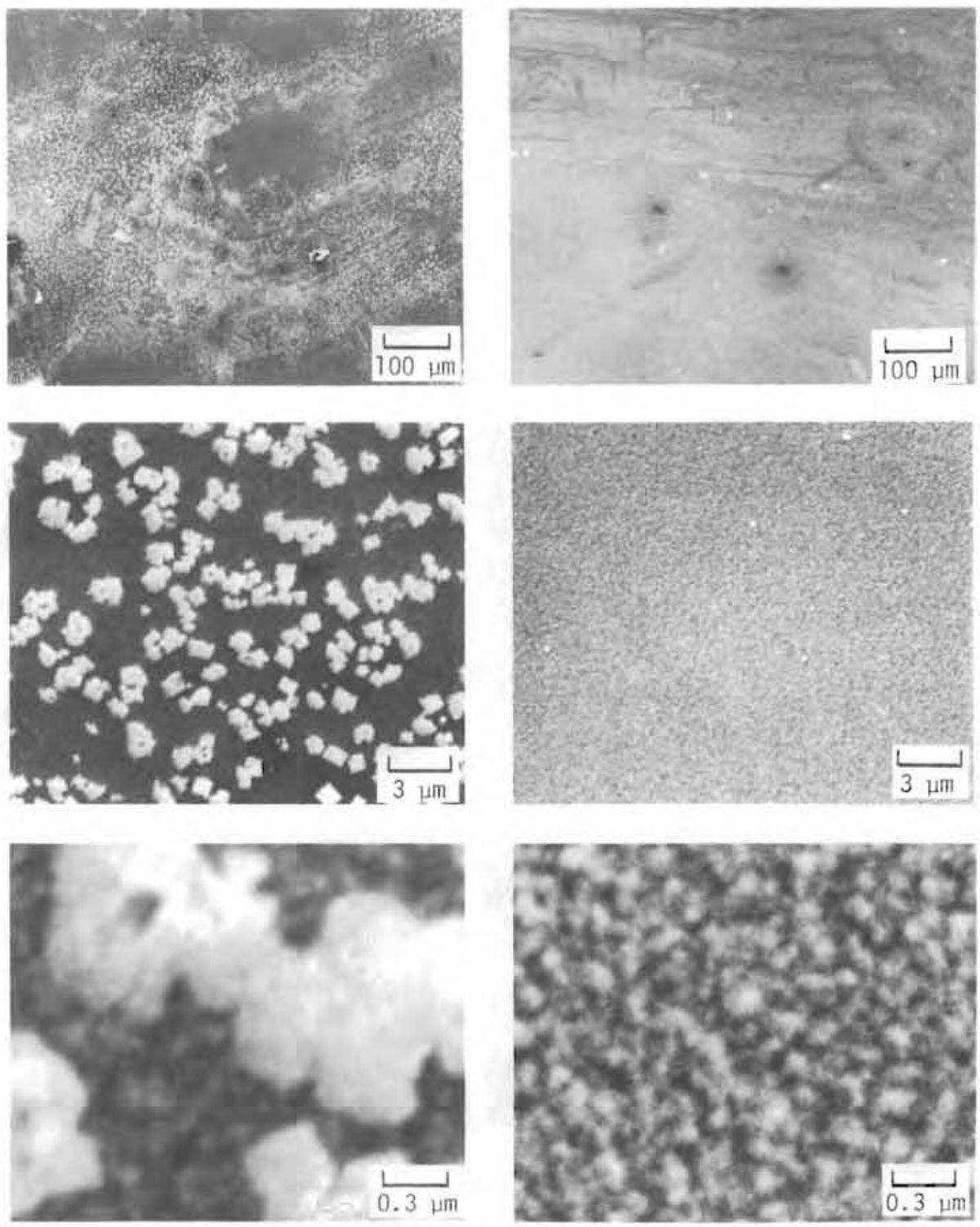

A. FINGERPRINT ON SILVER LAYER

B. VISUAL STAIN ON COPPER LAYER

FIGURE 2.3. Examples of Obvious Surface Defects. Normally neither of these defect types should occur, since the metal surfaces are not touched by hand nor allowed prolonged exposure to air during production. The metal surface would be covered by the final paint backing before handling. 

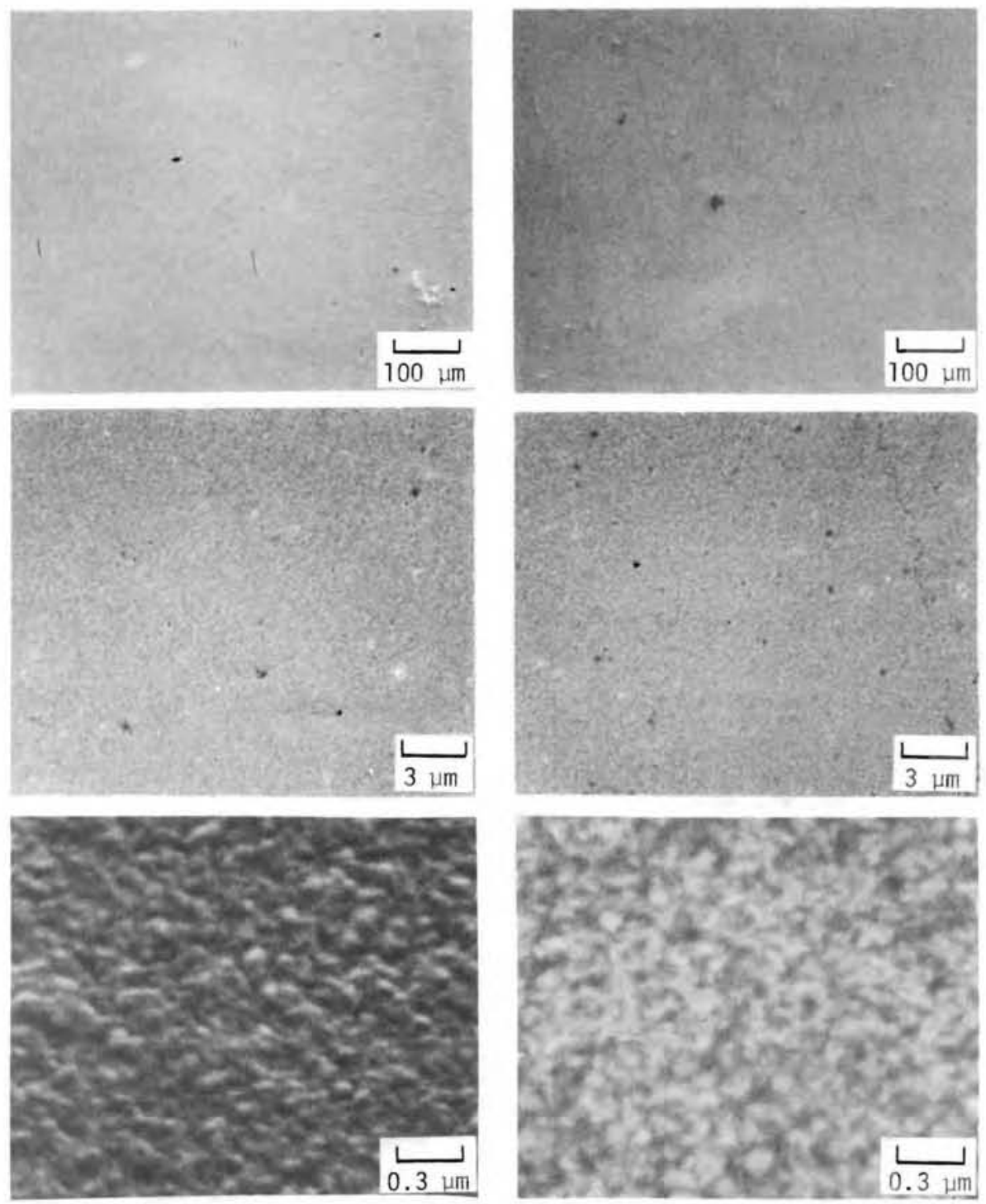

A. SILVERED ONLY

B. COPPER OVER SILVER

FIGURE 2.4. Production Mirrors by Gardner. The apparent metal particle size is about the same as for the mirrors of Figure 2.1 ( $0.1 \mu \mathrm{m}$ average) but the general surface structure appears to be smosther. A few pores through the metal layers are observed. 

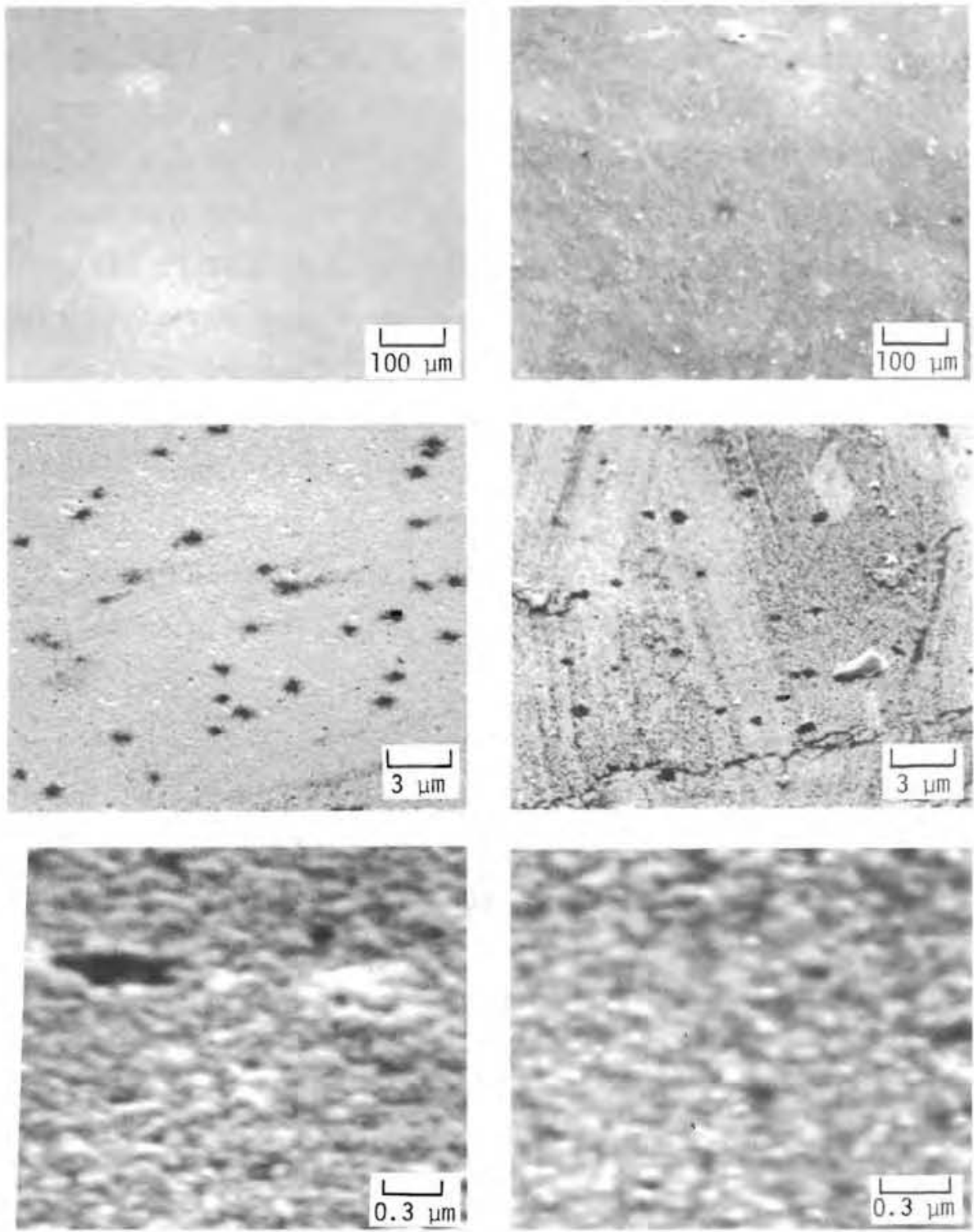

SILVERED ONLY

B. COPPER OVER SILVER

FIGURE 2.5. Production Mirrors by Carolina. These mirrors were allowed to stand in air (enclosed in a plastic bag) for 5 months before examination. Some handling abrasion is evident on the copper surface. The cause of the black spots (actually holes in the silver and copper layers) is not known; microprobe analysis does not show any reaction products such as $\mathrm{Cl}^{-}$or $\mathrm{S}^{2-}$. Inadequate glass cleaning might cause this kind of structure. 
Even when the silver layer appears sound and uniform, a distribution of nucleation centers occasionally occurs on the mirrors (Figure 2.6). In some cases, these have been shown by microprobe to contain sulfur and appear to be the centers of reaction regions. These centers could be the forerunners of eventual deterioration or reaction spots. Even the application of a thin plastic film over the copper coated surface prior to shipment and storage did not prevent the occurrence of these nuclei reaction centers (Figure 2.7). It is concluded that the reaction began while the mirror was still exposed to the manufacturing environment where the metal films were deposited. However, when companion mirror coupons were allowed to proceed along the same production line to completion with the application of normal backing paint, these reaction points were not observed upon removal of the paint with glacial acetic acid. Apparently, the paint provided the necessary protection before exposure to the environmental contaminant. Approximately 4 months elapsed between production and analysis.

Some unpainted production mirrors which had been stored in a vacuum desiccator for the five months between production and examination showed bright particles of silver lying on the silver surface which were approximately 10 times larger than the normal substrate particles (Figure 2.8). These particles apparently were produced at the time of the original silver deposition. They are probably a result of some condition existing in the manufacturing process which promoted the agglomeration. Preliminary experimental data obtained during this study indicate that such agglomeration processes may become significant at temperatures between $100^{\circ} \mathrm{C}$ and $200^{\circ} \mathrm{C}$. This phenomenon and the occurrence of spots or holes observed in other mirrors may be related. (For example, compare Figures 2.5, 2.6, 2.8 and 2.34.) The silver particles are too large to be covered with the thin copper overcoat.

Another sample was examined in an attempt to determine whether the large silver particles could be the result of aging in the vacuum desiccator for several months. The second mirror was produced on the same production line as the mirror of Figure 2.8 but it was allowed to complete the production sequence and was painted. It was not stored in the vacuum desiccator. The 

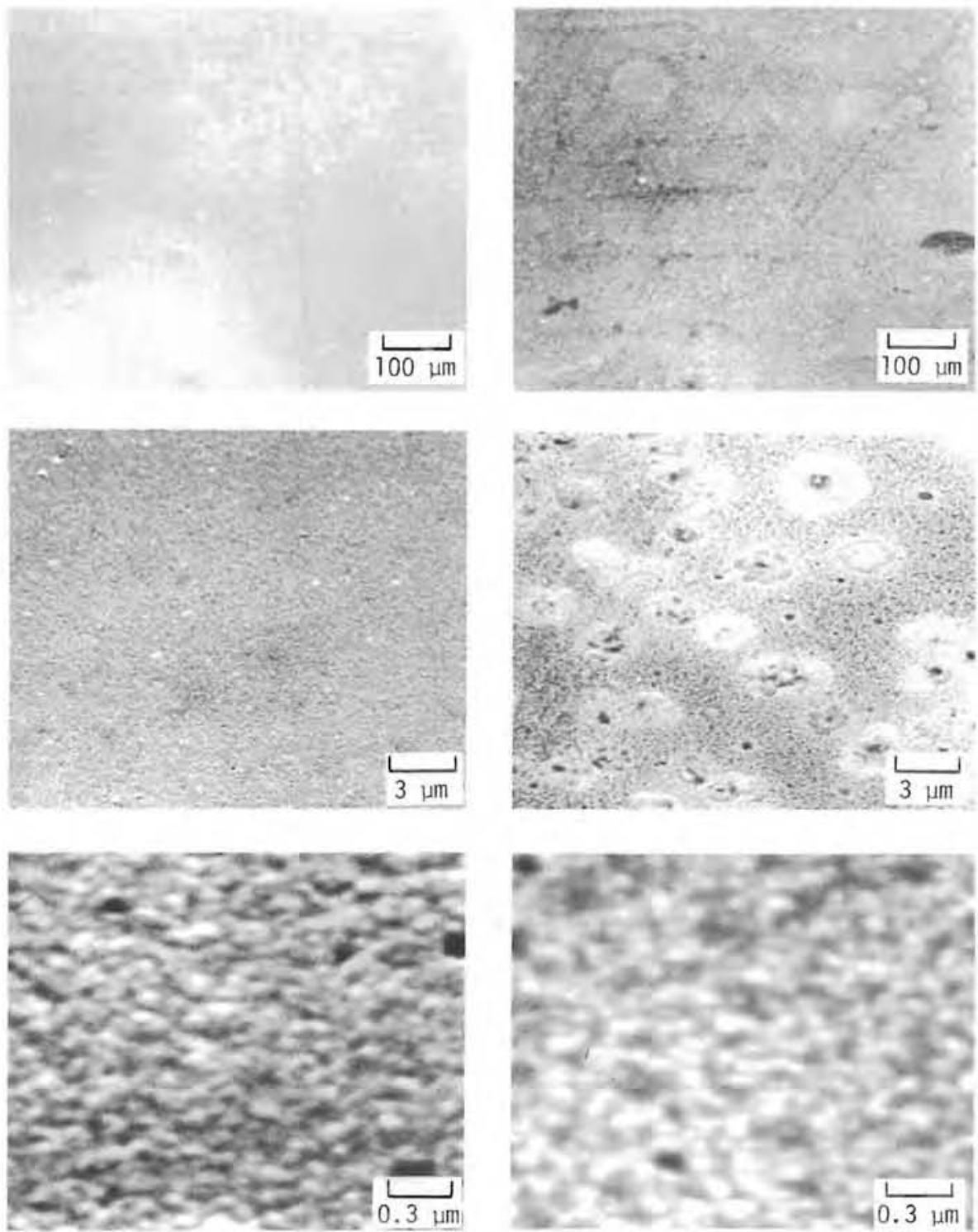

A. SILVERED ONLY

B. COPPER OVER SILVER

FIGURE 2.6. Production Mirrors by Falconer. The silver layer appears uniform, except for some holes in the metallic layer. The copper layer was unprotected during the 4 months between fabrication and these micrographs. The abundant nucleation centers, some of which have been shown by microprobe to contain sulfur, appear to be the centers of reaction regions. The form is reminiscent of the nucleation structure observed after long term exposure of some finished mirrors to exterior conditions. 

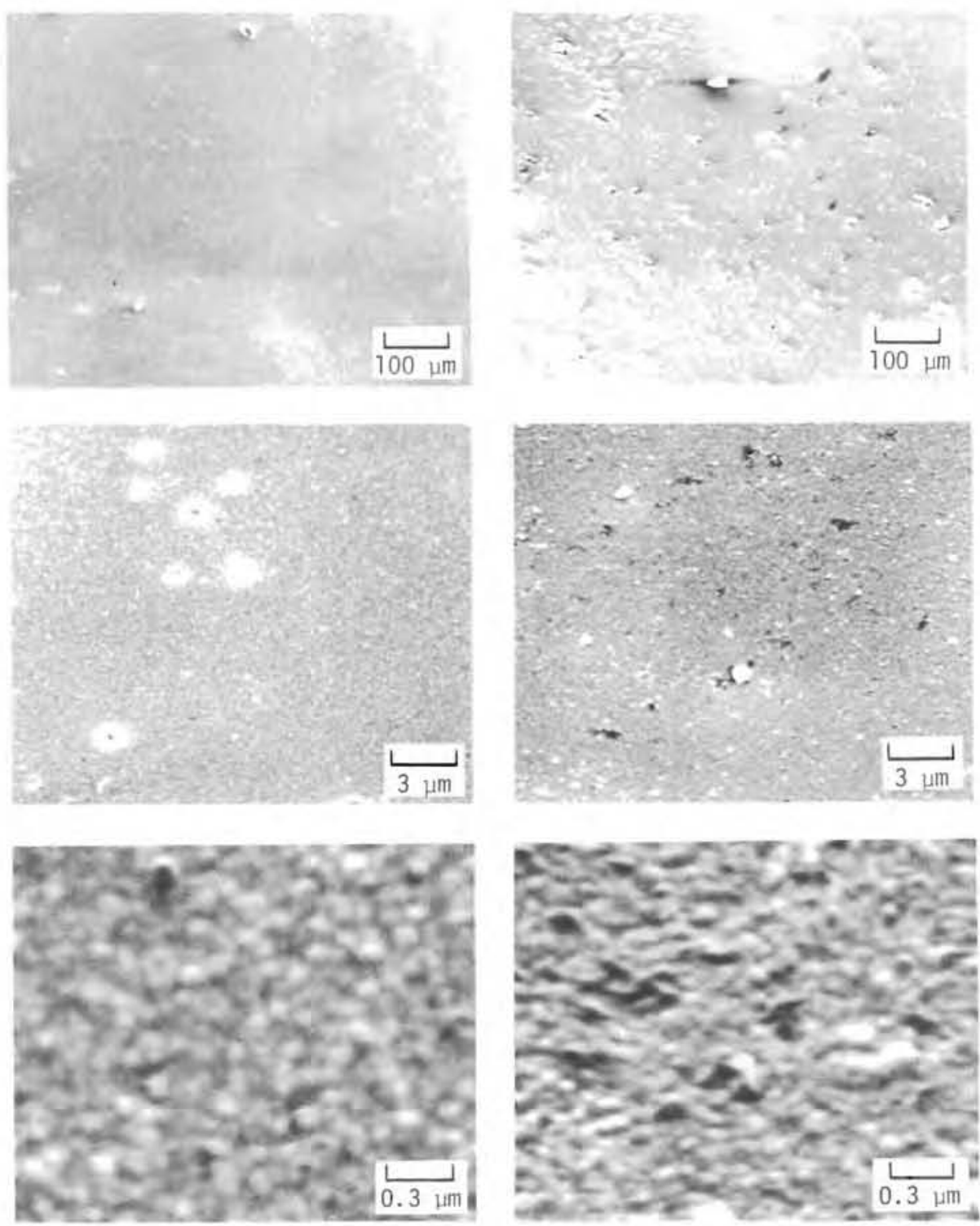

A. COPPER OVER SILVER

(PROTECTIVE PLASTIC REMOVED)

B. COPPER OVER SILVER

(PAINT REMOVED)

FIGURE 2.7. Silver-Copper Layers (After Removal of the Protective Coatings). A thin plastic strippable film (applied by the mirror manufacturer) covered the copper surface of mirror A. Nucleation sites are present, and only a small reaction zone is evident. Remnants of the paint applied to mirror B during the normal production process still cling to the surface. Some porosity is evident, but the mirror does not show reaction nuclei. 

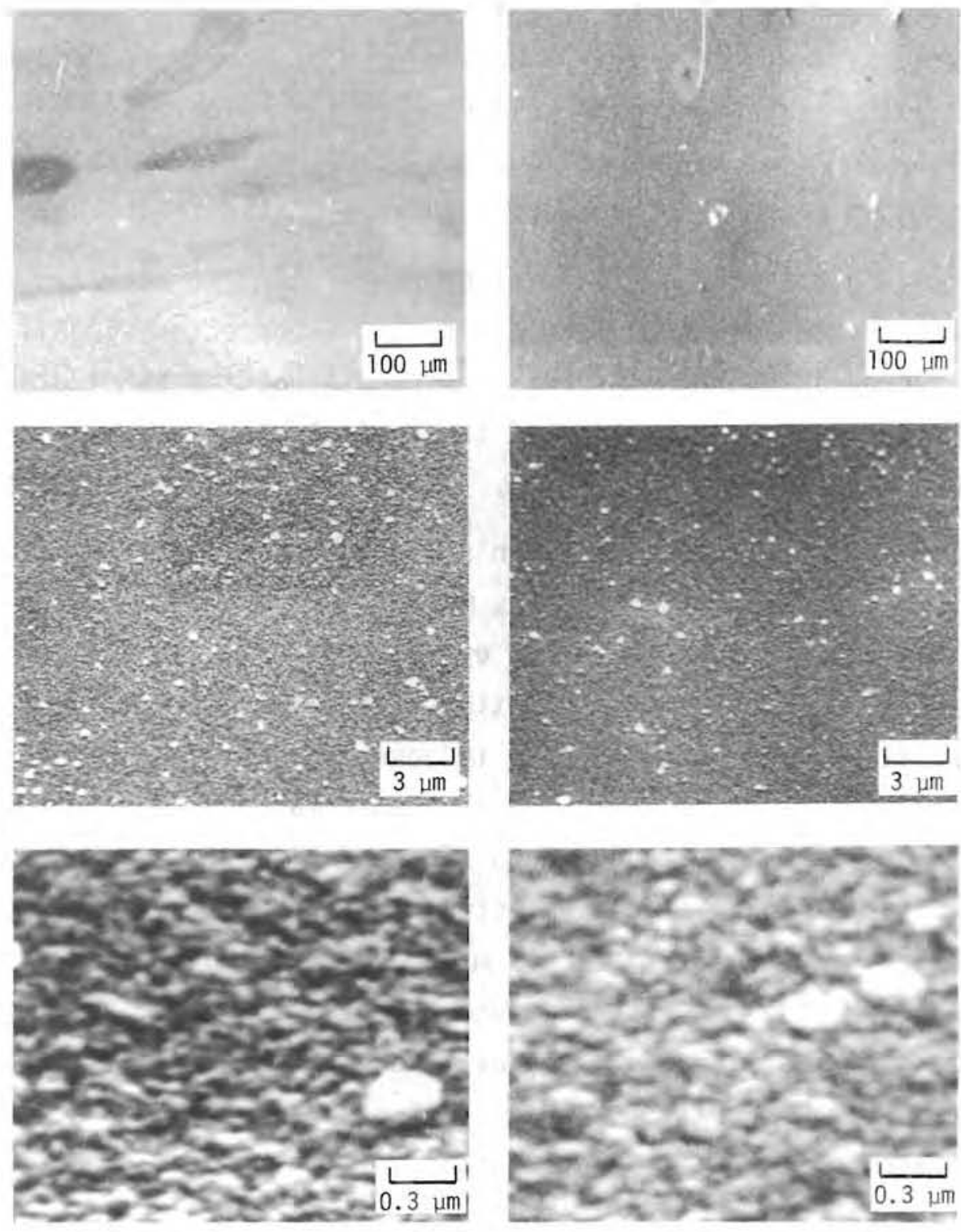

A. SILVERED ONLY

B. COPPER OVER SILVER

FIGURE 2.8. Production Mirrors by Binswanger. The bright particles on mirror A are silver, approximately 10 times the diameter of the normal substrate particles. The large particles on mirror B contain about 5 to 1 silver to copper. 
metallic layers were examined after the paint was stripped using glacial acetic acid (Figure 2.9). Both samples have large silver particles on the surface which indicates that they resulted from production procedures. It is important to note that the acetic acid removed the paint layer intact and caused no detected microstructural changes. This was substantiated by examining an uncoated mirror before and after an acetic acid treatment.

The silver/glass bond may be weak or nonexistent in localized regions of a new mirror, even though the weak bond cannot be detected visually. In some cases the silver-glass bond is known to strengthen after fabrication as evidenced by comparing the results of tape-pull tests immediately after and several hours after silver deposition. This is not always the case however.

An example of a weak bond between silver and glass on new mirrors is illustrated in Figure 2.10. When this mirror specimen was mounted in epoxy resin for metallography purposes, the epoxy very readily crept between the glass and the silver during encapsulation. Application of the backing paint during fabrication does not appear to improve the silver glass bonding appreciably. However, in other cases the bond has remained very strong even with environmental exposure during the 3 to 17 years after fabrication. In Figure 2.11, two examples of field tested mirrors are shown. In some regions of the nondegraded areas of these old mirrors, the bond appears to be extremely tight, even after long exterior exposure, despite the fact that extensive deterioration and reaction of the metal layer has taken place in other regions of the same mirror. From this evidence, it can be concluded that if the silver to glass bond is weak at production, it may become a contributing (but not sufficient) condition for deterioration of the mirror.

Laboratory Variations of Process Parameters

While laboratory-produced mirrors are not necessarily representative of commercially practical products, they are very useful in exploring the effects of variations in the coating process. For example, a high quality mirror (as judged by microstructure) can be achieved under carefully controlled and standardized laboratory conditions (Figure 2.12). 

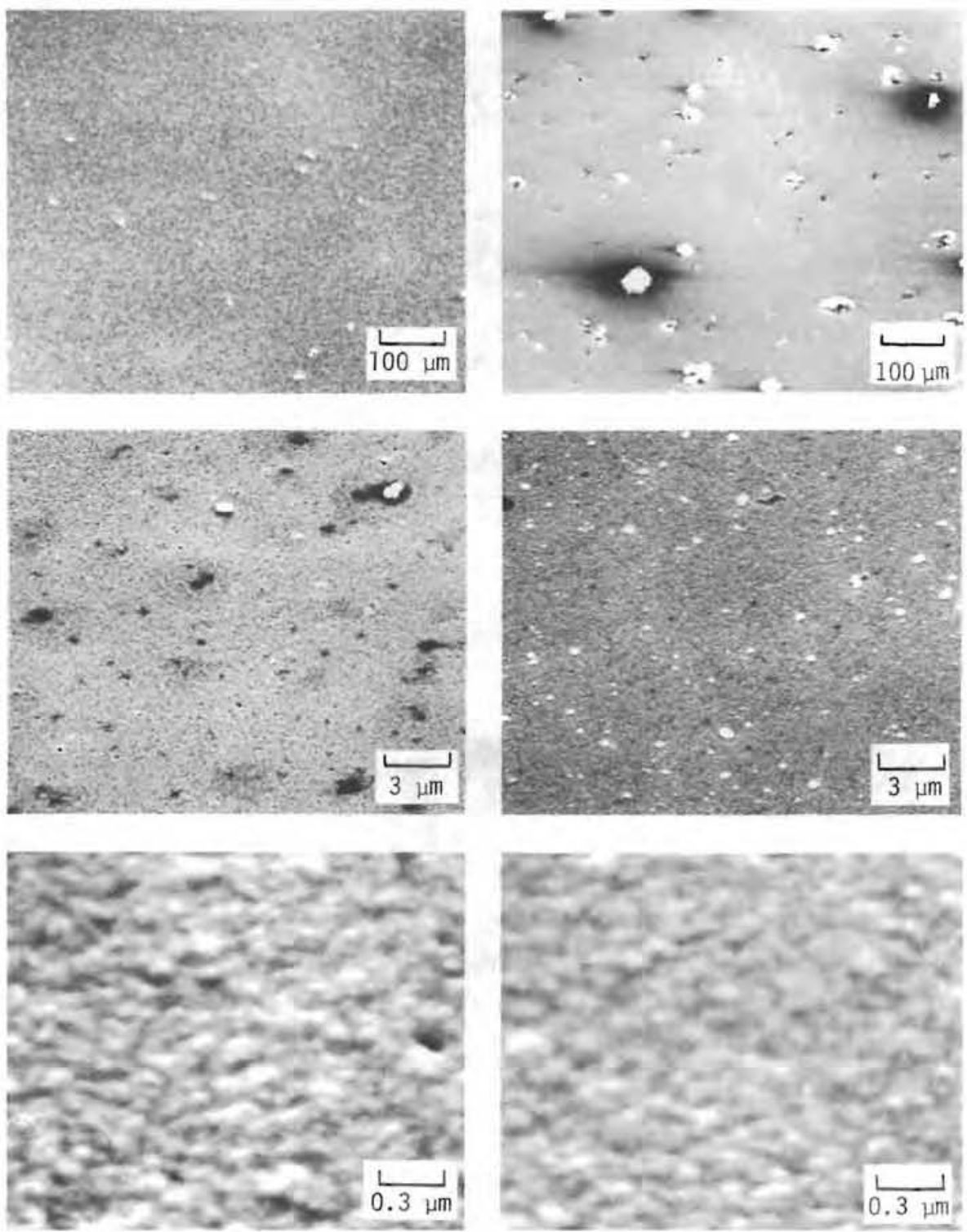

A. BARE $\mathrm{CU} / \mathrm{Ag}$ SURFACE AFTER

1 HOUR IN GLACIAL ACETIC

B. Cu/Ag SURFACE AFTER REMOVAL OF PROTECTIVE PAINT LAYER USING GLACIAL ACETIC ACID

FIGURE 2.9. Copper/Silver Surfaces After Removal of Backing Paint. Both these mirrors were soaked in glacial acetic acid for 1 to 2 hours. The paint film floats off intact, but no other microstructural effects are evident. Mirror $A$ is a nonabraded piece of the unbacked mirror in Figure 2.5B. Mirror $B$ was a painted mirror from the same production run as Figure $2.8 \mathrm{~B}$, and also shows the $\mathrm{Ag} / \mathrm{Cu}$ particles on the surface. 

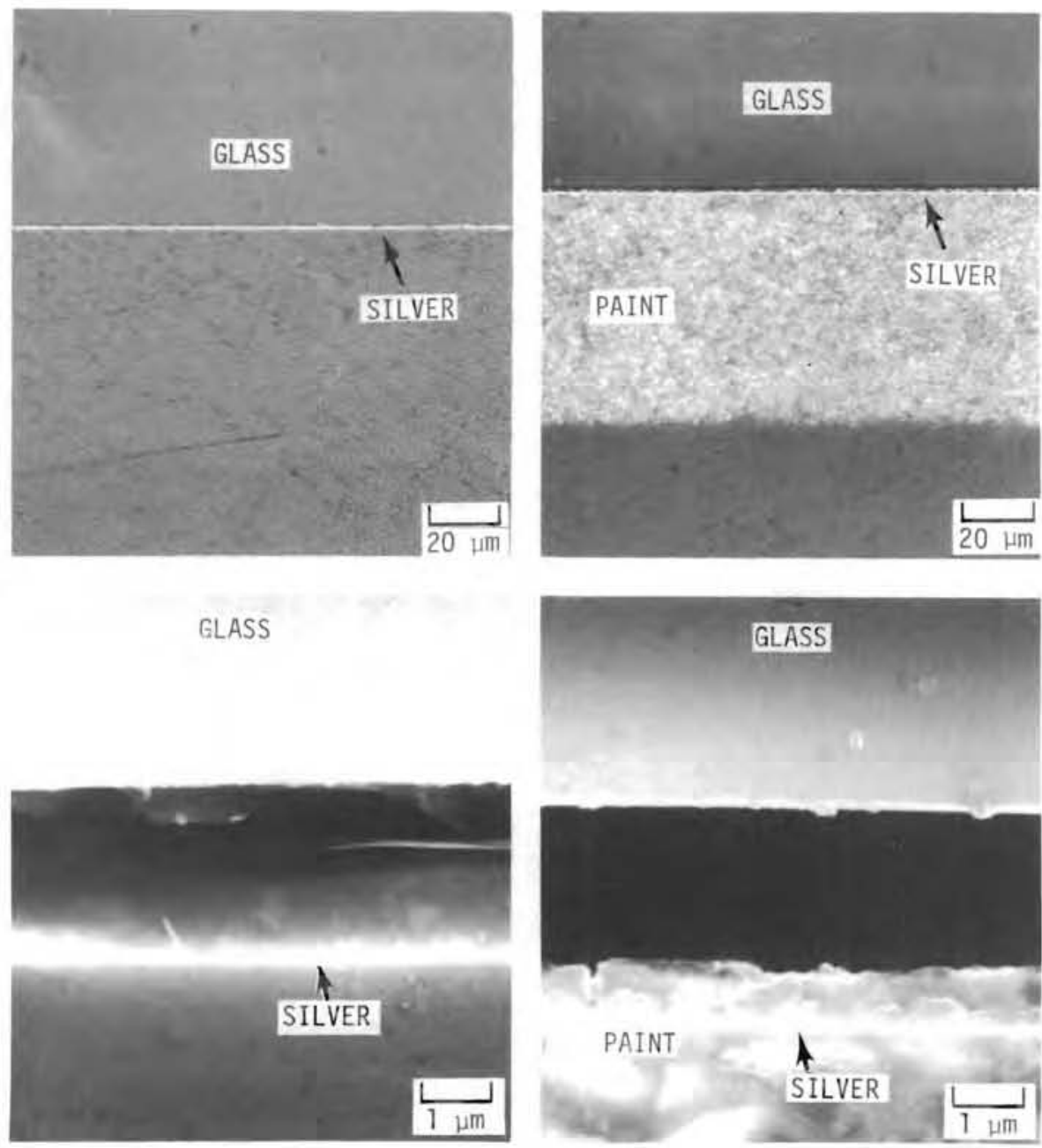

A. COPPER OVER SILVER ONLY

B. WITH PROTECTIVE PAINT BACKING

FIGURE 2.10. Bonding Between Silver and Glass on New Mirrors. Most of the glass-silver interfaces of new mirrors appear to be weakly bonded, allowing penetration of the epoxy resin between glass and silver during encapsulation for metallography. Bare copper/silver (A) and paintprotected metal layers behave the same way. 

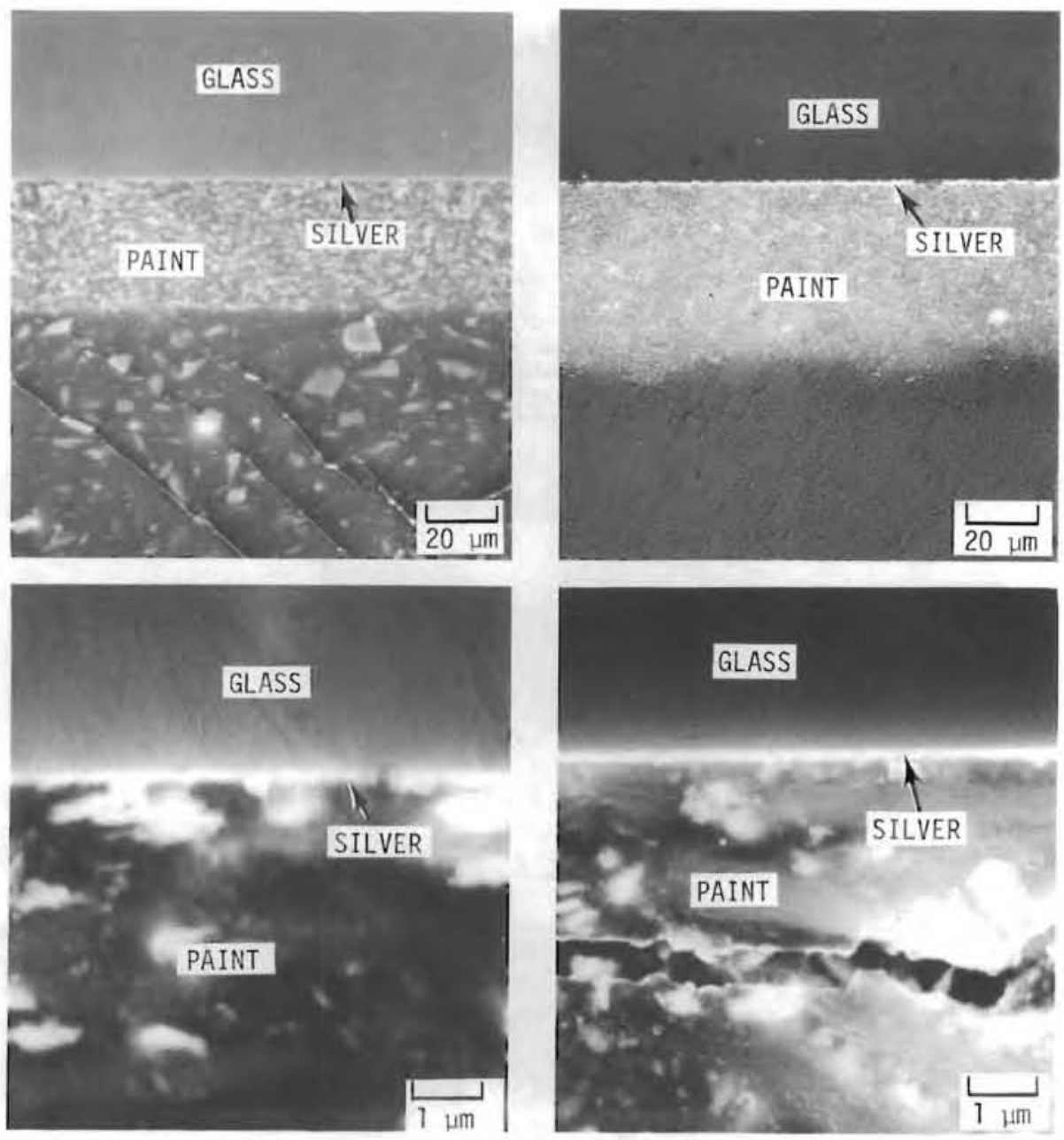

A. ONE YEAR EXTERIOR EXPOSURE

B. 17 YEARS EXTERIOR EXPOSURE

FIGURE 2.11. Silver-Glass Bond on Aged Mirrors. The silver-glass bond is known to strengthen after fabrication. On nondegraded areas of old mirrors the bond usually appears to be extremely tight even after long exterior exposure. 

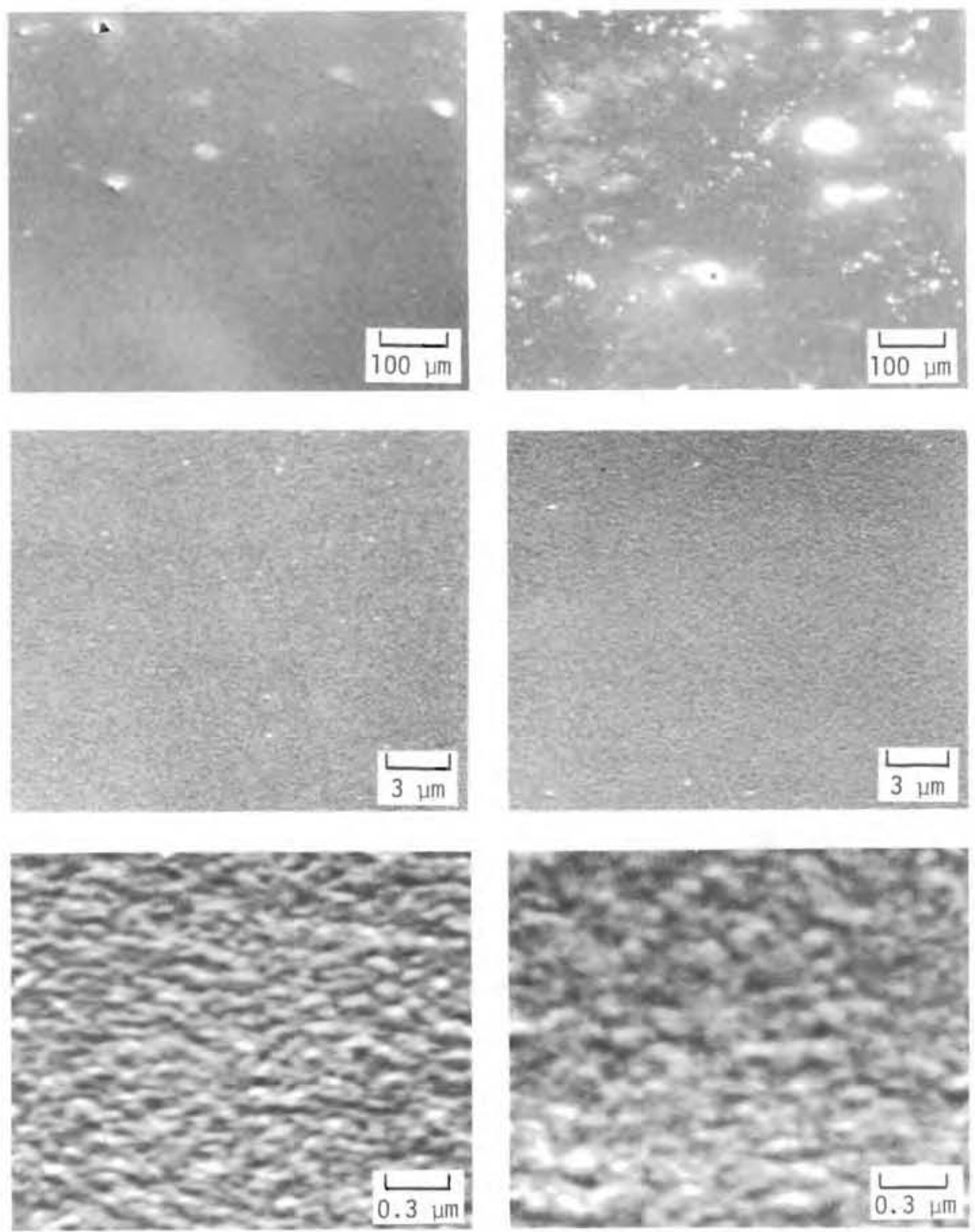

A. SILVERED ONLY

B. COPPER OVER SILVER

FIGURE 2.12. Laboratory Mirror Production by PPG. Under carefully controlled conditions excellent silver and copper layers can be produced as shown here. The surface debris on the copper layer is probably a result of repeated handling. Both these surfaces were unprotected during the 5 months between fabrication and this examination, but show no evidence of any surface deterioration. 
Some of the effects of changes in mirror fabrication method are evident from a series of specimens illustrated in Figures 2.13, 2.14, and 2.15. These specimens were selected from a series of 47 fabrication experiments performed by London Laboratories Limited in their Connecticut laboratory in which two different silver solution systems and two different methods of copper reduction deposition were used to deposit copper and silver layers of varying thicknesses (Table 2.4). The mirrors shown in Figure 2.13 all have the commercially accepted normal thicknesses of silver and copper, yet they differ markedly in the quality of their rear surfaces, ranging from "normal" to a surface with large silver particles and a sprinkling of stains or holes throughout. Differences appear to result from the mirroring chemistry and conditions used.

The mirrors shown in Figure 2.14 all were fabricated using about 10 times the normal thickness of copper backing over a normal silver layer, again using three variations in mirroring procedures. As can be seen, there were large nucleation centers with holes in one mirror and apparent surface debris on another. In Figure 2.15 the effects of different methods of application and layer thickness are very clear. In the top pair only one third the usual silver thickness was used; although the surface of the glass is showing through in some places, the metal surface smoothness is typical of an "average" production mirror. In the middle row, the copper thickness is approximately 10 times that normally applied commercially and the surface layer is rather rough. Doubling the amount of copper again (as shown in the bottom row) further increases the surface roughness.

These data demonstrate that the method of application and layer thicknesses have a pronounced effect on the surface structure of the metal layer. It should be recognized that these photomicrographs have shown the back (copper) surface of the mirror and not the reflecting glass/silver interface. As such they may only provide an indirect indication of actual mirror condition. However, in several cases complete penetration, even through a thick copper layer is obvious. Other experiments in these studies also have shown that silver and copper layers are intermixed beyond the nominal planar 

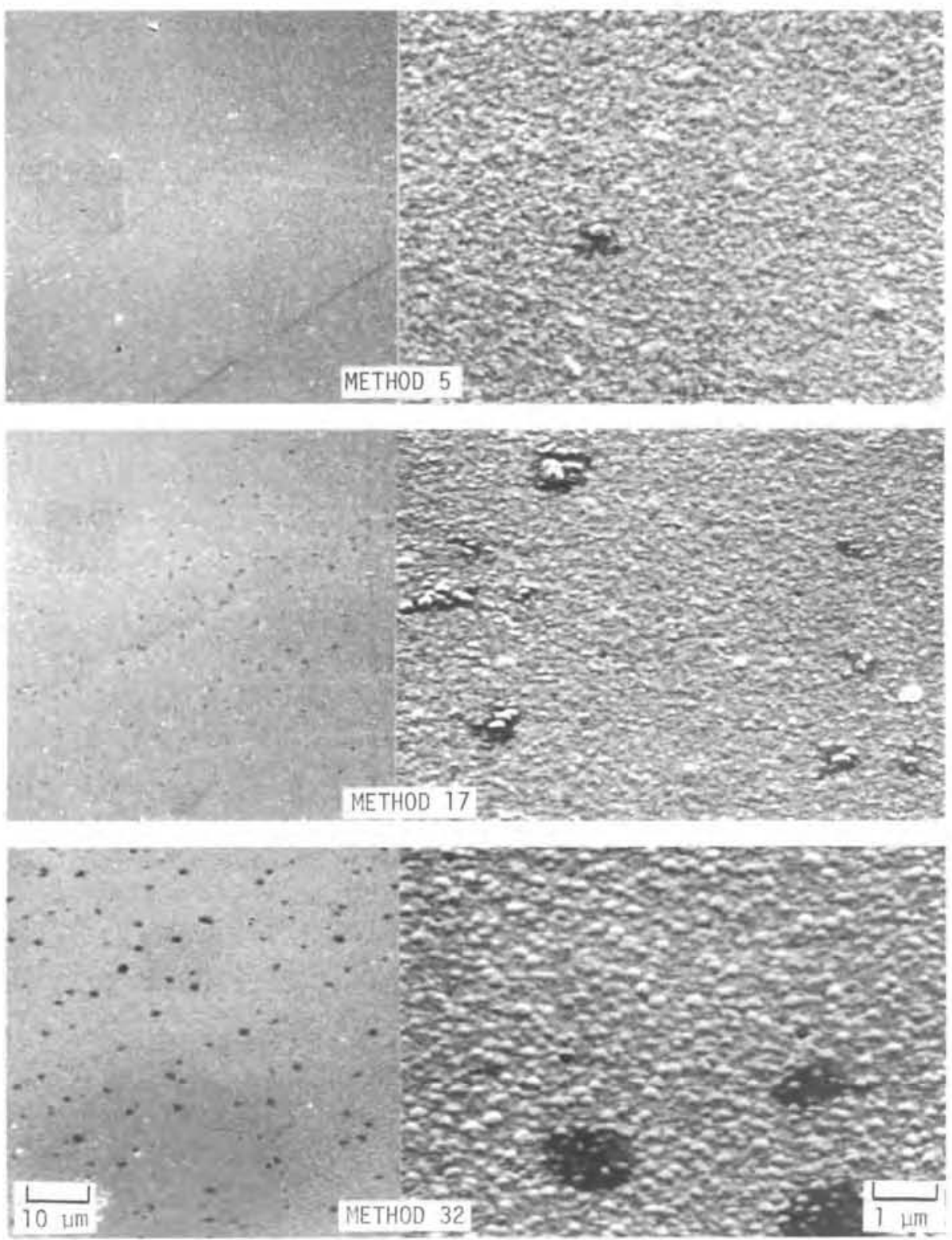

FIGURE 2.13. Effect of Changes in Mirror Fabrication Method. These three mirror samples have normal silver and copper thicknesses, but were produced by different silvering and copper reduction chemistry (see Table 2.4). 

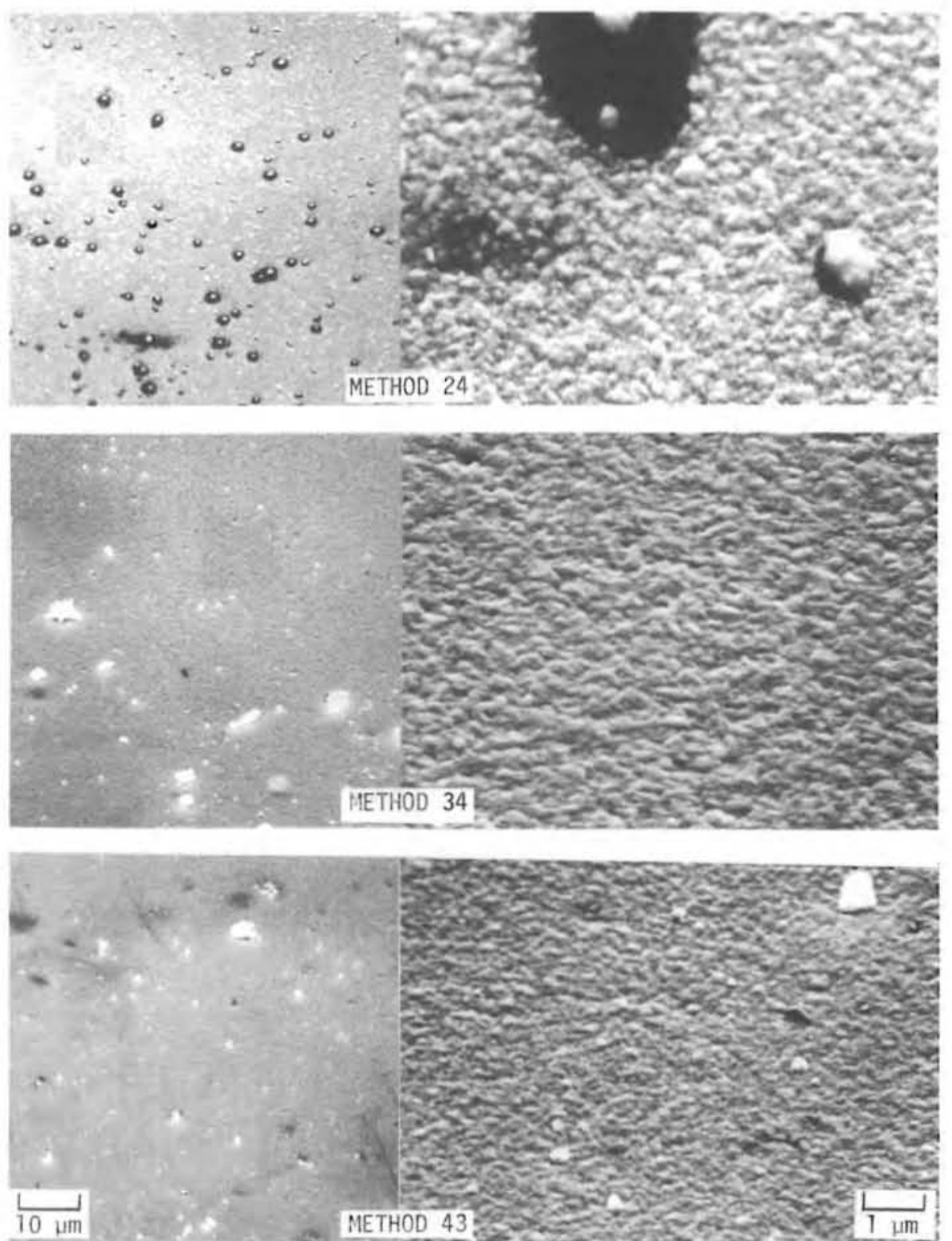

FIGURE 2.14. Effect of Changes in Mirror Fabrication Method. These mirror samples all contain about 10 times the normal thickness of copper backing, but each was made by a different combination of methods (see Table 2.4). 

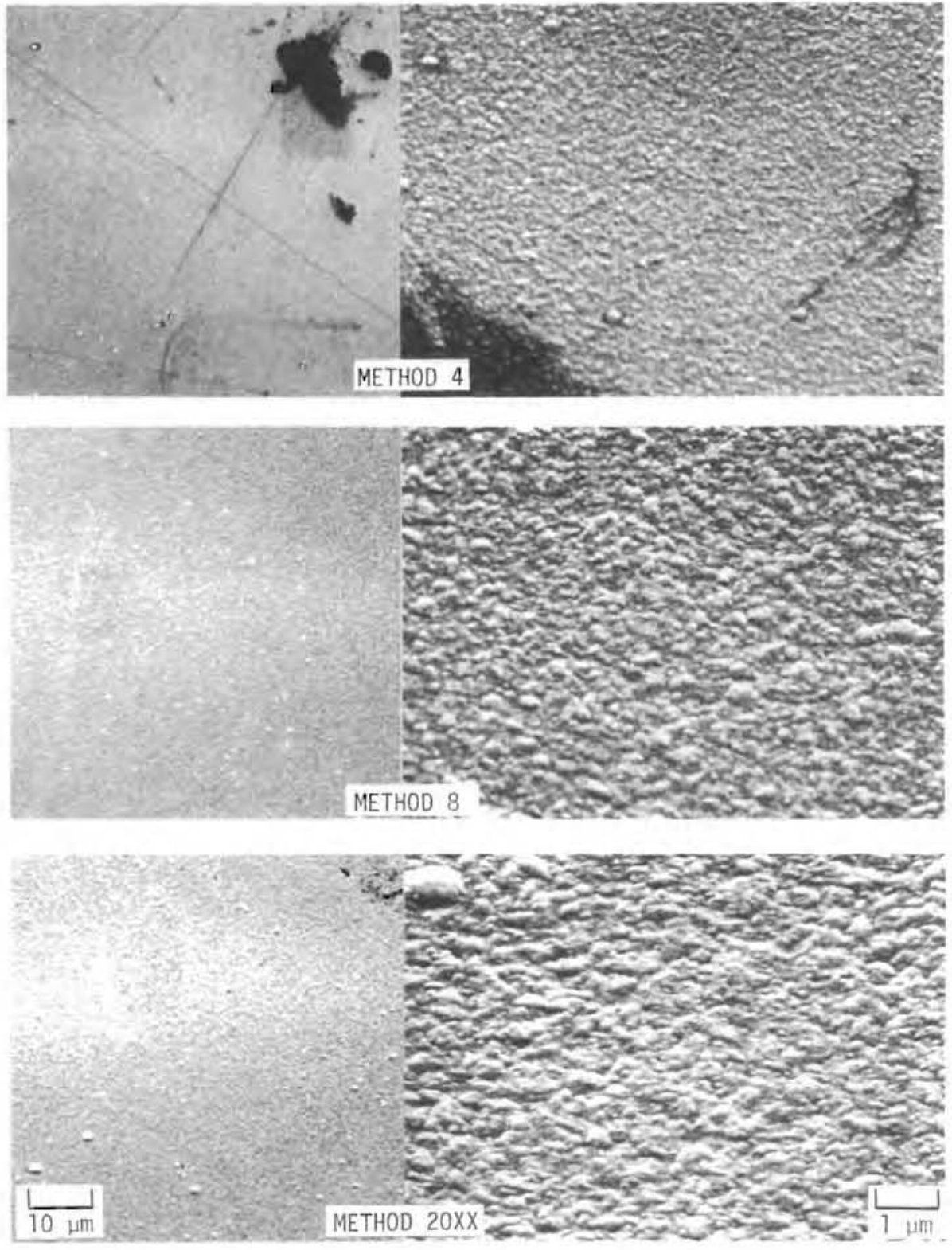

FIGURE 2.15. Effect of Changes in Mirror Fabrication Method. Microstructure of metal layers differs with method of application and layer thickness. Top: one-third normal silver; middle: 10 times normal copper; bottom: 20 times normal copper (see Table 2.4). 
TABLE 2.4. Mirror Fabrication Conditions Used in Comparison Tests (a)

\begin{tabular}{|c|c|c|c|c|}
\hline $\begin{array}{c}\text { Fabrication } \\
\text { Method } \\
\end{array}$ & $\begin{array}{c}\text { Type of } \\
\text { Silver (b) }\end{array}$ & $\begin{array}{r}\text { Silver } \\
\text { Film Wt(c) } \\
\end{array}$ & $\begin{array}{c}\text { Type of } \\
\text { Copper }(d)\end{array}$ & $\begin{array}{c}\text { Copper } F i] \mathrm{m} \\
\text { Weight }(\mathrm{e})\end{array}$ \\
\hline 4 & 2 & 26 & LLL & 110 \\
\hline 5 & 2 & 86 & LLL & 27 \\
\hline 8 & 2 & 86 & LLL & 232 \\
\hline 17 & 3 & 73 & LLL & 27 \\
\hline $20 x x$ & 3 & 73 & LLL & 575 \\
\hline 24 & 3 & 85 & LLL & 292 \\
\hline 32 & 3 & 65 & GAL & 34 \\
\hline 34 & 3 & 65 & GAL & 280 \\
\hline 43 & 2 & 70 & GAL & 231 \\
\hline
\end{tabular}

(a) Selected specimens from an extensive test series conducted by London Laboratories Limited.

(b) Type of Silver Solution Used: 2 = two-part solution; $3=$ three-part solution.

(c) Silver and Copper Film Weights, $\mathrm{mg} / \mathrm{ft}^{2}$.

(d) Copper Type: LLL = London Lab Disproportionation Copper; GAL = Galvanic Copper.

interface region and that copper appears to play a role in mirror failure. The condition of the copper layer may therefore play an influential role in determining mirror stability.

The above mirror samples represent only a small part of the set of samples produced for this study on process variations. There is a definite need to continue this investigation on these and similarly prepared samples in order to determine if systematic trends exist.

Effects of Surface Contaminants on the Glass Substrate

The effects of the two extremes of heavily powdered glass and vigorously hand scrubbed glass were examined from samples provided by London Laboratories Limited (Figure 2.16). The uncleaned half of a normal piece of mirror glass 

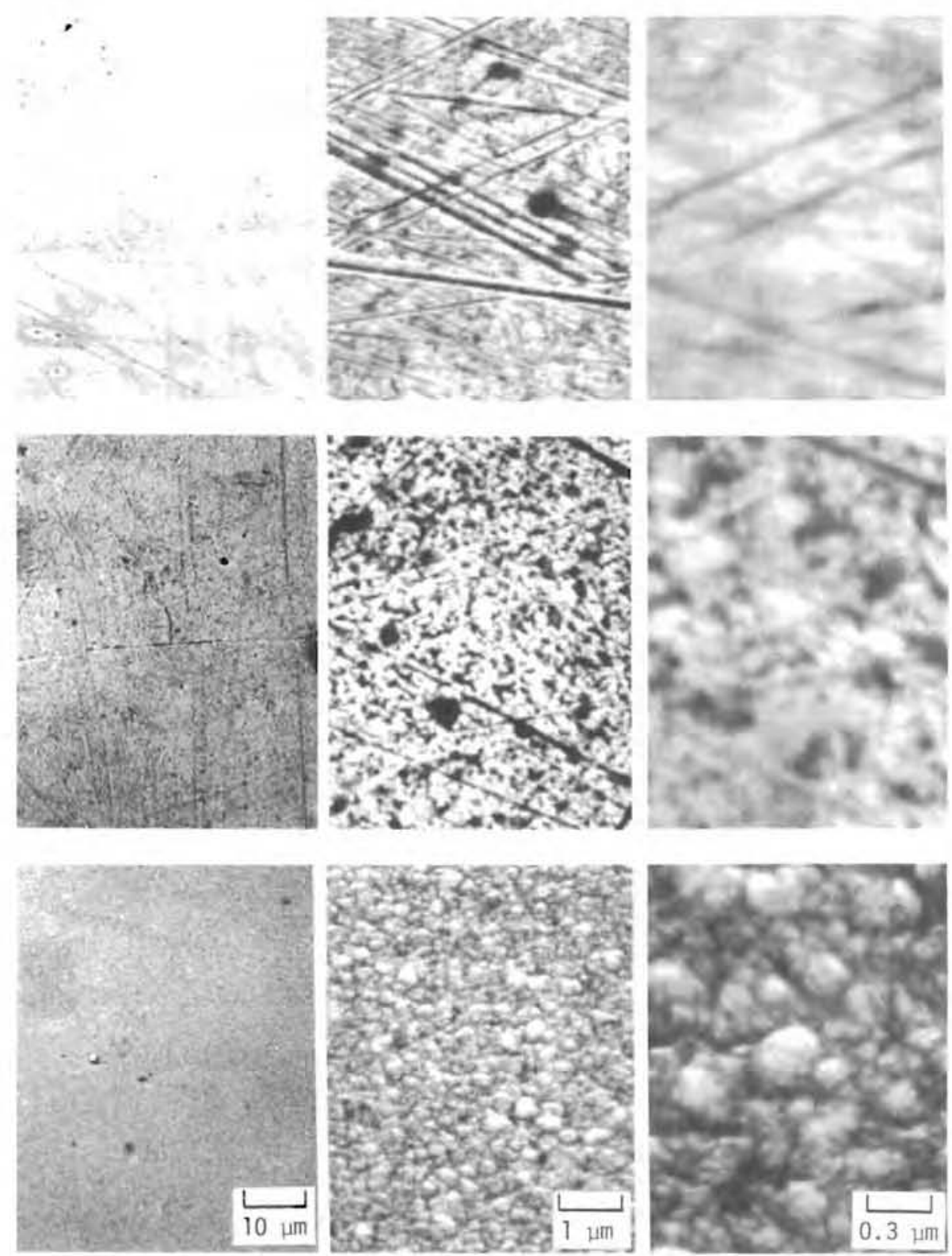

FIGURE 2.16. Effect of Precleaning Glass Surfaces on Mirror Microstructure. On the uncleaned glass the silver either peels off (top row of micrographs) or forms very porous poorly crystallized layer (middle row). When the same glass is vigorously scrubbed before silvering, the well-formed metal deposit is uniformly adherent with very little porosity (bottom row). 
did not silver well at all. Silver either peels off readily, as shown in the top row of micrographs, or forms a very porous poorly crystallized layer as shown in the middle row of micrographs. Glass surface scratches are still prominently visible in both cases when the glass has not been properly cleaned (e.g., scrubbed with $\mathrm{CeO}_{2}$ slurry) prior to application of the silver. However, when the same glass was vigorously scrubbed before silvering a good quality mirror was produced. Some of the fabrication defects observed in previous fabrication examples may have been due entirely or in part to inadequate cleaning of the glass before the stannous chloride sensitization and the silvering steps were applied.

Studies of Degraded Mirrors

A major effort was directed at the evaluation of aged mirrors. Samples were examined from the Sandia field test and from a 17-year uncontrolled exterior exposure in North Carolina. The effort was directed toward:

1) determining the microstructure and the composition of the defective areas;

2) comparison with nondefective areas in the same mirror; 3) comparison with new mirrors of recent vintage; and 4) comparison with defects or nonstandard effects found on the recent mirrors.

The Sandia Mirrors. The degraded mirrors obtained from Sandia Laboratories for examination were commercially coated. They were then mounted into a test heliostat structure (foam sandwich construction) and exposed to the exterior environment at Livermore, CA for one year. During this period several defect areas developed that were visually noted from the front surface. The heliostat structure was subsequently disassembled to allow a postmortem examination of the degraded mirror areas. It was noted at the time of disassembly that the heliostat structure used had inadvertently allowed water to collect or condense and remain against the painted surface of the mirror. That interface was wet when the structure was separated.

Typical defects from that mirror are shown in Figures 2.17 and 2.18. The photographs show both a front and rear view of the mirror. The largest defect spots tend to lie in a linear geometrical pattern, but they are surrounded by what is potentially a more serious wide distribution of small spot degradation. It is the small spot degradation which is apparently a 


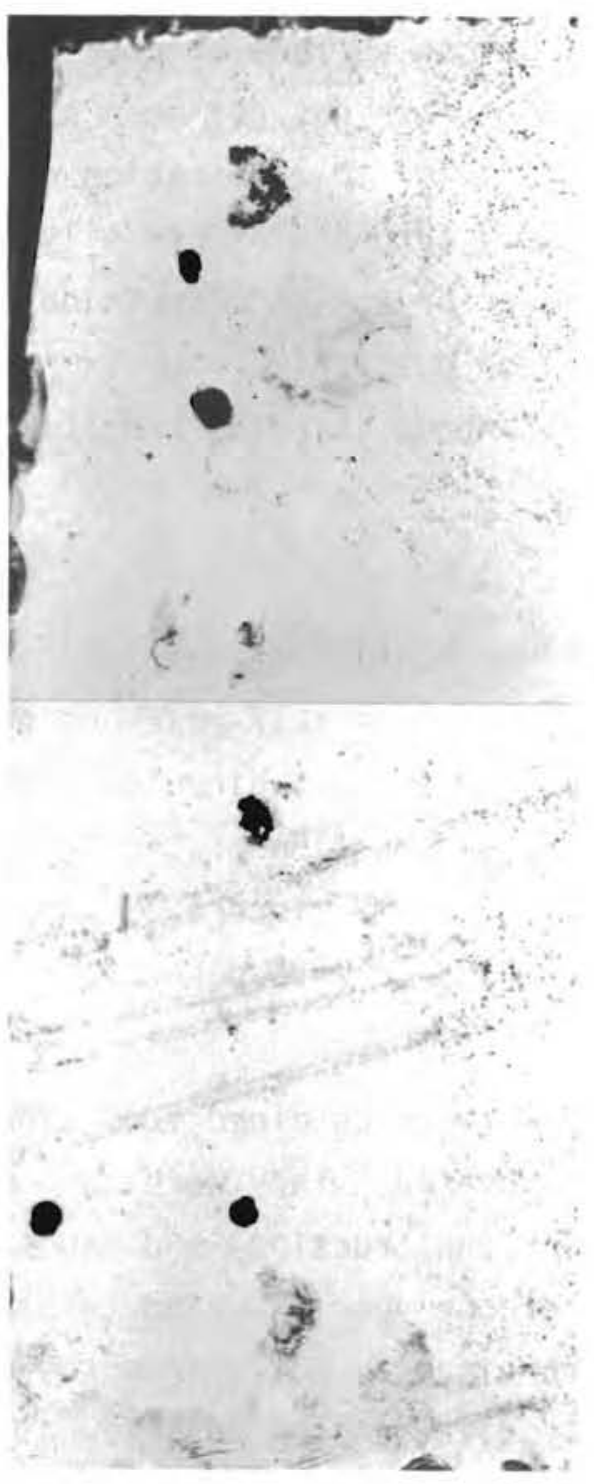

A. FRONT (GLASS) SIDE

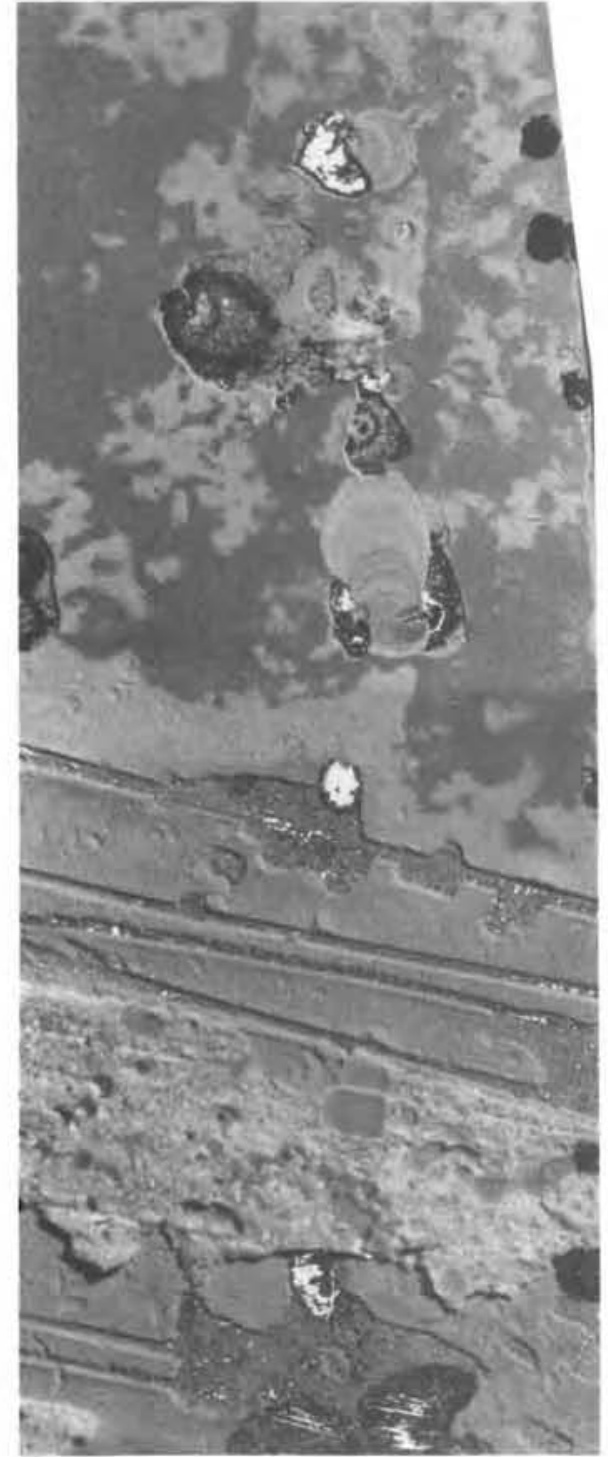

B. REAR VIEW (BACKLIGHTED)

FIGURE 2.17. Large Defect Spots in Sandia Field Test Mirror. The largest defect spots tend to form a linear pattern surrounded by a random distribution of small spot degradation. The rear view shows the original paint and the foam backing partially removed. 

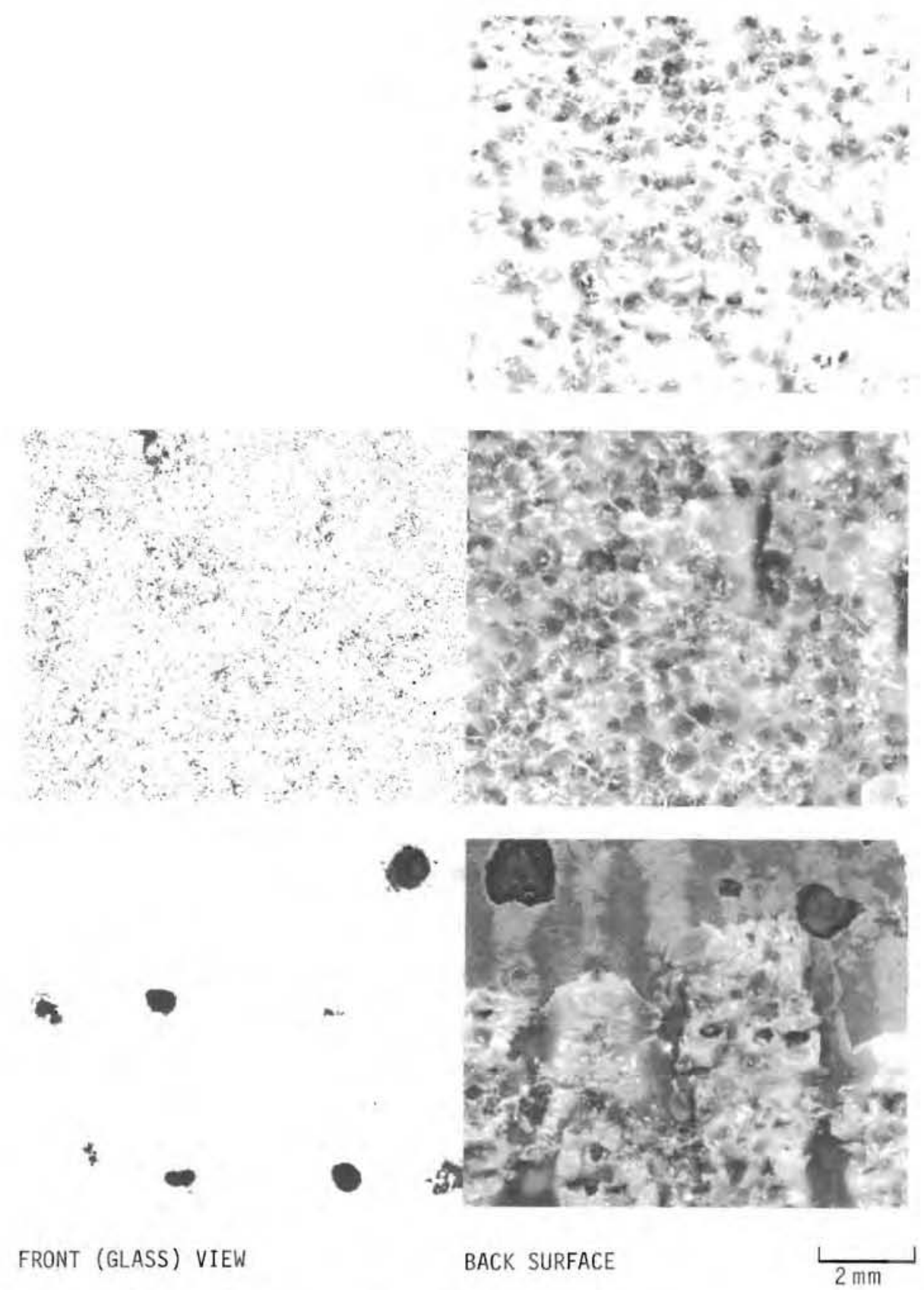

FIGURE 2.18. Typical Mirror Surface Features of Sandia Mirror. The mirror surface condition included nearly likenew areas, fine spot degraded regions, and aligned spots about $1 \mathrm{~mm}$ in diameter. The back appears uniformly covered with foam except for rake marks resulting from application of the adhesive for the foam backing. 
growing phenomenon, and it is much more extensively distributed. The rear view shows the original paint and the foam backing partially removed. A detailed examination of the typical areas on this mirror (Figure 2.18) show that the large spots are aligned with the rake marks left by the application of adhesive for the foam backing. Apparently the physical disturbance of the raking process was a contributing, or perhaps major, factor in the failure evidenced by the large spots. However, the fine structure, which not only surrounds those large spots but is also widely distributed over the entire mirror, is potentially more significant and could be expected to grow in size with further exterior exposure. This random degradation does not limit itself to edges of the mirrors; in fact, more deterioration appears to occur in the interior of mirrors than on the edges, as the edges are relatively clear in this specimen.

As discussed earlier the silver to glass bond appears to be relatively weak. The extent of silver/glass debonding in this mirror was less than that observed in some recently fabricated mirrors al though some separation was observed. Figure 2.19 shows a typical undegraded area in which the silver is partially debonded from the glass. The details at the right end of this separated section suggest that separation might have occurred even before paint was applied because the paint appears to have penetrated through a break in the silver film to lodge between silver and the glass. Examination of the surface of the silver where it has separated from the glass (Figure 2.20) shows that the silver surface is relatively smooth, suggesting again that the initial bond to the opposing glass surface was very weak. Compositional variations measured by EDX accompany the SEM photograph. Copper accompanies the silver in the separated nondefect regions. The front surface view through the glass did not reveal a mirror failure at this point on the mirror.

As mentioned earlier, fine spot deterioration appears to be of more significance because it is more widely distributed. Figure 2.21 shows the details of the edge view of a typical example of this kind of defect spot. Of particular interest is the fact that the spot where degradation has occurred appears to have involved a reaction with the glass layer itself, rather than simply oxidizing or otherwise reacting with the silver layer alone 

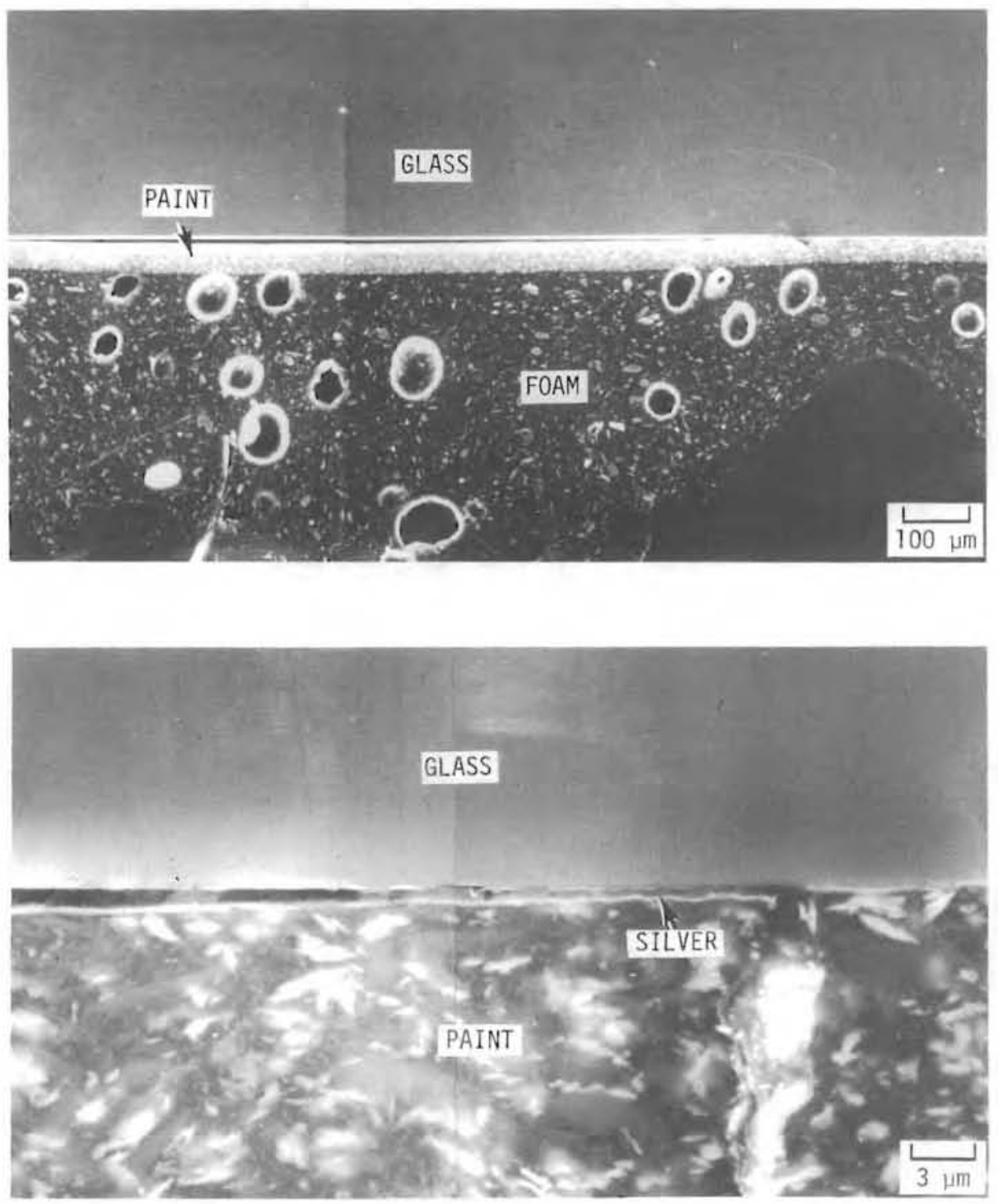

FIGURE 2.19. Separation of Silver from Glass in an Undefected Area of the Sandia Mirror. Even in some nondegraded areas the silver is partially debonded from the glass, with separations of up to $10 \mu \mathrm{m}$. 


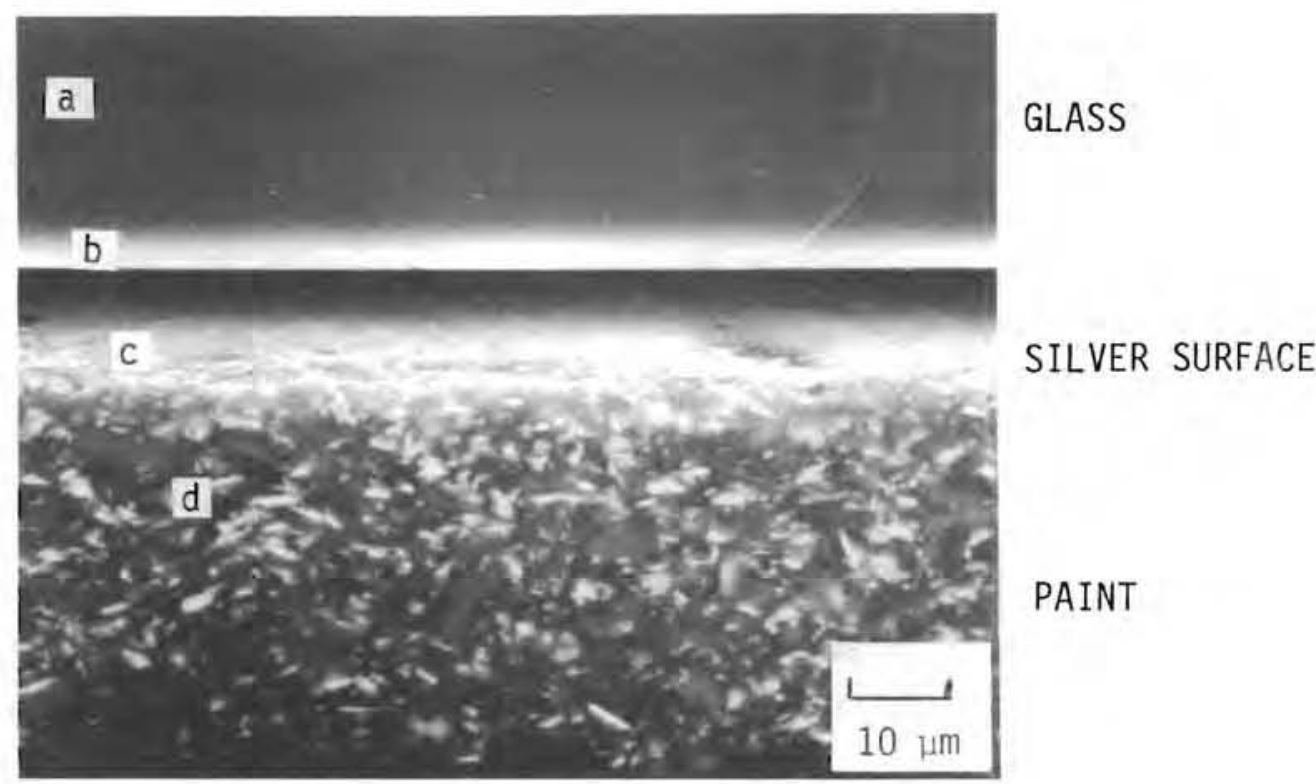

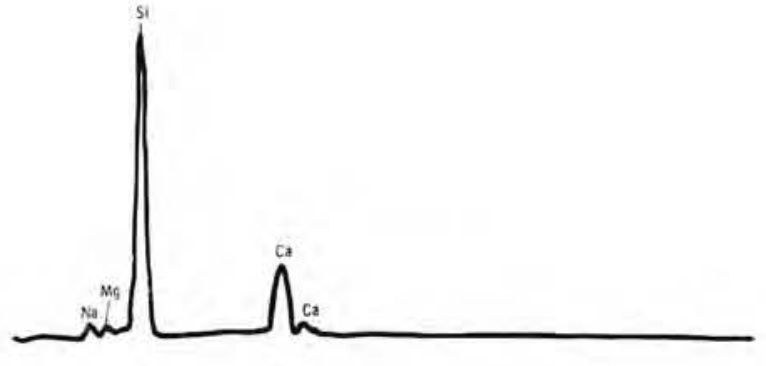

a

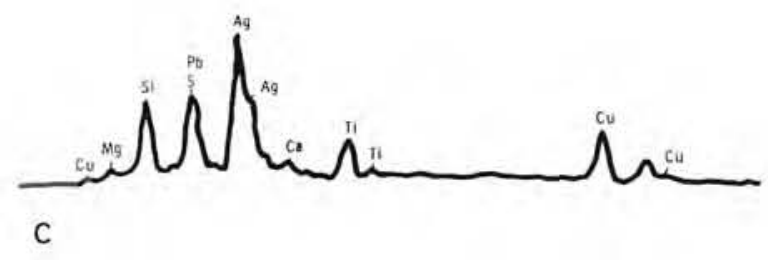

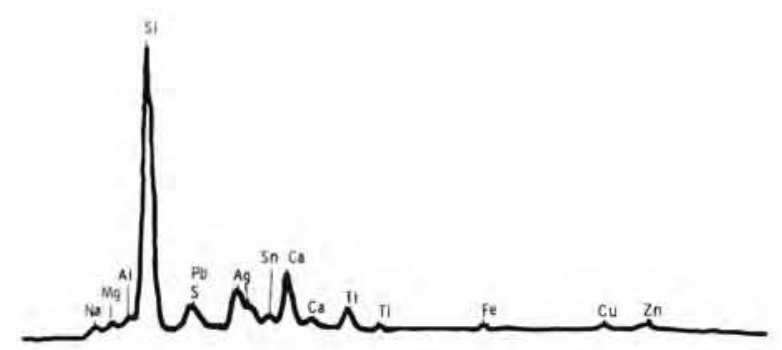

b

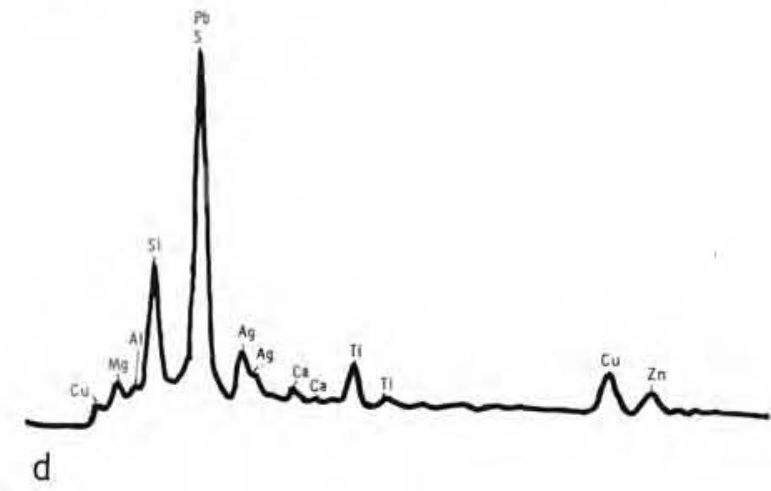

FIGURE 2.20. Looking Down into Opening Between Glass and Silver. The exposed silver surface looks relatively smooth, suggesting that the initial bond to the opposing glass surface was very weak. The composition as a function of position is indicated below. 

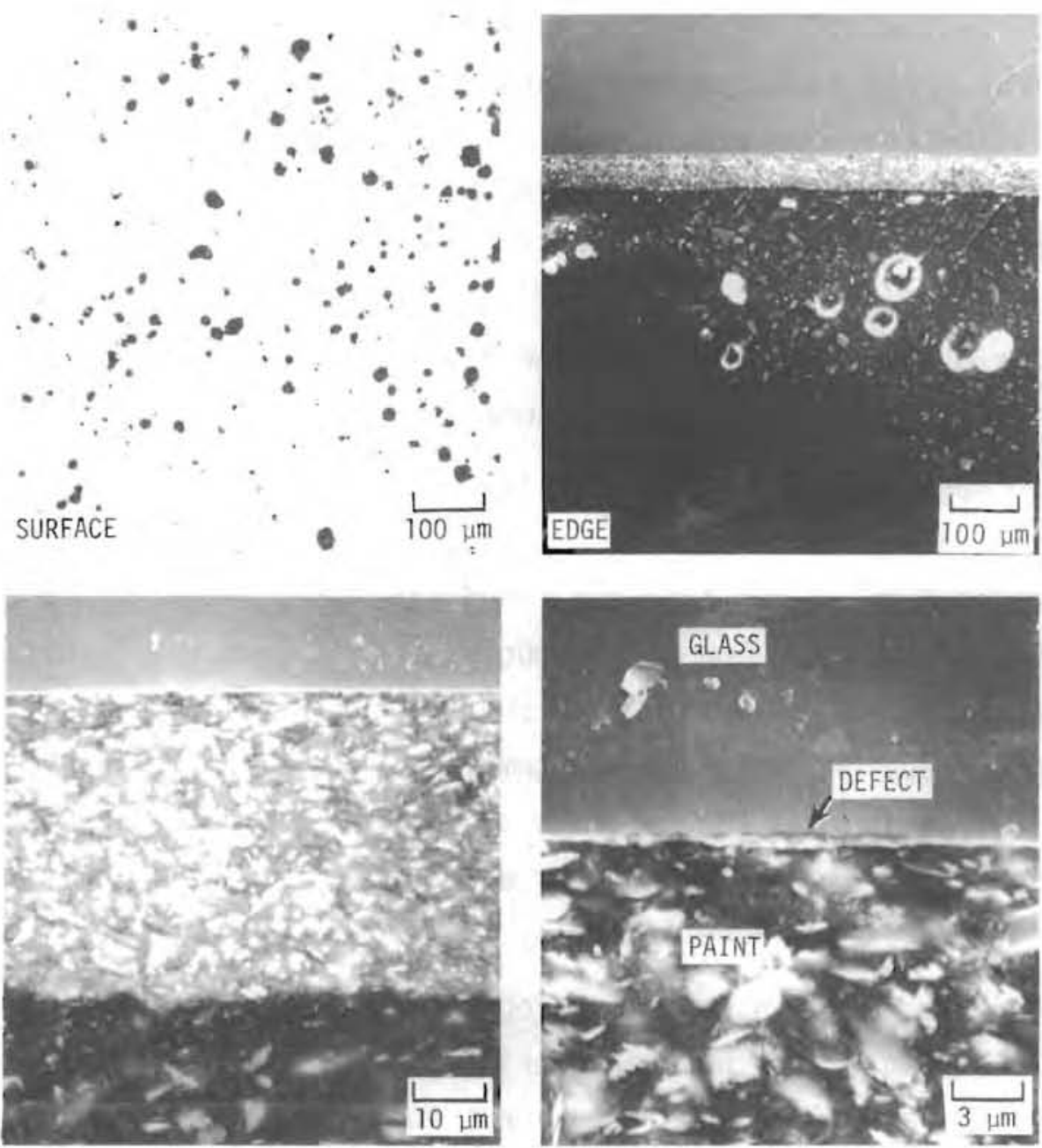

FIGURE 2.21. Fine-Spot Degradation on Sandia Mirror. This mode of degradation occurs to some extent over the entire specimen of field-tested mirror, and is very abundant in the vicinity of the large defects. 
(Figure 2.22). Reaction with the silver apparently has occurred also, since the thickness of the silver layer is substantially increased directly under the defect spot. The attack zone appears to penetrate into the surface about $2000 \mathrm{~A}$ indicating that the glass itself is involved in the failure mechanism. Copper is essentially absent in the defect region, even though it occurs in its normal proportions in the immediately adjacent nondefect area. This absence of copper in a defect region is a typical characteristic of all defect regions examined, even though the copper distribution on the original mirror and in nondegraded areas is reasonably uniform and intact.

In large spot degradation such as illustrated in Figure 2.23, some other characteristics are common. First, the large spots are always surrounded by fine-spot degradation of the type described earlier. Also, the large spots themselves usually contain one or two nucleation centers. In addition, the paint backing directly over the defect spot always blisters, and eventually, in a prolonged reaction, will rupture completely as shown in the lower view of Figure 2.23. This behavior suggests that either there is a buildup of pressure of gaseous reaction product as a result of the degradation process or the outer paint layers were initially in compression.

$X$-ray fluorescence maps of the defect area, compared to a clean nondefect region, further illustrate the characteristics of these regions. Figure 2.24 shows a nondefect area immediately adjacent to a large spot and the glass to metal bond is tight and intact. The width of the silver $x$-ray band suggests that the silver may have diffused into the glass a short distance. (The uniform scattering of spots is instrument background noise.) The thin layer of copper (about 1/3 the thickness of silver in a normal mirror deposition) is at the proper location, but it appears to contain holes at one or two locations within the area shown. If the function of the copper is to provide a sacrificial layer, preventing direct reaction of the silver with such reactants as chloride or sulfide, then the presence of holes through the copper would make this protective layer vulnerable for future attack.

Figure 2.25 is centered on a large defect spot in this degradation area. Both silver and copper are completely absent although a small amount of 

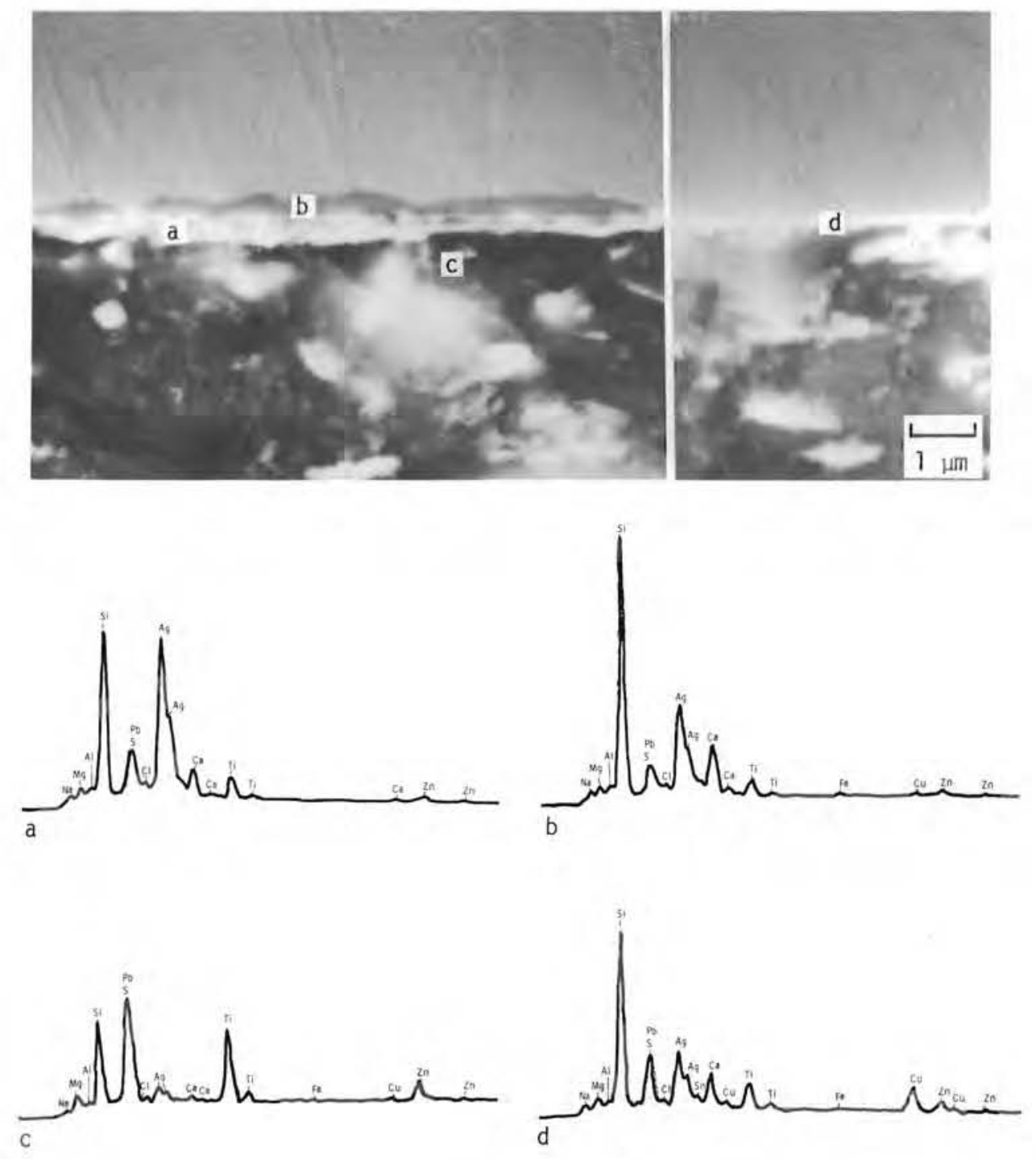

FIGURE 2.22. Edge View Details of Fine Spot Degradation. In the defect areas the silver layer is thickened. The attack zone appears to penetrate into the glass surface about $2000 \AA$. Copper is essentially absent in the spot region, although it occurs in its normal proportion in the nondefect areas immediately adjacent. 

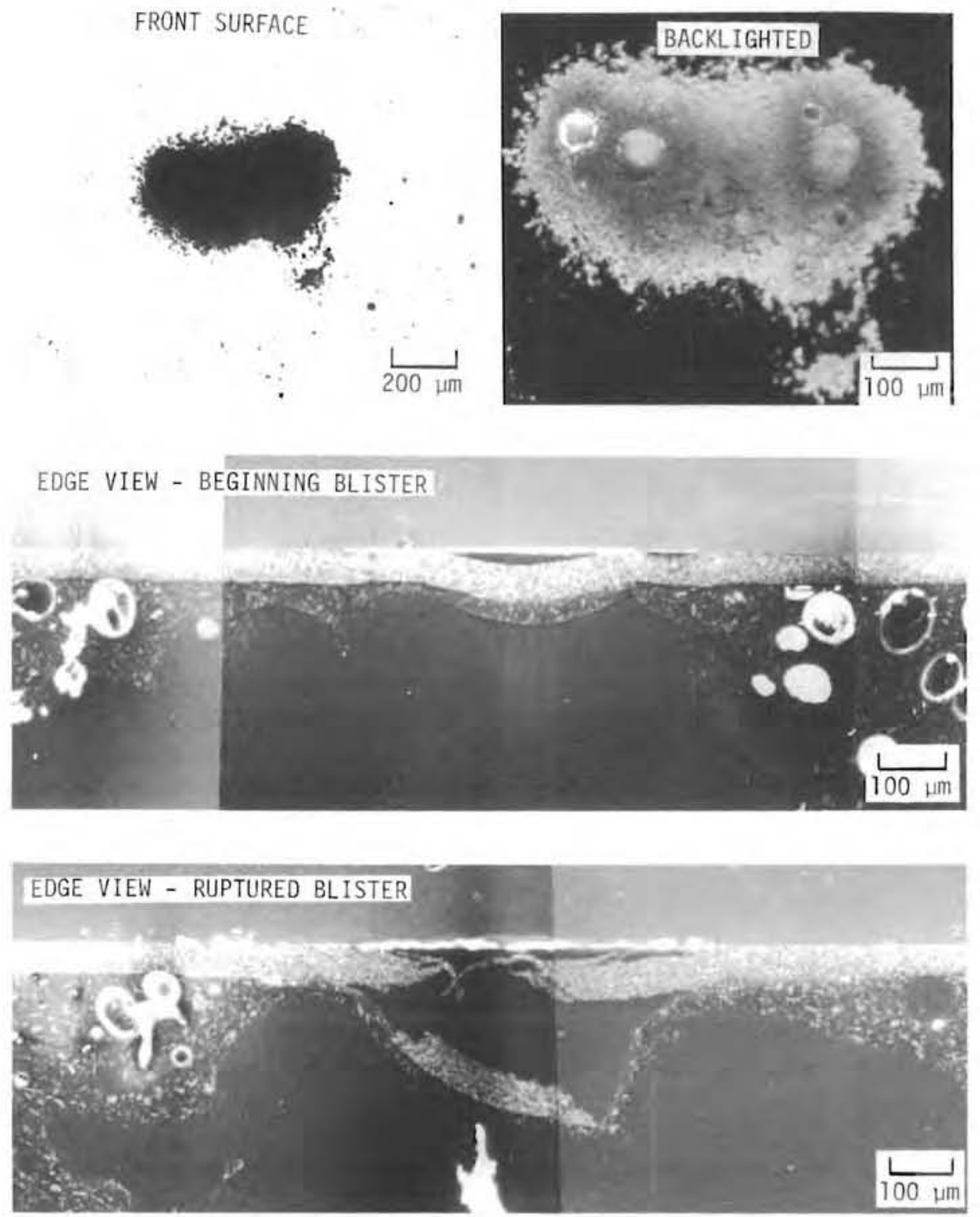

FIGURE 2.23. Typical Large Spot Degradation. The large spots are always surrounded by fine spots and contain one or two nucleation centers. The paint backing blisters over the large spot, and eventually ruptures as degradation progresses. 

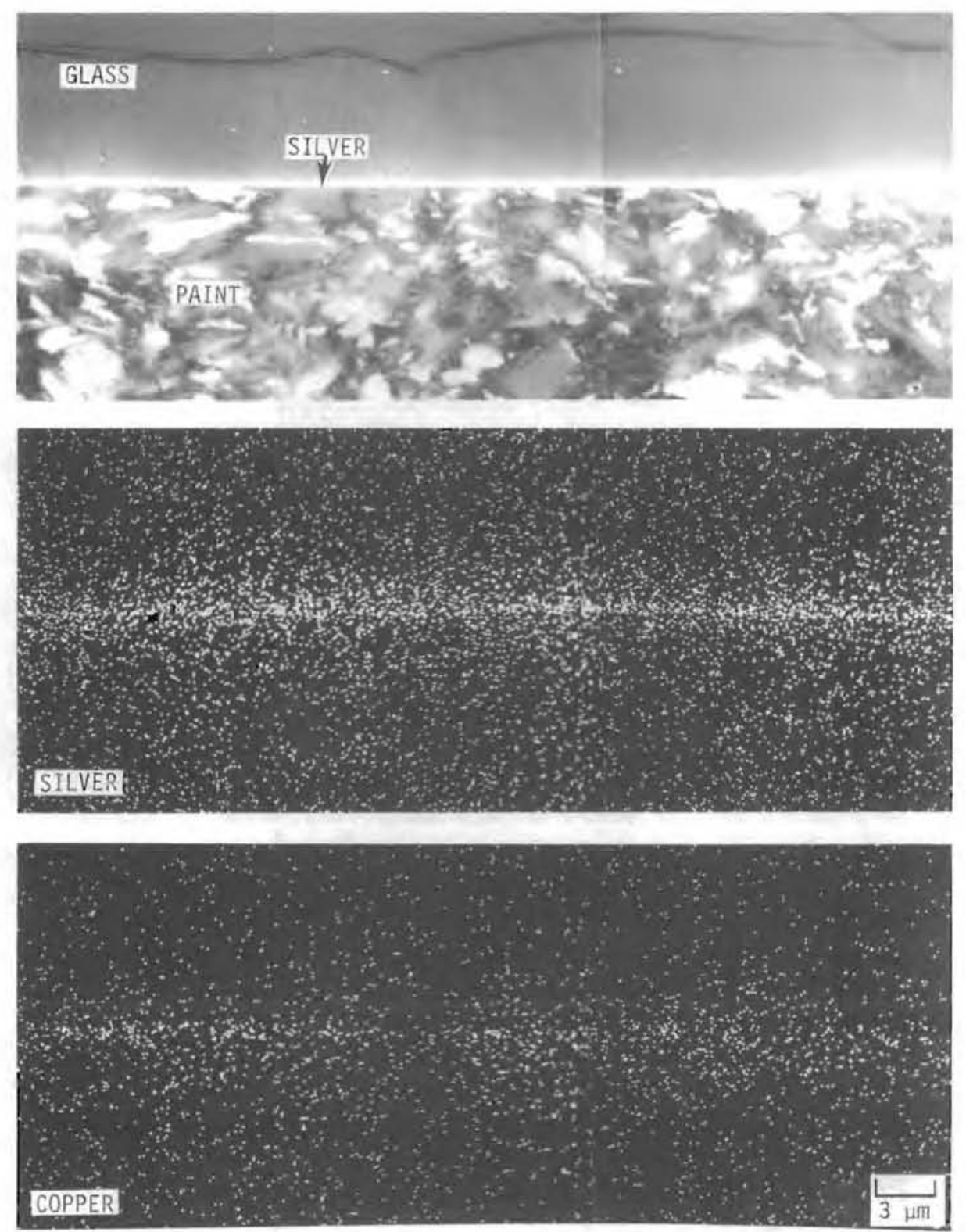

FIGURE 2.24. X-Ray Fluorescence Maps of Edge View of Glass/ Silver/Copper Bond. In nondefect areas immediately adjacent to a large spot, the glass/ metal bond is tight and intact. 

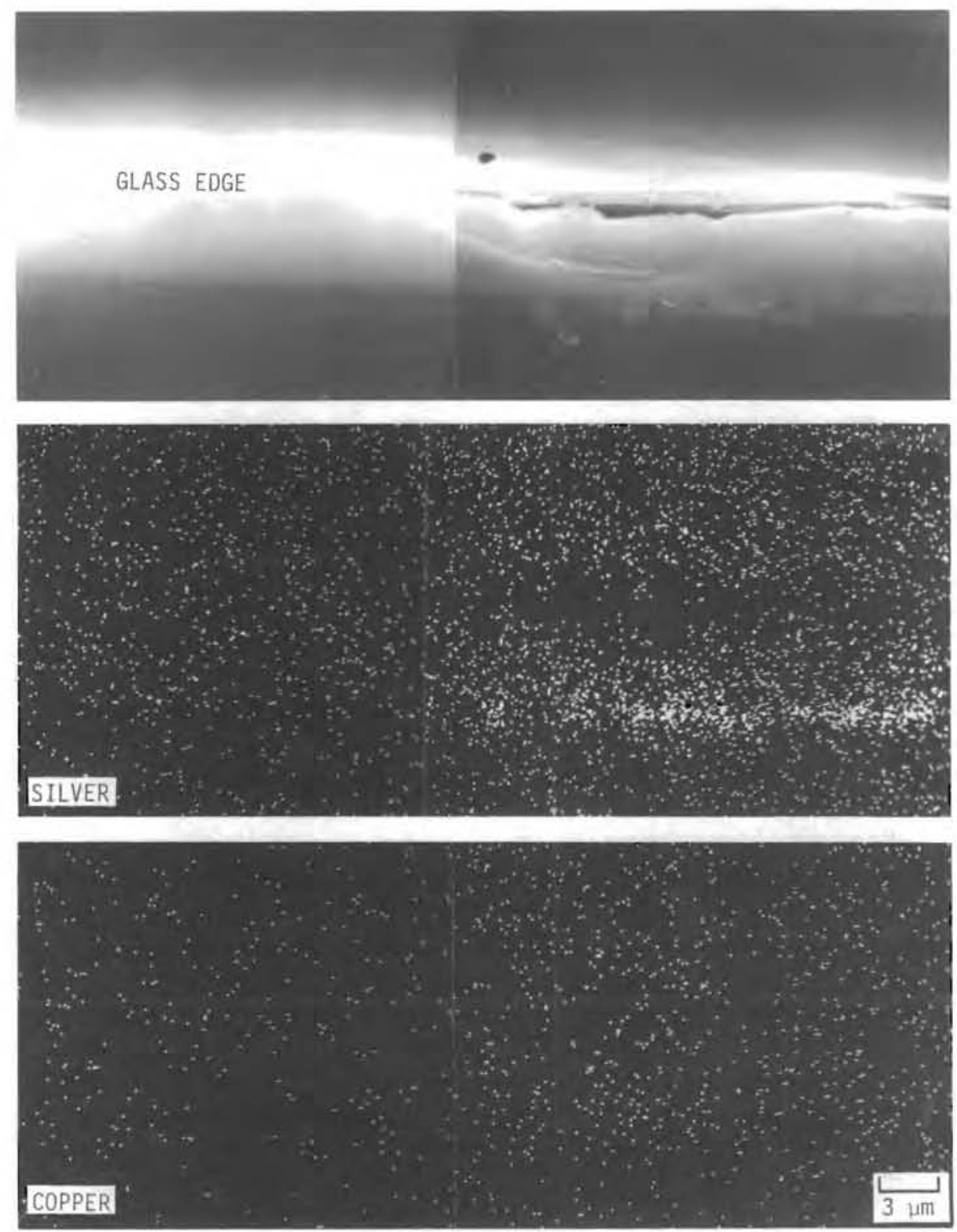

FIGURE 2.25. X-Ray Fluorescence Maps of Edge View of Large Defect Spot. At the center of large degradation spots both silver and copper are absent, although a little silver shows around the edges. The adjacent glass appears corroded and embrittled. 
silver shows around the edges as illustrated on the right of this figure. The glass appears to be corroded and embrittled and obviously has undergone a severe attack of some type. For example, compare this with Figure 2.24 in the nondegraded area where the glass remains smooth and intact. This again suggests, as in the case of fine-spot degradation, that a glass reaction contributes to the failure of the mirror.

Whereas the previous conclusions were derived from edge views of defective and sound regions of the mirror, additional information can be obtained by examining the large defect spots in the regions where the paint has peeled off in the course of the failure. One such spot is shown in Figure 2.26 in which the original foam backing and the accompanying paint layer have been removed. The black region in the center of the micrograph is bare glass. It is surrounded by a fine silver layer totally devoid of the original copper cover. Silver has agglomerated into large particles in some regions of the defect. This is seen in the bright area on the left side where the particles occur atop the fine silver layer. The characteristics of the agglomerated silver are more clearly shown in Figure 2.27, where it is apparent that the agglomeration is similar to that which might be expected from heating and partial sintering of the initial silver layer. The larger particles also are reminiscent of those which occurred in some of the original fabrications of mirrors, particularly as shown in Figure 2.8 and 2.13. A low concentration of chloride was observed in this region, primarily in the larger particles with none seen in the fine structured silver layer. Chloride probably was not a major contributing factor in the failure of this region of this mirror.

The Carolina Mirrors. As a routine procedure during the fabrication of mirrors at the Carolina Mirror Corporation, samples of production mirrors are put into exposure racks on the roof of the plant. Some of the mirrors have been supported on edge so their plane surfaces are free of contact with other objects, while others have been laid flat and in some cases stacked with their plane surfaces in contact with other mirrors. Figure 2.28 shows examples of the effect of 17 years of exterior exposure in a light industrial environment on a pair of mirrors under these two mounting conditions. The free-standing 

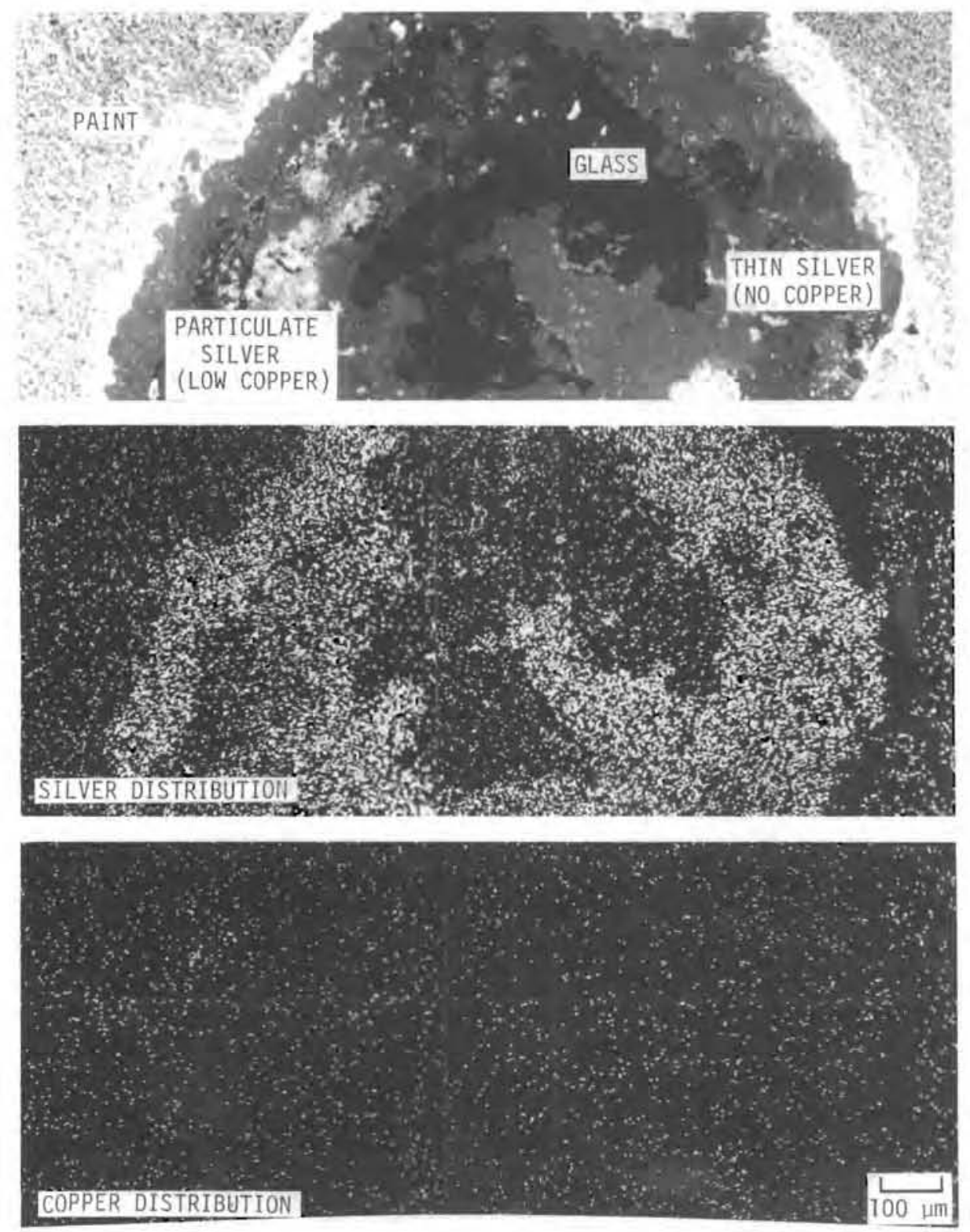

FIGURE 2.26. Details of Paint-Side View of Large Defect Spot. The center is bare glass surrounded by a fine silver layer and clusters of large silver particles. Copper is entirely absent across the full spot diameter. 

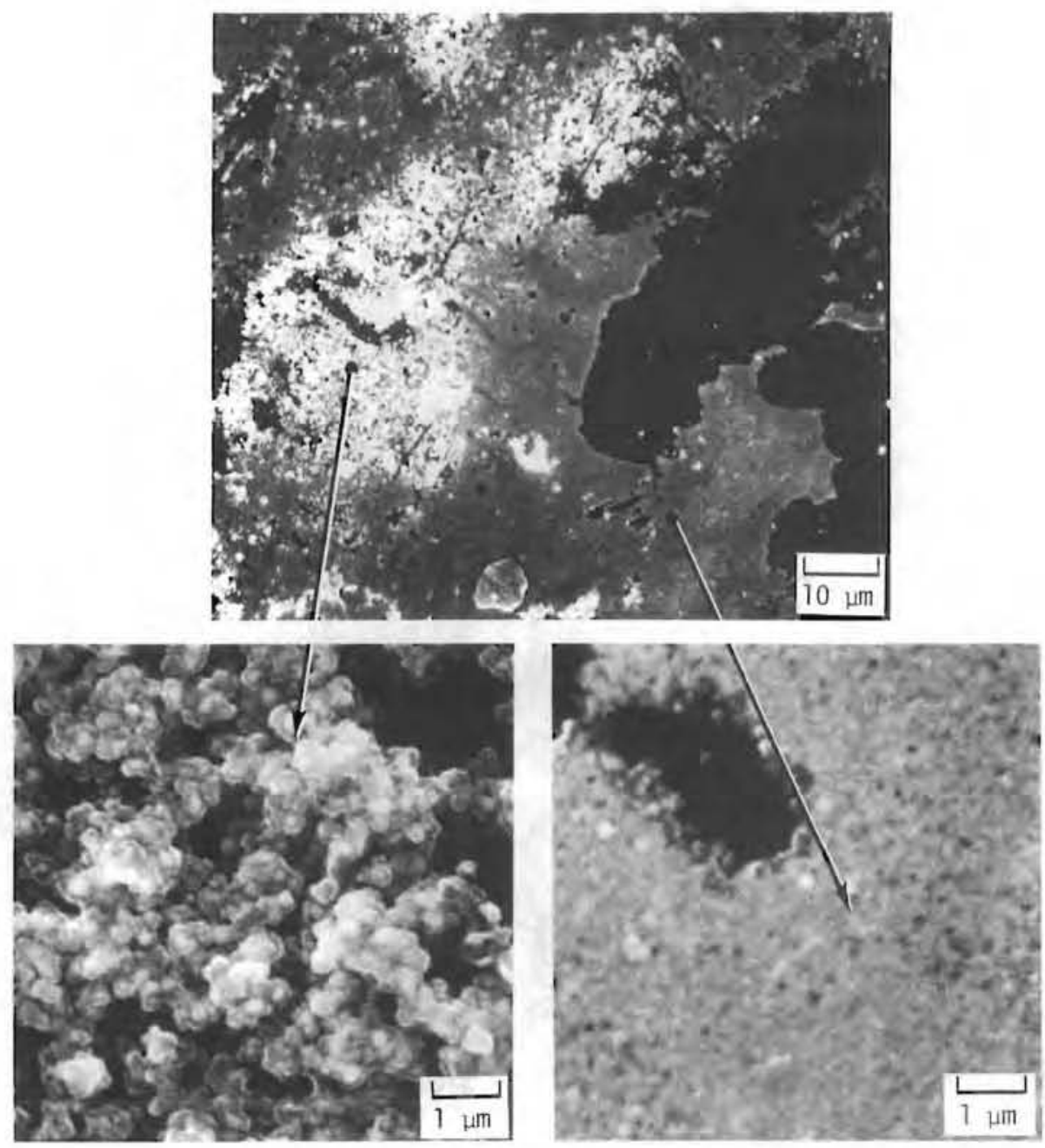

FIGURE 2.27. Microstructure of the Silver Layer at Large Mirror Defects. In the circumferential areas of large defect zones some of the silver has been converted to much larger agglomerated particles. The resulting form is similar to that which might result from heating and partial sintering of the original silver layer. 

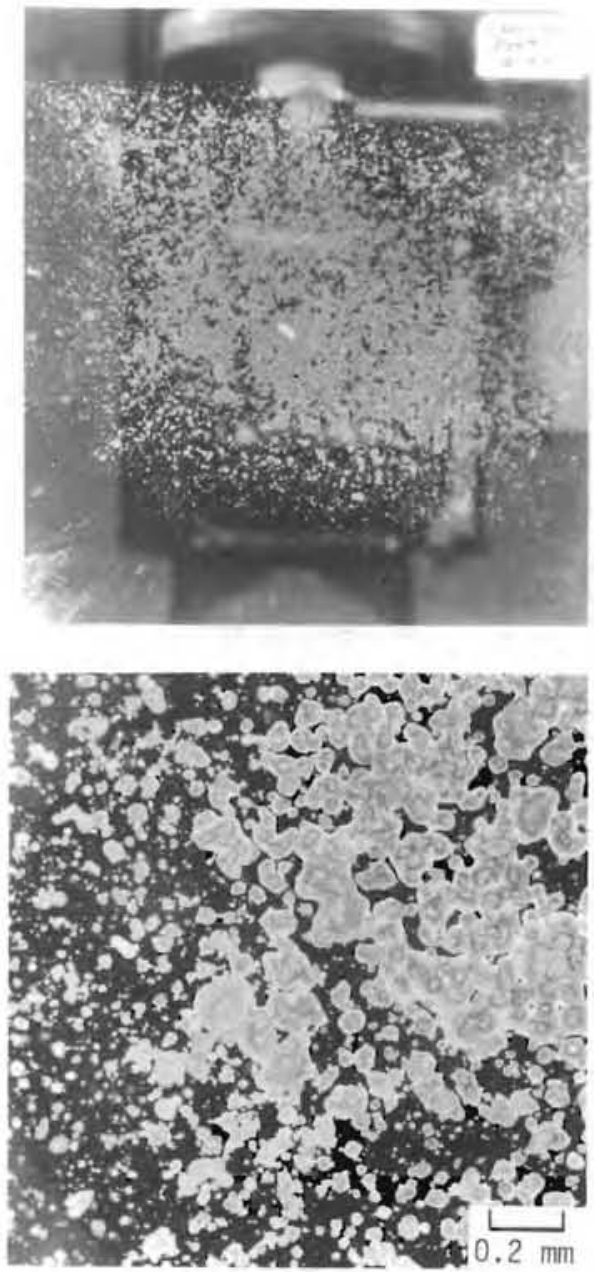

A. STACKED
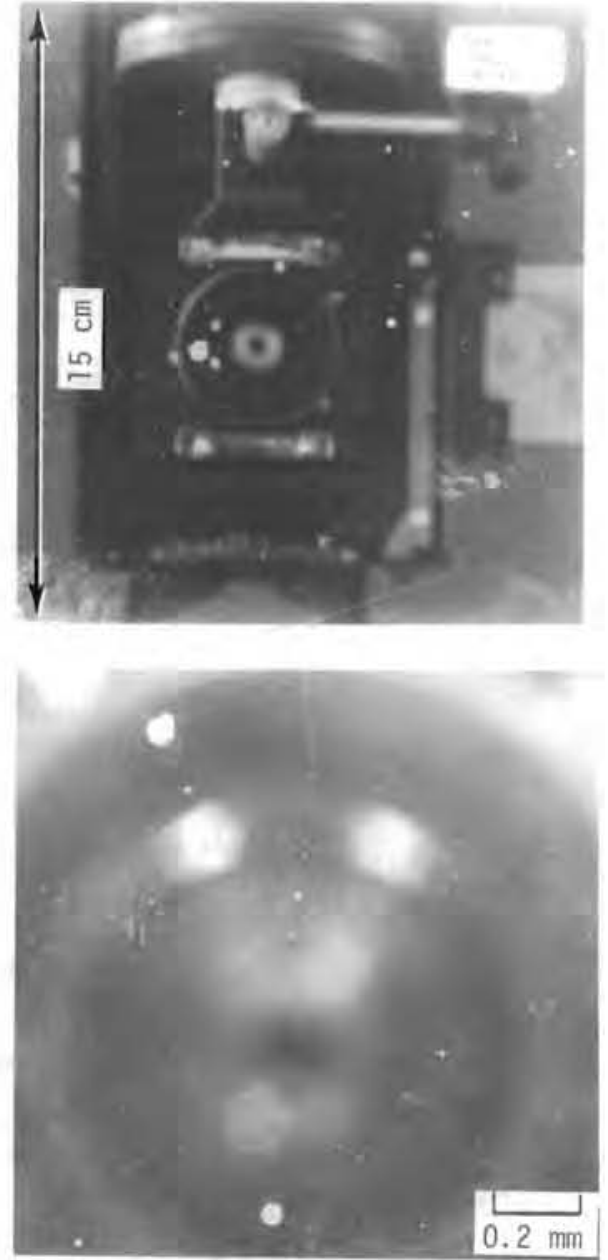

B. FREE-STANDING

FIGURE 2.28. Camera "Self-Portrait" View of Exterior-Aged Mirrors. These two samples show the effect of 17 years of exposure to light-industry exterior environment. Mirror A was one of a stack of mirrors laid flat. Mirror B stood on edge, free of contact from other objects. 
mirror was virtually unchanged after 17 years, whereas the stacked mirror, with little opportunity for free circulation of air or evaporation of moisture, shows severe attack. Nearly all of the degradation on both mirrors occurred away from the edges where the greatest exposure to long-term moisture might be expected.

Progressive stages of mirror degradation in defect regions selected from the center of Figure 2.28A are shown in Figure 2.29. As the failure reaction progresses, the extent of the reaction zone increases. It is not as obvious here as in the early stage reactions on Sandia field test mirrors that reaction has occurred in the glass. Yet the disintegration of the silver layer is quite evident, as is the slight bubbling of the paint immediately adjacent to the defect zone. It is also clear that silver is almost totally missing in this region in the final disintegration stages.

When deterioration has become as extensive as in this region, the paint backing on the mirror is only discontinuously bonded. Although it cannot be mechanically stripped completely without damage to the underlying metal surface, it can be removed intact and with all of the adhering components still attached by application of glacial acetic acid (Figure 2.30). The original mirror (upper left) has been treated with glacial acetic acid to remove the paint layer shown on the lower right. The remaining glass at lower left is viewed from the back (original paint side) and shows a mirror image of the upper (glass side) view. The entire degradation area on the mirror consists of individual and adjoining spots, each of which is composed of concentric circular structures surrounding the central dark nucleus. The central nuclei remain firmly attached to the paint, leaving only a partial ring structure adhering to the glass after the paint is removed as described.

Details of a single spot and its nuclear ring structure are seen in Figure 2.31 which shows both the resulting glass and its opposing paint layer after stripping with acetic acid. The center core in this large defect spot (now retained on the paint) is silver chloride. The black rings and the central area on the glass have been completely stripped and apparentiy were regions of very weak silver/glass bonds. The corresponding positions, showing 

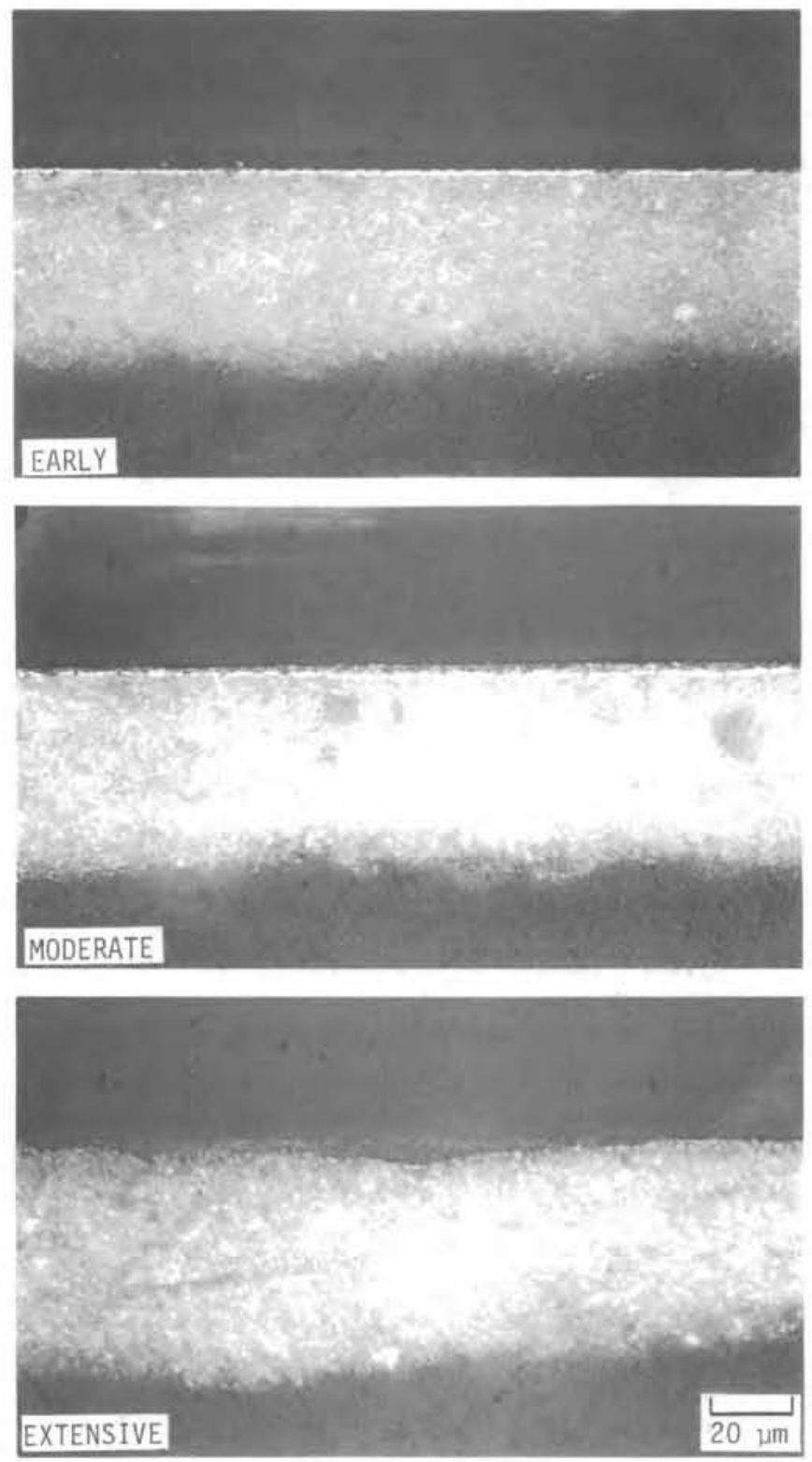

FIGURE 2.29. Failure of Glass/Silver Bond with Progressive Degradation. The silver layer broadens and disintegrates as the glasssilver interface gap widens with continuing degradation. 


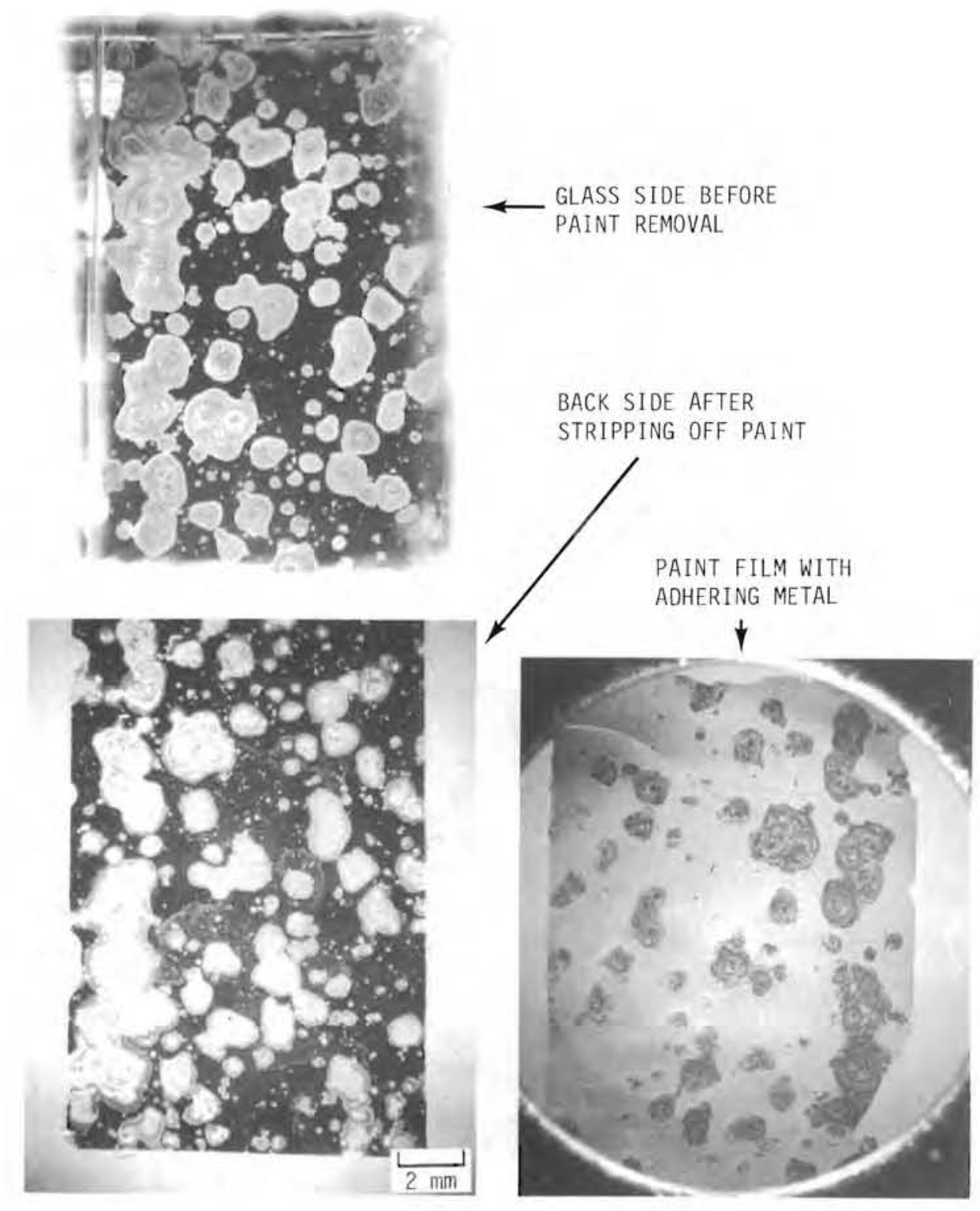

FIGURE 2.30. Features of an Extensively Degraded Aged Mirror. As seen through the glass, the degradation consists of individual and adjoining spots each composed of concentric rings surrounding a central dark nucleus. After stripping the glass retains some of the spot rings, but the nuclei and alternate rings remain firmly attached to the paint. 


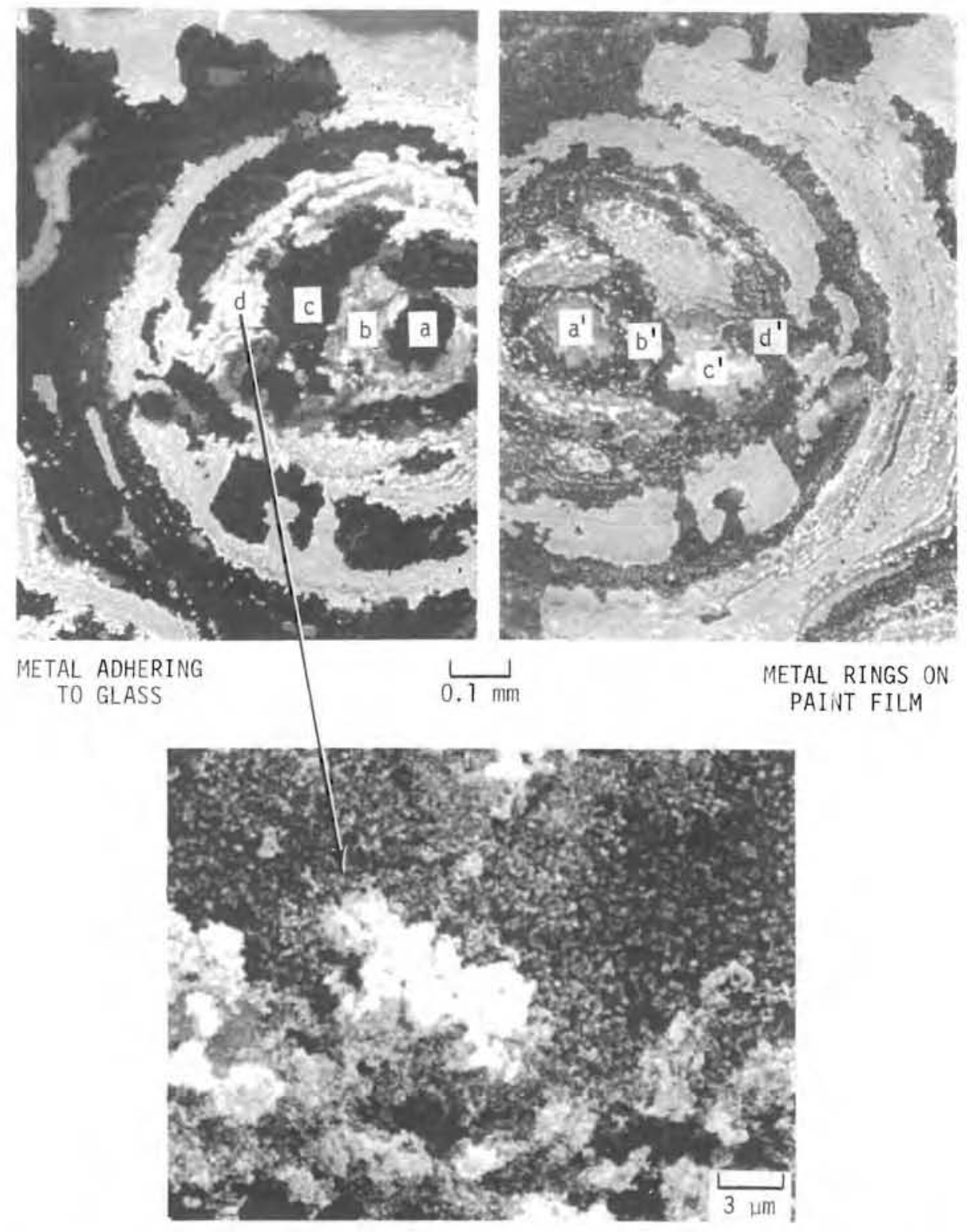

FIGURE 2.31. Details of Ring Structure of 01d Mirror Degradation. The center core in this large defect spot is silver chloride. The black rings on the glass have been completely stripped; the corresponding (light) rings on the paint are primarily silver chloride (see Figure 2.32). 
as light colored rings on the paint, are primarily silver chloride. Still retained on the glass itself in the light colored rings are the larger silver particles which have a low chloride content. These silver particle deposits are very similar to some which occurred in the much shorter exposure Sandia mirror (Figure 2.27). Compositions of the successive rings are shown in the EDX spectra for the corresponding glass and paint views in Figure 2.32. For comparison, Figure 2.33 shows a reference spectrum for clean uncoated glass and for paint alone.

It must be concluded from these data that the presence of chloride played a significant role in the extensive failure of these areas of this mirror. However, a more comprehensive mechanism for failure is needed to account for the presence of larger particle nonchloride silver, the phenomenon of the tightly adhering ring structure, the absence of copper and the almost complete absence of degradation on the adjacent free standing mirror during the test period.

Effects of Heat on Silver Structure

Silver has a tendency to agglomerate at elevated temperatures. A series of experiments was performed to demonstrate the effect for chemically deposited mirrors. Several commercially produced mirrors without a copper on paint backing were heated for $30 \mathrm{~min}$ at temperatures ranging from $100^{\circ} \mathrm{C}$ to $350^{\circ} \mathrm{C}$ in $50^{\circ}$ intervals. SEM micrographs for three of the mirrors are shown in Figure 2.34.

The resulting silver particles are reminiscent of the particle formations seen in the degraded mirrors and in some of the new mirror samples. Production mirrors are often heated as high as $120^{\circ} \mathrm{C}$ during fabrication. Overheating of the metallic layers in localized regions could cause this type of agglomeration. The effects of agglomeration on the optical properties of the mirror are shown in another section of this report.

Effects of Water on Mirror Integrity

The effect of the presence of water has also been examined briefly in controlled experiments. As has been described before, the penetration of water appears to be a major contributor to the failure of outdoor mirrors. 


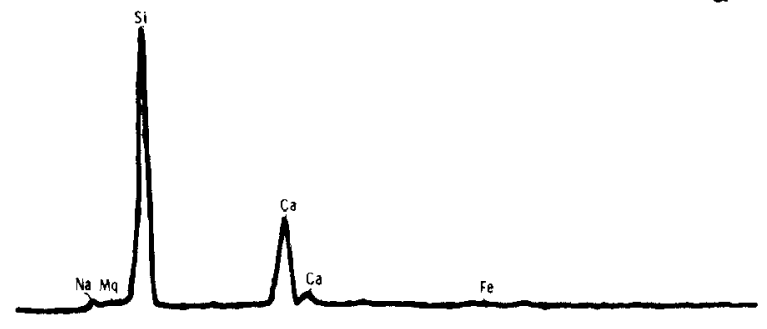

b

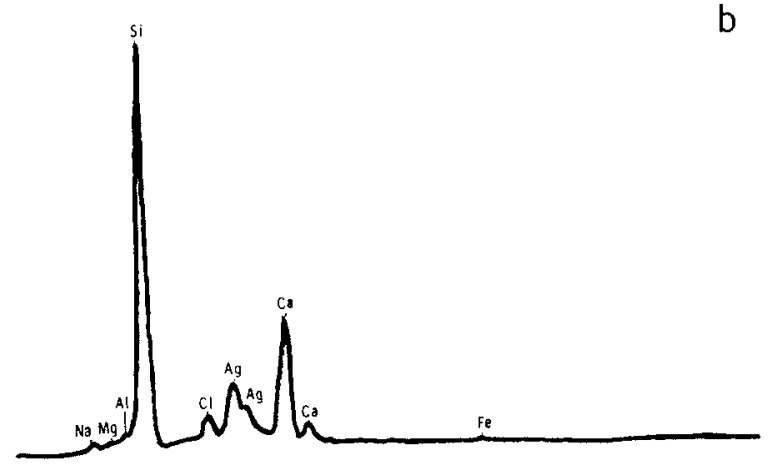

C
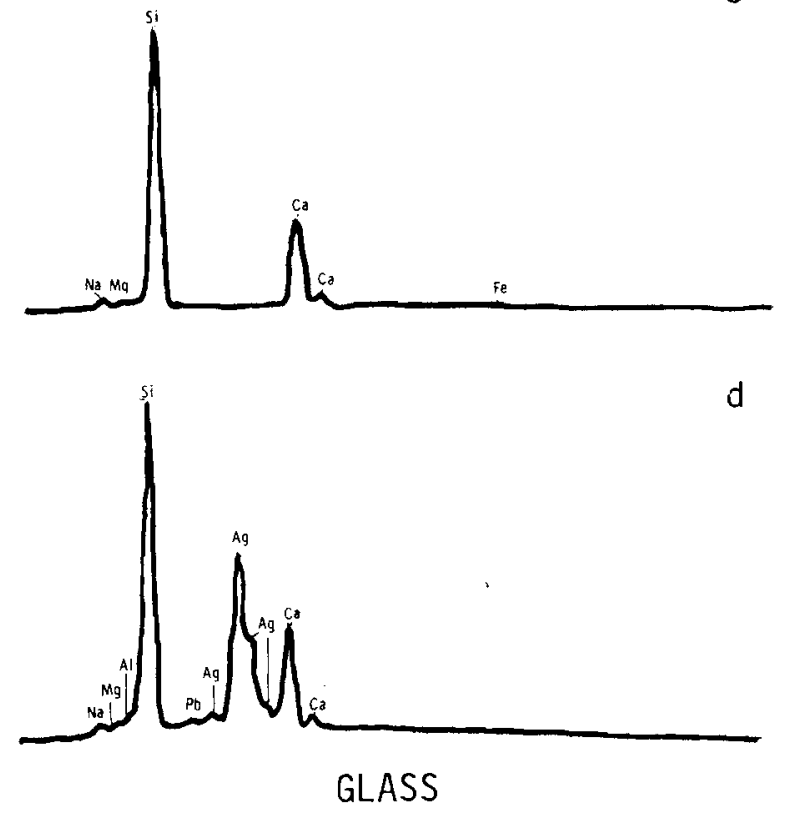

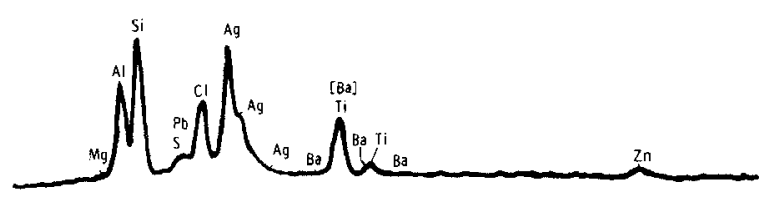

$b^{\prime}$

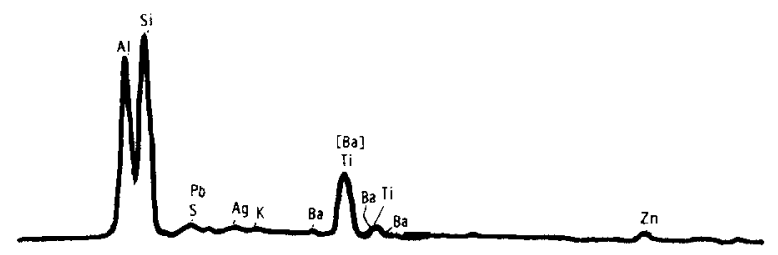

$C^{\prime}$

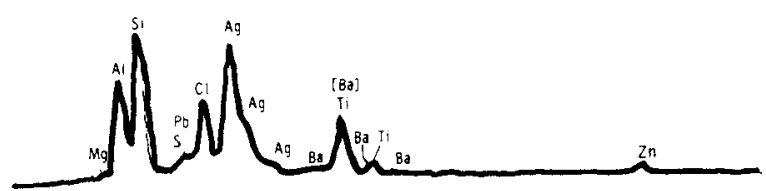

$d^{\prime}$

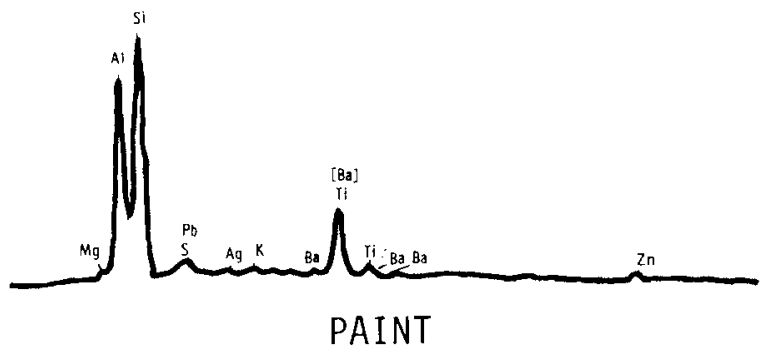

FIGURE 2.32. EDX Spectra of Corresponding Concentric Rings of Degradation Product (See Figure 2.31). 


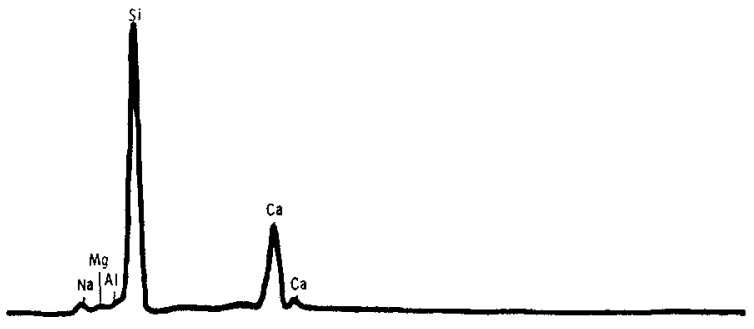

CLEAN GLASS

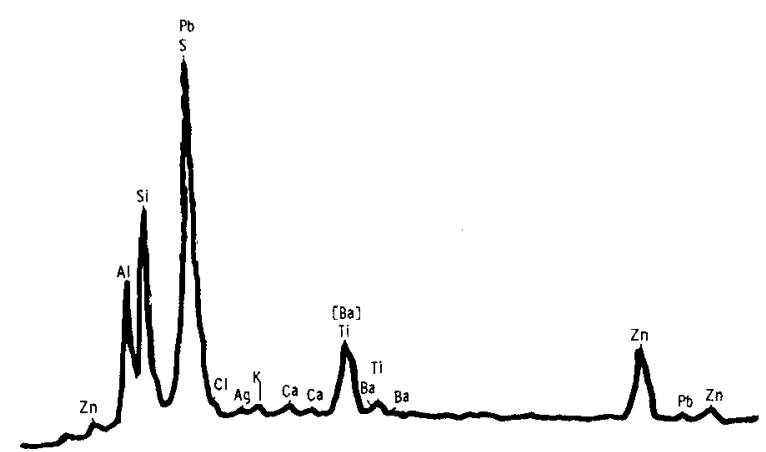

PAINT ONLY

FIGURE 2.33. Reference EDX Spectra for Clean, Uncoated Glass and for Paint Alone

This is particularly true when the water may be entrapped in the interior of the mirror structure. Therefore, it is informative to examine the characteristics of mirror surfaces after subjecting new, unbacked commercial mirrors to boiling water for 3 hours. As shown in Figure 2.35, the silver layer gradually peels away as it is heated. Silver nodules appear on the exposed glass immediately adjacent to the remaining silver layer, approximately $700 \mathrm{~A}$ in diameter (comparable to the original $\mathrm{film}$ thickness) and scattered randomly about $1000 \AA$ apart on the glass. The spacing of these nodules increases with distance from the remaining silver metal layer until they are essentially absent at distances greater than 2 microns from the metal edge. Microprobe examination of the nodules shows that they are metallic silver particles. The structure suggests that these are the adhesion sites of silver to glass, and that the hot water reaction has served to release the original bond. As the nodules continue to be exposed to the hot water they also are released from the glass surface. 

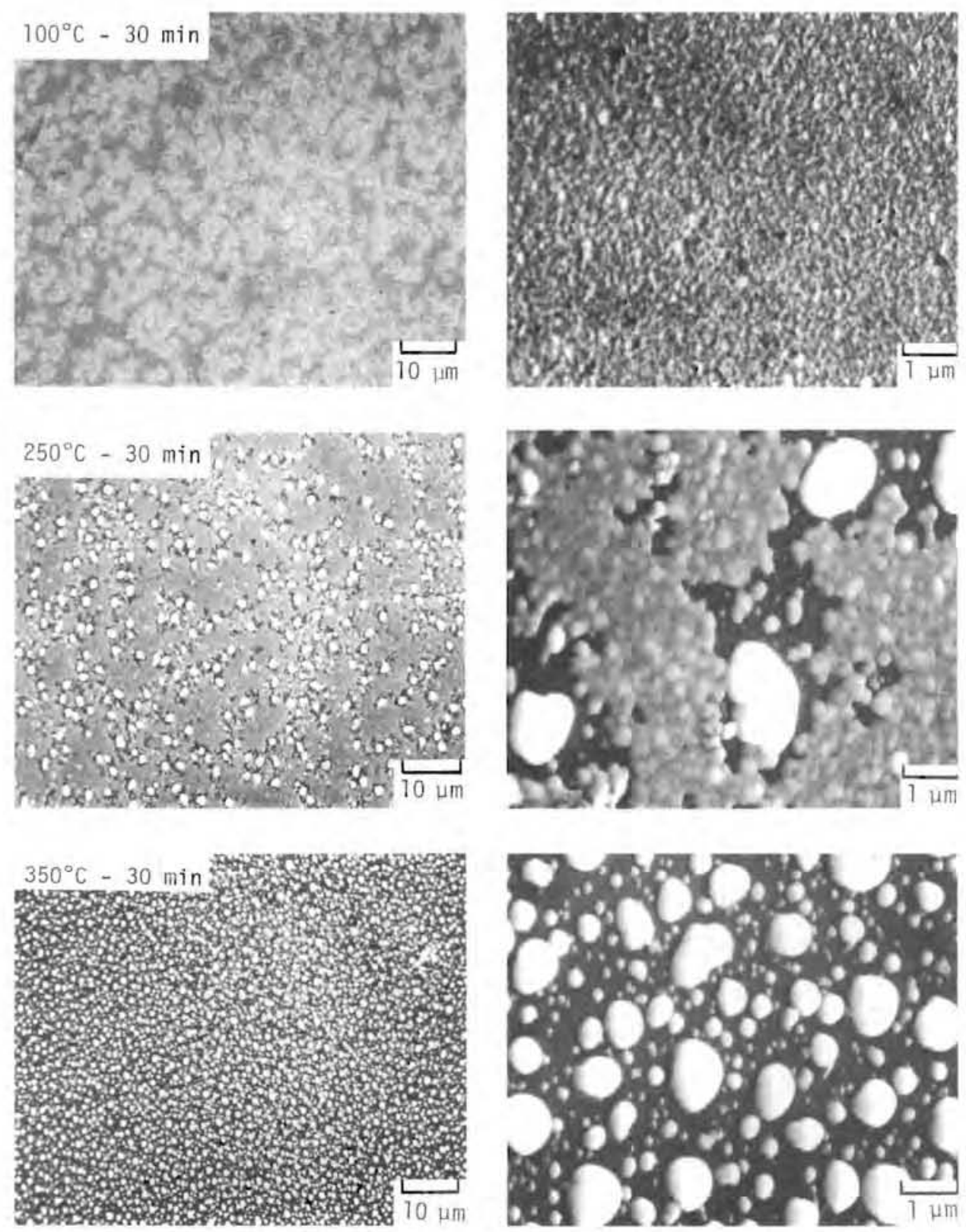

FIGURE 2.34. Silver Agglomeration. The effects of heating the silver layer in dry air for 30 minutes at $100^{\circ} \mathrm{C}$, $250^{\circ} \mathrm{C}$ and $350^{\circ} \mathrm{C}$ are shown in the SEM photographs. 


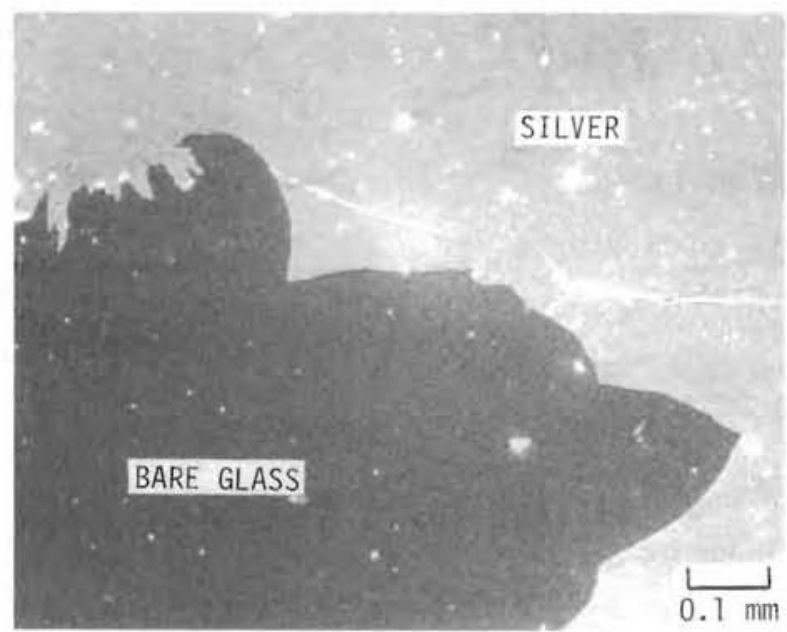

SILVER

FIGURE 2.35. Mirror Degradation in Hot Water. The silver layer on a commercial mirror gradually peels away as it is heated in water at $100^{\circ} \mathrm{C}$. Silver nodules initially about $700 \AA$ in diameter and spaced about $1000 \AA$ apart gradually disappear after continued exposure. 
AES, ESCA AND SIMS ANALYSIS

Introduction to the Techniques

AES is a powerful surface analytical technique. Auger electron energy point scans yield semiquantitative elemental analyses at selected positions on the surface of a given sample. The detection limit for most elements is on the order of $0.1 \%$ of a monolayer. Auger $x-y$ maps of the sample surface can be produced by using a scanning primary electron beam, yielding qualitative information about spatial elemental variations. Spatial resolution is limited by the size of the electron beam, which was 5 microns in most of the work presented here. AES, in combination with ion milling, yields variations in elemental composition as a function of depth. In addition, chemical information can be gained in special cases from Auger peak shape changes and peak energy shifts.

The ability to determine chemical state information is the principal advantage of ESCA. Peak shape changes and energy shifts are usually much more dramatic than in the case of AES. Depth profiles are possible when ESCA is used in combination with ion milling. Beam damage to the surface of the sample is usually less of a problem with ESCA than with AES because the electrons are produced by an incident $x$-ray beam. On the other hand, spatial resolution is much poorer because of the relatively large size of most $x$-ray beams that are of appropriate intensity for use in this technique.

Sensitivity gains for some elements of several orders of magnitude over either ESCA or AES can be realized with the application of SIMS. This technique is particularly useful in trace element analysis. Another major advantage is that hydrogen and compounds of hydrogen can be detected. AES and ESCA are insensitive to hydrogen. The principal disadvantage of SIMS is that the relative sensitivities for different elements and for identical elements in different chemical environments vary over as many as five orders of magnitude. Thus, SIMS is of 1 imited usefulness in quantitative analysis. For the complex problems encountered in the study, a combination of AES, ESCA and SIMS seems most appropriate. 
Analysis of glasses and glass-metal interfaces pose special problems in the application of electron and ion spectroscopies. Such samples are often electrical insulators, and thus charge buildup occurs when electron and/or ion beams are incident upon them. Charging causes considerable deterioration of the energy spectra. Both charging and local heating caused by the incident beam can seriously degrade the sample and give incorrect elemental analyses, especially in the case of alkalis.

A number of techniques are used to overcome the charging problems. Both the electron and ion beams are rastered across the sample to reduce the charge density, particularly in the vicinity of the glass-metal interface and in bulk glass. This procedure, of course, reduces spatial resolution. In addition the electron and ion beams are balanced in order to produce a net beam that is approximately neutral. The energy of both beams is generally held to no more than $2 \mathrm{keV}$ to minimize sample damage. Also the samples are mounted at an angle of $60^{\circ}$ off normal to the primary electron beam to reduce both beam penetration and charging effects. The samples are cooled to liquid nitrogen temperatures in order to reduce alkali mobility. Finally, samples are wrapped in indium foil with small holes cut in it for analysis. The foil facilitates cooling and reduces charging.

Analysis of Sandia Mirrors

Auger depth profiles of the Sandia mirrors were first attempted directly on the exterior surface of the paint layer, with hopes of sputtering successively through the paint, copper, and silver layers, and into the glass. Because of the thickness of the paint layer and its resistance to sputtering, it was necessary to remove the paint prior to analysis. The paint was stripped with $p$-xylene in an ultrasonic cleaner or with glacial acetic acid. In some instances, it was possible to mechanically peel the paint from the mirror, with minimum damage to the sample.

Photographs of the front and back sides of the Sandia mirror sample are shown in Figures 2.36a and 2.36b. Figure 2.36a shows that there are areas essentially free of corrosion, areas with fine corrosion spots, and areas exhibiting large corrosion spots. Figure $2.36 \mathrm{~b}$ shows the linear corrugation 


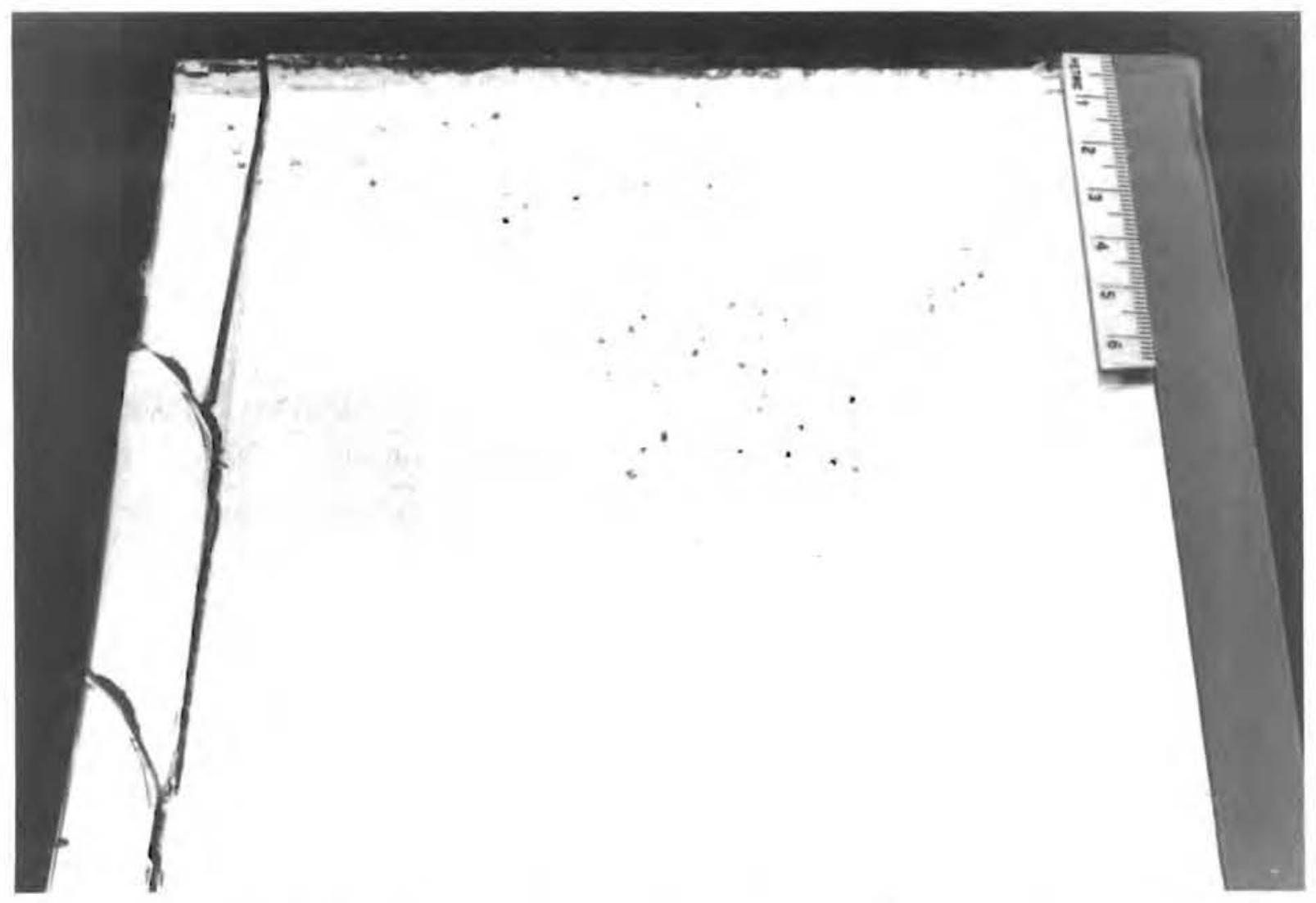

FIGURE 2.36a. Front (Glass) Side of the Degraded Sandia Heliostat Mirror. Samples on the left hand side were cut for analysis from both corroded and uncorroded sections of the mirror. 


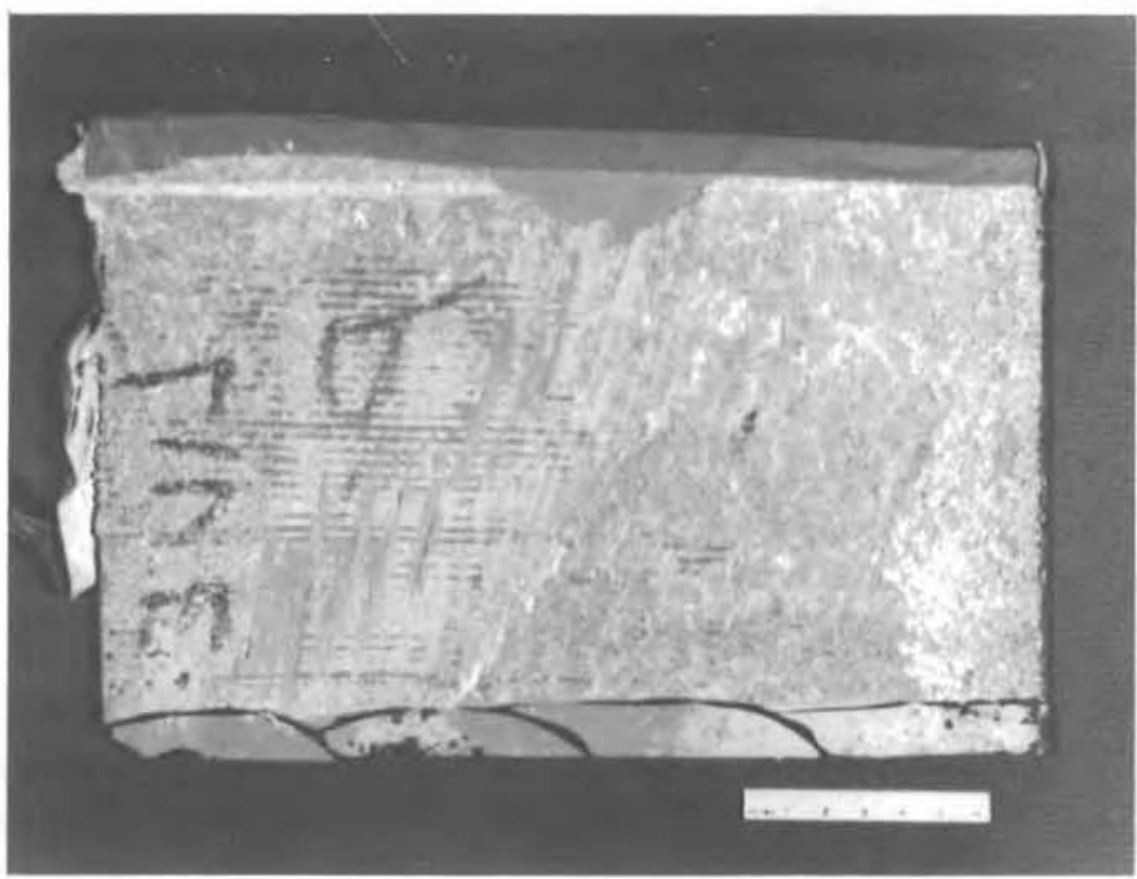

FIGURE 2.36b. Back (Paint, Adhesive and Residual Foam) Side of the Same Mirror

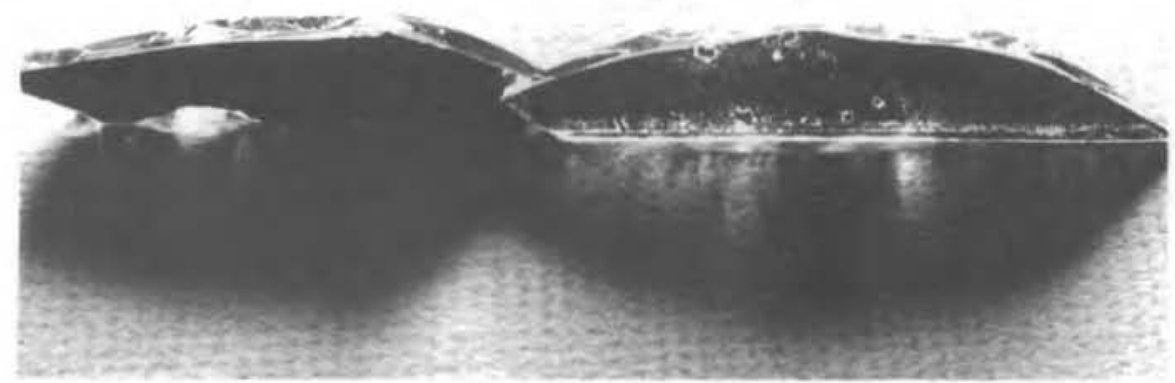

FIGURE 2.36c. Two Sections With Backing Paint Stripped Using P-Xylene. The sample on the left shows little degradation, while the sample on the right exhibits extensive corrosion. 
pattern of the adhesive applied during the assembly of the heliostat panel. Figure 2.36c shows two samples that were taken from the mirror and stripped of paint in an ultrasonic cleaning bath. The sample on the left is opaque and apparently free of corrosion. The sample on the right has numerous corrosion spots and shows regions apparently free of metal overlayers.

One of the most obvious features of the Sandia mirror is the nonuniformity of the copper layer. This can readily be seen in the sequence of micrographs in Figure 2.37. Figure 2.37a is a SEM micrograph of an area of the mirror having extensive fine corrosion spots. Figures 2.37b-d are Auger $x-y$ maps of the same region. In these micrographs, the bright areas correspond to high concentrations of the element identified below the photographs. Note specifically that copper and silver quantities are inversely related. These results should not be interpreted to mean that there are regions without silver, but rather that copper coverage on the silver layer is incomplete.

Figure 2.38 shows an Auger depth profile of an uncorroded area. There exists essentially pure regions of copper and silver. There are also areas where the copper and silver layers have apparently interdiffused. Figure 2.39 shows a similar profile of an area exhibiting fine corrosion spots. The actual depth profile was taken near but not on the corrosion spots. Considerable mixing of copper and silver is again indicated. Also, the total amount of copper is reduced from that seen in Figure 2.38. Figure 2.40 is an Auger depth profile of an area with more extensive corrosion. Here, the amount of silver is reduced over that seen previously. In general, Figures 2.38-2.40 show that the thicknesses of the metal layers are not uniform. Areas of the mirror showing degradation generally have relatively thin silver and copper films.

The apparent interdiffusion of the copper and silver layers can be interpreted in several ways. Although the expected solid solubility of copper in silver below $200^{\circ} \mathrm{C}$ is on the order of a few tenths of an atomic percent (Hansen 1958), the AES data indicate mixing of one to two orders of magnitude higher than the expected solubility limit. Still, it is possible that bulk miscibility curves for silver and copper do not apply within 


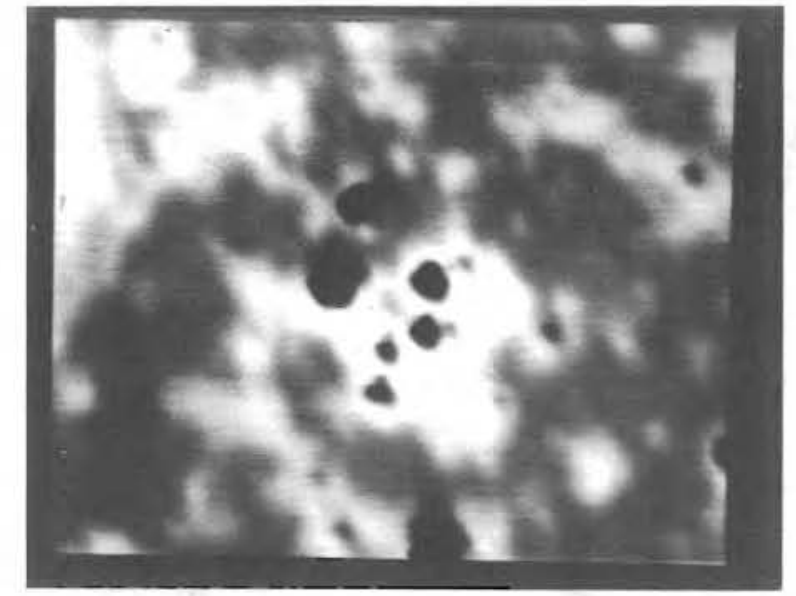

a

SEM (250X)

N

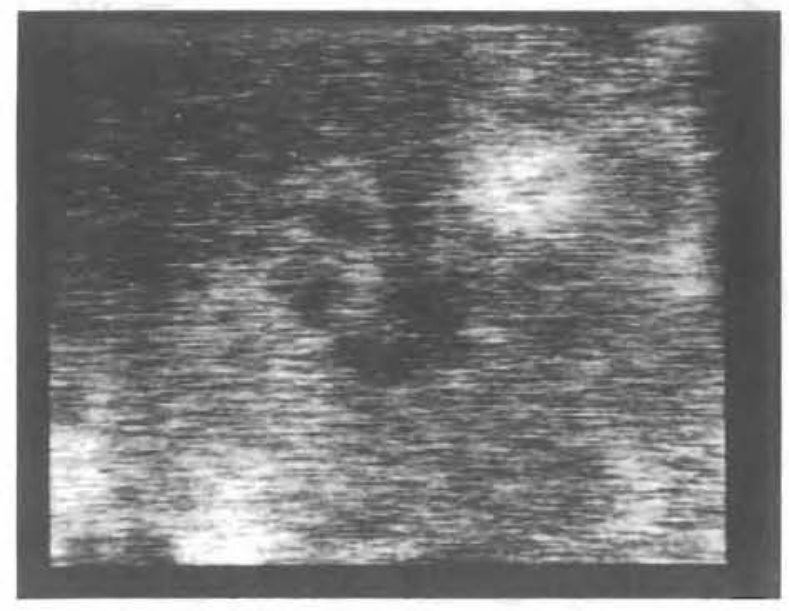

$\mathrm{Fe}$

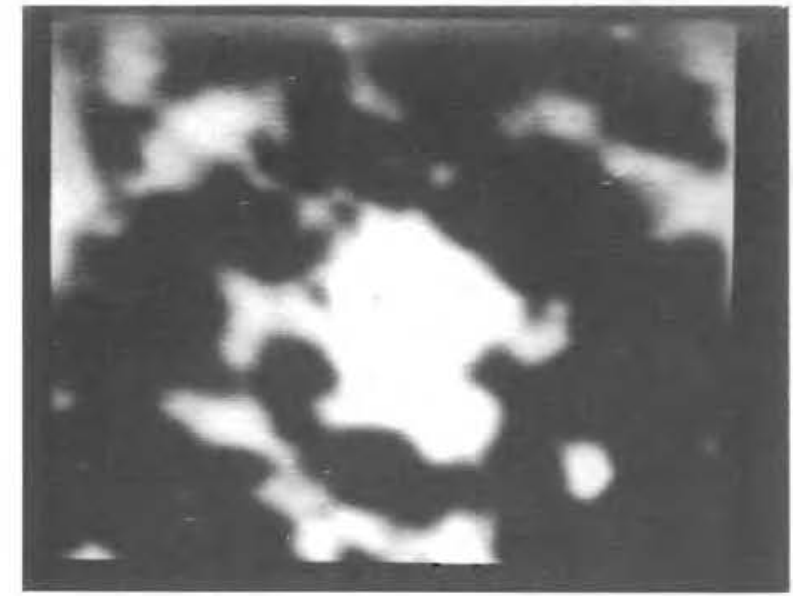

$\mathrm{Ag}$

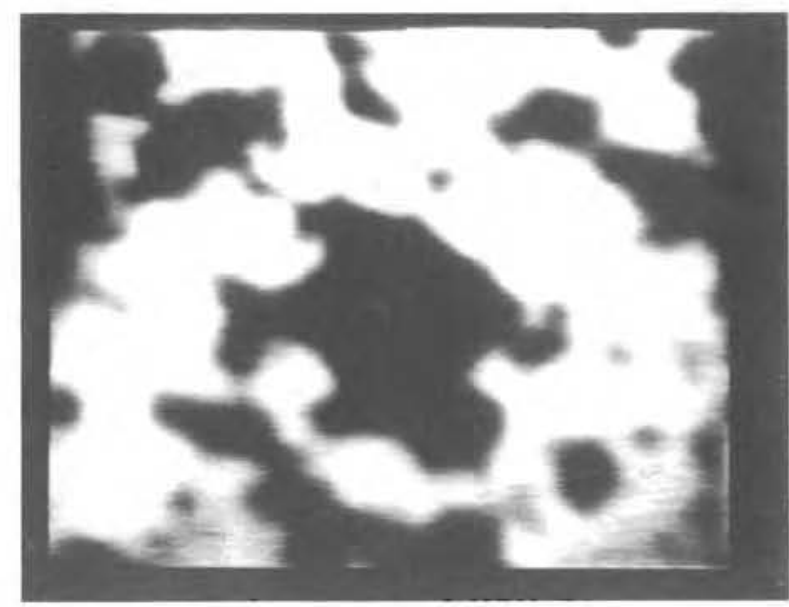

$\mathrm{Cu}$

FIGURE 2.37. SEM and Scanning Auger Micrographs of a Degraded Section of the Sandia Mirror Showing the Inverse Relationship Between Copper and Silver 


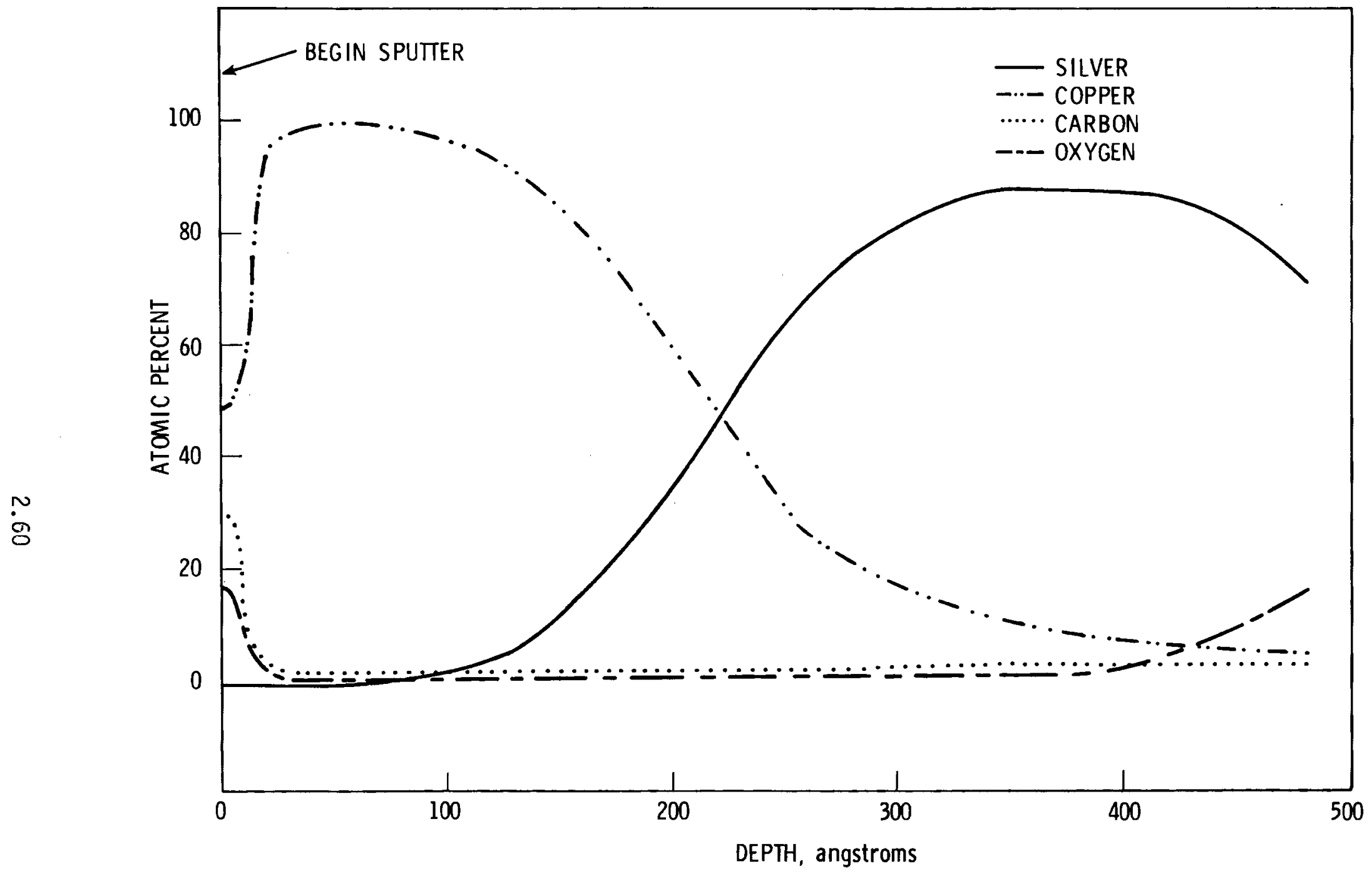

FIGURE 2.38. Auger Depth Profile of an Uncorroded Section of the Sandia Mirror. While regions of essentially pure copper and silver exist, extensive interdiffusion of copper and silver is indicated. 


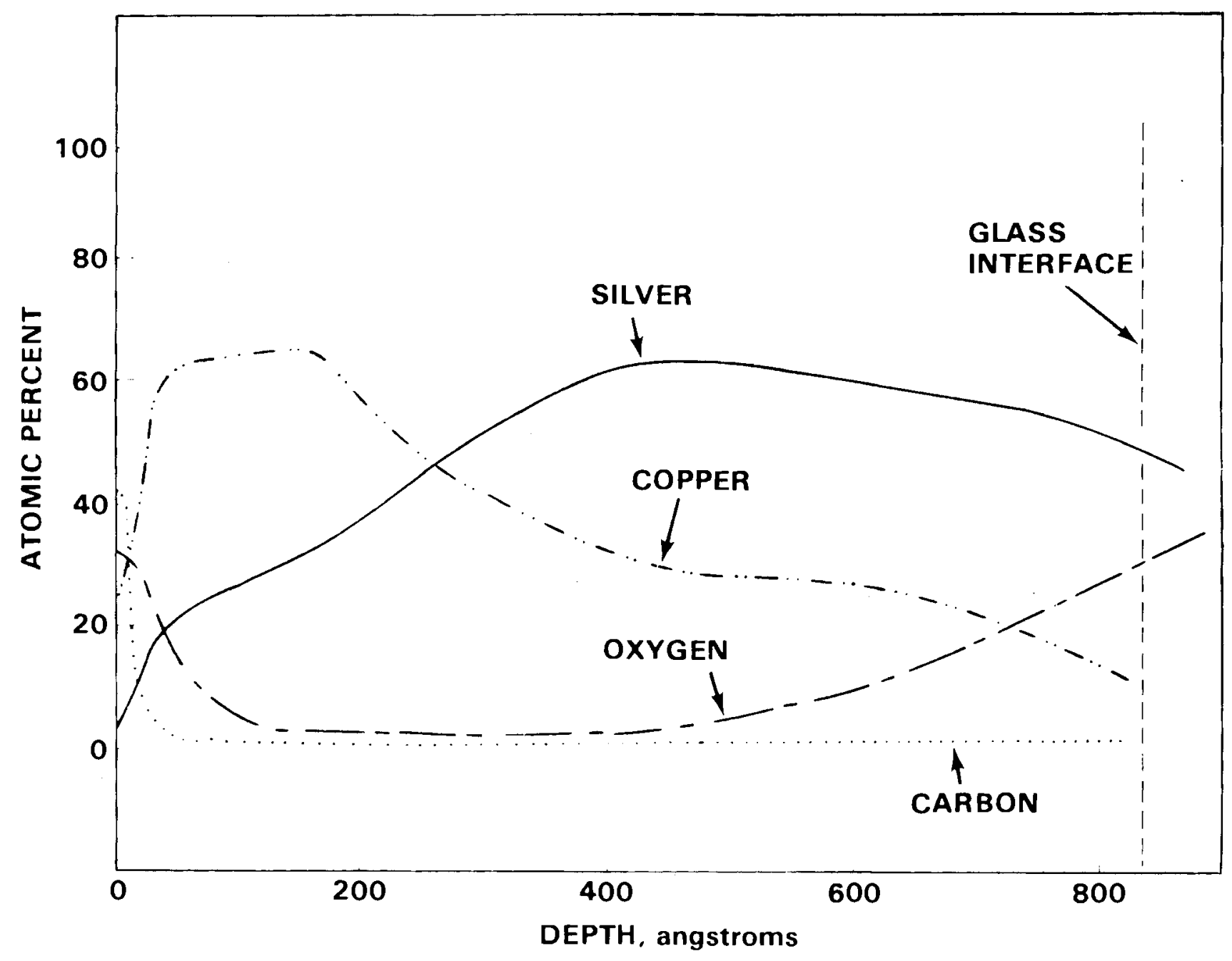

FIGURE 2.39. Auger Depth Profile of a Section of the Sandia Mirror Having Numerous Corrosion Pits. The total amount of copper is considerably less than that found in uncorroded areas. 


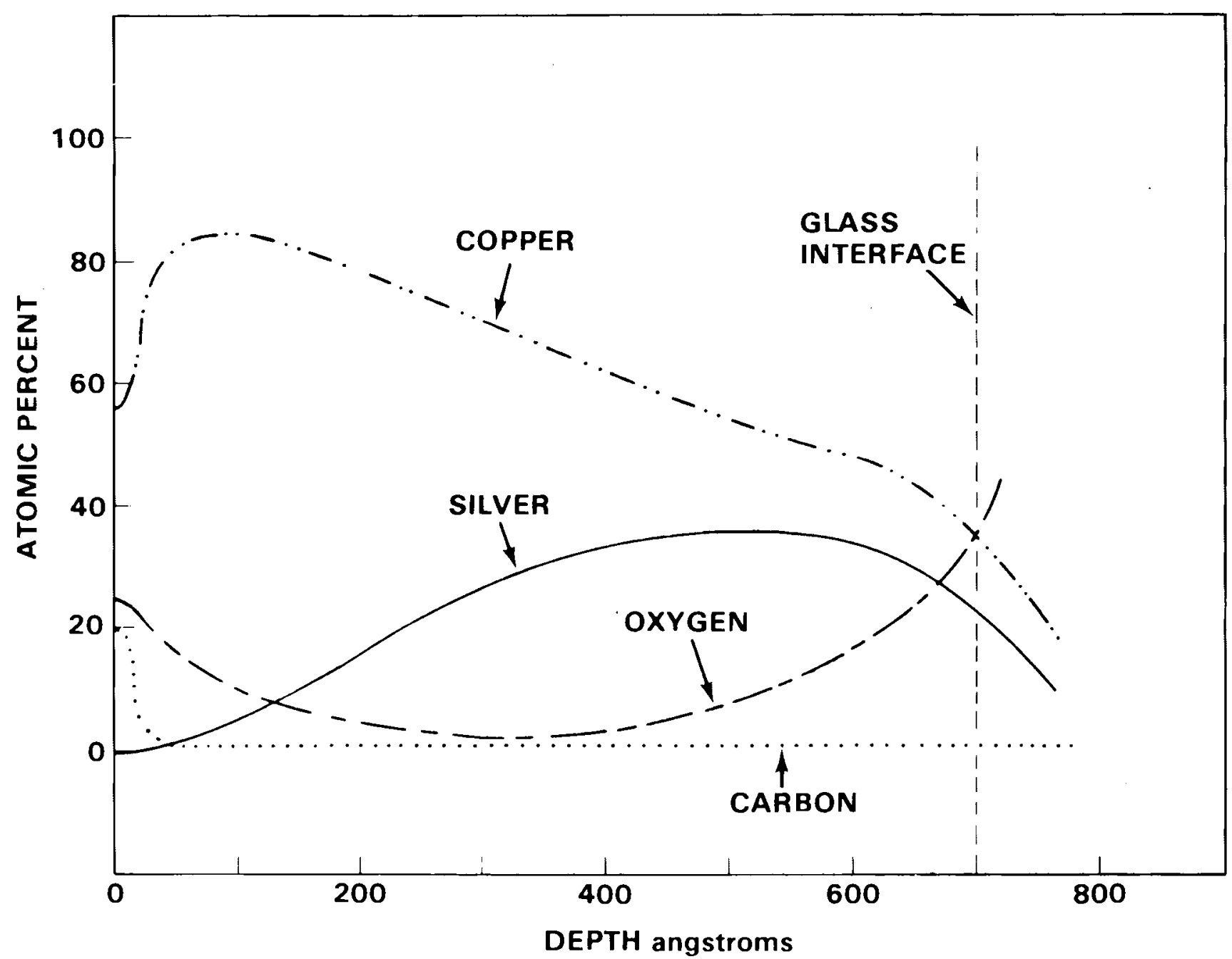

FIGURE 2.40. Auger Depth Profile of a Section of the Sandia Mirror Showing More Extens ive Degradation. The total amount of silver is considerably less than observed in uncorroded regions. 
several hundred angstroms of the interface between the two metals, and interdiffusion of silver and copper actually occurs. Many examples are known of the failure of macroscopic thermodynamics to describe microsystems.

On the other hand, the apparent interdiffusion may be an artifact of the data acquisition methods. For example, the sputtering process may broaden the interface region due to "knock on" phenomena, where the incident argon ions directly strike surface atoms, driving them into the bulk. The expected lattice damage region for the $2 \mathrm{keV}$ argon ions used in these experiments should be roughly $20 \AA$ or less. However, mixing regions of several hundred angstroms can be seen in Figures 2.39 and 2.40. In addition, the extent of mixing varies over the mirror surface. Thus, it is not likely that the ion sputtering process contributes significantly to the observed results.

Silver and copper could exist in the form of a matrix of islands on the substrate, with dimensions smaller than the diameter of the probing electron beam ( 5 microns). If silver deposits as small islands on the glass, copper could be deposited between these islands as well as on top of them. The relatively large electron beam would then probe an average of several silver islands as well as the spacings between them. The result would be a depth profile indicating significant intermixing of the two metals. The island growth thesis is supported by the asymmetry of intermixing shown in Figure 2.38.

The activation energy for silver diffusion in bulk copper has been determined by tracer diffusion measurements to be $46.5 \mathrm{kcal} / \mathrm{mole}$ with a pre-exponential factor $\left(D_{0}\right)$ value of $0.63 \mathrm{~cm}^{2} / \mathrm{sec}$ (Aski11, 1970, p. 45). Similar measurements for copper diffusion in bulk silver yielded values of $46.1 \mathrm{kcal} / \mathrm{mole}$ and $1.23 \mathrm{~cm}^{2} / \mathrm{sec}$ for the activation energy and pre-exponential factor, respectively (Askill, 1970, p. 50). The fact that the activation energies are essentially identical and pre-exponential factors are similar indicate that, if silver and copper intermixing were to occur via bulk diffusion, silver should penetrate the copper film to roughly the same depth that copper penetrates the silver film. The depth profile of Figure 2.38, from a nondegraded section of the Sandia mirror where the copper layer was relatively uniform and thick, shows that copper is present throughout the silver layer, 
while the reverse is not true. These results support the model that silver forms islands on the glass surface, and that copper is deposited between the grains during the manufacture of the mirror.

The expected amount of copper and silver interdiffusion can be calculated from the kinetic parameters of Askill (1970). Assuming that the Sandia mirror was held at $100^{\circ} \mathrm{C}$ for the period of one year, interdiffusion to depths less than $0.03 \AA$ is expected. At $200^{\circ} \mathrm{C}$ for one year, a mixing depth of less than $15 \AA$ is expected. If the kinetic parameters quoted above are correct, volume diffusion should not have contributed significantly to the depth profiles of Figures 2.38-2.40.

Apparent interdiffusion of oxygen and silver is observed at the glasssilver interface. Because of the relatively large solubility of oxygen in silver, these results are not unexpected. It is not necessary for silver to exist in islands in order to explain these results.

A number of Auger point scans were recorded at different positions near and inside a large corrosion spot on the Sandia mirror. For this experiment the paint was mechanically removed in order to minimize the loss of corrosion products through interaction with the solvents. Figure 2.41 is a scanning electron micrograph of one of the analyzed areas. The letters a-d on the micrograph refer to the positions on the sample where the Auger spectra shown in Figure 2.42a-d were taken. Figure 2.42a indicates a considerable amount of copper and oxygen. Iron, silver, carbon, potassium, and chlorine were also detected. Thus, this position, which is just outside the degraded area, has principally copper oxide at the surface. The presence of silver in the spectrum indicates that the copper film is likely to be relatively thin at this position. The source of the other contaminants is unclear. Figure 2.42b shows less copper than seen in Figure 2.42a, but shows higher levels of calcium, sulfur, and oxygen. The spectrum shown in Figure $2.42 \mathrm{c}$, which was taken just outside of the center of the corrosion spot, shows enhanced levels of silver, chlorine, and carbon. It should be noted that very little copper is present at this position. Lack of copper near degraded areas of the mirrors was a feature found consistently. The source of the chlorine may be 


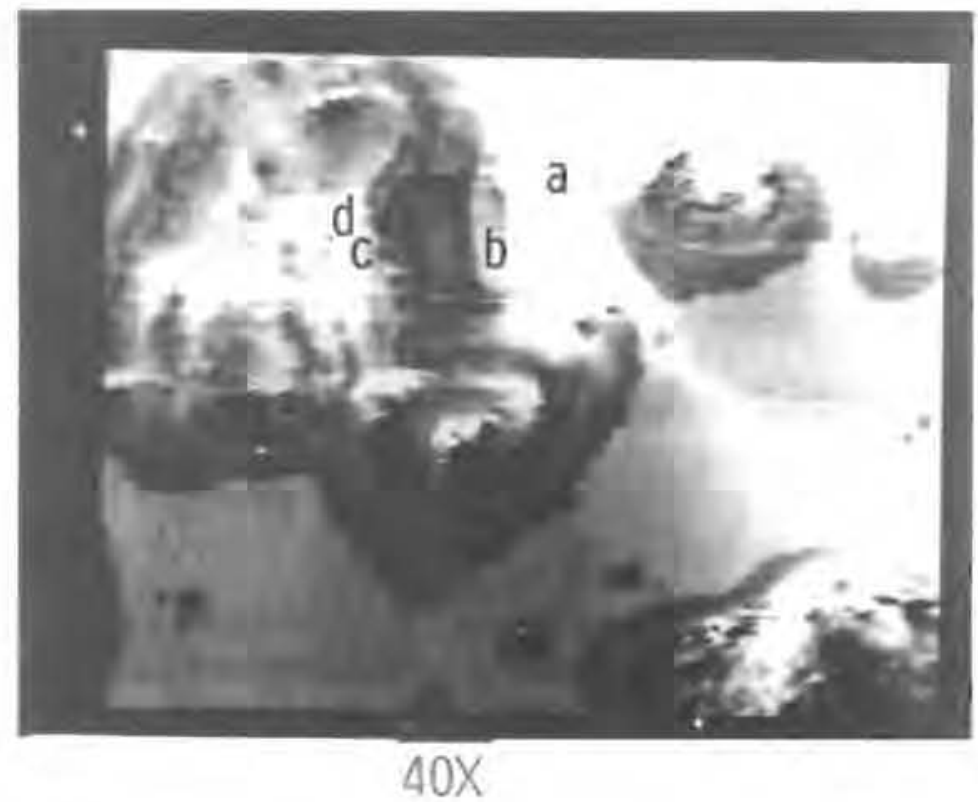

FIGURE 2.41. SEM Micrograph of a Degraded Section of the Sandia Mirror in Which the Paint Backing was Mechanically Removed

due either to environmental exposure or to treatment of the glass with tin chloride prior to silver deposition. Finally, Figure 2.42d, which is representative of the corrosion spot centers, show strong silicon, calcium, and oxygen signals, and is characteristic of a weathered glass surface. of particular interest is the presence of a relatively strong tin signal. Tin signals of the magnitude shown in this figure seem to be restricted to corrosion spots. When sputter profiles were performed away from corrosion spots, tin could not be detected at the silver-glass interface with AES. However, tin is probably segregated within only a few atom layers at the silver-glass interface. Since sputter rates of roughly $10 \AA / m i n$ are typically used, detection of the tin at the interface may be quite difficult.

A depth profile was taken about $5 \mathrm{~mm}$ away from a large corrosion spot in an area that showed no obvious corrosion itself. This profile is given in Figure 2.43. Notice that the silver is quite pure in the center of the 

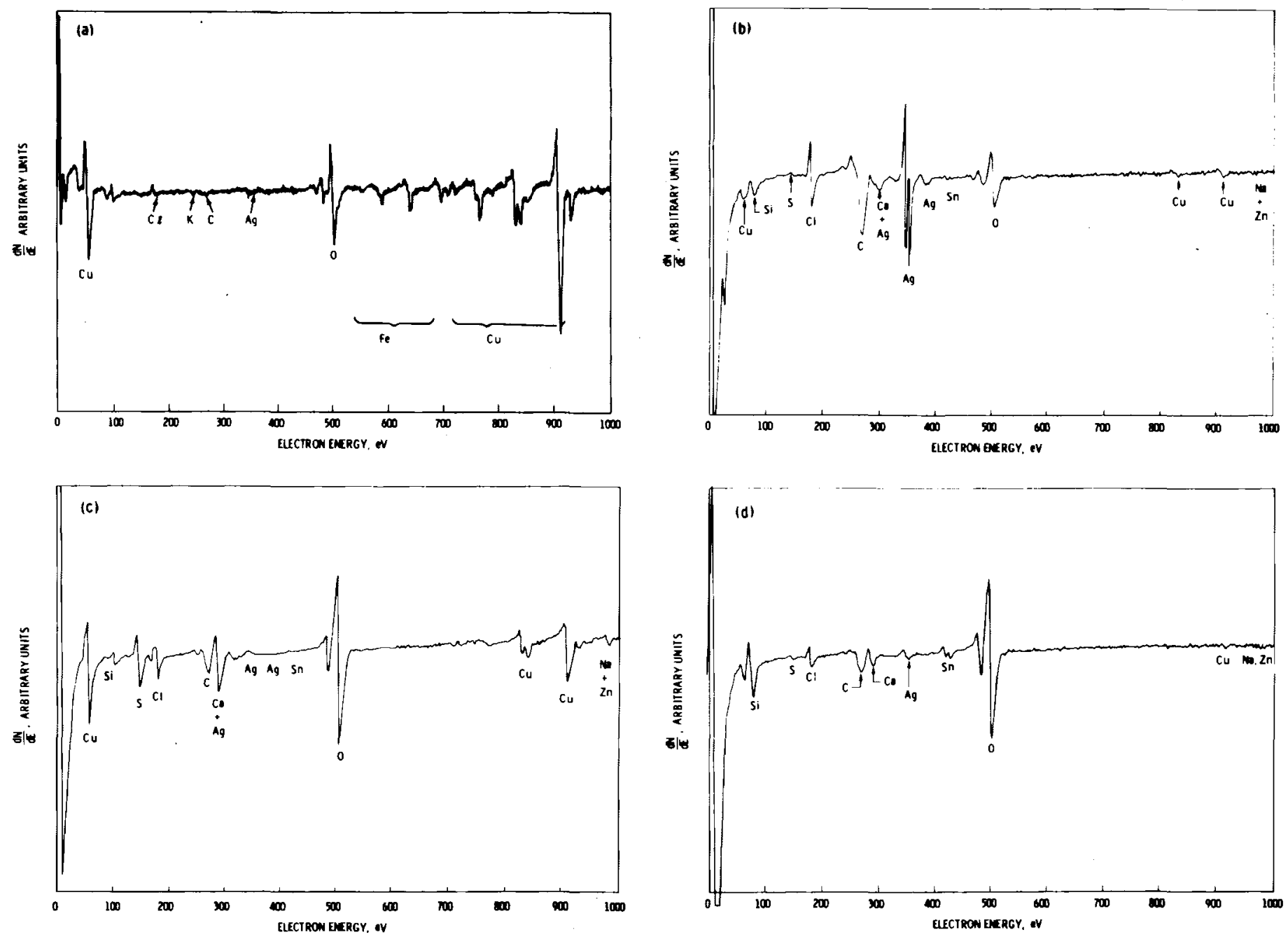

FIGURE 2.42. Auger Point Scans Taken at Positions a-d of Figure 2.41. The spectra range from that of copper oxide outside of the corrosion spot (position "a") to that typical of a weathered soda-lime-silicate glass in the center of the corrosion spot (position "d"). Note the relatively strong tin signal in spectra "d" 


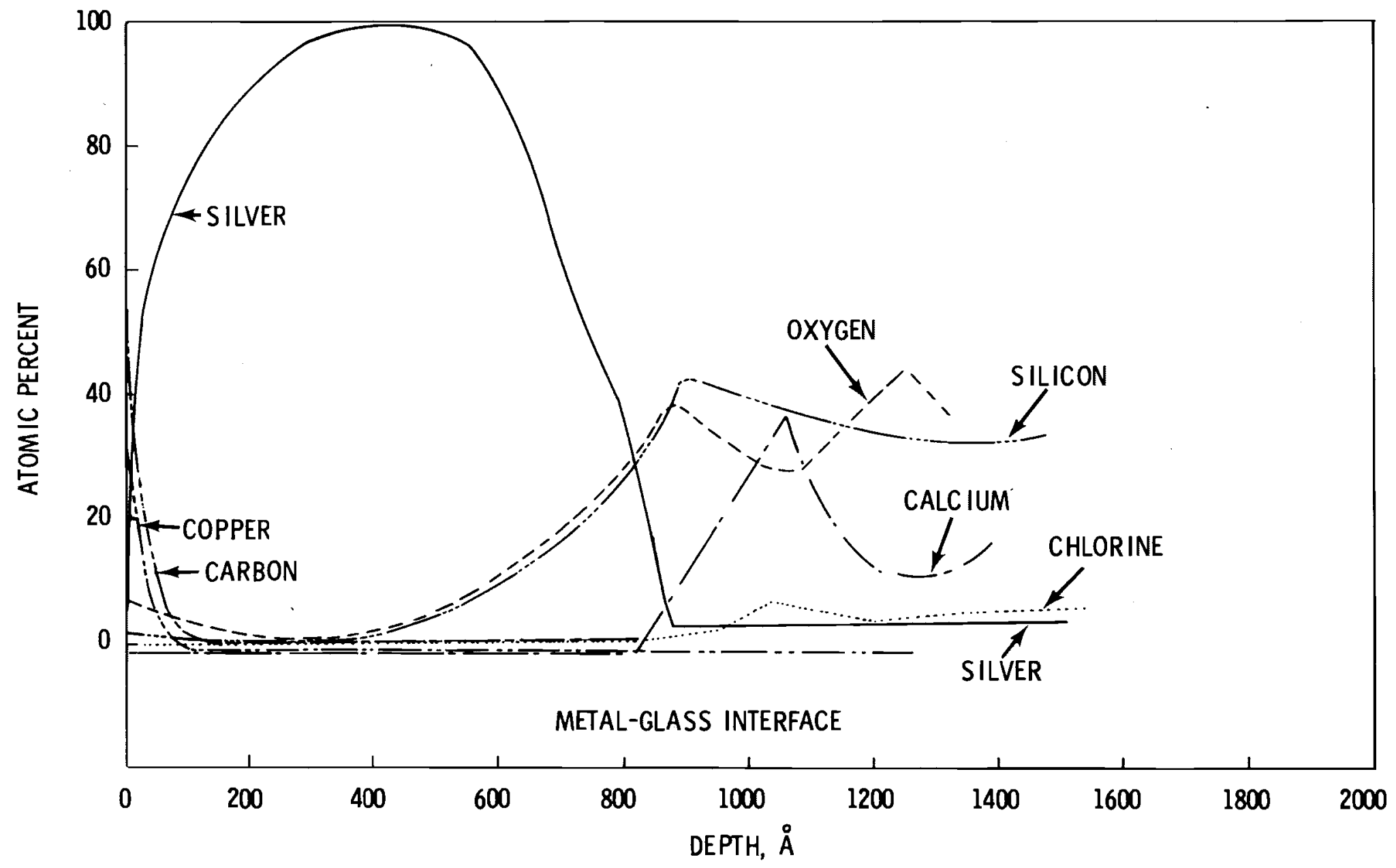

FIGURE 2.43. Auger Depth Profile of the Sandia Mirror Taken Adjacent to a Corrosion Spot. The silver layer is quite pure in spite of the close proximity to extensive corrosion. Silver and chlorine are present in approximately equimolar quantities several hundred angstroms deeper than the silver-glass interface. 
layer. Note also the small amount of $\mathrm{Cu}$ on the surface. As was seen previously, the glass-metal interface is evidenced by a rise in the oxygen and silicon levels. Calcium is strongly enhanced at the glass-metal interface but falls off and returns to higher levels at further distances into the glass. A particularly interesting feature is that silver and chlorine are present in the glass in approximately equimolar quantities to a depth of at least several hundred angstroms beyond the metal-glass interface. This finding is unusual in that silver is highly mobile in soda-lime silicate glasses, whereas the much larger chloride ions should be much less mobile. It is generally accepted that silver ions can diffuse into the glass bulk and ion exchange with the even more mobile sodium ions. Because of the large differences in the mobilities of silver and chloride ions, diffusion into the glass bulk as an ion pair is unlikely. Rather, silver should penetrate the glass to much greater depths than the chlorine (as chloride ions). Unfortunately, the analysis was ended before sputtering to sufficient depths to demonstrate this expectation.

The source of the chlorine is most likely the mirror manufacturing process, rather than environmental exposure. In Figure 2.43, the silver layer is relatively free of impurities. No chlorine is found until the silver-glass interface is reached. Chlorine extends from this point into the glass bulk for at least several hundred angstroms. Diffusion of chloride ions from the environment through the silver film to the glass is unlikely. Analys is of London Lab Samples

Depth profile experiments were conducted with AES, SIMS, and ESCA on a specially prepared London Laboratories sample to assess the importance of thorough glass cleaning. A single piece of glass was prepared using different cleaning procedures on each half. The glass had been powder packed at the time of production with plastic powder treated with adipic acid. One half of the mirror was thoroughly cleaned using an extended, hard scrub with a cerium oxide slurry followed by a deionized water rinse. This scrub was far in excess of the standard production line scrub procedure and was expected to 
yield a cleaner glass surface for coating. The second half of the surface was not scrubbed and was only rinsed with deionized water.

The AES and SIMS profile for the cleaned portion are given in Figure 2.44. A sputter profile was also performed using ESCA. Unlike AES or SIMS measurements, the ESCA data were taken with the ion milling beam turned off after sputtering for selected intervals. This technique has the advantage of minimizing electrical charging problems.

For the cleaned portion of the mirror, an essentially pure copper layer approximately $2000 \AA$ thick was found. Considerable mixing of the copper and silver layers at the metal-metal interface was found. Again, the possibility of the existence of fine structure smaller than the electron beam diameter cannot be ruled out. Auger profiles show the abrupt appearances of calcium and silicon at or near the metal-glass interface. Oxygen penetrates the silver lattice to a greater depth than silicon. As discussed previously, this result is expected since oxygen is highly soluble in silver.

If the metal-glass interface is defined as the point in the profile where silicon is detectable and copper is no longer detectable, the data show that calcium has been leached from the vicinity of the metal-glass interface to a depth of several hundred angstroms. Sodium does not reach the bulk glass concentration for at least $1000 \AA$ past the interface. Leaching of calcium and sodium from glass surfaces by water has often been reported, where it is postulated that hydrogen replaces calcium and sodium by ion exchange (Das, 1969; Clark, et al., 1976). It should be noted that some alkali and alkaline earth depletion on the float glass surface is expected prior to mirror manufacture, due to atmospheric exposure. Thus, the actual contribution of the mirror manufacturing process to the leached layer formation is not clear from these data.

Figure 2.45 shows ESCA spectra taken after $215 \mathrm{~min}$ of sputtering (see corresponding depth scale on Figure 2.44). As in the case of the AES data, copper was detected in addition to major elements of the glass substrate (Si and 0 ). 

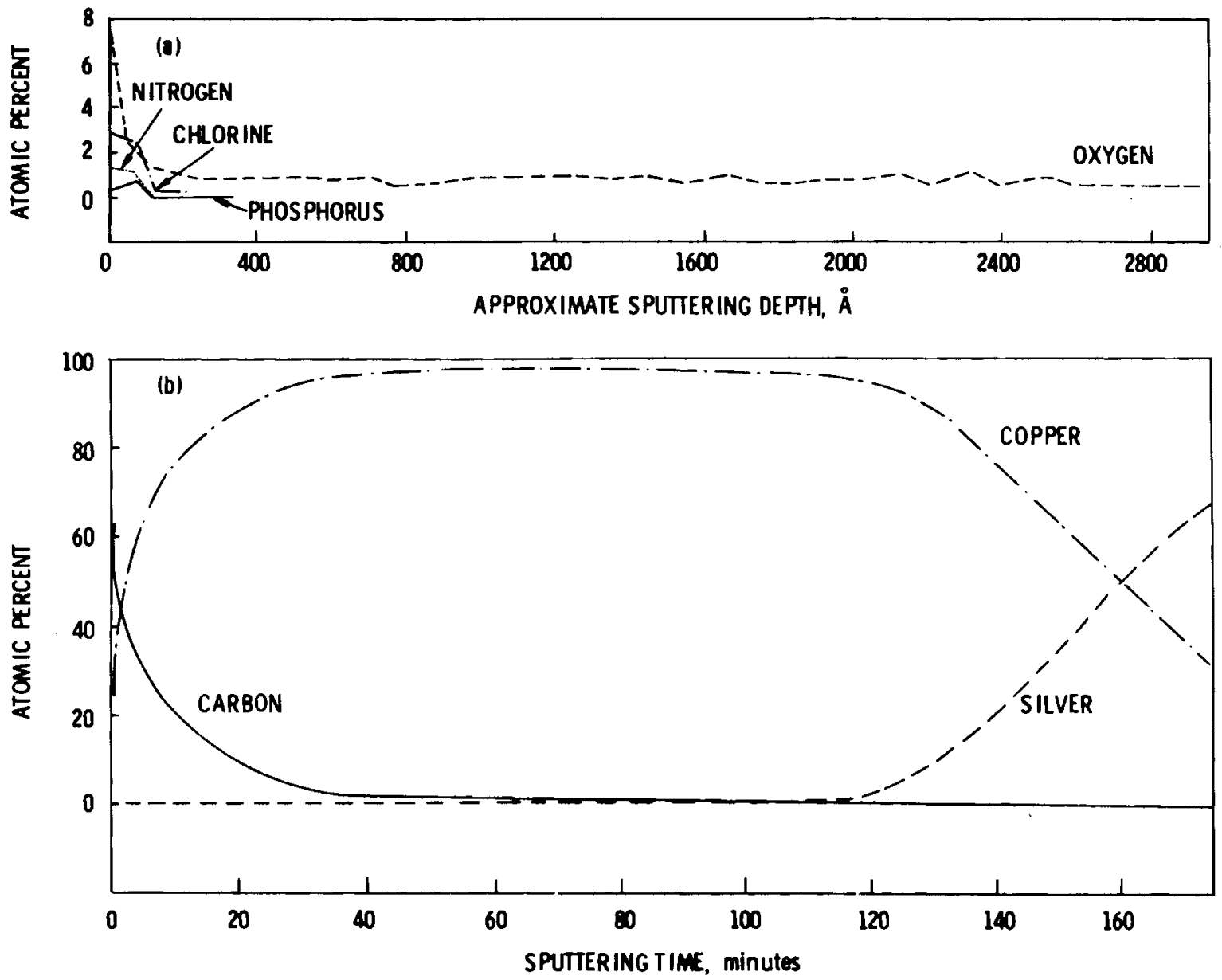

FIGURE 2.44. Auger and SIMS Depth Profiles of the London Lab Mirror Coated on the Hard Scrubbed Glass. (c) through (e) show a continuation of (a) and (b). 

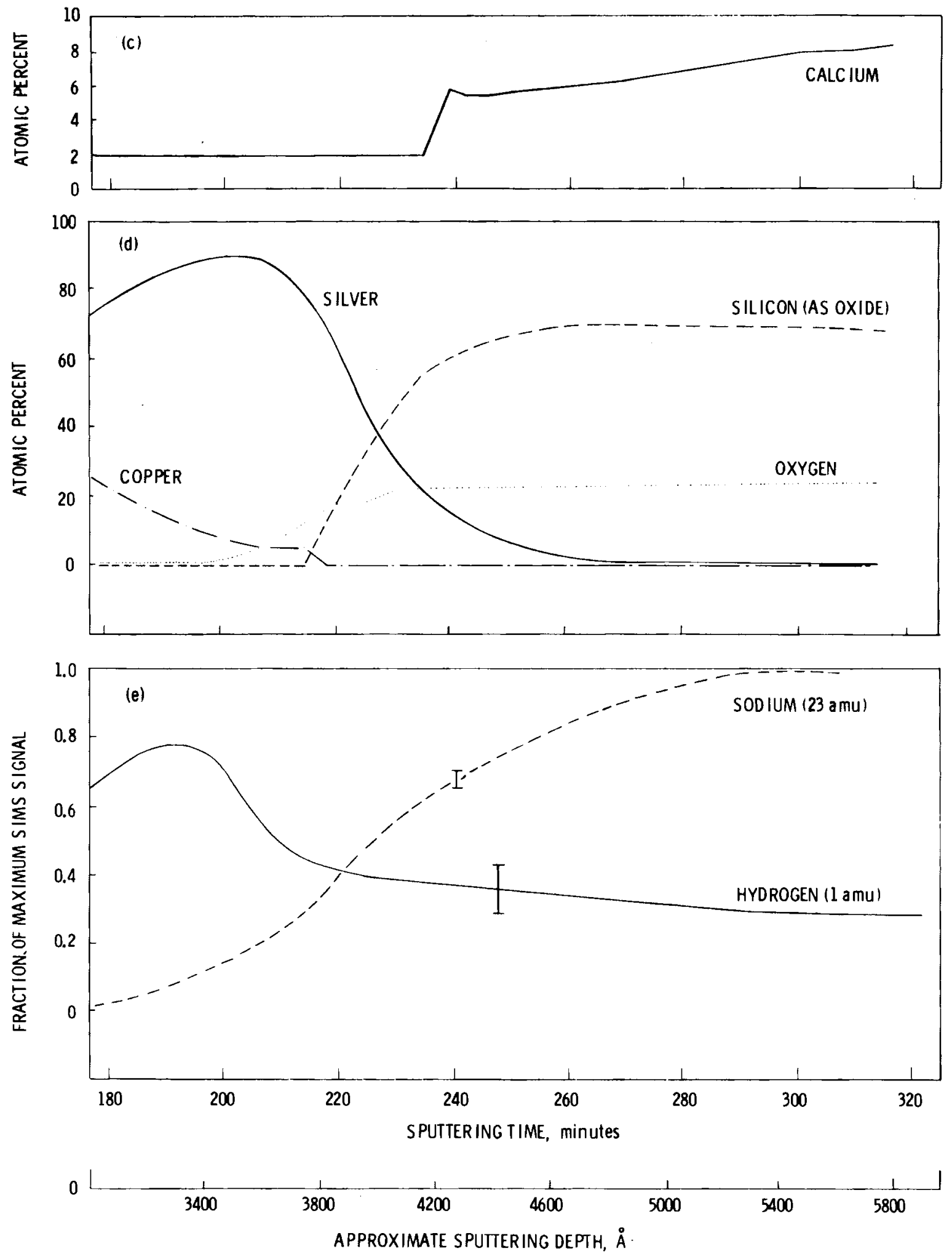

FIGURE 2.44. (Continued) 


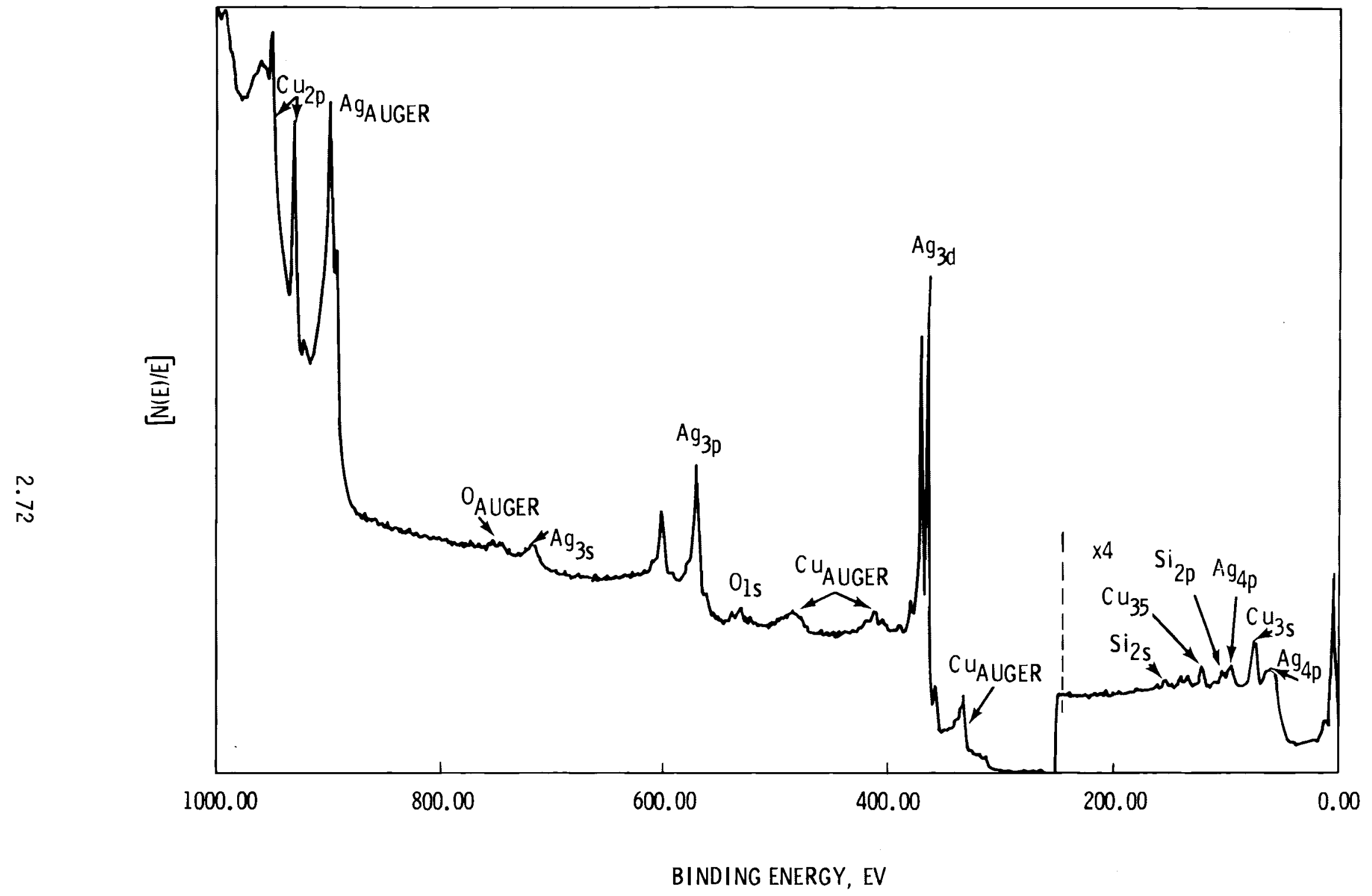

FIGURE 2.45. ESCA Point Scan of London Labs Cleaned Substrate Mirror after 215 Minutes of Sputtering 
Silver was found to penetrate the glass to depths in excess of $1000 \AA$, as shown in Figure 2.44d. This is somewhat surprising, given that the mirrors were reasonably new. Notice that no chlorine was detected within the glass or the silver, as had been found with the degraded Sandia mirror. This rules out the requirement of diffusion of silver and chloride ions as ion pairs, which is unlikely anyway due to the large size of the chloride ion.

More striking were dramatic changes in the silver Auger peak shapes, from that corresponding to silver in the metal film to that of silver in the glass matrix. Figure 2.46a shows the 340 to $350 \mathrm{eV}$ spectra of metallic silver. Figures $2.46 \mathrm{~b}$ and $2.46 \mathrm{c}$ show a gradual transition to that of silver in a glass matrix, given in Figure $2.46 \mathrm{~d}$. The peak shape shown in the latter figure remained constant as long as silver could be detected in the glass. Since valence (4d) electrons are involved in this Auger transition, this peak should be sensitive to chemical changes.

It is generally accepted that silver can diffuse at an appreciable rate in glass only as silver ions. Association of the silver ions with the glass network oxygen atoms would yield silver oxide. Thus, major chemistry changes are expected. However, it is uncertain whether these changes are being reflected in the Auger spectra shown in Figure 2.46. Since the glass is electrically insulating, some charge buildup could occur during Auger analys is, despite efforts to minimize these effects. Charging has often been found to broaden and/or shift the signals. Since the silver Auger peaks are relatively sharp and are closely spaced, a small amount of charge broadening could cause the two peaks to merge.

ESCA data of the $\mathrm{Ag} 3 \mathrm{~d}_{3 / 2}$ and $3 \mathrm{~d}_{5 / 2}$ doublet were recorded in the vicinity of the silver-glass interface to specifically look for chemistry changes. Special care was taken to watch for and to compensate for any sample charging. The data did not indicate that changes in silver chemistry had occurred up to the glass-metal interface. However, a shift to lower energy of the $3 d_{3 / 2}$ and $3 d_{5 / 2}$ peaks of approximately $0.5 \mathrm{eV}$ was observed after sputtering well into the glass. The position of the silver peaks in the glass is consistent with 

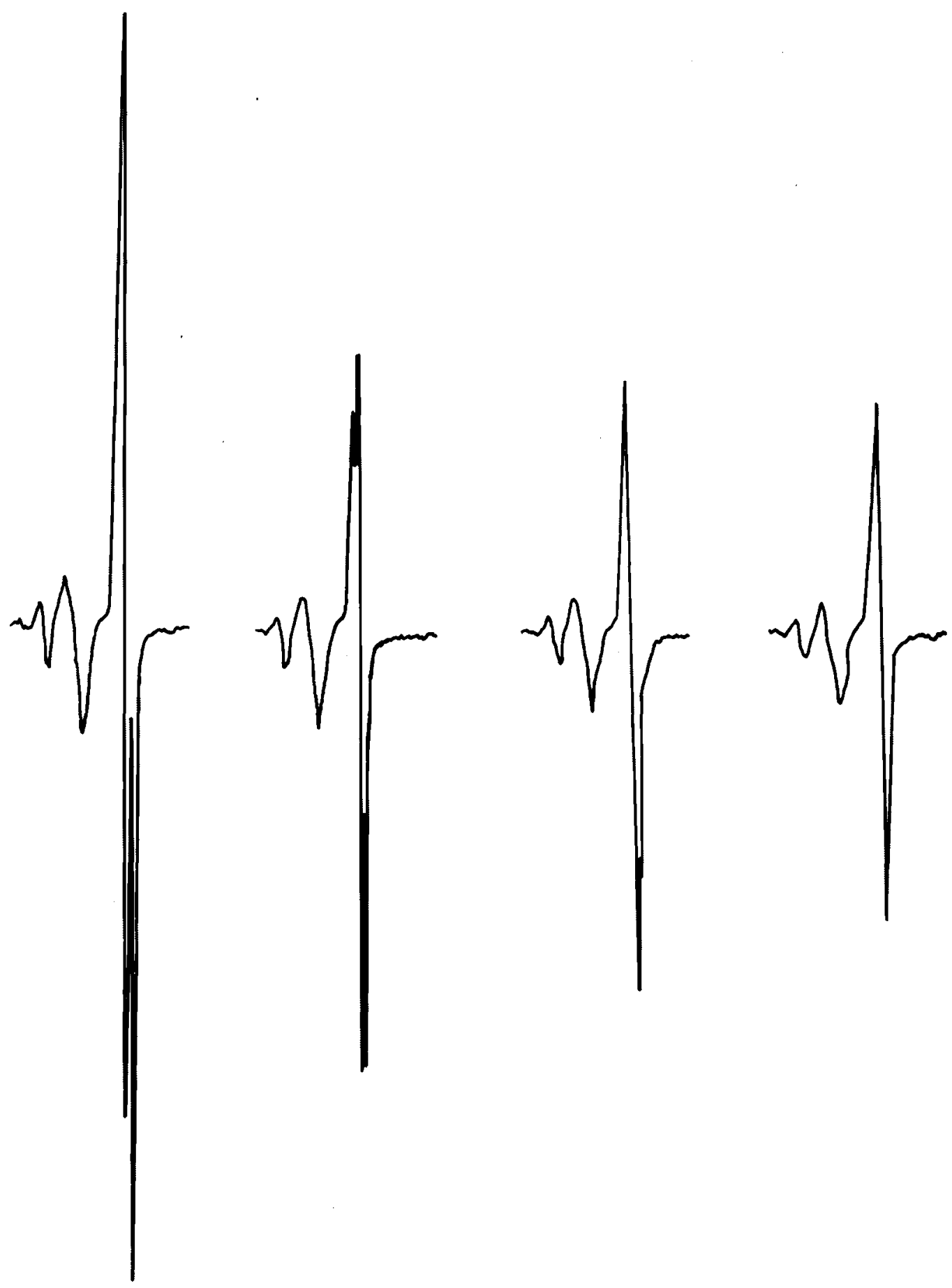

(a)

(b)

(c)

(d)

FIGURE 2.46. Changes in the 350-355 eV Silver Auger Peak Shape From the Metal Layer (a) Through the Glass-Metal Interface to Glass (d). The shape changes are expected to be due to electrical charging of the sample, which can broaden the peaks. 
that of silver oxide or hydroxide, as determined from standard spectra. Further studies are needed to determine the depth in the profile where the silver chemistry changes.

In addition to silver chemistry changes, a special effort was made to look for tin in the silver-glass interface region. Tin was detected with ESCA after approximately 230 minutes of sputtering (see corresponding depth scale of Figure 2.44). The tin signals were found to be highly localized as a function of depth, and thus serve the useful purpose of pinpointing the position of the original glass surface. It is interesting that the energy shift in the silver $3 d$ lines to an oxide form was not absolutely determined until after the detection of tin.

These results are consistent with the model that silver deposition begins at specific and separate tin nucleation sites on the glass. During a sputter profile, the separate disconnected silver islands may charge relative to each other and to the surrounding silver. This charging may account for the changes in the silver Auger spectra. One would not expect to observe tin until essentially all of the silver islands are sputtered away. After all of the silver islands are removed, the remaining silver spectra are due to silver in the glass, which should have a different chemistry than the silver in the islands. It is possible that the areas between the silver nuclei would be sputtered to the glass before the areas covered by the nuclei itself. The resulting profile would indicate that more silver-glass interdiffusion occurs than is correct.

An ESCA survey was taken after 300 minutes of sputtering (see corresponding depth scale in Figure 2.44), and is shown in Figure 2.47. Weak silver and copper signals were detected at this point. While low levels of silver could be detected with AES as well, no copper could be detected. Again, due to residual electrical charging in the AES analysis, ESCA may be more sensitive to copper in the glass matrix. On the other hand, the probing $x$-ray beam used in ESCA is much larger than the primary electron beam in AES. Thus, the copper detected by ESCA after 300 min of sputtering may be due to effects from the edge of the sputter crater. 


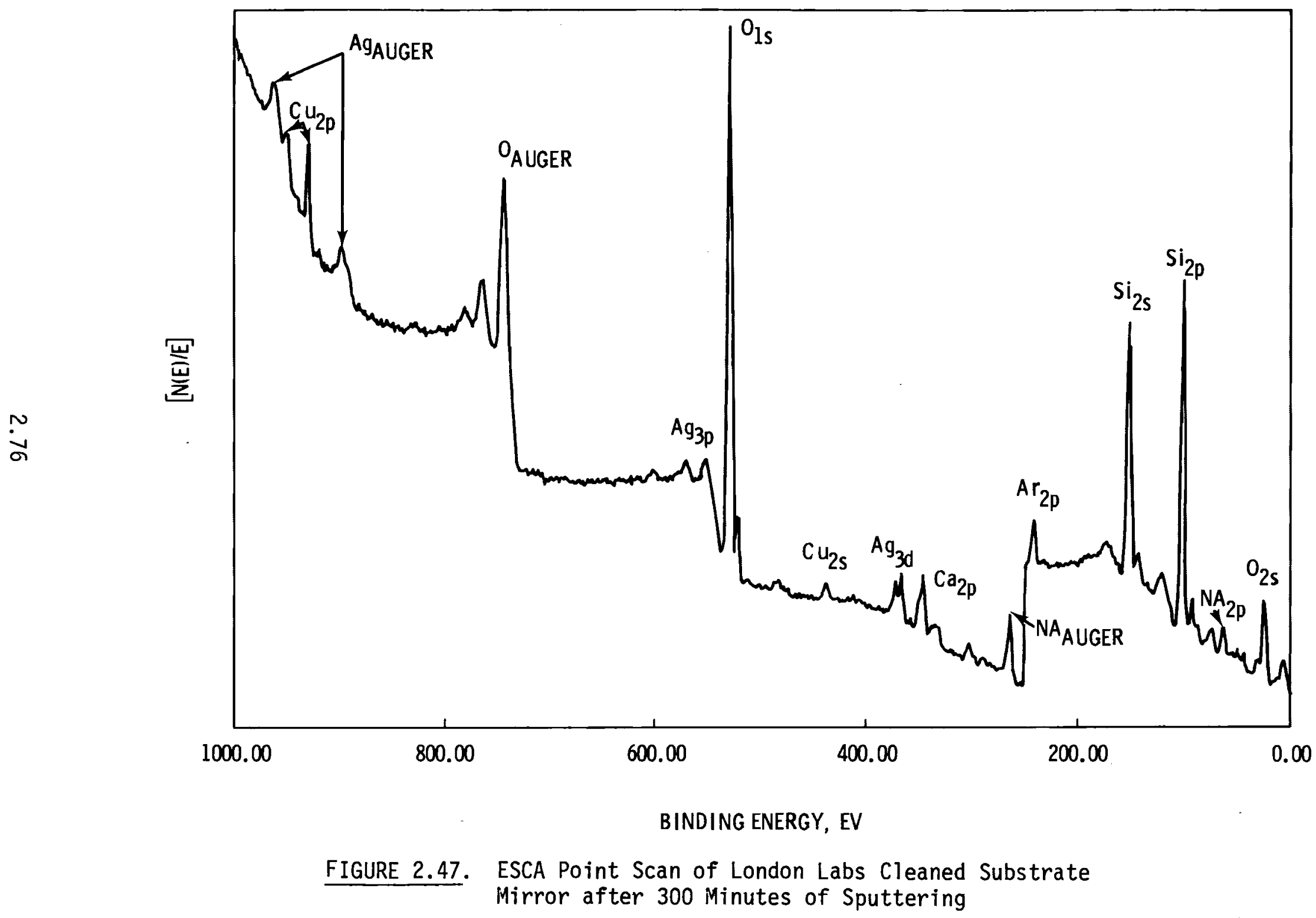



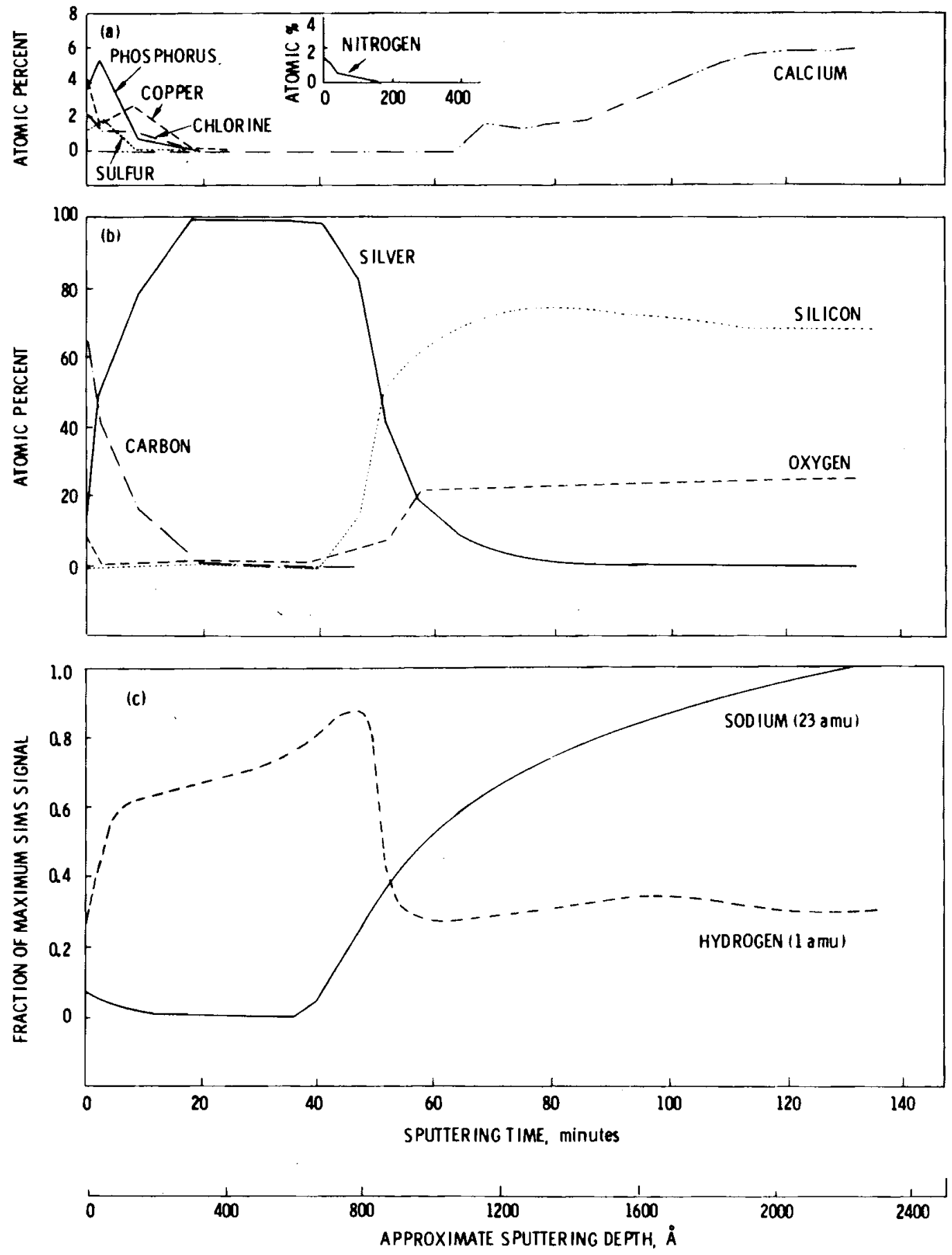

FIGURE 2.48. Auger and SIMS Depth Profiles of the London Lab Mirror Coated on Unscrubbed Glass. With the exception of the hydrogen profile, the elemental variations in the vicinity of the metal-glass interface are similar to that of the scrubbed glass. 
As shown in Figure 2.48, very similar results were found in the case of the mirror with the unscrubbed substrate as was found in the previous case. The only obvious difference between the two samples was that the copper layer was very uneven on the mirror with the unscrubbed substrate. Analysis was performed in an area of low copper. Total amounts of silver on the two samples were nearly equal. Diffusion of silver into the glass proceeded to approximately the same depth past the metal-glass interface. The hydrogen SIMS signal shown in Figure $2.48 \mathrm{c}$ is increased close to the glass-metal interface. This should be contrasted to the corresponding cleaned mirror SIMS spectra (Figure 2.44e) which is smooth.

Analysis of the Carolina Mirror

AES and ESCA analyses were performed on the components of an aged Carolina mirror after the paint was stripped from the mirror's rear surface. Data were recorded after sputtering to a depth of $20 \AA$ on both the metal layers and the newly exposed paint surface. Lead (paint component) and silver signals were present on both surfaces; but copper was seen only on the glass surface. This was observed in spite of the fact that the normal mirror structure of silver/copper/paint might be expected to segregate the silver and paint on opposite sides of the copper layer. Two possible reasons for this elemental distribution are solid state diffusion within the layers or a nonuniform copper layer at the time of coating. If the copper layer growth produces grains with smaller lateral dimensions than the interrogating beam, then the actual surface could consist of both silver/copper/paint and silver/paint regions. Sampling with a relatively large beam would then yield the type of results noted in this experiment. It is also interesting that silicon was found on the metal side of the sample and not on the paint side. Additional experiments would be necessary to provide definitive explanations of the physical behavior observed.

An AES depth profile showing the interrelation of copper and silver on the Carolina mirror surface is given in Figure 2.49. This analysis, which was performed with a $2000 \mathrm{~A}$ diameter primary electron beam, showed copper and silver interdiffusion similar to that seen using a 5 micron beam. Thus, if 


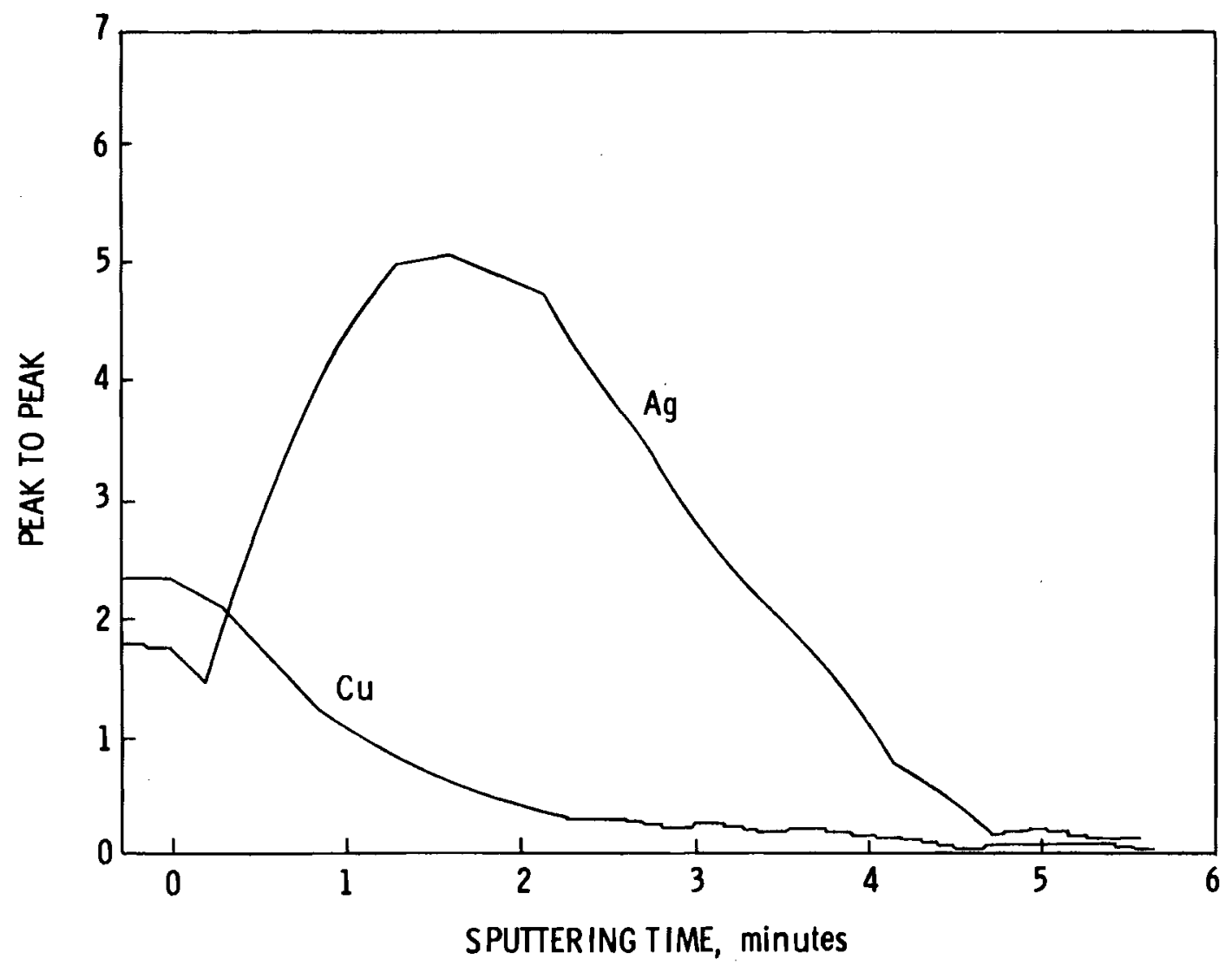

FIGURE 2.49. Auger Depth Profile of a 17-Year-01d Mirror Supplied by the Carolina Mirror Corporation

copper and silver microstructure is the cause of the apparent interdiffusion, crystallites smaller than $2000 \AA$ must exist.

Further experiments are desirable using an Auger Electron Spectrometer, with a beam size of $500 \AA$ or less. To map the sample surface, these experiments could resolve the question of whether silver and copper layers are extensively interdiffused or if there are separate $\mathrm{Cu}$ and $\mathrm{Ag}$ nuclei which are interleaved.

\section{Analysis of Tin Chloride Sensitization}

Figures 2.50 and 2.51 show some preliminary ESCA data recorded to study the manner in which a dilute $(30: 1) \mathrm{SnCl}_{2}$ in deionized distilled $\mathrm{H}_{2} \mathrm{O}$ is bonded to a glass surface. Figure 2.50 shows the glass surface after it has 
been cleaned with cerium oxide and rinsed in distilled $\mathrm{H}_{2} \mathrm{O}$. No cerium was detected with ESCA, however there is a large carbon peak ( 270 at\%). An intermediate ESCA survey of the same glass surface was recorded after $20 \AA$ were removed by sputtering. Most of the carbon was then concentrated on the outer surface with only 210 at\% left after this mild sputter. Figure 2.51 shows the ESCA survey after the glass shown in Figure 2.50 was dipped into the dilute $\mathrm{SnCl}_{2}$ solution. The sample was not rinsed after the $\mathrm{SnCl}_{2}$ bath. The $\mathrm{Sn}_{3 \mathrm{~d}}$ peaks are easily measured along with the $\mathrm{Cl}_{2 \mathrm{p}}$ spectra. Some detached Sn spectra were observed which indicates the $S n$ is in the form of a chloride and/or oxide. Further experiments are needed to obtain standardized spectra of $\mathrm{Sn}$ compounds so that the spectra on the glass can be deconvoluted to determine the chemical state of the Sn.

$\underline{D}_{2} \underline{0 \text { Experiment }}$

A solution of complexed silver in $\mathrm{D}_{2} \mathrm{O}$ was used in the preparation of a silver mirror on soda-lime-silicate glass in order to ascertain the depth of the reaction layer that occurs during normal mirror processing. This mirror was subsequently sputter-profiled using SIMS, as shown in Figure 2.52. The position of the metal-glass interface in the figure is most clearly shown by the rapid increase in the silicon signal. The sio signal rises with the Si signal and is then reasonably constant with depth into the glass. The $\mathrm{SiOH}$ and SiOD signals, however, rise sharply at the metal-glass interface, and then decay as a function of depth. The SiOH and SiOD signals show the depths to which $\mathrm{H}_{2} \mathrm{O}$ and $\mathrm{D}_{2} \mathrm{O}$ (and/or the corresponding anions or cations) have penetrated and reacted with the glass. The extent to which water reacts with the substrate glass during mirror preparation may strongly affect the durability of the mirror. More experiments are obviously needed to further explore this thesis.

\section{OPTICAL PROPERTIES}

The solar weighted optical properties of a number of samples were examined to determine the effects of silver thickness and agglomeration. The following is a summary of those investigations. 


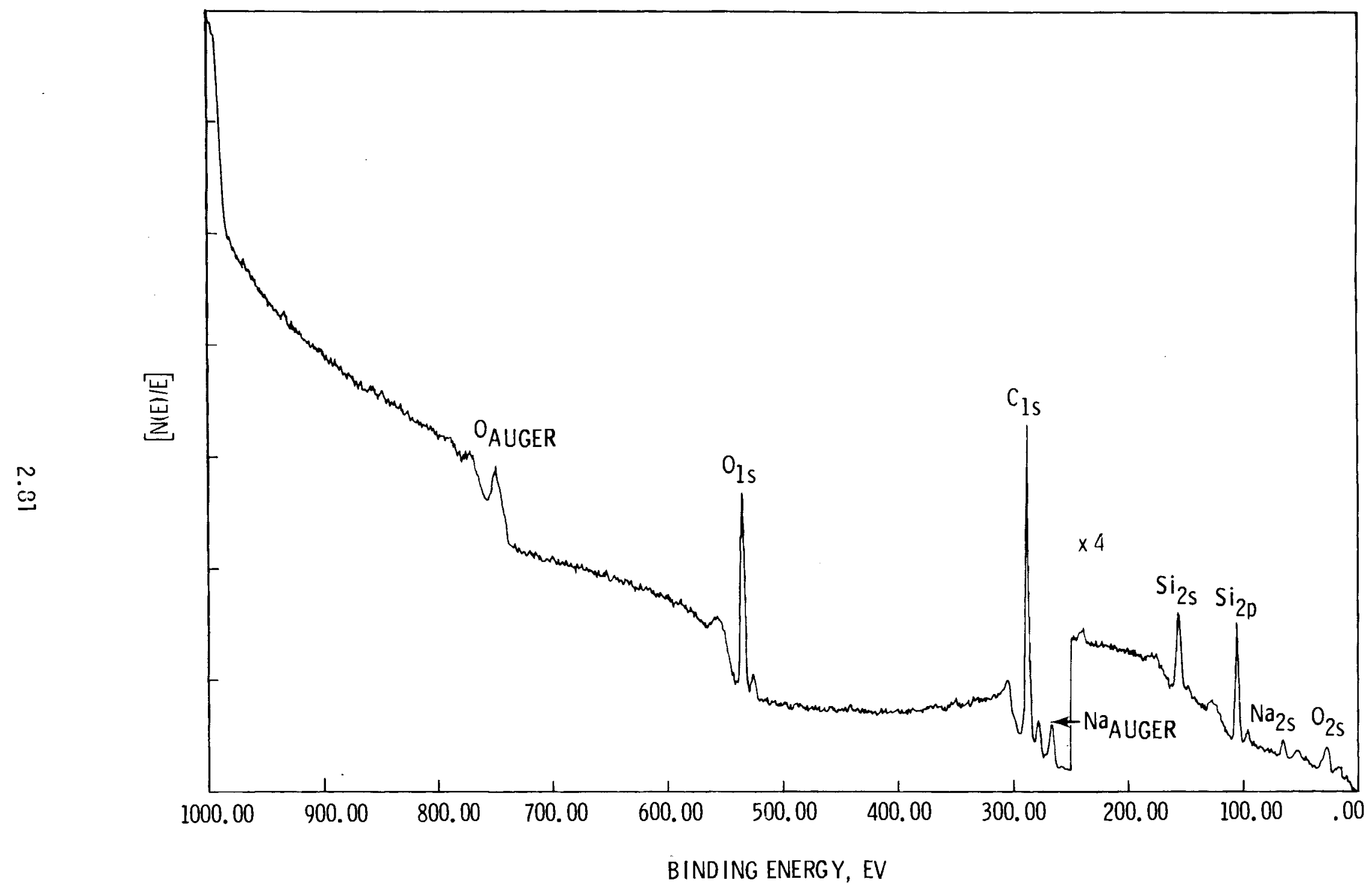

FIGURE 2.50. ESCA Survey of a Soda-Lime-Silicate Glass which had been Cleaned with Cerium Oxide and Rinsed in Distilled Water 


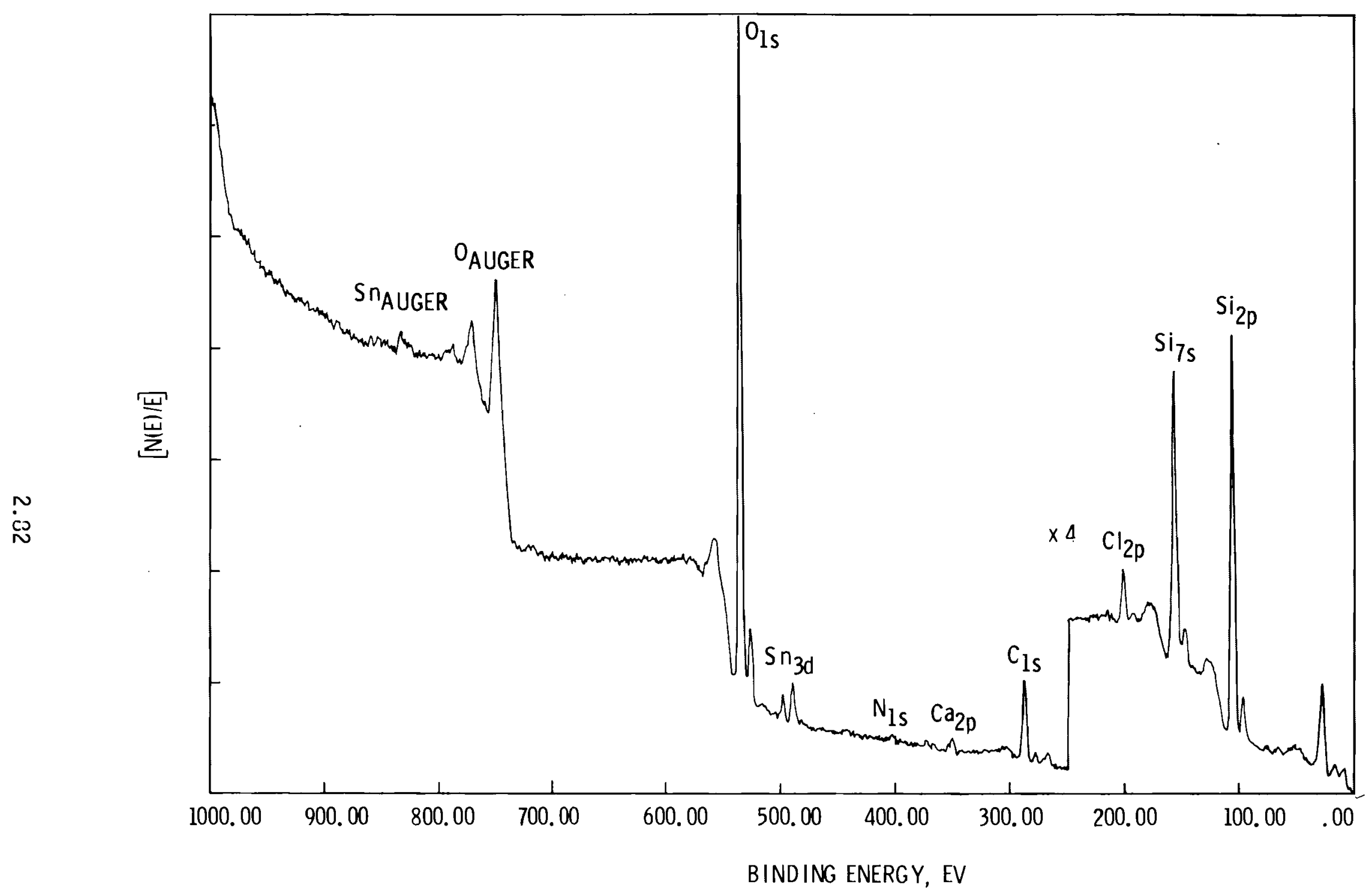

FIGURE 2.51. ESCA Survey of Soda Lime Glass After it had been Dipped into a Dilute $\mathrm{SnCl}_{2}$ Solution. Tin was clearly detected in the form of an oxide or chloride. 


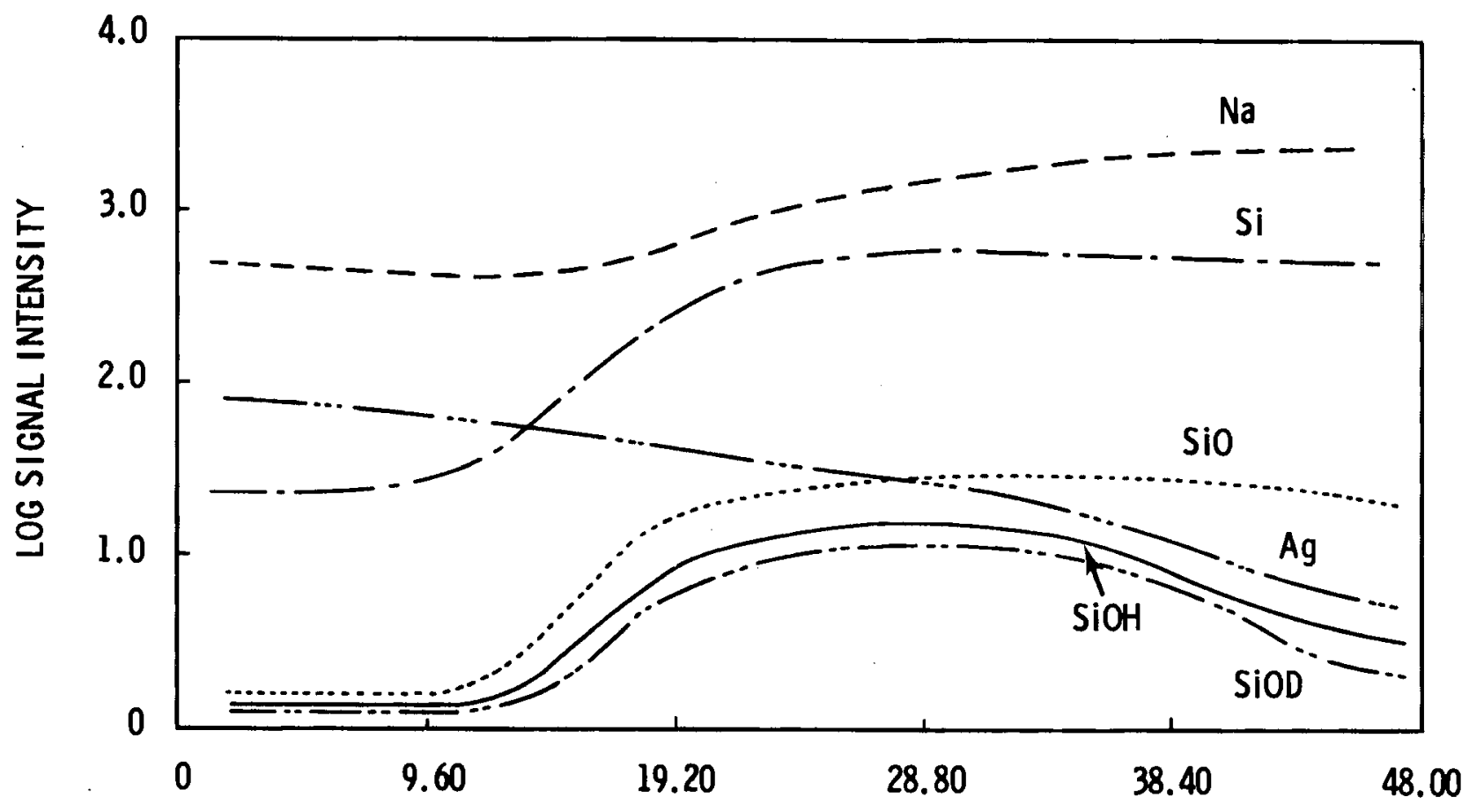

SPUTTER TIME (MIN)

FIGURE 2.52. SIMS Profile of a Silvered Mirror Which Was Chemically Deposited Using $D_{2} 0$ in the Silvering Solution. Evidence for deuterium penetration into the glass is present in the Si-OD signal.

\section{Effect of Silver Thickness on Solar Reflectance}

It is logical to assume that the thickness of the silver layer should have an effect on the solar reflectance of the mirror. It has also been asserted that the thickness of the copper layer plays a similar role. Furthermore, the method of deposition of these layers could influence the reflectivity.

In order to resolve these questions London Laboratories Limited prepared the series of samples listed in Table 2.5. The samples have varying thicknesses of silver and copper deposited by different techniques. Either twoor three-solution silvering chemistries were used to deposit a silver layer between $26 \mathrm{mg} / \mathrm{ft}^{2}$ and $188 \mathrm{mg} / \mathrm{ft}^{2}$. The silver layer was overcoated with a 


\section{TABLE 2.5. Sample Identification Chart}

\begin{tabular}{|c|c|c|c|c|}
\hline $\begin{array}{c}\text { Sample } \\
\text { Number }(a)\end{array}$ & $\begin{array}{c}\text { Type of } \\
\text { Silver }(b)\end{array}$ & $\begin{array}{c}\text { Silver } \\
\text { Thickness } \\
\left(\mathrm{mg} / \mathrm{ft}^{2}\right)(\mathrm{c})\end{array}$ & $\begin{array}{c}\text { Copper } \\
\text { Thickness } \\
\text { (mg/ft' })\end{array}$ & $\begin{array}{c}\text { Solar } \\
\text { Reflectance }(e) \\
\end{array}$ \\
\hline \multicolumn{5}{|c|}{ LONDON LAB DISPRO COPPER } \\
\hline $\begin{array}{l}1 \\
3 \\
4 \\
4 \times \\
5 \\
6 \\
7 \\
8 \\
9 \\
10 \\
11 \\
12 \\
13 \\
14 \\
15 \\
16 \\
17 \\
18 \\
19 \\
20 \\
20 x \times \\
21 \\
22 \\
23 \\
24 \\
25 \\
26 \\
27 \\
28\end{array}$ & $\begin{array}{l}2 \\
2 \\
2 \\
2 \\
2 \\
2 \\
2 \\
2 \\
2 \\
2 \\
2 \\
2 \\
3 \\
3 \\
3 \\
3 \\
3 \\
3 \\
3 \\
3 \\
3 \\
3 \\
3 \\
3 \\
3 \\
3 \\
3 \\
3 \\
3\end{array}$ & $\begin{array}{r}26 \\
26 \\
26 \\
26 \\
86 \\
86 \\
86 \\
86 \\
151 \\
151 \\
151 \\
151 \\
45 \\
45 \\
45 \\
45 \\
73 \\
73 \\
73 \\
73 \\
73 \\
85 \\
85 \\
85 \\
85 \\
155 \\
155 \\
155 \\
155\end{array}$ & $\begin{array}{r}27 \\
59 \\
110 \\
220 \\
27 \\
58 \\
116 \\
232 \\
27 \\
60 \\
100 \\
200 \\
27 \\
62 \\
125 \\
251 \\
27 \\
60 \\
140 \\
288 \\
575 \\
26 \\
62 \\
145 \\
292 \\
27 \\
50 \\
140 \\
282\end{array}$ & $\begin{array}{l}0.837 \\
0.811 \\
0.839 \\
0.836 \\
0.866 \\
0.863 \\
0.865 \\
0.867 \\
0.881 \\
0.872 \\
0.878 \\
0.878 \\
0.842 \\
0.854 \\
0.868 \\
0.865 \\
0.874 \\
0.878 \\
0.880 \\
0.878 \\
0.873 \\
0.874 \\
0.869 \\
0.865 \\
0.869 \\
0.882 \\
0.886 \\
0.884 \\
0.880\end{array}$ \\
\hline
\end{tabular}

\section{GALVANIC COPPER}

$\begin{array}{rrrrr}29 & 3 & 188 & 34 & 0.874 \\ 30 & 3 & 188 & 127 & 0.875 \\ 31 & 3 & 188 & 254 & 0.856 \\ 32 & 3 & 65 & 34 & 0.867 \\ 33 & 3 & 65 & 140 & 0.877 \\ 34 & 3 & 65 & 280 & 0.873 \\ 35 & 3 & 34 & 34 & 0.853 \\ 36 & 3 & 34 & 128 & 0.868 \\ 37 & 2 & 140 & 34 & 0.875 \\ 38 & 2 & 140 & 108 & 0.887 \\ 40 & 2 & 140 & 216 & 0.885 \\ 41 & 2 & 70 & 35 & 0.886 \\ 42 & 2 & 70 & 115 & 0.863 \\ 43 & 2 & 70 & 231 & 0.885 \\ 44 & 2 & 27 & 34 & 0.848 \\ 45 & 2 & 27 & 133 & 0.865\end{array}$

(a) Samples provided by London Laboratories, Ltd., New Haven, CT.

(b) 2 = two part solution; 3 = three part solution

(c) $70 \mathrm{mg} / \mathrm{ft}^{2} \approx 700 \AA$, nominal thickness in commercial mirror.

(d) $25 \mathrm{mg} / \mathrm{ft}^{2} \approx 300 \AA$, nominal thickness in commercial mirror.

(e) Weighted using Moon's AM 2 terrestrial solar spectral irradiance data and a best fit approximation routine. 
copper layer from $27 \mathrm{mg} / \mathrm{ft}^{2}$ to $575 \mathrm{mg} / \mathrm{ft}^{2}$. The copper was deposited by either disproportionation or galvanic interaction. The same run of ordinary float glass was used for all the samples.

The spectral reflectance of the second surface mirrors was measured and weighted to Moon's AM 2 terrestrial solar irradiance distribution. The results are shown in Table 2.5 and summarized in Figure 2.53.

While there appears to be a definite correlation of reflectance with silver thickness, there is no similar correlation with copper thickness. The minimum silver thickness necessary for high solar reflectance is approximately $70 \mathrm{mg} / \mathrm{ft}^{2}$. There also appears to be a systematic enhancement $(\sim 1 \%)$ when the two-part silver and galvanic copper are used. Further study would be required to confirm this observation.

\section{Effects of Silver Agglomeration on Solar Reflectance}

As discussed in an earlier section, six samples of commercially produced mirrors were subjected to heating in air for $30 \mathrm{~min}$. The temperatures ranged from $100^{\circ} \mathrm{C}$ to $350^{\circ} \mathrm{C}$ in $50^{\circ} \mathrm{C}$ increments. SEM photographs clearly show that agglomeration occurred.

These same samples were measured for first surface solar reflectance. No copper overcoat had been applied. The results are shown in Figure 2.54. There is evidently some enhancement in reflectivity ( $22-3 \%$ ) due to the agglomeration. Further tests are underway to verify the results.

Clearly the effects of temperature can be highly detrimental to reflectance. This could have a profound effect on encapsulation and protection concepts that require high processing temperatures.

\section{CONCLUSIONS}

A number of conclusions can be formulated from the experimental observations discussed in this chapter. They are summarized briefly below:

a. Defects and degradation occur much faster when the back surface of the mirror is subjected to "trapped" water, as compared to free "breathing" conditions. 


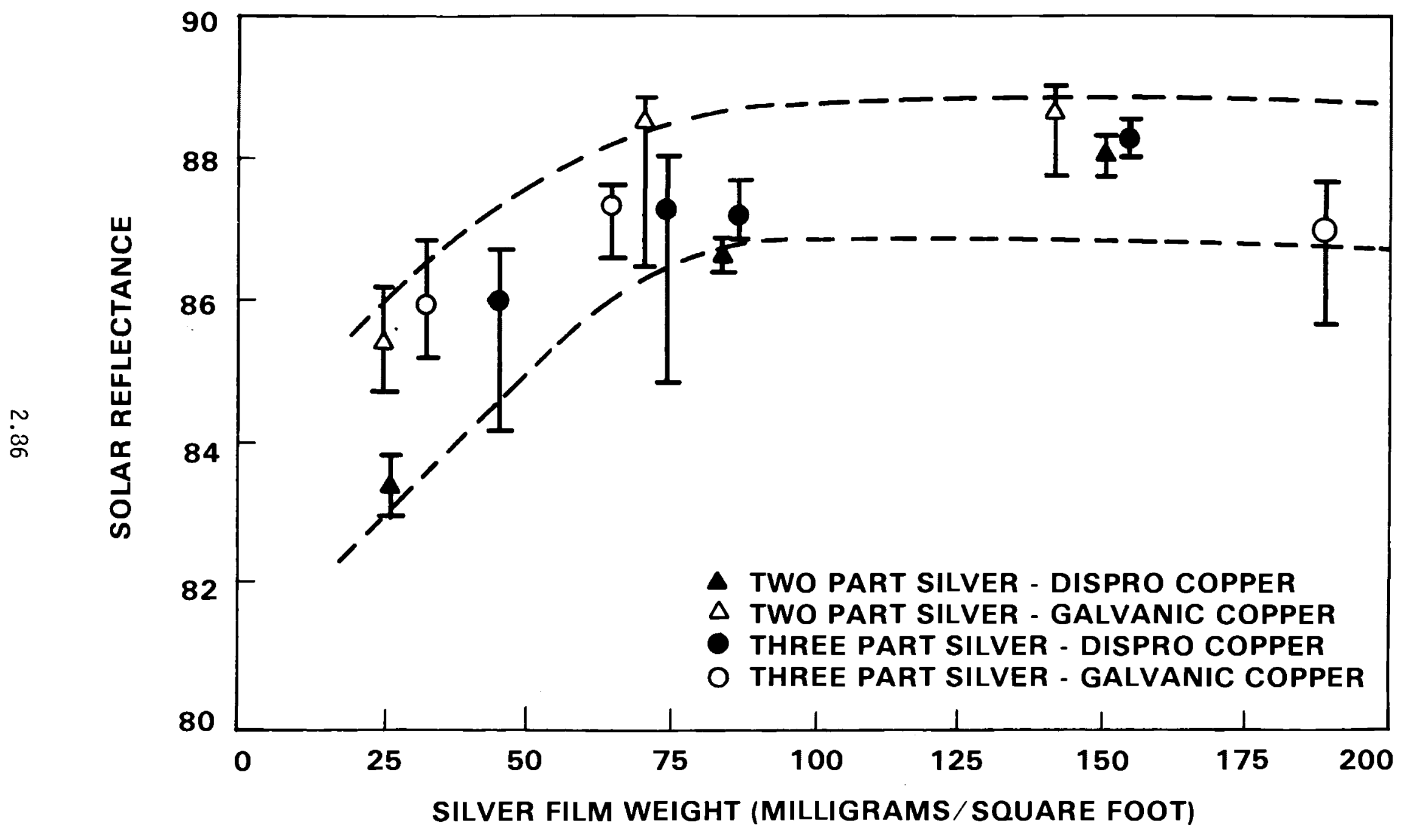

FIGURE 2.53. Variations in the Silver Thickness and Deposition Technique Influence the Solar Reflectance of the Mirror 


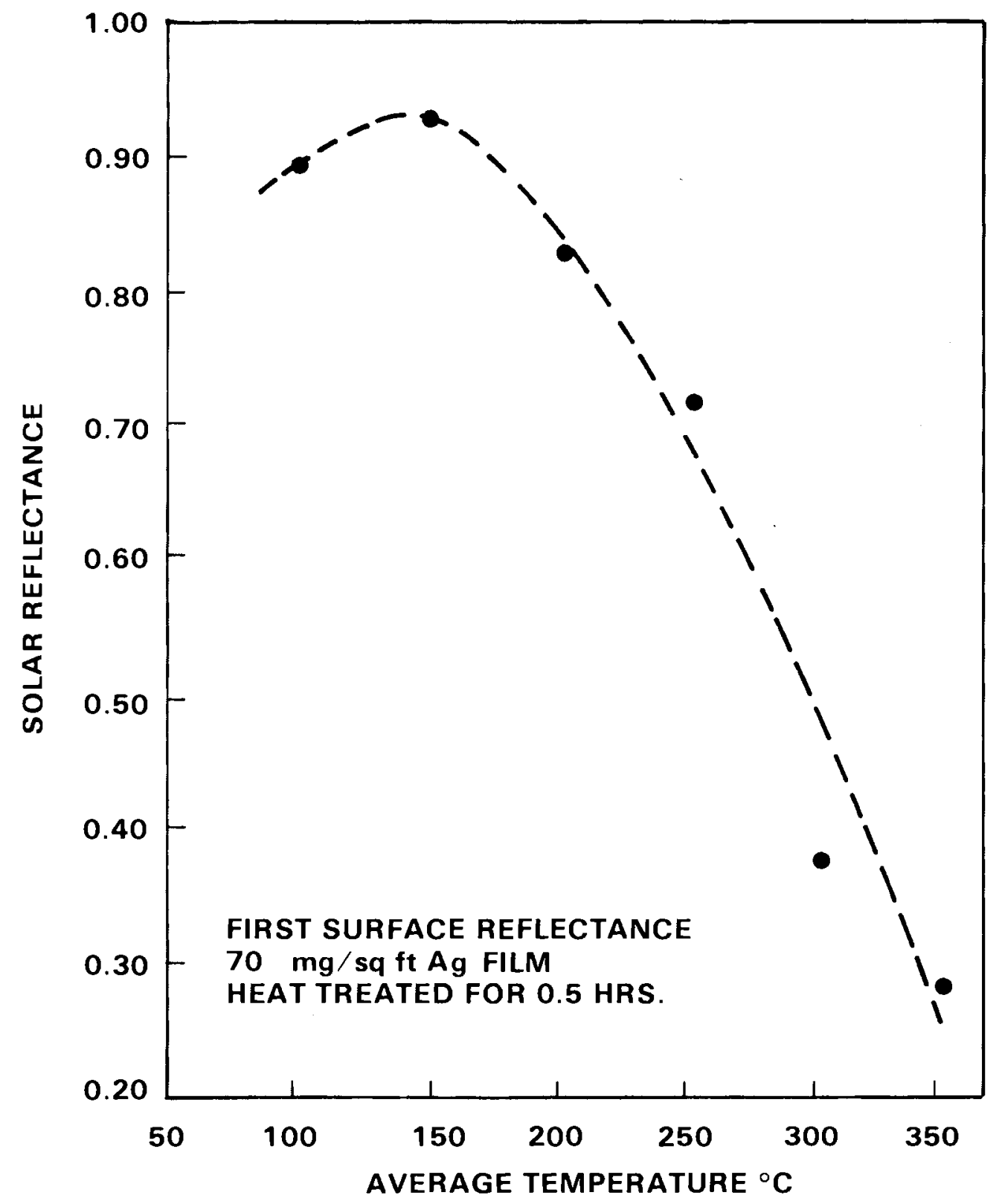

FIGURE 2.54. The Solar Reflectance as Influenced by the Amount of Silver Agglomeration 
b. Degradation centers are generally comprised of individual defect sites with nucleation centers surrounded by concentric reaction rings.

c. Degradation is encouraged by physical stressing of the backing, for example, application of adhesive by raking.

d. Separation of the glass and silver occurs frequently and without visible evidence or apparent degradation of mirrors; the bond between silver and glass is more easily broken than that between silver, copper, and paint.

e. The copper commonly is completely absent from individual defects and in the degraded areas. It also has been seen in diminished concentration near the defect areas and varies widely in concentration on a microstructural basis over the surface of new mirrors.

f. Paint backing is generally blistered at defects and in degraded areas, suggesting existence of internal forces in the metal and paint areas surrounding defects.

g. Paint components do not appear to be a source of mirror failure. This source cannot be completely discounted, however, as leaching of reactive paint components in low concentration could result from water penetrating through the paint layer.

h. Degradation occurs in a similar manner independent of the presence of chloride or sulfide ions.

i. Degradation occurs most frequently in the interior of mirror panels and not at the edges. This is true even when they are sandwiched loosely with other mirrors. This suggests that water penetration may be through the backing and not just through the unsealed edges.

j. "Best Practice" commercial mirrors differ widely in their metal surface structure and in the frequency of observed imperfections, which may consist of holes, oversized large silver particles, and uneven deposits.

k. Even carefully controlled laboratory fabrication of mirrors may lead to imperfect mirroring deposits of types similar to those seen with general production mirrors. 
1. The effect of fabrication defects on long term behavior is still uncertain, but some forms of imperfect initial microstructure appear to be related to the defect structure which ultimately develops (e.g., surface holes, reaction centers, large silver particles).

m. The silver and the copper layers consist of microparticulates, but the final density in the layer is near theoretical density.

n. Tin used as a stannous chloride sensitization agent in the fabrication of mirrors is occasionally detected later at the silver glass interface. Its occurrence is nonuniform and is not clearly related to the degradation forms observed.

o. The silver attachment to glass appears to be spotty in the original mirrors. This condition could be related to the tin distribution or to glass cleanliness.

p. The glass surface appears to be reacted, degraded or corroded at mirror failure areas.

q. Controlled experiments show that the reaction of hot water with the silver only mirrors leaves a scattered silver "attachment site" deposit of nodules on the glass which disappear as the reaction continues.

$r$. At elevated temperatures, a dry mirror may develop the same kind of large silver particle distribution on its surface as is observed commonly in the degraded mirror regions.

s. Silver and copper layers are largely intermixed. While it is possible that interdiffusion on an atomistic scale has occurred, it is most probable that silver exists in the form of islands with dimensions smaller than the spatial resolution of the analytical techniques employed.

t. Silver has been found to penetrate the glass substrate to depths on the order of hundreds of angstroms in relatively short time periods.

u. Chlorine has been found to diffuse into the glass substrate to depths of at least several hundred angstroms on some degraded mirrors. 
v. $D_{2} 0$ experiments have shown that significant reaction of the glass with solvent water occurs during mirror preparation.

w. The glass substrate shows a depletion of both calcium and sodium in the vicinity of the glass-metal interface. These ions are replaced by silver and hydrogen ions.

$x$. Degraded areas of the mirrors consistently show low levels of copper.

$y$. Tin can be detected at the original silver-glass interface and its position in the depth profile can be used as a reference point to measure atomic diffusion.

z. Silver chemistry does change when it diffuses into the glass.

aa. The thickness of the silver layer does affect the solar reflectance of the silver mirror for films less than about $75 \mathrm{mg} / \mathrm{ft}^{2}$.

bb. The thickness of the copper layer has little effect on solar reflectance even for thin silver films $\left(25 \mathrm{mg} / \mathrm{ft}^{2}\right)$.

cc. There is probably some correlation between solar reflectance and method of deposition. Two percent improvements may be possible with the correct selection of chemistry.

dd. Significant silver agglomeration can occur for processing temperatures in excess of $150^{\circ} \mathrm{C}$. While some agglomeration appears to enhance reflectivity, extensive agglomeration is detrimental to the optimal performance. 


\section{REFERENCES}

Askill, J., 1970, "Tracer Diffusion Data for Metals, Alloys and Simple 0xides," IFl Plenum, New York.

Clark, D. W., et a1., 1976, "Aqueous Corrosion of Soda Silica and Soda-Lime Silica Glass," The Journal of American Ceramic Society, 59:1-2.

Das, C. R., 1969, "Theoretical Aspects of the Corrosion of Glass," The Glass Industry, pp. 422-427.

Hansen, M., 1958, "Constitution of Binary Alloys," McGraw-Hill, New York, p. 18 . 
1 
CHAPTER 3

SILVER DEPOSITION AND PROTECTION: ADVANCED CONCEPTS 
CHAPTER 3

\section{SILVER DEPOSITION AND PROTECTION: ADVANCED CONCEPTS}

\section{INTRODUCTION}

The advanced mirroring concepts task was approached with the following constraints in mind: retain the silver as the reflective metal, use float glass as the superstrate, use solution chemistry as the deposition process, and any changes in the production process must be cost effective. The object of the advanced concepts study is to define a means of extending the life expectancy of the silver-glass mirror. In keeping with this objective the chemistry of mirror deposition has been investigated in conjunction with encapsulation ideas to inhibit degradation.

\section{PRESENT MIRROR CHEMISTRY}

Deposition Overview

The alternative methods for reducing mirror degradation will be a function of the manufacturing process, the chemistry involved in the deposition process, the silver protection scheme, the raw materials used, and the weathering stresses. The manufacturing process is outlined in Chapter 1 of this report and will not be discussed here. The subtleties of the actual chemistry of the mirroring process are not public knowledge since trade secrets are protected rigorously to defend market advantages. A primary reference of the mirror industry is Mirrors by Bruno Schweig (1973). The reference describes the various techniques incorporated in the entire mirroring process, from the glass superstrate to the paint backing. It is a valuable source, but lacking as a scientific approach to understanding the mirroring process.

In order to better understand the mirror deposition process and the degradation mechanisms, a small mirroring operation which simulates the actual manufacturing process has been established at PNL. The methods for 
producing the PNL mirrors loosely follow Schweig's recipe. They also incorporate additional information obtained during the industry survey and subsequent PNL experimentation. The following is a list of the pertinent points in each of the process steps that is worthy of further emphasis.

Glass. The glass used by the industry is usually the least expensive available. In most cases soda lime silicate float glass is used. Float glass has two distinct sides, a tin side and an air side. The tin side fluoresces under ultraviolet illumination. The air side is preferred in making mirrors, presumably in order to insure the best silver to glass adhesion. There is only limited industry experience with alternative glass composition such as the aluminosilicate or borosilicate glasses.

Cleaning. When glass is shipped it is packed with a variety of packing material to keep the sheets separated. These materials are usually a mildly acid paper or an acid treated plastic particulate. Whichever packing material is employed, the glass surface must be cleaned for silvering to be effective. The cleansing agent in common use is a $\mathrm{CeO}_{2}$ paste, a light abrasive which is scrubbed on the surface of the glass with either rubber scrubbers or nylon brushes. It is rinsed from the glass with copious amounts of deionized water. Deionized water is used as the solvent in all subsequent solutions to avoid contamination and the introduction of unwanted precipitates.

Sensitization. A stannous chloride solution is used to "sensitize" the glass surface. This results in faster silver deposition and improved silverglass adhesion. The $\mathrm{Sn}^{2+}$ is unstable in the solution, and within a day significant quantitites will oxidize to $\mathrm{Sn}^{4+}$. This oxidation is not desired and can be inhibited by the addition of a strong acid; $\mathrm{HCl}$ is effective, and a pH 2.8 solution is used at PNL. The strength of the $\mathrm{SnCl}_{2}$ solution is $0.047 \%$ by weight. However, the strength of the $\mathrm{SnCl}_{2}$ and acid may be varied somewhat and still be effective. This solution is sprayed onto the glass surface, after which the glass surface is rinsed with deionized water to remove excess $\mathrm{SnCl}_{2}$. 
Silvering. In the preparation of mirrors at PNL, a two-solution method is used. The first solution, containing the silver, is composed of a $0.5 \%$ silver nitrate solution with the addition of $0.9 \%$ ammonia. This forms the $\mathrm{Ag}\left(\mathrm{NH}_{3}\right)_{2}^{+}$complex in the solution and has a $\mathrm{pH}$ of approximately 8.8 . The second solution contains the reducing agent. Historically this has been made with a variety of substances. The essential ingredients are an aldehyde and a strong hydroxide source. This solution has a pH of 9.75. Here again, changes in solution concentrations can be made and still be effective. The solutions are sprayed onto the glass where the reduction reaction takes place leaving a metallic silver film. After this step the glass is rinsed with deionized water. The silver layer coated by the industry averages approximately $700 \AA$ in thickness.

Coppering. Copper deposition step has not yet been fully investigated at PNL. It is expected that a two-solution reaction will be used. A weak copper solution can be used which is based on a copper salt, usually a sulfate. This is mixed as a $0.5 \%$ solution with $\mathrm{H}_{2} \mathrm{SO}_{4}$ added as an acid catalyst. The copper is reduced to a metal using a slurry of metallic iron filings in deionized water. After deposition, the copper solutions are thoroughly rinsed from the surface with deionized water. Standard industry coatings deposit a $300 \AA$ (typical) film, which is then dried at up to $250^{\circ} \mathrm{F}$ to remove residual water from the metallic layers.

Paint Backing. Historically the mirror backing has been made of a variety of substances, from shellac to polymer paint coatings. Test mirrors prepared at PNL have not been coated beyond the copper layer, thus no insights have been gained at PNL beyond what was discussed in the industry survey chapter. The paint serves the purpose of protecting the metal layers during handling and in some instances can form a moisture barrier to inhibit degradation.

\section{ADVANCED CONCEPTS FOR MIRROR PROTECTION}

In seeking a solution to the mirror degradation problem the question evolves as to the major mechanism responsible for degradation. Water seems to be the culprit. Water, especially in highly acidic or basic solutions, is 
involved in ion exchange with the glass and dissolution of the silica structure. This in turn leads to degradation of the reflecting surface. One approach that might be used to extend the life expectancy of the mirror is to encapsulate the metallic layer and thereby prevent additional water in the atmosphere from reaching the interface and reacting with the glass. A quite different approach is to alter the chemistry of the manufacturing process, incorporating some kind of additive as an internal protective measure at the glass-silver interface. Both these approaches are being considered at PNL. The work initiated to date is summarized briefly below.

Encapsulation Concepts

Encapsulation is a technique of surrounding the mirror layers with an impermeable cover to keep interaction of the mirror with the environment to a minimum. Several different ideas were pursued, bearing in mind the fragile nature of the metal layers.

The current encapsulation technique for interior mirrors involves the use of a paint backing to protect the metal layers during shipping and handling. Review of and research on paint backings are being investigated elsewhere. For this phase of the project four other types of encapsulation techniques were explored.

Ceramic Frit. The ceramic frit is a powder ceramic material which is blown onto the backside of the mirror. It is waterproof, easy to apply and durable. The problem with the ceramic frit is the curing. To cure the frit it must be heated to temperatures ranging from $400^{\circ} \mathrm{C}$ to $650^{\circ} \mathrm{C}$, depending on thickness of the frit layer and type employed. Unfortunately, these temperature ranges would oxidize the metal layers, increase ionic and metal mobilities and possibly agglomerate the silver layer. Maximum temperature tolerances of the silver layer are approached at $150^{\circ} \mathrm{C}$ in the atmosphere. After this point solar reflectivities begin to significantly decrease. Experiments are presently underway to determine exactly what is happening to the chemically deposited silver layer as a function of temperature, both in the atmosphere and in vacuum. Reflectance, silver migration, oxidation and agglomeration are being characterized. 
Electrostatic Bonding. Electrostatic bonding involves charging a piece of glass with high voltage and then placing it onto the surface to be bonded. The glass bonds electrostatically thus avoiding perturbation of the metal layer surfaces by physical contact. Here again, hovever, temperatures on the order of $400^{\circ} \mathrm{C}$ are needed for effective polarization of the glass. As discussed in Chapter 2, temperatures in this regime may degrade the mirror severely. The investigation is continuing.

Aluminum-Ethyl Vinyl Acetate. The Al-EVA technique involves the deposition of aluminum on the backside of the mirror followed by a coating of an ethyl vinyl acetate polymer. In this procedure the glass must be heated to $180^{\circ} \mathrm{C}$. This might be a plausible technique since the manufacturing process temperature may be low enough to avoid serious silver deterioration. Currently, the manufacturing process can handle only small samples and is somewhat technology intensive. The concept has not yet been tested in terms of leachability, so its effectiveness has yet to be determined. However, samples have been prepared by the Spire Corporation for evaluation during the next fiscal year.

Solder Glass. The solder glass technique has the same problem as many glass encapsulation methods with respect to temperatures. The minimum melting point is $484^{\circ} \mathrm{C}$ for a lead borosilicate solder glass. It may be possible to bond at the edges as is done in the television picture tube industry. This decreases the amount of heat that would be applied to the mirror, but the concept must be further investigated to determine feasibility for large mirror panels. The principal concern is controlling the mechanical stress caused by the high thermal gradients in the region of the joint.

\section{Modifying the Deposition Chemistry}

The data presented in Chapter 2 strongly suggest that one of the weakest links in the mirror structure is the silver to glass interface. The SEM data clearly show examples where the silver layer has debonded from the glass in both new and degraded mirrors. This suggests that a key to extending mirror lifetime could lie in modifying the chemistry at the silver-glass interface to insure a better silver to glass bond or less corrosion of the glass itself. 
It is well known that water can degrade the glass surface (Kranskopf, 1979). One can propose a degradation mechanism for the glass surface which involves the attack of a hydroxide ion on the glass matrix. The hydroxide ion is generated under ambient environmental conditions through an equilibrium process involving water. More significantly, the mirror production process introduces hydroxide concentrations into the glass matrix several orders of magnitude greater than the normal water equilibrium.

The manufacturing process could then initiate the degradation of the glass with subsequent degradation promoted by environmental moisture. Recall the results of the $\mathrm{D}_{2} \mathrm{O}$ experiment described in Chapter 2 which showed that the reaction layer for $0 D^{-}$penetration was $300-500 \AA$. This appears to be a sufficient depth to initiate significant attack on the silicate structure. As the silicate matrix dissolves, the glass interface will degrade causing the silver layer to appear to delaminate from the glass surface.

If this degradation process is correct, one might expect to see some $\mathrm{Si}$ remaining with the $\mathrm{Ag}$ in the delaminated sections of the mirror. The EDX spectra in Figure 2.20 shows that this is indeed the case. However, the data are not conclusive considering a significant amount of $S i$ was also found in the paint layer. Clearly, more detailed experiments are required to verify this hypothesis.

Based on industry experience, the actual silver to glass bond is not very strong, but appears to be enhanced considerably by the tin sensitization step. One can speculate that the tin acts as an intermediary bonding to the glass surface and to the silver deposited above it. The tin probably then forms the basis of nucleation "islands" (de Minjer and Boom, 1973). Minimal concentration levels indicate the separation of these islands should be on the order of $1000 \AA$. The SEM photo in Figure 2.35 lends some credence to this thesis since the silver tends to adhere to the glass in clumps spaced on that order of magnitude. Thus the silver to glass bond may be tenuous at best.

Assuming that either or both of the above pictures are correct, several "fixes" which might inhibit or at least retard the degradation process can be 
suggested. Presumably, appropriate modifications in the surface chemistry of the glass obtainable through the use of more effect coupling agents could increase the silver-glass bond strength considerably. It might also be possible to modify the surface of the glass in such a way as to increase its resistance to hydroxide attack, thereby preserving the integrity of the silver to glass interface. There is insufficient data to suggest which approach will provide the best solution in the long term.

Lanthanide Doped Mirrors. If the supposition that the dissolution of the glass matrix is responsible for the degradation is correct, it may be possible to include additives in the mirroring process which tie up the excess hydroxides on the glass surface and arrest the initial attack on the silicate network. Several classes of elements might be used. Time constraints restricted the PNL study to one class that aquates very well and may provide a means of inhibiting the reaction at the interface. This class is the lanthanide ions $\left(\mathrm{La}^{3+}, \mathrm{Dy}^{3+}, \mathrm{Pr}^{3+}, \mathrm{Na}^{3+}, \mathrm{Sm}^{3+}\right.$ and $\mathrm{Er}^{3+}$ ). The supposition is that the lanthanide ions $\left(\mathrm{Ln}^{3+}\right)$ will bond equally well to water and hydroxide ions. Complexes such as $\mathrm{Ln}(\mathrm{OH})_{9}^{-6}$ and $\mathrm{Ln}\left(\mathrm{H}_{2} \mathrm{O}\right)_{9}^{3+}$ can form at the interface. Since the hydroxides and water at the interface would be coordinated around the lanthanide ions, movement into the glass matrix would be inhibited. The interfacial diffusivities should decrease and the ion exchange and silicate dissolution should be retarded. Thus the mirror life expectancy should be extended.

The small scale mirroring operation at PNL was implemented to test the lanthanide concept. The lanthanides were ordered from Stohler Isotope Chemicals, the spray guns from the Paache Air Brush Company, and the tin and silvering chemicals from London Laboratories Limited. Only deionized distilled water was used in all the processes. The lanthanides were dissolved in separate solutions and the $\mathrm{pH}$ adjusted to match the tin solution. A $0.1 \%$ solution of the lanthanide chloride salt was made as a stock solution.

Three different kinds of mirrors were made to test each salt. A control mirror was made without lanthanides, a mirror was made with lanthanides only, 
and then a mirror was made with lanthanides and $\mathrm{SnCl}_{2}$ applied simultaneously. Float glass was used with the air side being silvered. No copper backing was applied.

The deposition experiment showed that tin is still desirable as a sensitizing agent. Visual observations of the finished mirrors indicate that the lanthanides by themselves may not act as good nucleation sites for silver deposition. However, the lanthanide-tin (II) chloride solutions produced good mirrors.

Time constraints did not permit a thorough evaluation for durability. However, the mirrors were screened for durability by using a leach bath of boiling deionized water as discussed earlier. Samples of a control mirror made by the traditional silvering process at PNL, a lanthanide mirror, and a mirror supplied to PNL by a commercial mirror manufacturer were inserted vertically in the bath so that they were half immersed. After a 3-hour test both the control and commercial mirrors had degraded appreciably, while the lanthanide mirror showed considerably less degradation (see Figure 3.1). This same test was performed for 8 hours with the same qualitative result. This test has been performed 7 times with the same results each time. $\mathrm{Nd}^{3+}$, $\mathrm{Ln}^{3+}, \mathrm{Er}^{3+}$ and $\mathrm{Sm}^{3+}$ have all been tested. On the basis of this abbreviated screening test, it appears that the lanthanide concept has some merit.

An AES depth profile of one of the Sm doped mirrors did not reveal any trace of the lanthanide. This suggests a major buildup of lanthanide species (for example as a thick hydroxide deposit) is not involved. We believe it likely that the rare earths enter the glass surface as modifiers as opposed to entering the silica network. In that role, they effectively block openings in the structure that normally allow rapid transport of alkali, $\mathrm{H}^{+}$, etc. More work is needed to establish whether a monolayer type protection is involved or whether a more diffuse blocking mechanism occurs in which a relatively thick gel-interface region is stabilized.

The use of lanthanides in the industrial process has one distinct advantage. It can be implemented with no capital investment. Since the solution can be codeposited with the tin chloride sensitization solution, no modification of the wet process silver production line is required. 

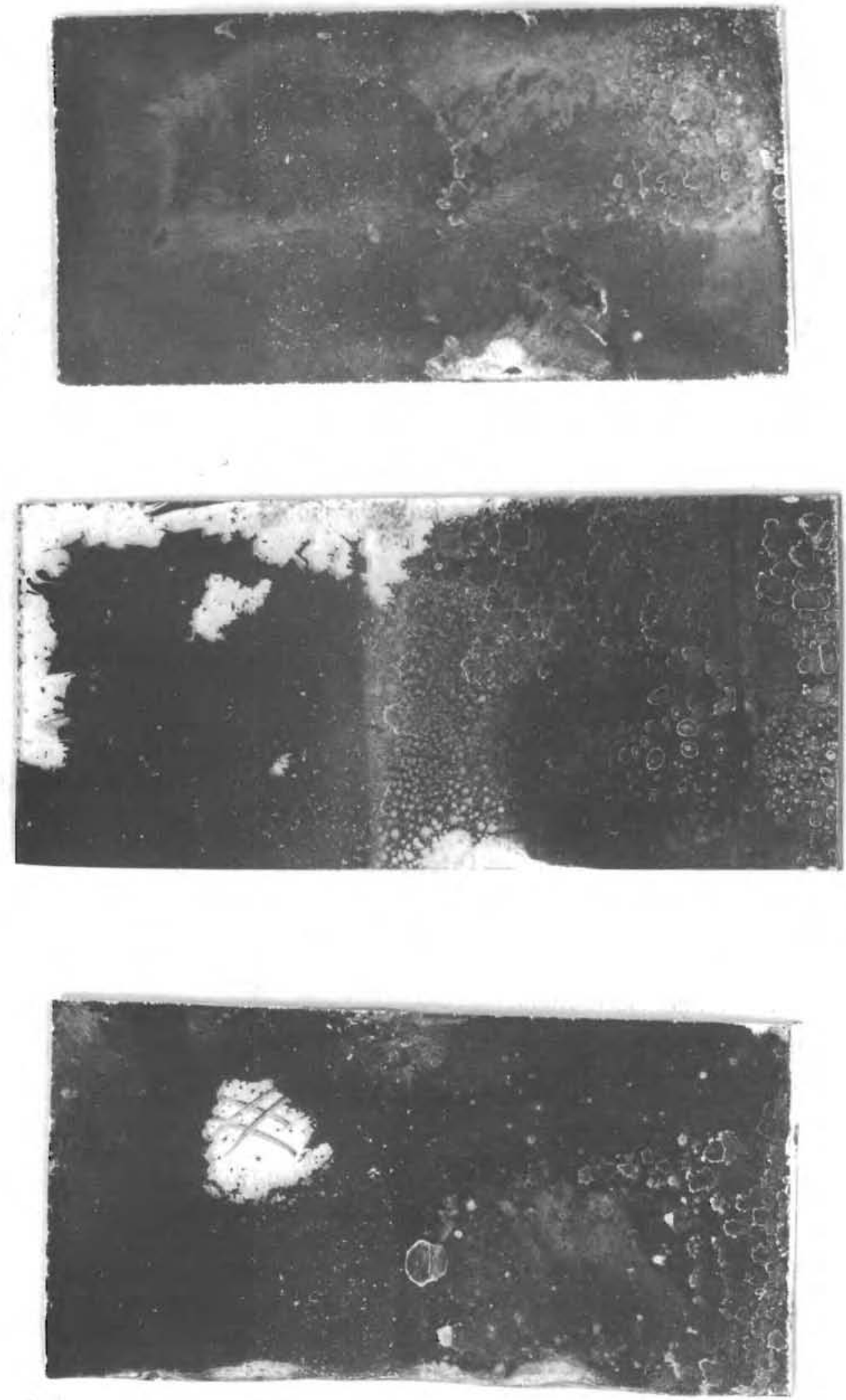

FIGURE 3.1. Mirrors After Leach Bath Test. The 1anthanide mirror on the top fared considerably better than either the PNL control mirror or the commercial mirror. 
It should be pointed out that high purity lanthanide salts are expensive. But, since the more common salts that were used proved equally effective in our preliminary studies, it may not be necessary to use the highly processed reagent grade chemicals. Since the chemical separation of the individual elements in the lanthanide series is a major contributor to the cost, it may be possible to produce more cost-effective salts by allowing cruder mixtures. In addition, the optimum concentration of lanthanides in solution has not been determined. The $0.1 \%$ solution used appears to be effective, but no lower bound on concentration has been established.

Much more experimental work and environmental testing is necessary to fully assess the validity of the concept. However, based on these preliminary results, an invention report has been submitted and a patent application filed.

\section{CONCLUSIONS}

Several methods of extending the life expectancy of silver-glass second surface mirrors are being investigated. They center around encapsulation of the metal reflecting layer and modification of the wet process silver deposition chemistry.

There is speculation based on some very preliminary theoretical and experimental evidence that suggests encapsulation by itself will not be totally effective in guaranteeing long life of mirrors produced today. It is possible that corrosion of the glass surface leading to the dissolution of the silver-glass interface is responsible for a major portion of the mirror deterioration. The degradation process may in fact be initiated or accelerated by the wet chemistry silver deposition process.

This is not to say that lifetime gains would not be realized by an effective moisture barrier on the back surface of the mirror because they undoubtedly would. At this time very little is known about the kinetics of the chemical interactions at the silver-glass interface. Much additional effort is required to understand the detailed degradation mechanisms before a definitive solution can be proposed. 
Some preliminary work utilizing lanthanides as modifiers at the silverglass interface shows promise for increasing the mirror's resistance to moisture attack. These studies should continue through a proof-of-concept phase. Other chemical systems and alternative glass compositions which either enhance the silver-glass bond strength or inhibit glass corrosion at the interface should be investigated.

\section{REFERENCES}

Kranskopf, K. B., 1979, Introduction to Geochemistry, p. 133, McGraw-Hill, Inc., New York, NY.

de Minjer, C. H., and P. F. J. r. d. Boom, 1973, "The Nucleation with $\mathrm{SnCl}_{2}$ $\mathrm{PdCl}_{2}$ Solutions of Glass Before Electroless Plating", J. Electrochem. Soc., December 1973, p. 1644.

Schweig, B., 1973, Mirrors, Pelham Books, London. 

APPENDIX A

MIRROR MANUFACTURERS 


\section{APPENDIX A}

\section{MIRROR MANUFACTURERS}

National Association of Mirror Manufacturers

5101 Wisconsin Ave., Suite 504

Washington, DC 20016

(202) $966-7888$

Membership Directory

NATIONAL ASSOCIATION OF MIRROR MANUFACTURERS

American Mirror Company

602 E. Stuart Dr.

P.0. Box 67

Galax, VA 24333

(703) $236-5111$

Bassett Mirror Company

P.0. Box 627

Bassett, VA 24055

(703) 629-7511

Binswanger Mirror Company

1355 Lynnfield Rd.

Suite 205

P.0. Box 17127

Memphis, TN 38117

(901) 761-3150

Buchmin Industries

$1485 \mathrm{E}$. Curtis

Reedley, CA 93654

(209) 888-2017

Carolina Mirror Corporation

P.0. Box 548

Elkin Road

N. Wilkesboro, NC 28659

(919) $838-2151$

Chromalloy Mirror

1700 Dowling Street

Houston, TX 77003

(713) 223-4951
Cincinnati Mirror Corp.

9865 Wayne Avenue

Cincinnati, $\mathrm{OH} \quad 45215$

(513) $771-5242$

Colonial Mirror and Glass Corp. 142 - 19th Street

Brooklyn, NY 11232

(212) $499-9880$

Crest Mirror and Door Co. 2801 Tuolumne Street

Vallejo, CA 94590

(707) $552-7676$

Falconer Plate Glass Corp. 500 S. Work Street

Falconer, NY 14733

(716) 665-6422

Gardner Mirror Corporation

Highway 268E

P.0. Box 638

N. Wilkesboro, NC 28659

(919) 838-2111

Gilded Mirrors, Inc.

RFD \#4

Maryville, TN 37801

(615) 856-3066

Hoyne Industries

Suite 725, The Tower

Rolling Meadows, IL 60008

(312) 364-2350 
Lenoir Mirror Company

1658 Norwood Street

P.0. Box 1650

Lenoir, NC 28645

(704) 728-3271

Metropolitan Mirror \& Glass Co. 31 Warren Place

Mount Vernon, NY 10550

(914) 668-5074

New Galax Mirror Corp.

209 East Grayson Street

Galax, VA 24333

(703) $236-2961$

01 son Mirrors

19800 Meredith Drive

Strathmore, CA 93267

(209) 568-1721

Radiant Mirror Co.

5631 Ferguson Drive

Los Angeles, CA 90022

(213) $685-4730$
Ronco Mirror Co.

4358 W. Roosevelt Road

Chicago, IL 60624

(312) 826-4366

Stroupe Mirror Co.

102 East Holly Hill Road

P.0. Box 278

Thomasville, NC 27360

(919) $475-2181$

Toledo Plate \& Window Glass Co.

1042 Utica Street

P.0. Box 927

Toledo, $\mathrm{OH} 43693$

(419) 241-8291

Virginia Mirror Company

300 South Moss Street

Martinsville, VA 24112

(703) $632-9816$

Willard Mirrors, Inc.

Factory District

P.0. Box 1426

Fort Smith, AR 72902

(501) 783-6184 
APPENDIX B

RECOMMENDED SPECIFICATIONS FOR

SECOND SURFACE SILVERED MIRRORS

FOR CENTRAL RECEIVER HELIOSTAT APPLICATIONS 
APPENDIX B

RECOMMENDED SPECIFICATIONS FOR

SECOND SURFACE SILVERED MIRRORS

FOR CENTRAL RECEIVER HELIOSTAT APPLICATIONS

August, 1979

SCOPE

1.1 This specification applies to the second surface silvered mirrors used on heliostats for central power tower solar conversion concepts.

1.2 The specification reflects the specific requirements placed on the mirror silvering process for the mirrors produced for the Barstow Ten Megawatt Solar Pilot Plant Facility.

APPLICABLE PUBLICATIONS

2.1 The following publications are applicable to this standard.

2.1.1 Canadian Government Specifications Board Standard for Mirrors, Silvered CAN2-12.5-M76, September 1970.

2.1.2 Interim Federal Specification, Mirrors, G1ass, DD-M-004116 (GSA-FSS) Apri1 5, 1968.

2.1.3 Specification for Flat Glass for Central Receiver Heliostat Applications, July 26, 1978. Appendix D. Heliostat Glass Survey and Analysis, M. A. Lind and J. M. Rusin, PNL-2868/UC-62 (September 1978).

2.1.4 American Society for Testing and Materials (ASTM), D3359-78 Measuring Adhesion by Tape Test.

2.1.5 American Society for Testing and Materials (ASTM), B117, Method of Salt Spray (Fog) Testing.

2.1.6 P. Moon, "Proposed Standard Solar Radiation Curves for Engineering Use", Journal of the Franklin Institute 320: 604, Table III, 1940. 


\section{REQUIREMENTS}

3.1 Mirror Production Requirements. The mirrors shall be second surface wet process silvered glass. The glass shall be coated with silver on one surface with the silver protected by a metallic copper film and a suitable organic coating. The detail coating requirements shall be as follows:

3.1.1 Glass. The glass used shall be supplied by the government from the special low iron run of float glass resulting from DOE solicitation ET 78-B-03-2221.

3.1.1.1 The glass shall be examined for edge damage and staining prior to metallization. Any glass stained beyond the tolerable limits or having edge defects exceeding the minimum requirements described in the specification cited in 2.1 .3 shall be set aside for reclamation by the government.

3.1.1.2 Only the atmospheric side of the glass shall be metallized. Since the glass may be recut before mirroring it will be necessary to use a UV source to determine the tin side of the sheet by observing the fluorescence.

3.1.1.3 The glass shall be handled only with gloves in order to minimize surface contamination before and during mirror processing.

3.1.1.4 Thorough abrasive scrubbing of the glass before metallization is required. A cerium oxide paste is recommended.

3.1.2 Silver Layer. The silver layer shall be a coating of chemically deposited silver.

3.1.2.1 The coating shall be free of defects or visible blemishes in the reflecting surface. Lifting or separation of the silver from the glass, pinholes, haze, spots, sulfide or chloride residue or other visible defects are unacceptable.

3.1.2.2 The minimum thickness of the silver layer shall be 70 milligrams per square foot to insure maximum solar reflectivity. 
3.1.3 Copper Layer. The silver layer shall be protected with a layer of chemically deposited copper.

3.1.3.1 The copper layer shall be optically opaque and cover the silver layer completely.

3.1.3.2 The nominal thickness of the layer shall be in excess of 30 milligrams per square foot to insure adequate silver protection.

3.1.4 Paint Coating. A suitable organic protective coating shall be applied to the copper backing in conformance with standard industry practice.

3.1.4.1 The paint shall be applied using a curtain coater in accordance with the paint manufacturers' recommendations.

3.1.4.2 The minimum acceptable coating thickness shall be in compliance with the paint manufacturer's recommendations. It is expected that the coating thickness will be approximately $8 \mathrm{~g} / \mathrm{ft}^{2}$.

3.2 Other Production Requirements. Generally accepted industry practice for high quality mirror production shall be used. The following requirements shall also apply:

3.2.1 Deionized Water. Filtered deionized water which is free of particulate contaminants shail be used exclusively from the scrub rinse through the copper deposition steps of the process. Water with a minimum electrical resistivity of 1 Megohm-cm is required.

3.2.2 Processing Temperatures. The maximum temperature of the metaliic layers sha 11 not exceed $150^{\circ} \mathrm{C}$ during the process in order to minimize the detrimental effects of silver agglomeration.

3.2.3 Test Coupons. As a minimum requirement one set of test coupons shall be inserted into the line at the beginning of each shift and at one hour intervals thereafter. The coupons will be used for real time process evaluation and for retention as archive 
specimens for future reference relative to mirror performance. One additional coupon shall be prepared during each shift for salt spray testing as described in 3.3.4.

\subsubsection{Each set of coupons shall consist of five samples with} minimum dimensions of one-foot square. The glass shall be cut from the government supplied stock. One coupon shall be removed after the silver deposition rinse step and before the copper deposition rinse step. One coupon shall be removed after the copper deposition step and before the paint application step. Three coupons, one at each line edge and one in the center of the line, shall go through the entire processing line.

3.2.3.2 The partially processed coupons shall be used for the tests specified in 3.3.2 and 3.3.3.

3.2.3.3 The three coupons processed through the entire line shall be retained for the permanent record and post process examination. They shall be indelibly labeled on the back side with the date and time the sample was produced and its lateral position on the line (left, center, right). They shall be stored in a clean dry environment as specified by the the purchaser.

3.3 Performance Requirements. The following performance criterion shall be met by each set of the hourly sample coupons.

3.3.1 Solar Reflectance. The solar reflectance shall exceed 0.900 reflectance units.

3.3.1.1 The solar reflectance shall be calculated from the measured spectral reflectance of the finished mirror coupons and Moon's AM 2 terrestrial solar spectral irradiance data cited in 2.1.6. 
3.3.2 Film Thickness. The thickness of the paint, copper and silver layers shall be evaluated from the hourly coupons using standard industry procedures. Analys is of each set of coupons and necessary production adjustments shal1 be completed before the next set of coupons is taken.

3.3.2.1 Paint thickness may be determined by weight gain.

3.3.2.2 Silver and copper thickness shall be determined by dissolving the metal layer, titrating the resulting solutions to their endpoints.

3.3.2.3 The samples must meet the minimum requirements outlined in 3.1 .

3.3.3 Film Adhesion. The adhesion of the silver only and silver/copper layers shall be tested using a tape test.

3.3.3.1 The tape test recommended is described in ASTM D 3359.

3.3.3.2 The films shall remain intact and show no delamination during the tests.

3.3.4 Accelerated Environmental Testing. The salt spray test described in ASTM B117 shall be performed on one sample taken during the middle of each shift. This test will be performed to provide comparative data on mirror durability as per customary industry practice.

3.3.4.1 The tested samples shall be labeled as referenced in 3.2.3.3 and saved with the archival samples.

3.3.4.2 The salt spray test shall be run for $300 \mathrm{hr}$ with a $20 \%$ salt solution.

3.3.4.3 Acceptable samples do not display significant degradation during the tests.

3.4 Reporting of Test Results. A11 test results shall be recorded and reported to the government or its representative. 
3.4.1 The records shall include the date and time of the test, the name of the tester and testing laboratory.

3.5 Test Failures. The designated sample coupons will be used to determine the quality of the production run as outlined in 3.3.

3.5.1 The segments of the production run which fails the tests described in 3.3 may not be accepted.

3.5.2 In no case should any portion of the run on low iron glass be discarded or destroyed.

3.6 Final Cleaning and Inspection. Before packing the mirrors must be cleaned and inspected.

3.6.1 The front surface of the glass shall be cleaned free of dirt and residual chemical contamination in accordance with good industry practice.

3.6.2 The edges of the mirror shall not have defects in excess of those outlined in 2.1.3.

3.7 Labeling. Each mirror shall be labeled on the back surface with the manufacturer's name and the date and hour of manufacture.

3.7.1 The hour of manufacture can be coded to allow for ease of marking provided a key is supplied to the purchaser.

3.8 Packaging. Finished mirrors shall be packaged in accordance with good industrial practices. See 2.1.2.

3.8.1 Felt or paper separators shall be incorporated to separate the mirror sheets.

3.8.2 Each storage container shall be labeled to allow complete identification of the contents. 


\section{DISTRIBUTION}

No. of

Copies

\section{OFFSITE}

\section{Technical Information Center}

\section{B. Ackerman}

Corning Glass Works

Main Plant, Bldg. 8-5

Corning, NY 14830

M. Adams

Jet Propulsion Laboratory

4800 0ak Grove Drive

Pasadena, CA 91108

R. Assink

Sandia Laboratories

Box 5800

Albuquerque, NM 87115

B. Baum

Springborn Laboratories

Endfield, CT 06082

E. Beauchamp

Sandia Laboratories

Box 5800

A1buquerque, NM 87115

P. Bender

Ford Motor Company

Glass Division

3000 Renaissance Center

PO Box 43343

Detroit, MI 48253

M. Berry

Boeing Engr. and Const.

P0 Box 3707

Seattle, WA 98124

J. Bigger

Electric Power Research Institute

P0 Box 10412

Palo Alto, CA 93403
No. of

Copies

J. K. Blackburn

Carolina Mirror Corp.

P0 Box 548, Elkin Rd.

N. Wilkesboro, NC 28659

F. Blake

Northrup, Inc., Blake Laboratory

Suite 306

7061 S. University Blvd.

Littleton, CO 80122

T. Blaney

Sunpower Systems Corp.

510 So. 52nd St.

Tempe, AR 85281

F. L. Bouquet

Jet Propulsion Laboratory

4800 0ak Grove Drive

Pasadena, CA 91108

G. Bowen

Booz, Allen \& Hamilton, Inc.

8801 E. Pleasant Valley Rd.

Cleveland, $\mathrm{OH} 44131$

G. E. Brandvold, 4713

Sandia Laboratories

Box 5800

Albuquerque, NM 87115

G. Braun

DOE Division of Solar Technology

20 Massachusetts Ave.

Washington, DC 20545

A. Brugg

Air Temescal

Solar Coating Dept.

14511 Romine Rd.

Carleton, MI 48117 
No. of

Copies

T. D. Brumleve, 8451

Sandia Laboratories

Livermore, CA 94550

J. J. Buggy

Westinghouse Electric Corp. Box 10864

Pittsburgh, PA 15236

V. Burolla

Sandia Laboratories

Livermore, CA 94550

K. Busche

Busche Energy Systems

7288 Murdy Circle

Huntington Beach, CA 92647

B. Butler

Solar Energy Research Institute 1536 Cole Blvd.

Golden, CO 80401

P. Call

Solar Energy Research Institute

1536 Cole Blvd.

Golden, CO 80401

W. Carroll

Jet Propulsion Laboratory

4800 Oak Grove Drive

Pasadena, CA 91108

R. E. Cambron

Springborn Laboratories

Walter St.

Endfield, CT 06082

A. A. Churm

DOE Chicago Patent Group

9800 South Cass Avenue

Argonne, IL 60439

G. Cottingham

Brookhaven National Laboratory

Upton, NY 11973
No. of

Copies

T. Coyle

Solar Energy Research Institute

1536 Cole Blvd.

Golden, C0 80401

D. Culler

Gardner Mirror Corp.

P0 Box 638, Hwy. 268E.

N. Wilkesboro, NC 28659

A. Czanderna

Solar Energy Research Institute

1536 Cole Blvd.

Golden, C0 80401

D. Dees

Sandia Laboratories

Box 5800

Albuquerque, NM 87115

W. R. Delameter, 8451

Sandia Laboratories

Livermore, CA 94550

T. A. Dellin, 4723

Sandia Laboratories

Box 5800

Albuquerque, NM 87115

E. J. Dempsey

London Laboratories Limited

Box 3637

Woodbridge, CT 06525

B. Dennis

Dow Corning

MS 520

Saginaw Road

Midland, MI 48640

M. De Vries

Donnelly Mirrors Inc.

49 w. 3rd St.

Holland, MI 49423 
No. of

Copies

R. Eagan

Sandia Laboratories

Box 5800

Albuquerque, NM 87115

C. R. Easton

McDonnel1 Douglas

Astronautics Co.

5307 Bolsa Ave.

Huntington Beach, CA 92647

P. J. Eicker, 8326

Sandia Laboratories

Livermore, CA 94550

S. D. Elliott

DOE San Francisco Operations office

1333 Broadway

Wells Fargo Bldg.

Oakland, CA 94612

R. A. England

Martin Marietta

MS S0403

PO Box 179

Denver, CO 80201

H. E. Felix

Solaramics Inc.

1301 El Segundo Blvd.

El Segundo, CA 90245

M. J. Fish, 8326

Sandia Laboratories

Livermore, CA 94550

C. R. Frownfelter

PPG Industries, Inc.

One Gateway Center

Pittsburg, PA 15222

J. Garate

General Electric

1 River Road

Schenectady, NY 12345
No. of

Copies

R. L. Gervais

McDonnel1 Douglas Astronautics

5301 Bolsa Ave.

Huntington Beach, CA 92647

F. P. Gerstle, 5844

Sandia Laboratories

Box 5800

Albuquerque, NM 87115

R. Gillette

MS 9 A-46

Boeing Engr. and Const.

P0 Box 3707

Seattle, WA 98124

J. E. Gilligan

$11 T$ Research Institute

10 W. 35th St.

Chicago, IL 60616

J. D. Gilson, 8453

Sandia Laboratories

Livermore, CA 94550

T. S. Gold, 8320

Sandia Laboratories

Livermore, CA 94550

R. N. Griffin

General Electric

Bldg. 23, Rm 278

1 River Road

Schenectady, NY 12345

G. Gross

Solar Energy Research Institute 1536 Cole Blvd.

Golden, CO 80401

B. Gupta

Solar Energy Research Institute 1536 Cole Blvd.

Golden, CO 80401 
No. of

Copies

M. U. Gutstein

DOE Division of Solar Technology

20 Massachusetts Avenue

Washington, DC 20545

B. Hahn

OCLI

2789 Giften Ave.

Santa Rosa, CA 95403

W. Haller

Chief, Inorganic Glass Section

Institute for Materials

Research

National Bureau of Standards

Washington, DC 20234

T. Heard

London Laboratories Limited

Box 3637

Woodbridge, CT 06525

T. R. Heaton

Martin Marietta Corporation

PO Box 179

Denver, C0 80201

J. S. Herbert

ASG Industries, Inc.

PO Box 929

Kingsport, TN 37662

T. Hisakado

SUNSHINE Project Operation Bureau

5-8-2, Marunouchi, Chiyoda-ku

Tokyo, Japan

R. Hobbs

General Electric Company

P0 Box 8661 - Room 7310

Philadelphia, PA 19101

P. L. Hofmann

Battelle

505 King Ave.

Columbus, $\mathrm{OH} 43201$
No. of

Copies

D. Horgan

Solar Energy Research Institute

1536 Cole Blvd.

Golden, CO 80401

R. H. Horton

General Electric Co.

Energy Systems

One River Road

Schenectady, NY 12345

C. G. Howard

Booz, Allen \& Hamilton, Inc.

8801 E. Pleasant Valley Road

Cleveland, $\mathrm{OH} 44131$

L. D. Jaffe

Jet Propulsion Laboratory

4800 0ak Grove Dr.

Pasadena, CA 91103

G. M. Kaplan

DOE Division of Solar Technology

20 Massachusetts Avenue

Washington, DC 20545

E. L. Katz

Aerospace Corporation

Solar Thermal Projects

Energy Systems Group

PO Box 92957

Los Angeles, CA 90009

E. Lam

Bechtel National Inc.

MS 50/16

P0 Box 3965

San Francisco, CA 94119

S. Lamensdorf

Binswanger Mirror Co.

1355 Lynnfield Rd., Suite 205

PO Box 17127

Memphis, TN 38117 
No. of

Copies

C. M. Lampert

Lawrence Berkeley Laboratory

B1dg. 62, Rm. 235

University of California

Berkeley, CA 94720

H. Leggett

Hughes Aircraft Company

MS X-122, B1dg. 20

Culver City, CA 90230

J. A. Leonard, 4725

Sandia Laboratories

Box 5800

Albuquerque, NM 87115

I. E. Lewis

Ford Aerospace

3939 Fabian Way

Palo Alto, CA 94303

V. L. Lindberg

Ford Glass Technical Center

25500 West Outer Drive

Lincoln Park, MI 48146

R. Livingston

Solar Energy Research Institute

1536 Cole Blvd.

Golden, C0 80401

T. Martin

CE Glass Division

825 Hylton Rd.

Pennsarken, NJ 08110

K. Masterson

Solar Energy Research Institute 1536 Cole Bivd.

Golden, CO 80401

10 C. L. Mavis

Sandia Laboratories

Livermore, CA 94550
No. of

Copies

Mrs. McHugh

Sanders Associates

95 Canal St., MS MER12-1214

Nashua, NH 03061

D. D. McKinny

C-E Glass

825 Hylton Road

Pennsauken, NJ 08110

J. Megland

PRC 1 EAC

7600 01d Springhouse Rd.

McClaine, VA 22102

J. Meylan

Battelle

7, Route de Drize

1227 Geneva

Switzerland

L. Melamed

DOE Division of Solar Technology 20 Massachusetts Avenue

Washington, DC 20545

B. E. Mi11s, 8315

Sandia Laboratories

Livermore, CA 94550

W. Mitchell

Solaramics Inc.

1301 El Segundo B1vd.

E1 Segundo, CA 90245

W. Moore

Veda, Inc.

400 N. Mobil, Bldg. D

Camarillo, CA 93010

R. E. Mutzberg

PPG Industries, Inc.

1377 0akleigh Dr.

East Point, GA 30344 
No. of

Copies

W. J. Nagle

Ford

23400 Michigan Ave.

Dearborn, MI 48124

E. Nelson

ACUREX Corporation

485 Clyde Avenue

Mountain View, CA 94042

H. F. Norris, Jr., 8451

Sandia Laboratories

Livermore, CA 94550

L. P. 01dham

Martin Marietta Corp.

MS S8120

PO Box 179

Denver, C0 80201

D. Peters

Construction Resources Inc.

4120 West Maple Rd.

Suite 205

Burmingham, M.I 48010

S. G. Peglow, 8451

Sandia Laboratories

Livermore, CA 94550

R. Pettit, 5842

Sandia Laboratories

Box 5800

Albuquerque, NM 87115

J. A. Pietsch

Northrup, Incorporated

302 Nichols Drive

Hutchins, TX 75141

C. J. Pignolet, 8451

Sandia Laboratories

Livermore, CA 94550

S. Pohlman

Solar Energy Research

Institute

1536 Cole Blvd.

Golden, CO 80401
No. of

Copies

J. E. Rannels

DOE Division of Solar Technology

20 Massachusetts Avenue

Washington, DC 20545

H. E. Remmers

175 Pawnee Dr.

Boulder, CO 80303

P. de Rienzo

Aerospace Corporation

El Segundo Boulevard

El Segundo, CA 90274

H. Roberts

Solar Energy Research Institute

1536 Cole Blvd.

Golden, CO 80401

D. Rostoker

Pittsburg Corning

800 Presque Isle Drive

Pittsburg, PA 15239

I. Rubenstein

3005-I Romaric Ct.

Baltimore, MD 21209

J. Schrauth

Jena Glaswerk Schott

\& Gen., Inc.,

11 East 26th Street

New York, NY 10010

Roger Schriven

PPG Industries, Inc.

PO Box 9

Roseanna Dr.

Allison Park, PA 15101

J. C. Schumacher

Schumacher \& Associates

2550 Fair Oaks Blvd., Suite 120

Sacramento, CA 95820 
R. N. Schweinberg

DOE San Francisco Operations Office 1333 Broadway

Wells Fargo Bldg.

Oakland, CA 94612

A. K. Seth

Solar Energy Group

Centre of Energy Studies

Indian Institute of Technology

Haug Khas, New Dehli

110029 , India

J. Shelby

Sandia Laboratories

Livermore, CA 94550

A. F. Shoemaker

Corning Glass Works

Corning, NY 14830

C. Sivertz

10812 Madrona Dr.

RR1

Sidney, BC

Canada

A. C. Skinrood

Sandia Laboratories

Livermore, CA 94550

W. Smyrl

Sandia Laboratories

Box 5800

Albuquerque, NM 87115

B. Steifeld

Sandia Laboratories

Box 5800

Albuquerque, NM 87115

D. A. Steinmeyer

McDonnell Douglas Astronautics 5301 Bolsa Ave.

Huntington Beach, CA 92647
H. Sund

Ford Aerospace

3939 Fabian Way, T33

Palo Alto, CA 94303

H. R. Swift

Libby Owens Ford Company

Technical Center

1701 E. Broadway

Toledo, $\mathrm{OH} 43605$

T. Tanaka

Electrotechnical Laboratory

5-4-1, Mukodai, Tanashi

Tokyo, Japan

J. Thornton

Solar Energy Research Institute

1536 Cole Blvd.

Golden, CO 80401

W. Tomlinson

Environmenta 1 Library

758 Eddy St.

Univ. of Montana

Missoula, MT 59812

P. Tremblay

Foster-Miller Associates

135 Second Ave.

Waltham, MA 02154

R. Turner

Flaconer Plate Glass Corp.

500 S. Work Street

Falconer, NY 14733

C. N. Vittitoe, 4231

Sandia Laboratories

Box 5800

Albuquerque, NM 87115

10 J. Vitko

Sandia Laboratories

Livermore, CA 94550 
No. of

Copies

R. R. Walters

E. Systems

Energy Technology Center

P0 Box 6118

Dallas, TX 75222

J. D. Walton, Jr.,

Engineering Experiment Station Georgia Institute of Technology Atlanta, GA 30332

R. C. Wayne, 8450 Sandia Laboratories Livermore, CA 94550

L. Weinstein

McDonnel1 Douglas Astronautics Co. 5301 Bolsa Ave.

Huntington Beach, CA 92647

D. Wiley

Guardian Industries Corp. 43043 W. Nine Mile Road

Northville, MI 48167

10 W. G. Wilson

Sandia Laboratories

Livermore, CA 94550

G. Yaeger

Buckmin Industries

1485 E. Curtis

Reedley, CA 93654
No. of

Copies

B. Zelenka

175 Pawnee Dr.

Boulder, CO 80303

ONSITE

2 DOE Richland Operations Office

H. E. Ransom

R. Stewart

88 Pacific Northwest Laboratory

C. Q. Buckwalter

T. D. Chikalla

W. J. Coleman

J. L. Daniel

K. Drumheller

J. S. Hartman

M. A. Lind (50)

R. P. Marshall

L. R. Pederson

A. M. Sutey

M. T. Thomas

R. Turcott

Publishing Coordination

Technical Information J0 